\title{
Partnership at Work
}

The partnership arrangements established between the Irish Airports' Authority, Aer Rianta, and its trade unions in the mid 1990s were amongst the most far-reaching of their kind in promoting union and staff involvement in all aspects of company decision-making from work groups and departments to the making of corporate strategy. Radical organizational change was envisaged in this path-breaking partnership. Significant achievements were recorded. Major commercial challenges were addressed and partnership effectively came to displace traditional industrial relations arrangements and postures in key areas. A decade later, however, the partnership had broken down.

This book presents the story of the Aer Rianta partnership, charting its origins, progress, achievements, obstacles and eventual demise. Partnership at Work is based on access to parties, documents, observation on how the partnership functioned and three surveys of the company's workforce. As detailed, in-depth studies of workplace partnership are rare in the international literature, the analysis provided in this book makes an important contribution to the understanding of employment relations. The account given by William K. Roche and John F. Geary is balanced and instructive and allows for a comprehensive understanding of the functioning and outcomes of partnership.

William K. Roche is Professor of Industrial Relations and Human Resources at the School of Business, University College Dublin, and Honorary Professor at the School of Management and Economics, Queen's University Belfast. John F. Geary is Associate Professor of Industrial Relations and Human Resources and Director of Doctoral Studies at the College of Business and Law, University College Dublin. 


\section{Routledge research in employment relations}

Series editors: Rick Delbridge and Edmund Heery

Cardiff Business School, UK

Aspects of the employment relationship are central to numerous courses at both undergraduate and postgraduate level.

Drawing from insights from industrial relations, human resource management and industrial sociology, this series provides an alternative source of research-based materials and texts, reviewing key developments in employment research.

Books published in this series are works of high academic merit, drawn from a wide range of academic studies in the social sciences.

1 Social Partnership at Work Carola M. Frege

2 Human Resource Management in the Hotel Industry Kim Hoque

3 Redefining Public Sector Unionism UNISON and the future of trade unions Edited by Mike Terry

4 Employee Ownership, Participation and Governance A study of ESOPs in the UK Andrew Pendleton

5 Human Resource Management in Developing Countries Pawan S. Budbwar and Yaw A. Debrah

6 Gender, Diversity and Trade Unions International perspectives Edited by Fiona Colgan and Sue Ledwith

7 Inside the Factory of the Future Work, power and authority in microelectronics Alan Macinlay and Phil Taylor 
8 New Unions, New Workplaces

A study of union resilience in the restructured workplace Andy Danford, Mike Richardson and Martin Upchurch

9 Partnership and Modernisation in Employment Relations Edited by Mark Stuart and Miguel Martinez Lucio

10 Partnership at Work

The quest for radical organizational change

William K. Roche and John F. Geary

11 European Works Councils

Pessimism of the intellect, optimism of the will?

Edited by Ian Fitzgerald and John Stirling

12 Employment Relations in Non-union Firms

Tony Dundon and Derek Rollinson

13 Management, Labour Process and Software Development Reality bytes

Edited by Rowena Barrett

14 A Comparison of the Trade Union Merger Process in Britain and Germany Joining forces?

Jeremy Waddington, Marcus Kabmann and Jürgen Hoffmann

15 French Industrial Relations in the New World Economy

Nick Parsons

16 Union Recognition

Organising and bargaining outcomes

Edited by Gregor Gall

Also available from Routledge:

Rethinking Industrial Relations

Mobilisation, collectivism and long waves

Jobn Kelly

Employee Relations in the Public Services

Themes and issues

Edited by Susan Corby and Geoff White 
The Insecure Workforce

Edited by Edmund Heery and John Salmon

Public Service Employment Relations in Europe

Transformation, modernisation or inertia?

Edited by Stephen Bach, Lorenzo Bordogna, Giuseppe Della Rocca and David Winchester

Reward Management

A critical text

Edited by Geoff White and Janet Druker

Working for McDonald's in Europe

The unequal struggle?

Tony Royle

Job Insecurity and Work Intensification

Edited by Brendan Burchell, David Ladipo and Frank Wilkinson

Union Organizing

Campaigning for trade union recognition

Edited by Gregor Gall

Employment Relations in the Hospitality and Tourism Industries Rosemary Lucas 


\section{Partnership at Work}

The quest for radical organizational change

William K. Roche and John F. Geary

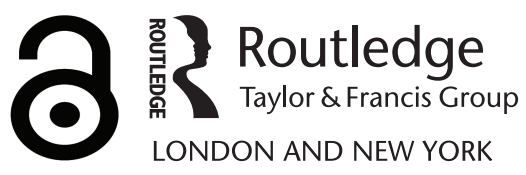


First published 2006

by Routledge

Published 2017 by Routledge

2 Park Square, Milton Park, Abingdon, Oxon OX14 4RN

711 Third Avenue, New York, NY 10017, USA

Routledge is an imprint of the Taylor E Francis Group, an informa business

Copyright ( 2006 William K. Roche and John F. Geary

Typeset in Garamond by Wearset Ltd, Boldon, Tyne and Wear

The Open Access version of this book, available at www.tandfebooks.com, has been made available under a Creative Commons Attribution-Non Commercial-No Derivatives 4.0 license.

British Library Cataloguing in Publication Data A catalogue record for this book is available from the British Library

Library of Congress Cataloging in Publication Data

A catalog record for this title has been requested

ISBN13: 978-0-415-30434-4 (hbk) 


\section{Contents}

List of illustrations viii

Preface $\quad x$

1 Understanding voluntary partnership 1

2 The case and research methods 36

3 The emergence and development of partnership 43

4 Partnership and commercial strategy 66

5 Senior managers 91

6 Middle managers 116

WITH ALASTAIR MCPHERSON

$\begin{array}{lll}7 & \text { Trade unions } & 138\end{array}$

8 Employee attitudes and behaviour $\quad 167$

9 Dual commitment 204

10 The breakdown of partnership 214

11 Advocates, critics and partnership 245

Appendix 257

Bibliography $\quad 262$

$\begin{array}{ll}\text { Index } & 271\end{array}$ 


\section{Illustrations}

\section{Figures}

3.1 The development of constructive participation 50

3.2 The evolution of partnership arrangements 58

9.1 Scatterplot of union and organizational commitment 208

\section{Tables}

2.1 Workforce survey 41

3.1 Workplace partnership principles and arrangements 52-3

5.1 Advantages and disadvantages of constructive participation 108

7.1 Attitudes to the effectiveness of unions 150

7.2 Effects of involvement in partnership on attitudes towards unions 152

7.3 Effects of involvement on union commitment 154

$\begin{array}{lll}7.4 & \text { Shop stewards, activists and constructive participation } & 161\end{array}$

7.5 Attitudes to unions and to constructive participation 163

8.1 Disparities between actual and preferred levels of task participation

8.2 Disparities between actual and preferred levels of communicative participation $\quad 176$

8.3 Effects of staff category and location 177

8.4 Membership of groups and committees 180

8.5 Multiple membership of groups and committees 181

8.6 Levels of engagement with constructive participation 182

8.7 Attitudes to constructive participation 184

8.8 Aspects and assessments of involvement 187

8.9 Effects of constructive participation on attitudes to

8.10 Influences on organizational commitment 192

8.11 Effects of constructive participation on changes in work practices 193

8.12 Influences on the way employees worked 194 
8.13 Regular work group membership in the maintenance trades

8.14 High constructive participation involvement, attitudes and behaviour

8.15 Involvement in constructive participation and areas of concern

9.1 Categories of commitment to union and company

9.2 Cluster analysis of commitment scales

9.3 Latent class cluster models fitted to union and company commitment scales

A1 Scales of involvement with constructive participation

A2 Union commitment scales

A3 Attitudes to constructive participation scales

A4 Organizational commitment scales 


\section{Preface}

The partnership arrangements agreed between the Irish Airports' Authority, Aer Rianta and its unions in the mid 1990s, were among the most radical of their kind in making provision for employee involvement and union participation at multiple levels in the affairs of the company. Nothing short of radical organizational change was envisaged in this path-breaking partnership. Less than a decade later, the Aer Rianta partnership had broken down, despite having recorded a number of significant achievements. This book presents the story of the Aer Rianta partnership, charting its antecedents, operation, outcomes and eventual demise.

We were originally invited to examine the Aer Rianta partnership by the Irish Department of Public Enterprise. We have enjoyed an unusual level of access to the parties involved in the Aer Rianta partnership during the course of our research. All meetings and documents were accessible over a period of four years that extended to the high tide of co-operative joint activity. All the main parties were accessible over an even longer period, extending to the breakdown of the partnership. We enjoyed access to surveys that had been conducted as part of the preparations for the introduction of partnership. We conducted our own survey during the high tide of the partnership. We sat for several years on the Joint Union Company Group that oversaw the operation of partnership activities, and on several strategic partnership groups. We were asked to participate in the activities of these bodies not as researchers alone but as ordinary members. When the partnership had broken down, we were asked by management and unions to assess the lessons to be learned and to provide guidance as to a possible future modus of working through partnership. As a result of our work on the Aer Rianta partnership, we joined with some of the main parties involved, as well as with other companies and union officials active in operating partnerships, to create the Partnership Learning Network. The network is committed to exploring the lessons that can be learned from earnest and practical initiatives in partnership in Ireland.

In all these ways, the Aer Rianta partnership has provided an important focus for our professional lives as academics and researchers over a number of years, and we hope the level of access we enjoyed and the opportunity this 
provided to explore the dynamics of partnership in depth make for a balanced and instructive book that adds to the international literature on the pursuit of radical organizational change through involvement and participation. It seemed clear to us that such a study is necessary given the paucity of detailed studies of partnership in the literature. With the exception of Saul Rubinstein and Tom Kochan's excellent Learning from Saturn (2001), there have been few detailed case studies of the functioning and outcomes of partnership.

The book is organized in the following way. Chapters 1 and 2 outline the theoretical and methodological background to the study. Chapters 3 to 9 examine in depth the evolution of the Aer Rianta partnership up to what we have referred to as its high-water mark in the late 1990s. Chapter 3 examines the antecedents and 'architecture' of 'constructive participation', the term coined by the parties to describe their joint initiative, and outlines the operation of the joint initiative up to the point where it engaged with significant commercial challenges faced by the company and its unions. Chapters 4 to 9 explore the core themes that have focused the international literature on partnership arrangements. Chapter 4 examines the relationship between partnership, commercial strategy and governance. Chapters 5 and 6 look at the role of senior and middle managers in the operation of partnership. Chapter 7 focuses on the role of union officials and activists. Chapters 8 and 9 examine the effects of partnership on employees' attitudes and behaviour. Chapter 10 develops the story into a detailed examination of the breakdown of partnership, when - extending the metaphor of tides introduced above - the tide ebbed fast on constructive participation. Chapter 11 presents the study's main conclusions and links these to major issues of debate in the partnership literature.

Since the completion of our fieldwork, and as anticipated in Chapter 10, Aer Rianta has been reorganized. In late 2004 the new state-owned Dublin Airport Authority assumed responsibility for the former company's assets and liabilities. Significant responsibility for day-to-day operations was delegated to the Cork and Shannon Airport Authorities. In due course these authorities may assume full responsiblity for the management, development and assets of Cork and Shannon airports.

We have incurred significant debts and have been able to work with some remarkable people during the course of this study. We would like to thank Brendan Tuohy, currently Secretary General of the Department of Communications, Marine and Natural Resources, for inviting us to undertake a study of partnership in Aer Rianta and for providing financial support to the study. Michael McDaid liaised effectively between the Department and the research team in the project's early years. Martin Brennan also acted as a helpful link between the Department, the company and the University College Dublin (UCD) research team. We owe a particular debt of gratitude to George O'Connor, Bernard Brown and Dan Miller, whose vision, tenacity and professionalism were responsible, in large measure, for constructive 
participation. They continuously dialogued with us on the issues involved to a degree that has been for us both unique and uniquely instructive. We are also grateful to other senior figures in Aer Rianta, especially John Burke, the company's former CEO, Margaret Sweeney, the last Aer Rianta CEO, Oliver Cussen, Deputy CEO, Brendan Daly, Frank O'Connell, Damian Lenagh and Hugh Duggan. Among the union officials and activists interviewed, we would like in particular to thank John Flannery, Carmel Hogan, Tony Kenny, Linda Tanham, Kay Kearns, Peter Tobin, Eddie O'Grady and Tom Kenny. We would also like to express our gratitude to worker directors, Peter Dunne, Pat Fitzgerald and Rita Bergin. We are grateful as well to many other managers, at a variety of levels, to trade union activists, facilitators and employees who consented to be interviewed for the study. Presentations on the principal research findings were made to the Aer Rianta senior management group and to the Joint Union Company Group, and we would like to acknowledge the helpful comments made at both presentations.

Alastair McPherson worked as a senior research officer on the project during the first intensive phase of fieldwork and contributed to the design and management of the survey. He also supplied background documentation to Chapter 3 and contributed to the drafting of Chapter 6, where his contribution to authorship is acknowledged. Teresa Brannick provided very helpful advice and excellent technical assistance with respect to the management of the survey, especially in the area of sampling, and we would like to acknowledge her expertise with gratitude. The Survey Unit of the Economic and Social Research Institute, Dublin processed the survey data. We would also like to acknowledge the access allowed by ESRI, and, in particular, by Professor Chris Whelan, to the two earlier surveys conducted by the ESRI for the Joint Union Company Group in Aer Rianta. At UCD, Claire Kenny, Tony Dobbins, Enda Hannon and Alison Carey also provided valuable research assistance at various stages during the course of the project. Tony Kerr, Geraldine O'Brien and Tom Murphy gave helpful feedback on drafts of several chapters. John Benson also contributed constructive advice on the study as a whole. Geraldine McEvoy supplied superb technical support, particularly through her work on the composition of data tables, and Joy O'Hora and Vera Bolger also assisted with some of the graphs contained in the text.

We are indebted to Ed Heery for his encouragement for our work on the book and for his support as series editor. We would also like to thank four anonymous academic reviewers for their constructive and incisive comments on the proposal for the current manuscript. We would like to acknowledge the encouragement and forbearance of Joe Whiting, Annabel Watson, Yeliz Ali and Terry Clague at Routledge. Some of the material contained in Chapter 8 appeared in 'Advocates, Critics and Union Involvement in Workplace Partnership: Irish Airports', British Journal of Industrial Relations, 2002, 40(4): 659-89 and in 'Workplace Partnership and the Displaced Activist Thesis', Industrial Relations Journal, 2003, 34(1): 
32-51. We would like to thank the editors of the BJIR, Ed Heery, and of the IRJ, Brian Towers, for permission to incorporate this material into the book. Some of the material in Chapter 9 appears in 'Workplace Partnership and the Search for Dual Commitment', in Mark Stuart and Miguel Martinez-Lucio, eds, Partnership and the Modernization of Employment Relations, Routledge. We would like to thank the editors for permission to use this material in the book.

Last but by no means least, we are indebted to our families, Mary and Kevin and Ber, Muireann and Aoife for their love, support and forbearance.

Bill Roche and John Geary University College Dublin 



\section{Understanding voluntary partnership}

The subject of this book is the functioning and effects of voluntary partnership arrangements between management, unions and employees. The book draws on a significant case study of voluntary partnership in the Irish Airports' Authority, Aer Rianta. This chapter sets the scene for the detailed examination of the Aer Rianta partnership throughout the book. It examines the concept of voluntary partnership and outlines the main themes and questions that have focused the study of voluntary partnership arrangements in general.

\section{Approaches and features}

The emergence on a widespread basis of various forms of co-operative employment relations arrangements in workplaces and enterprises is an important feature of the past two decades. Initiatives to foster co-operative employment relations have emerged in unionized and non-union workplaces and in the public and private sectors of the advanced economies (US Department of Labor 1996; EPOC 1997; Gill and Krieger 2000; Roche 2000; 2002). In Anglo-Saxon countries neither legislation nor collective agreements mandate works councils as a standard vehicle for employee or union representation in workplace or company decision-making. In these countries, especially the UK, Ireland, the United States, Canada, New Zealand and Australia, the incidence of voluntary co-operative arrangements has been significant, and these arrangements have provided an important channel for employee and union voice in organizational decision-making. Voluntary cooperative arrangements have attracted academic attention in the AngloSaxon countries, either directly or as features of broader programmes of innovation in work organization and employment relations (Cooke 1990; Appelbaum and Batt 1994; Cutcher-Gershenfeld and Verma 1994; Kochan and Osterman 1994; Ichniowski et al. 1996; Boxall and Haynes 1997; Guest and Peccei 1998; Knell 1999; Verma and Chaykowski 1999; Roche and Geary 2000; 2004; Osterman et al. 2001; Rubinstein and Kochan 2001; Geary and Roche 2003; Terry 2003a and b; Kelly 2004).

The involvement of trade unions in the design and operation of new 
forms of shared decision-making in firms and workplaces is widely viewed as the critical factor differentiating the concept of partnership from the more general issue of employee involvement or new forms of work organization. Partnership arrangements introduced in co-operation with unions often include both direct and indirect or representative means of engaging employees and union members in organizational decision-making. Notwithstanding the significance of voluntary partnerships in the unionized sectors of Anglo-Saxon countries and the growing academic interest in what they represent and why they have emerged, it remains striking how little rigorous attention has been devoted at the micro-level to the functioning, antecedents and effects of partnership arrangements. William Cooke's 1990 book, Labor-Management Co-operation, based on a study of US manufacturing, remains the most detailed survey-based analysis of the antecedents, features and effects of partnership in the US. More recently, Guest and Peccei (2001) have examined the features and effects of partnership arrangements in companies affiliated to the Involvement and Participation Association (IPA) in the UK, while Roche and Geary (2000) have examined the incidence in Ireland of approaches to handling change based on partnership and involvement. The case-study literature has been dominated by a small number of North American exemplars, in particular the Saturn Plant (Rubinstein and Kochan 2001), the Shell Sarnia plant in Canada (Heckscher 1988) and the General Motors-Toyota NUMMI joint venture in California (Grattan 1997). Exemplary and brief case studies have also been reported in the UK literature (Knell 1999). Only recently have rigorous case studies been reported in the UK, based on the experiences of companies such as United Distillers and Allied Distillers Limited (Marks et al. 1998). Kelly (1999; 2004) has also presented an important critique of some cases that have been widely regarded as exemplars of partnership in the UK, including Blue Circle Cement, Hyder (Welsh Water) and Asda.

No agreed definition or conceptualization of partnership exists in either the academic or policy literatures (Guest and Peccei 2001: 208). Three broad and overlapping approaches to conceptualizing partnership can be identified. Two of these treat partnerships involving unions within more general portrayals of partnership that encompass employee involvement and non-union companies. The first broad approach to conceptualizing partnership focuses on the principles and practices that shape co-operative employment relations arrangements. Thus, Guest and Peccei (1998; 2001) and Knell (1999) locate partnerships in which unions are involved within more general co-operative employment relations arrangements operating on the basis of a series of principles and 'beliefs and attitudes' which are seen as anchoring a distinctive set of partnership practices. Working on the basis of the definition and conceptualization of partnership developed by UK-based lobby group the Involvement and Participation Association, and a survey of IPA member companies, Guest and Peccei $(1998 ; 2001)$ undertook a study of partnership practices. Through the survey they largely inductively estab- 
lish the principles, attitudes and beliefs and practices associated with partnership. The principles of partnership are seen to entail 'good treatment of employees now and in the future', including an affirmation of financial participation and the disclosure of business information; the principles of (accepting) 'employee rights and benefits', including the right to independent representation; on the employee/union side, partnership is seen also to involve 'employee responsibilities' in such areas as flexibility, commitment to business goals and a willingness to bring about improvements in production processes (Guest and Peccei 1998: 20). The 'beliefs and attitudes' underlying partnership involve an acceptance of the role of trade unions and a willingness to accommodate multiple interests in the running of the enterprise. The partnership practices that are seen to flow from such principles, attitudes and beliefs include direct employee involvement, representative involvement in decisions regarding employment issues and broader organizational policies; flexible forms of job design and a focus on quality; the use of performance management systems; employee share ownership programmes (ESOPs); communication practices; harmonized terms and conditions of employment and practices aimed at promoting employment security (Guest and Peccei 1998: 24).

Adopting such an approach, Guest and Peccei established that some IPA 'partnership' companies harboured considerable ambiguity regarding the role and legitimacy of trade unions and the degree to which multiple interests needed to be recognized and accommodated in the running of companies. Evidence also emerged of managements' emphasis on employee contribution and less than balanced recognition of the principle of 'mutuality'. Finally, the incidence of 'partnership practices' is seen to vary significantly $(1998 ; 2001)$. As the features of unionized IPA member companies are not reported separately, no definite conclusion can be reached as to whether the unionized partnerships mirror the survey findings in general in reflecting ambiguous and diverse attitudes towards unions, employee contribution and mutuality, as well as variable levels of involvement, representative structures and partnership practices. Following the broad template of the approach of Guest and Peccei, Knell's (1999) study of exemplary cases of partnership in the UK also locates unionized partnerships within more general co-operative industrial relations arrangements and seeks to isolate 'a core set of values' that represent a 'partnership philosophy'. The core values of partnership are seen to involve 'trust and honesty', mutuality, the creation of a common vision, open management, reaching agreement without coercion, multifaceted employee voice mechanisms, a stress on involvement, ownership and responsibility, employment security (sometimes qualified in terms of 'employability'), fair reward and an emphasis on quality (Knell 1999: 19-22).

A second broad approach to conceptualizing partnership again incorporates unionized partnerships within the more general category of the 'mutual gains enterprise' (Kochan and Osterman 1994). What is distinctive about 
this approach, which draws extensively on US exemplary cases, is that it presents a multi-level model of 'principles guiding the mutual gains enterprise' (Kochan and Osterman 1994: ch. 3). At the 'strategic level', business strategies that assign priority to quality and innovation are seen to be necessary underpinnings of the mutual gains enterprise; top management commitment and ways of providing an effective voice for human resource issues and priorities in strategy-making and governance are also presented as generic principles at a strategic level (Kochan and Osterman 1994: 55-8). At a 'functional human resource policy level', commitment to mutual gains is seen to require staffing practices that promote 'employment stabilization', investment in training and development and compensation practices contingent on performance, especially contingent compensation practices such as profit- and gain-sharing that are seen to reinforce co-operation, contribution and participation (Kochan and Osterman 1994: 52-5). Finally, Kochan and Osterman also identify a series of workplace-level practices that underpin mutual gains enterprises, including high standards of employee selection, broad job task design and teamwork, employee involvement in problemsolving and a climate of trust and co-operation (Kochan and Osterman 1994: 47-52).

The final approach focuses directly on cases of partnership involving unions and conceptualizes partnership mainly in terms of the structures of decision-making arrangements that are put in place to promote co-operation between management and unions and management and employees. Thus, Cooke's major work on partnership in US manufacturing focuses on direct (team-based) and representative (committee-based) 'co-operative efforts' that occur outside traditional contract negotiation; contain formalized mechanisms for union and/or employee inputs into management decision-making, and are intended to improve performance in a variety of ways (Cooke 1990: 3). Cooke's approach includes as instances of partnership cases where companies remain ambiguous or even hostile towards unionization (Cooke 1990: ch. 3). A second example of this broad approach is provided by a seminal paper by Cutcher-Gershenfeld and Verma (1994). Drawing on North American exemplars, these researchers focus on cases of partnership where unions and managements are involved in 'joint governance' arrangements. These arrangements are distinguished from initiatives of the type identified by Cooke, which are regarded as a long-established feature of North American industrial relations (Cutcher-Gershenfeld and Verma 1994: 551). Joint governance involves an 'ongoing formal process where workers and their immediate supervisors or union and management leaders bear joint responsibility for making decisions (Cutcher-Gershenfeld and Verma 1994: 551; emphasis in the original). Joint responsibility means the equal sharing of decisionmaking power, understood in the procedural sense that the joint committees, forums or groups addressing issues subject to co-operation consist of equal numbers of labour and management representatives, or operate on a consensus basis - implying that either side enjoys the power of veto 
(Cutcher-Gershenfeld and Verma 1994: 551-2). In the cases portrayed by Cutcher-Gershenfeld and Verma as instances of joint governance, the scope of decision-making is sometimes narrow (i.e. it may be restricted to a single issue such as training or contracting out) and sometimes broad, encompassing multiple issues and extending possibly to the fundamentals of competitive strategy. In some instances of joint governance of broad scope, for example, Saturn or Shell Sarnia, it would appear that co-operative engagement between management and unions effectively subsumes collective bargaining, rather than operating on a parallel track, as in the definition proposed by Cooke.

Clearly a good deal of overlap exists between these approaches to defining and conceptualizing partnership. Particularly striking is the symmetry between the approach of Guest and Peccei, with its emphasis on principles, attitudes and beliefs leading to practices, implying a hierarchical ordering of attributes of partnership and the more concrete multi-level model of Kochan and Osterman. Equally clearly, it emerges that empirical cases falling within the scope of unionized partnerships consistent with these definitions and conceptualizations may be characterized in practice by varying levels of acceptance of such principles as the legitimacy of unions and their role in decision-making; by varying degrees of emphasis on mutual gains as distinct from the expected contribution of employees; by varying forms of governance, both with respect to the scope of joint initiatives and with respect to the degree of decision-making power accorded to unions; by varying employment and human resource practices; and varying relationships between co-operative 'voice' channels and established collective bargaining arrangements.

While this variability or diversity of postures and practices has emerged mainly, as it were, in 'cross-section' in the literature outlined in this section, it is also plausible to suppose that individual cases of partnership may reveal considerable variability in longitudinal terms: with important changes in postures, functioning and effects occurring as partnerships develop, confront barriers and challenges and adapt in the face of attempts by the parties to grapple with problems and challenges and their experiences of successes and failures along the way. This raises the issue of the dynamics of partnership arrangements and of the influences that may shape these dynamics. Such influences are considered in outline here to provide a basis for the thematic focus of this study. Individual chapters of the book will review the literature pertaining to influences on partnership in more detail.

\section{Influences and dynamics}

\section{Strategy and governance}

The literature on partnership has adopted from the wider human resource management (HRM) literature the premise that the viability of co-operative 
forms of industrial relations depends on the firms involved pursuing competitive strategies that assign priority to quality and innovation rather than depending solely on cost-based competition to secure advantage. Unless such attributes as commitment, motivation, loyalty and skill are required for firms to compete successfully, partnership may be impossible to sustain over time (Kochan and Osterman 1994: ch. 3). Even where competition pivots in important respects around quality and innovation, strains may arise as firms seek to accommodate to pressures on costs and to short-term, cost-related commercial challenges (Colling 1995). A further important issue with respect to the viability of partnership arrangements is the longterm viability of quality-differentiated commercial strategies in industries and markets subject to deregulation and increasingly intense cost pressures (Colling 1995; Crouch and Streeck 1997).

Even where competitive postures may be conducive to partnership, it is recognized that specific mechanisms for integrating human resource and industrial relations policies and practices with strategic decision-making, for example influential human resource executives, works councils or similar structures, have an important bearing on the viability of partnership arrangements (Kochan and Osterman 1994: ch. 3). Only thus can those policies and practices be taken into direct account when strategic options and opportunities are being considered and strategic choices are being made. Without specific mechanisms for 'strategic integration', strategic and operational priorities and decisions may become disconnected, leading to a possible proliferation of tensions and contradictions.

The priority accorded to partnership arrangements and ultimately their sustainability is also widely understood as being predicated on wider systems of corporate governance in firms, and in particular the influence of capital markets versus bank-based credit in financing firms' capital requirements (Kochan and Osterman 1994: ch. 5; Streeck 1997; Ferner and Quintanilla 1998). In the case of public sector organizations, where the state may be the main or sole 'shareholder', the posture of governments towards governance is of obvious importance, particularly as it is well documented that both managements and unions in the public sector routinely attempt to win support for, or to block, employment and employment relations proposals through complex and often informal dealings with senior civil servants and ministers and even with back-bench and local politicians (Ferner 1988; Hastings 1994; 2003).

\section{Organizational boundaries}

Discussions of how competitive strategy may dovetail with the creation and maintenance of partnership commonly take as given that the boundaries of the business unit will remain stable over the medium term. It has recently been argued that when such an assumption is untenable, major difficulties may arise with respect to the attraction or durability of partnerships (Oster- 
man et al. 2001: ch. 3; Rubinstein and Heckscher 2003). Rubinstein and Heckscher (2003: 192) note that, while radical initiatives in 'co-management' in the US (the term, as they use it, appears cognate to 'joint governance') have been shown to lead to higher productivity and lower cost, the diffusion of partnership arrangements of this kind has nevertheless remained limited, while existing initiatives are under pressure. Rather than attributing this state of affairs mainly to such inertial forces as 'old-line thinking on the part of managers and union leaders', Rubinstein and Heckscher believe that it may reflect the cardinal priority now attributed by businesses to achieving flexibility in turbulent markets (2003: 195-6).

Partnership is seen to impose constraints on flexibility as a consequence of expectations and assurances with respect to the maintenance of pay and job security and commitment to training and retraining. In turbulent competitive conditions, firms are seen to focus on core competencies to secure competitive advantage. They may as a consequence promote the vertical disintegration of their operations: divesting themselves of non-core activities and entering a series of alliances with other companies that may include resort to outsourcing (Rubinstein and Heckscher 2003: 196-7). Such an approach may be seen by firms to offer greater flexibility and promise than partnership. Rubinstein and Heckscher accept that it remains an open question whether competitive forces promoting vertical disintegration may become so generalized and intense as to displace partnership of the kind that has become familiar in North America. They nevertheless suggest the possible emergence of a qualitatively new kind of 'networked partnership' that crosses organizational boundaries - the prototypes of which are barely visible at present (2003: 202-3). What is important in the present context is the observation, informed by empirical observation of some of the leading US initiatives in co-management, that turbulent markets and fluid organizational boundaries may pose serious challenges even to those partnerships seen to be capable of delivering the highest flexibility and the most impressive results with respect to costs, productivity and quality.

\section{Senior management}

Closely related to the basis on which firms seek to compete and the role of industrial relations and human resource arrangements in firms' competitive postures, is the issue of corporate values or ethos (Kochan and Osterman 1994; Osterman 1994). It is recognized that, while market pressures are important influences on the choices that firms make, such choices are seldom determined by markets alone. Corporate values may thus be significant in shaping firms' strategies and their choice of employment systems and specifically in sustaining partnership-based approaches to employment relations (Kochan and Osterman 1994: ch. 4; Guest and Peccei 1998; Jacoby 1997). Senior management is recognized as being of pivotal importance in underwriting and communicating values that emphasize stakeholding and 


\section{Understanding voluntary partnership}

viewing employees as resources in a partnership context (see especially Kochan and Osterman 1994: 56-8).

Top management support is also generally recognized as a prerequisite for sustained human resource and industrial relations innovation, especially so when the innovations involved seek to alter radically the status quo and involve significant challenges to vested interests (Kochan and Osterman 1994: ch. 3). In normative models of change, top-level management is commonly seen as pivotal in articulating and communicating a vision of change and in signalling to lower-level management the priorities and behaviours that will find favour or result in sanctions. This view has been underlined in the literature on partnership (see Appelbaum and Batt 1994; CutcherGershenfeld and Verma 1994; Knell 1999). If top-level managers are seen as the key articulators, communicators and agents reinforcing changes and innovation, senior line managers often emerge in the wider HRM literature as the 'heroes' of programmes of change and innovation (Kochan et al. 1986; Guest 1987; Storey 1992; Storey and Sisson 2002; Hastings 2003). Forced to accommodate to external commercial pressures, it is senior line managers who are seen to establish the main strategic and operational parameters of change programmes in human resources and industrial relations - commonly in the context of a realignment of power and roles as between line managers and personnel specialists. Where senior line managers drive change programmes and assume responsibility for new practices, the sustainability of innovations is seen to be enhanced. Such a model of the transformative role of senior line managers has again entered the literature on partnership (see especially Kochan et al. 1986).

\section{Middle managers}

Middle managers have almost universally received bad press in standard accounts of the functioning of partnership and related programmes for employee involvement. They have been viewed, in the main, as among the most implacable opponents of partnership and related initiatives. Driven by the defence of sectional interests, middle managers have been seen as seeking to oppose such initiatives because they disturb established hierarchical ways of working, dilute the authority of middle managers and ultimately, through their commonplace association with delayering, pose a threat to promotional ladders and job security (Cooke 1990; Hyman and Mason 1995). A perspective that seeks to locate middle managers' resistance to partnership and involvement in the context of organizational systems and processes, both formal and informal, has challenged this standard view. While not doubting that middle management resistance to partnership may be fuelled to a significant degree by the defence of sectional interests, this perspective draws attention to the ways in which the intensity of middle management resistance may be shaped by a series of factors in the organizational context in which middle managers work. Such factors as perceived 
divisions or inconsistencies in the management hierarchy towards partnership and involvement initiatives, possible rhetorical rather than real support for such initiatives - resulting in uneven coverage and optional engagement or non-engagement by managers in general - and a divorce between the objectives of partnership and control processes that hold middle managers accountable in the main for the achievement of 'hard' business results, may intensify middle management resistance (Marchington 1995). The possibility of incongruence between partnership and wider 'organizational subsystems' thus provides a richer perspective within which to examine middle managers' responses to partnership (Fenton-O’Creevy 1998; 2001).

\section{Unions and activists}

Some key commentators, particularly in the United States, have argued that partnership provides unions with a means of simultaneously promoting their own revival and greater worker participation and involvement (Kochan et al. 1986; Heckscher 1988; Kochan and Osterman 1994; Kochan 1995; Rubinstein and Kochan 2001: ch. 4). Adversarial modes of representation are seen to have the effect of locking unions and their members into arm's-length dealings with employers, curtailing their capacity to exercise voice and contributing to a low-trust spiral, which ultimately becomes self-reinforcing. Freeman and Rogers (1999) compliment this analysis by presenting evidence from the US that employees seek independent but co-operative representation in their dealings with employers. In the case of Europe, Regini (1995: ch. 5) has made a similar point - claiming that workers have become resentful of and estranged from traditional union postures and have sought dynamic but forceful union representation showing greater flexibility and far-sightedness and less indifference to the circumstances of firms.

Such writers, but especially those writing from the vantage point of the US, show an awareness of the challenges involved for unions in seeking to represent their members in new ways and of the peril that non-reciprocated partnership could damage and undermine the position of unions. The alternatives open to unions appear, however, less compelling, and partnership is seen explicitly to provide a means of extending the frontier of collective bargaining and of union influence. Such an outcome may occur in instances where traditional collective bargaining is institutionally insulated and secured from decisions emanating from partnership arrangements; or where partnership is supported by a nexus of complementary employment practices, to be considered below, that may focus both parties on the gains that can accrue from co-operation in the long run. Some observers, writing from a more sceptical standpoint, have likewise noted the willingness of unions in some European countries to enter various forms of voluntary cooperative arrangements in circumstances where they enjoy strength and security (Streeck 1995). While some major theorists of partnership are emphatic that unions - like employers - retain their order of priorities while 
working through partnership and only make pragmatic choices as to the best means of pursuing these priorities (see especially Cooke 1990: ch. 2; Cohen-Rosenthal and Burton 1993), critics of partnership claim that it amounts to a policy of union moderation that may commonly result in incorporation (Kelly 1996; 1999; Terry 2000).

A number of contributors recognize that the construction and operation of partnership arrangements may accord union officials and senior shop stewards a more prominent role, possibly resulting in a centralization of decision-making over industrial relations within the workplace and the firm. In such circumstances the traditional advocacy role of shop stewards and activists, as well as their role in defending workplace agreements, may be undermined (see Kelly 1999 and Rubinstein and Kochan 2001 for alternative versions of this scenario). Where this occurs, intra-union factionalism and conflict can result, ultimately even threatening the partnership arrangements around which the conflict originated. The 'displaced activist thesis', as this syndrome may be described (Geary and Roche 2003), has been identified in varying degrees of intensity in a number of UK and US studies of partnership (Marks et al. 1998; Clarke and Haiven 1999; Rubinstein and Kochan 2001). Less prominent but also noted in the literature is the possible isolation of the union sections and branches promoting partnership from their parent unions at national level. Reflecting the phenomenon of 'plant level syndicalism', first noted by Sorge and Streeck (1988), unions that opt to deepen co-operation with management at firm and plant level may incur the displeasure and censure of parent union organizations where they are seen to promote or agree to terms, policies, conditions and working practices that depart significantly from the terms set down in firm- or sector-level collective agreements, or that otherwise contravene national trade union policies and postures. The paradigm case here is provided by friction and conflict between the United Automobile Workers (UAW) and the union's local branch at Saturn over aspects of the Saturn partnership and its attendant work practices (Rubinstein and Kochan 2001: ch. 4).

At issue in the conflicting and overlapping views on the situation and prospects of unions under partnership are alternative dynamics that are seen to play out in strikingly different ways. The themes encompassed by these dynamics have only just begun to be the subject of systematic empirical inquiry and thus the general validity of the various positions outlined, or the contingent circumstances in which alternative dynamics might be triggered, remain open questions (see Geary and Roche 2003).

\section{Vertical alignment}

Empirical studies of participation during the 1970s suggested that the most effective forms of participation included both direct and indirect or representative arrangements (Wall and Lischeron 1977; IDE 1981). This theme has emerged with varying degrees of focus in the literature on 
partnership. Cooke's (1990) contribution to the partnership literature sought to distinguish between instances of labour-management co-operation in US manufacturing in terms of the focus and structure of the most important joint efforts or initiatives in operation, as judged by management and union officials. 'Team-based' initiatives describe instances where these parties attribute greatest importance to quality circles, work teams, quality of working life and employee involvement initiatives and - more problematically in conceptual terms - gain-sharing arrangements and employee share ownership programmes. 'Committee-based programmes', on the other hand, describe initiatives where greatest importance is attributed to labourmanagement committees and productivity committees (Cooke 1990: 63-4). This conceptualization of partnerships precludes a direct examination of whether both teams and committees operating in tandem and in close alignment may have specific and superior effects with respect to stakeholder interests rather than initiatives that may be viewed as either mainly committee-focused or team-focused. Working with the distinction forced on survey respondents, Cooke hypothesizes that team-based systems will have a higher impact on company performance (improvements in productivity and quality) and the quality of supervisor-employee relations than committee-based systems because such systems involve a larger proportion of the workforce and supervisors than committee-based systems (Cooke 1990: 96). The empirical results suggest, however, that the systems have similar effects in the main provided that teams in team-based systems meet frequently and regularly (Cooke 1990: 96). The issue of alignment within partnership arrangements - what we will here term 'vertical alignment' - arose indirectly in Cooke's consideration of the effects of union leaders' involvement in top-level joint steering committees, overseeing both team-based and committee-based systems. Cooke found that the extent of union leader participation in top-level partnership steering committees was related to the overall intensity of the co-operative effort between the parties and thus to the effects of partnership on the outcomes discussed above (Cooke 1990: 96-7). For Cooke this could be attributed to a series of specific effects of union leaders' involvement in top-level committees. These include a clear demonstration of support for the work of either team-based or committee-based programmes 'on the floor'; the promotion of interaction between plant managers and union officials, and the active policing of joint co-operative activities vis-àvis traditional contract administration (Cooke 1990: 97). Presumably top management involvement in such committees was regarded by Cooke as more assured and less variable than that of union officials and was not thereby deemed to have an effect on outcomes.

Kochan and Osterman (1994) go further than Cooke in presenting an explicit multi-level model of the mutual gains enterprise, wherein the viability and effectiveness of partnership arrangements is seen to depend on the existence of an interlocking set of postures, arrangements and practices at a series of levels ranging from the workplace, to the human resource function to senior management values and competitive strategy. Though these 


\section{Understanding voluntary partnership}

writers stress the need for partnership arrangements to involve mutually reinforcing sets of initiatives and arrangements initiatives at workplace and strategic levels, the effects of vertical alignment per se on the functioning of partnerships receives particular emphasis.

The most explicit and well-developed understanding of the significance of vertical alignment is outlined by Cutcher-Gershenfeld and Verma (1994). In a discussion of joint governance as a form of partnership, these writers attribute considerable theoretical importance to the alignment of direct and representative arrangements as an influence on the outcomes for stakeholders. Direct forms of involvement, such as team-working and problemsolving groups, are seen to be important in that they address the kinds of changes in practices and organizational systems that are likely to affect performance. Relatedly, they are seen to possess the capacity to involve a sizeable section of the workforce. In isolation, however, such initiatives are seen to pose problems of legitimacy because neither higher-level management nor trade union support has crystallized in formal joint arrangements that might provide 'cover' and security for managers, employees and union members. Without a higher forum to provide strategic guidance and integration, direct involvement initiatives might also suffer from a lack of focus and cohesion. A further problem that might arise is that direct involvement is likely to surface issues, such as the need for changes in organizational processes and systems, capable only of being addressed at a higher and more strategic level within firms. Should it not prove possible to address such higher-level issues, direct involvement could foster new tensions between management, employees and union members. In these ways, the effectiveness of direct forms of involvement is seen to be predicated on the existence of higher-level and representative arrangements (CutcherGershenfeld and Verma 1994: 566-7). Representative arrangements may also possess the capacity to integrate partnership initiatives in general into strategic decision-making, providing focus and cohesion for forms of direct involvement and the issues that they address.

In isolation, representative partnership arrangements involve too few people and are likely to have too little leverage over the kinds of changes that can shift the performance of organizations and improve the conditions of employees (Cutcher-Gershenfeld and Verma 1994: 564-7).

Guest and Peccei (2001: 228-32) found evidence consistent with this thesis in their survey of IPA member companies. High levels of direct involvement when combined with representative involvement in company decisions were associated with positive outcomes for the stakeholders to partnership: employers, employees and unions.

\section{Employment practices}

A number of ways of defining and conceptualizing partnership, as well as a series of models of partnership, assign a central role to a series of human 
resource, employment and industrial relations practices as both empirical features of initiatives that promote direct and representative involvement and as theoretical prerequisites for durable and effective co-operative effort. Kochan and Osterman (1994) in particular identify a set of human resource practices as important features of mutual gains enterprises and as major prerequisites for outcomes that benefit employers and employees. Of the various policies outlined by Kochan and Osterman, the bearing of contingent reward systems, especially those based on profit-sharing, share ownership and gain-sharing, on outcomes is most immediately apparent. To a significant degree, the notion of mutual gains is predicated on employees enjoying a tangible stake in the performance of the firms within which they are invited to regard themselves as partners. Practices promoting 'employment stabilization' also have a clear-cut bearing on partnership arrangements, in that they provide employees and unions with an assurance that they will not become victims of their willingness and efforts to work more productively (Kochan and Osterman 1994: 52-4). Other policies such as careful selection and a relatively high level of investment in human resource development support an approach that seeks to employ and develop people with the technical skills and behavioural disposition required to work on the basis of involvement in operational and possibly strategic aspects of organizational decision-making.

Cutcher-Gershenfeld and Verma (1994: 552-3) extend this set of practices by drawing attention to mechanisms for dispute resolution and problem-solving found in instances of joint governance and seen by them to be important influences on the stability and general effectiveness of such arrangements. Mechanisms like team leader mediation and a disposition to engage in interest-based bargaining are seen as important features of joint governance. In some instances these mechanisms may provide formal channels for resolving disputes and solving problems at multiple levels. In essence, these types of mechanisms can be seen as involving alternative dispute resolution (ADR) principles and practices when compared with the types of grievance and dispute resolution practices associated with traditional industrial relations arrangements.

Other key contributors to the partnership literature, such as Guest and Peccei $(1998 ; 2001)$ and Knell (1999) add little to this picture in theoretical terms, other than giving prominence to sets of communications practices as a core facet of partnership and, perhaps more contentiously, including performance management systems - as distinct from systems of this kind adapted to reflect partnership values and objectives - as human resourcerelated partnership practices (see Guest and Peccei 2001: 220-3; Knell 1999: 23-4). These writers also show that the incidence of such practices is highly variable in IPA partnership companies, although apparently less variable in other instances of partnership commonly viewed as exemplary cases. Guest and Peccei (2001) also find evidence that some human resource practices, especially ESOPs, have significant effects on partnership outcomes in IPA member companies. 


\section{Mutual gains and the balance of advantage}

It is a central premise of much of the partnership literature that co-operation delivers mutual gains - so much so that this concept represents the core principle in Kochan and Osterman's (1994) influential book, The Mutual Gains Enterprise. Sometimes, as in this book, the gains identified relate mainly to employers and employees, as the principal stakeholders in the enterprise. In other studies, possible institutional gains for unions as stakeholders in their own right are also identified more directly (Guest and Peccei 1998; 2001; Rubinstein and Kochan 2001; Roche and Geary 2002). The degree to which mutual gains are in fact realized in practice, for employees and employers, or for these parties and for unions, as well as the balance of advantage between the different stakeholders where gains arise, is only beginning to be examined empirically.

Guest and Peccei's $(1998 ; 2001)$ survey of IPA member companies in the UK established that the principles of partnership endorsed by employers appeared to emphasize employees' responsibilities to make a contribution to the performance of the enterprise to a significantly greater degree than the obligations of the enterprise with respect to employees' rights and benefits (Guest and Peccei 2001: 219-20). With respect to the legitimacy accorded to unions, as outlined above, there appeared to be considerable variability in the postures of the IPA members. On the basis of this evidence and the pattern of employment practices among the companies surveyed, Guest and Peccei (2001: 220) are led to the conclusion that in many cases mutuality may be unbalanced or 'lopsided'. The term 'constrained mutuality' is coined to portray cases in which the balance of advantage, in terms of principles endorsed and practices in place, manifestly favours management (Guest and Peccei 2001: 231). For Guest and Peccei, 'constrained mutuality', understood in this sense, is not without significant consequences for partnership outcomes. The survey results indicate that instances where mutuality is more balanced involve better outcomes for the three stakeholders: employers, employees and union representatives. In such instances, partnership practices are seen to connect with outcomes through their effects on the attitudes and behaviour of the parties, implying for Guest and Peccei (2001: 232) that 'too great a distortion in the balance of advantage would fail to lead to positive performance'.

The concept of constrained mutuality also resonates with one of the findings of Cooke's (1990: ch. 3) survey of co-operative arrangements in US manufacturing companies: the fact that a number of companies co-operate with unions while proclaiming themselves as either neutral towards or opposed to unionisation. The implications for the outcomes of partnership when mutuality is thus constrained ab initio are not, however, addressed in the study. Osterman's (1999) survey of new forms of work organization in US establishments finds that the use of high performance work systems (HPWSs) in non-union and unionized establishments results in gains in pro- 
ductivity, but that pay rises appear to be no more forthcoming as a result. Unionized establishments implementing high performance work systems appear less likely to have implemented lay-offs than establishments in general (Osterman 1999: ch. 4). Thus Osterman is led to conclude that, while high performance work systems provide the potential for mutual gains, these gains are not unambiguously realized - even in unionized establishments (1999: 114). Contrary to Guest and Peccei's claim that the outcomes associated with partnership practices are predicated on changes in employees' attitudes and behaviour, Osterman proposes that where, as in the US during the 1990s, the balance of power in the labour markets favours employers, employees may countenance and accommodate to outcomes that may entail highly skewed gains and that may even put them at a disadvantage. For Osterman, they may even show increased commitment to the firm in the face of such labour-market conditions (Osterman 1999: 114-15).

This kind of darker portrayal of the possible dynamics of partnership turns darker still in the work of critics of partnership. Drawing on evidence from a number of well-known UK partnership cases, John Kelly (1999; 2004) has argued that partnerships frequently originate in business conditions that put employees and unions at an acute disadvantage. In conditions of crisis or dislocation, employers are led to propose partnership arrangements on a take-it-or-leave-it basis; unions then operate as little more than the junior partner in work restructuring, and the inevitable result is that the outcomes of partnership are highly skewed in favour of employers.

The issue of whether partnership leads to mutual gains, and, even if it does, where the balance of advantage may reside in such gains, thus emerges from the research literature as empirically open or problematic. It also emerges as theoretically problematic, especially in the work of Osterman but also in the work of Kelly. Several questions are prompted regarding the implicit or explicit links from partnership arrangements and practices, through mutual gains, to attitudinal and behavioural changes, to positive outcomes for stakeholders. Could it be that partnership arrangements may alter attitudes and behaviour in the direction of higher commitment even in the context of skewed and unequal gains? This is Paul Osterman's question. Could it even be that partnership arrangements may result in highly skewed outcomes that grossly favour employers, without in any material way altering employees' attitudes and behaviour in the direction of commitment, and at the same time damaging unions' representative capacity? This is John Kelly's question.

\section{Collective bargaining}

It appears commonplace for collective bargaining and partnership arrangements to occupy separate and parallel spheres. Such a separation of channels and processes is indeed explicit in Cooke's (1990: 3) definition of 
labour-management co-operation. Textbooks on how to establish partnership also sometimes elevate such a separation of channels and processes into a major postulate. Thus Herrick's insists on the need to create a 'parallel organization' under partnership, wherein committees and groups established to promote co-operation and participation are established in 'parallel to the units of the primary organization' and 'parallel to the traditional collective bargaining structure, (Herrick 1990: xx and see also ch. 2). A later text on creating labour-management partnerships further advocated that such a parallel organization needed to be perpetuated under partnership, as any blurring or merging of co-operative and collective bargaining processes would amount to the dilution of union representation (Woodworth and Meek 1995: 96-109). Other than such prescriptive works, analytic studies also imply or point to the importance of the institutional separation of collective bargaining and partnership channels, especially when considering the rationale for union involvement (Strauss 1998a: 132-3; and see Roche and Geary 2003: 660-1).

But the issue is not so clear-cut. Other desiderata are also found in the prescriptive and theoretical literatures and other patterns are also empirically apparent. Lawler and Mohrman (1987) propose that collective bargaining may be altered in a qualitative sense under management-union co-operation through the advent and application of 'organic' or 'living' agreements. In the same way, Cutcher-Gershenfeld and Verma (1994: 567) propose that joint governance promotes 'procedural rule-making' and reduces the emphasis on 'substantive rules'. In some noted instances of joint governance, in particular at Saturn, joint problem-solving, involving integrative bargaining, appears to have nearly subsumed distributive bargaining channels and processes; indeed, judging from the evidence available on the dynamics of the Saturn partnership, distributive bargaining appears to have arisen in circumstances when partnership was in difficulty or crisis (see Rubinstein and Kochan 2001). In other reported cases of joint governance, it would also appear that management and unions can arrive at decisions in the areas subject to joint governance arrangements that may effectively subsume or override collective bargaining and contract administration (Cutcher-Gershenfeld and Verma 1994).

Even where collective bargaining structures and partnership arrangements may operate in parallel, questions arise regarding possible spillover effects between them (Strauss 1998a: 132-3). It has been reported, for example, that the high trust and positive employment relations climate fostered within partnership arrangements may render established collective bargaining channels less adversarial and even remove issues from the bargaining agenda in such channels (see O'Dowd 2002). The converse possibility should also be recognized - though is less often reported in the literature - that partnership arrangements and processes might be 'held hostage' to collective bargaining in circumstances where employers or unions wish to signal disaffection with progress with issues under negotiation in that 
channel. Other spillover effects with their own specific dynamics have also been reported: such as the instances, noted earlier, where partnership results in the disempowerment and displacement of union activists and shop stewards, once possessed of a secure status under collective bargaining, and may provoke 'displaced activists' in counter-offensives against partnership.

Also relevant here, but little examined in the research literature, is the issue of formal mechanisms for dispute resolution in circumstances where partnership arrangements have been established. Unless agreements instituting partnership formally identify specific mechanisms for conflict resolution within partnership channels - something that appears unusual outside North America but uncommon also in the US and Canada (CutcherGershenfeld and Verma 1994: 553) - the possibility arises that conflicts and disputes generated within partnership forums may by default be handled in an ad boc manner, or dealt with under established dispute resolution procedures. The latter response, in particular, could have potentially destabilizing effects on partnership arrangements and processes. This is because established dispute resolution procedures are premised on a series of principles and assumptions that partnership seeks to transcend: for example, that there exists between the parties a zero-sum conflict of interests, implying a win-lose outcome to conflicts, and that compromises must be brokered on the presumption that the parties share the low-trust attitudes and disposition associated with distributive bargaining postures (Walton and McKersie 1965).

\section{Pivotal events}

The operation and durability of partnership may be critically influenced by so-called 'pivotal events' and how they are handled (Cutcher-Gershenfeld 1988; Eaton et al. 2003). Though the concept may appear tautologous pivotal events are events with pivotal consequences - it is associated with occurrences that give rise to 'generic challenges' to partnership (Eaton et al. 2003: 14). Pivotal events are not understood as acute or discontinuous changes in the external environment. They are viewed rather as largely 'predictable' occurrences (Eaton et al. 2003: 57-63). Several such events are identified in a case study of the development of labour-management partnership in the US healthcare corporation, Kaiser Permanente. These include an industrial dispute which posed challenges to the mutually accepted principle of insulating partnership from normal collective bargaining and contract administration (Eaton et al. 2003: 25-33); problems of succession that arise when senior managers or union leaders instrumental in establishing partnership move on or retire (Eaton et al. 2003: 44); intensified competition and pressure on cost and work restructuring (Eaton et al. 2003: 58-9).

By giving rise to generic challenges, pivotal events are seen to trigger quite distinctive dynamics: the problems and challenges which they pose 
may either be resolved, in which case partnership arrangements are further institutionalized in a non-incremental manner; or the parties may fail to resolve these problems, in which case pivotal events may generate a 'partnership-ending crisis' (Eaton et al. 2003: 58-9). Thus underlying the concept of pivotal events and generic challenges is the idea that the development of partnership arrangements can be highly discontinuous. Many events and problems may affect the diffusion and institutionalization of partnership in an essentially incremental manner. Pivotal events, however, may be expected to have highly discontinuous effects: either accelerating the development of partnership, or destablizing partnership arrangements, depending on whether the parties can find solutions for such occurrences in accordance with partnership principles.

\section{Antecedents}

Many studies of partnership identify specific contingencies that lead employers and unions to create particular co-operative industrial relations arrangements. The types of contingencies commonly identified as antecedents of partnership include more intense competition, the anticipation of increasingly intense competition, commercial crises, the deregulation of hitherto regulated markets, and visionary senior managers and influential trade union leaders who share a commitment to forging innovative ways of working and new employment relationships.

Of greater interest and significance in the present context are more theoretically informed studies that systematically attempt to locate general antecedents of partnership and antecedents of particular forms of partnership, such as joint governance. Few such studies are found but from the available literature two theoretical models linking antecedents with partnership arrangements can be discerned. Also relevant here are what have been described as 'pivotal events', which appear to influence decisively the trajectory of partnership arrangements once they come into being: either spurring the institutionalization of the partnership or hastening the unravelling of cooperation.

\section{Normal competition theory: Cooke's deductive theory of partnership}

Cooke (1990) presents a deductive theory of the origins of co-operative industrial relations arrangements and seeks to test the theory on data from US manufacturing. In Cooke's framework, more or less normal or common competitive forces trigger co-operative arrangements. The emergence of cooperation is also influenced by a series of commonplace operational and financial features of firms. Cooke begins by noting that normally management and the workforce seek to maximize their respective gains or 'absolute utility' from the employment relationship. This dimension of the employ- 
ment relationship is characterized by inherent conflicts of interest: what one party gains, say in wages and conditions or in profits, is lost by the other or forgone. These conflicts of interest are resolved at any point in time by the exercise of 'relative power'. The absolute utility enjoyed by each party is dependent on the total utility derivable by both parties from the employment relationship. This variable-sum dimension of the employment relationship may induce the parties to co-operate in ways that will increase total utility over time. Total utility - the overall size of the 'pie' to be divided in the employment relationship - is a function not of the relative power of the parties but of the combined 'organizational power' of management and the workforce. Relative power then determines the distribution of a fixed sum of utility derivable from the employment relationship. Total power determines the size of the total utility available to the two parties (Cooke 1990: 21-3).

Each party to the employment relationship is assumed to utilize the combination of relative and total power it sees as best serving its own interests. In explaining the emergence of co-operative arrangements, the key concern is to identify the factors that first, influence the perceptions of one or both parties that the perceived benefits derived from increasing total organizational power by instituting co-operative arrangements outweigh the costs; and second, that influence the perceptions of each of the parties that the net benefits from co-operation are greater than those derived from the exclusive use of relative power. Cooke's basic thesis is that the likelihood that parties establish and succeed in managing joint programmes varies directly with the following perceptions for each party:

1 higher perceived benefits from co-operation;

2 lower perceived costs of co-operation;

3 higher perceived costs of relying on relative power options;

4 lower perceived benefits of relying on relative power options.

Cooke's explanatory strategy is to model econometrically the factors associated with either increasing or decreasing these perceived benefits and costs. In this, the focus shifts to managements' choices and to what are termed 'grand labour relations strategies'. External and internal factors are seen as shaping the perceived relative costs and benefits to management of opting for a 'co-operation strategy' over alternative 'union avoidance' strategies and what are termed 'mixed strategies'. Strategies of the latter type are seen as involving co-operation in unionized plants and union avoidance in nonunion plants (Cooke 1990: 47).

Executives choosing a co-operative or mixed strategy have concluded that some degree of co-operation yields greater benefits than non-co-operation. Those choosing a 'union avoidance' strategy perceive that they will derive greater net gain from relying strictly on their relative power than from juxtaposing relative power options and co-operative activities. In comparison to the mixed strategy, the union avoidance strategy and the co-operation 
strategy are more radical (more 'aggressive', as Cooke describes them) and more risky. This is obvious in the case of union avoidance. The risks in cooperation strategies are seen to inhere in the limited experience of unions and employers generally with creating and managing joint programmes, as well as in the organizational changes required to give effect to joint programmes.

Cooke's empirical test of this theoretical framework predicts that more serious market threats require more aggressive, riskier strategies. Thus, the greater the increase in import penetration in the sectors in which plants are located, the greater the likelihood that senior executives will opt for radical and risky co-operation strategies over mixed strategies. This prediction is confirmed empirically, as is a related prediction that these strategies are preferred over mixed strategies where the decline in employment experienced by corporations has been more serious. The higher the level of unionization in a corporation - as indexed by the proportion of its plants organized - the more likely it is that co-operation strategies will be pursued over alternative strategies. It is further predicted that the higher the labour intensity of corporations, the riskier co-operation and avoidance strategies become. The econometric results confirm such a pattern of association between differences in the labour cost proportion of total production costs and choice of strategy. Also, the larger the level of capital investment, the greater becomes the potential loss from radical and risky strategies that fail. Hence the prediction, confirmed statistically, that the higher the average sales volume per plant, the more likely corporations will be to choose the less risky mixed strategy over the alternatives. The fewer the number of plants, the less scope there will be for pursuing the mixed strategy and so the lower the likelihood that this strategy will be adopted. Finally, it is predicted that the tighter the cost pressures on sales across plants, the greater the gains to be extracted from joint programmes addressing cost-cutting or quality improvement or both, and so the greater the likelihood that corporations will choose cooperation over alternative strategies. Both predictions are confirmed statistically (see Cooke 1990: 54-7 for a summary of the statistical results, and Cooke and Meyer 1990 for detailed empirical results).

The underlying logic of Cooke's model points to the effects of more or less widely prevalent sets of competitive and operational/financial forces which are seen as exerting discrete influences over (management) perceptions of the costs and benefits inhering in strategies involving co-operation. In short, 'normal' competitive and operational forces are seen to trigger strategic choices as between co-operation and alternative strategies. These forces, acting in an incremental or additive manner, dispose managements towards co-operation as against alternative strategies. While Cooke's research might appear to provide powerful confirmation of this theoretical framework, a number of serious limitations are evident. While the underlying theory focuses on management and union assessments of the costs and benefits of co-operation, the empirical application of the theory is confined 
to data on management postures. Cooke further focuses not directly on the incidence of empirical co-operative arrangements, whether 'committee-' or 'team-based', but on broader 'grand labor relations strategies' from which such arrangements are seen to derive. This approach involves adding the complicating factor of posture towards unionization as an indicator of managements' grand strategies. The result is that firms categorized within the co-operative strategy include those in favour of joint arrangements and neutral towards unionization, as well as those in favour of such arrangements and opposed to unionization. The latter represent a sizeable proportion of Cooke's co-operation grand strategists. While, as noted above, research suggests that firms engaged in partnership with unions may commonly harbour considerable ambiguity towards unionization, the portrayal of firms opposed to unionization as 'co-operators' raises more serious conceptual and theoretical problems. Finally, the empirical test of Cooke's theory of managementunion co-operation is limited to a small sample of 58 publicly quoted manufacturing companies. Taken together, these problems pose the question as to whether all types of co-operative arrangements may have the types of antecedents proposed by Cooke, especially arrangements that make provision for joint governance, and whether, even if they do, these antecedents may be expected to operate in the discrete, additive manner proposed in Cooke's theory.

\section{Configuration theories of partnership}

What will be referred to as configuration theories of partnership locate the antecedents of co-operative arrangements in configurations or clusters of features and circumstances that affect firms, unions or both firms and unions. These frameworks also sometimes identify disjunctures in the commercial or industrial relations circumstances of firms as antecedents of co-operation, especially in the case of joint governance arrangements.

The kinds of circumstances identified by configuration theories include acute corporate crisis, or impending crisis and acute industrial relations crisis. Where circumstances such as these combine with high levels of unionization, 'unioniate' workforces, visionary senior executives and union officials and influential human resource management departments, the antecedents are seen to exist for co-operative arrangements that may displace established industrial relations structures and processes. Manifestly, no single one of these forces is uncommon. Combinations of these forces in configurations, however, are more unusual, and studies that underscore such configurations as antecedents involve an explanatory framework quite distinct from that advanced by Cooke.

Such a framework underpins Cutcher-Gershenfeld and Verma's analysis of the 'antecedents of joint governance' (1994: 561-3). Cutcher-Gershenfeld and Verma emphasize that crisis is commonly the key catalyst for the emergence of joint governance. But even acute crisis per se may be insufficient to 


\section{Understanding voluntary partnership}

trigger joint governance. The character of pre-existing relations between the parties also conditions their early reaction to crisis. Cutcher-Gershenfeld and Verma emphasize that 'relationship building (formal or informal) through advisory joint programmes' and some degree of 'strategic bargaining' over the survival and future direction of the business are also necessary antecedents for the emergence of joint governance arrangements (1994: 562-3). This framework also recognizes possible curvilinear relationships between commercial pressure and the genesis of partnership: too little impetus from the competitive environment is seen to lead to little change; too much impetus and acute crisis may dispose the parties to intensify a zero-sum approach to the conduct of industrial relations.

This approach seems consistent with Kochan et al.'s (1986) analysis of the circumstances triggering union involvement in strategic business decisions in the US during the 1980s. In contrast with initiatives involving the introduction of quality of working life, team-based and other parallel programmes', which arose in response to widely prevalent competitive trends, the engagement of unions in strategic business decisions tended to arise only in circumstances with well-defined features. So fundamental were the changes required of both parties that radical or strategic engagement through partnership was typically triggered by 'deep crisis' or 'severe environmental pressures' (Kochan et al. 1986: ch. 7). Also necessary for the emergence of strategic partnership was a high level of union organization. This gave unions bargaining leverage against alternative management responses to crisis, such as shifting production to non-union plants or engaging unions in no more than consultative or even cosmetic joint dialogue over the handling of crises (Kochan et al. 1986: 202-3).

Appelbaum and Batt's review of the evidence on workplace innovation in the United States also points to the origins of many significant innovations in 'special circumstances - a serious economic crisis, a charismatic leader, a green-field site, a new product line - as the impetus for change' (Appelbaum and Batt 1994: 72, emphasis added). Unusual circumstances appear to have been particularly pronounced where multi-stranded workplace transformation had occurred: 'work systems have tended to be transformed when three conditions are occurring: a crisis threatens the product line or market share, the company has the resources to gamble on a high-risk strategy, and top management is willing to take that risk' (Appelbaum and Batt 1994: 150).

Appelbaum and Batt (1994: 150) note, however, that the same circumstances often trigger downsizing and union exclusion. Other factors must therefore be prevalent to ferment workplace innovation, and among these may be the 'personalities and commitments of key individuals - the CEO, plant manager, and, where relevant, local and national union officials' (Appelbaum and Batt 1994: 157).

Drawing on case-study evidence for Ireland, Roche and Turner (1998) also emphasize the distinctive sets of circumstances that often represent the 
antecedents of significant partnership initiatives. Partnership arrangements commonly developed where management and unions faced an acute commercial or industrial relations crisis, or anticipated major imminent changes in companies' commercial circumstances. In subsidiaries of multinational plants, co-operation was sometimes triggered by local plants' attempts to persuade parent companies to fund further investment, sometimes where plants in other countries were vying for the same investment. Union density was typically high in partnership companies and unions were well organized - blocking alternative responses to crisis or more conventional rationalization programmes. The values of senior human resource and other executives were also often important in predisposing companies towards risky and uncertain programmes of co-operation. The presence of unions favourably disposed towards partnership, including supportive and influential union officials, also characterized many instances of partnership. Finally, good preexisting relationships between key figures on both sides, possibly born out of the joint handling of crisis, also allowed partnership to develop 'organically' out of 'strong bargaining' relationships of a more traditional character (Roche and Turner 1998: 99-101).

Roche and Turner further sought to distinguish the configurations of circumstances and features that shaped different types of partnership arrangements. Partnership arrangements based on consultative principles were more likely to emerge where many of these factors interact with low 'unionateness', as indexed by the limited engagement of union members in plantlevel union affairs. Joint governance arrangements, on the other hand, more typically developed where crisis, impending major commercial change and supportive pre-existing management and union postures, interacted with strong traditions of union activism and solidarity at plant level and possibly in the wider industrial community in which plants were located (Roche and Turner 1998: 100).

A similar type of explanatory framework underlies Knell's (1999) exploration of the antecedents of partnerships in the UK. Knell (1999: 17) notes that no single driver or catalyst encouraged the adoption of partnership in all of the case-study companies examined. Rather it was necessary to recognize the influence of 'clusters' of factors as antecedents of partnership. Four such clusters are identified. The first includes a well-developed adversarial collective bargaining tradition and a high level of unionzation. The 'route to partnership' in such circumstances had not been via a direct response to crisis in either the commercial circumstances of firms, or in their industrial relations. Rather the parties seem to have arrived at the view that adversarial relations ill suited their objectives. The second cluster identifies circumstances where partnership had evolved out of long-standing traditions of paternalistic employee relations rather than emerging as a step change or acute departure from established traditions. A third cluster involves circumstances in which partnership had been adopted in response to the transformation of work organization. A fourth cluster involves circumstances 
where partnership had been established at the inception of firms as a reflection of a coherent values-based philosophy by management (Knell 1999: 17-18). Knell does not consider whether the different configurations or clusters of antecedents give rise to different types of partnership arrangements. Nor is it clear with respect to several of the clusters identified, especially the first and second clusters, why or due to what changes the parties sought to depart from pre-existing traditions and to embrace partnership. The presumption must be that partnership in such circumstances developed gradually or incrementally over time.

In summary, two explanatory frameworks inform the limited research to date systematically examining the antecedents of co-operative industrial relations arrangements. Each framework attributes importance to commercial and competitive conditions, the features of plant managements and union organization. The manner in which these variables are conceived of as influencing the adoption of partnership, however, differs significantly between the frameworks. What has been termed normal competition theory is based on a straightforward linear view of the kind of influence exerted by variables like competitive pressure: the higher the level of competition, the greater the probability that executives and possibly union officials will take risks and opt for co-operation; the tighter the cost pressures on sales, the higher the probability that partnership will emerge, and so on. The alternative configuration framework emphasizes clusters of factors as the decisive influence, particularly acute crisis, or impending crisis, the parties' value systems and pre-existing industrial relations traditions.

It is notable that the two frameworks have emerged for the most part out of different research approaches. Cooke's theory is informed by survey-based research, which makes it technically difficult to discover and to model the kinds of complex antecedent effects associated with configuration theories. Configuration theories derive mainly from case-study approaches, which make it possible to identify and allow for complex causal patterns and alternative routes to partnership arrangements. Case-study approaches make it difficult to establish, however, the relative incidence of different configurations of antecedent conditions.

\section{The effects of partnership}

Some of the areas encompassed by partnership have been subjects of longrunning research interest, in particular the effects of job autonomy and teamwork on employees and organizational performance and the effects of participatory arrangements of various kinds on the parties to industrial relations (see Heller et al. 1998; Edwards et al. 2002a; Geary 2003 and Handel and Levine 2004, for summaries of research on these and related areas).

The earlier and the wider literature on participation shows that employees in general seek higher levels of influence over decisions affecting their work and work lives than commonly available to them. This encom- 
passes both task-level involvement and participation in organizational decision-making (Wall and Lischeron 1977; IDE 1981; Drago and Wooden 1991; Gallie and White 1993; Gallie et al. 1998; Freeman and Rogers 1999). A further body of research suggests that progressively higher proportions of employees favour further scope for involvement and participation (Kanter 1978; Heckscher 1988; Rose 1989; Inglehart 1997). The earlier and wider literature also reports that participation in its various forms, including task participation, teamwork, representative participation and communicative participation (information exchange), impacts positively on such areas as job satisfaction, levels of trust and attitudes to the employer (Blumberg 1968; IDE 1981; Lincoln and Kalleberg 1990; Gallie et al. 1998). The evidence with respect to the effects of participative arrangements in general on wage levels is more equivocal, with the most careful review of international evidence concluding that many involvement initiatives have no effect and that the average effect may be no more than a few percentage points (Handel and Levine 2004). The same review concludes that there is no evidence that involvement programmes consistently increase employment security (Handel and Levine 2004: 35-8).

Relatively little research has directly addressed the effects of voluntary partnership arrangements of the kind that have emerged in unionized workplaces over the past two decades. Given the limited direct evidence available on the operation and effects of partnership arrangements, it is perhaps not surprising that these issues are keenly debated in the partnership literature.

In reviewing the literature on the effects of partnership, two broad positions or groups of writers will be identified: the 'advocates' and the 'critics'. Subsequent chapters of the book will expand on these positions and seek to assess their respective merits by investigating the effects of different aspects of partnership in Aer Rianta on the company, on employees and on trade unions.

\section{Advocates}

Advocates derive their position from the view that adversarial industrial relations are no longer viable in the light of modern competitive pressures and the changing preferences of employees and union members. They are also influenced by what they judge to be significant evidence as to the positive effects of partnership arrangements on organizational performance, on employees' conditions of employment and on the effectiveness of trade union representation. These themes in the work of advocates will be considered in sequence.

\section{Employer outcomes}

Kochan and his colleagues have emerged as the strongest and most consistent advocates of partnership. Partnership arrangements, especially when 
based on mutual gains principles, backed by compatible human resource practices, are seen to deliver a series of organizational outcomes of interest to employers, including higher commitment among employees, higher productivity, lower costs, higher quality and higher profitability (Kochan et al. 1986; Kochan and Osterman 1994: ch. 3; Ichniowski et al. 1996; Osterman et al. 2001: 83-93; Rubinstein and Kochan 2001 and see Heckscher 1988). Effects such as these are underscored by Cooke's research on joint cooperative programmes in manufacturing, which associates both direct and committee-based forms of involvement with improvements in quality, productivity and supervisor-employee relations and increases in return on sales and added value per employee (Cooke 1990: ch. 4). Knell (1999) also identifies a series of positive outcomes for employers in his UK case studies advocating partnership. Knell's cases include non-union firms but the research does not distinguish any outcomes as specific to these. The outcomes identified include various dimensions of improved competitive performance, such as higher profits and higher turnover, lower levels of labour turnover and lower absenteeism (Knell 1999: 28-30). While Guest and Peccei (2001) cannot in the same sense be directly identified as explicit 'advocates' of partnership, their research nevertheless strengthens the advocacy of the IPA in pointing to a range of positive partnership outcomes. Again this research includes non-union firms but does not identify any outcomes as specific either to these or to unionized firms. Guest and Peccei (2001: 229-30) find that direct and representative participation and flexible forms of job design are associated with more positive employee attitudes and behaviours than less participative and flexible work arrangements. These, in turn, along with employee share ownership, are associated with higher labour retention and lower levels of absenteeism. Share ownership and retention are associated with better organizational performance in such areas as productivity, product/service quality and innovation, and thus with higher levels of sales and profits.

Black and Lynch have presented a series of survey-based and establishment-level studies of the impact of high performance work practices (HPWPs) (self-managed teams, job rotation, production workers trained during past year) on a series of outcomes in the United States. These studies also overlap with studies of partnership arrangements in unionized firms by examining whether unions mediate the effects of HPWPs on outcomes (Black and Lynch 1997; 2000; Black et al. 2004). Based on a 1994 establishment-level survey, Black and Lynch suggest that co-operative, or 'transformed' labour relations arrangements in unionized firms, comprising at least 50 per cent of non-managerial employees using computers and meeting regularly to discuss workplace issues, profit-sharing for non-managerial staff, total quality management (TQM) and benchmarking and at least 30 per cent of workers in self-managed teams, are associated with the highest levels of productivity (Black and Lynch 1997: 23-4 and Table 2). Black and Lynch (2000), using the same 1994 establishment data as well as data from a 
follow-up survey in 1997, again report an association between HPWPs and levels of productivity in manufacturing. Profit-sharing and employee stock options are also associated with higher productivity. Employee voice, defined as the proportion of workers meeting regularly to discuss workplace issues, is further associated with increased productivity in panel data, when voice is exercised in this sense in the context of unionized establishments (Black and Lynch 2000: 24).

\section{Employee outcomes}

Partnership arrangements have also been linked by some advocates with positive outcomes of various kinds for employees, including profit- and gain-sharing, more satisfying work, improved supervisory-employee relations and a higher level of employment security (Cooke 1990: ch. 4; Kochan and Osterman 1994; Ichniowski et al. 1996; Osterman 1999: ch. 4; Osterman et al. 2001; Rubinstein and Kochan 2001). Bearing in mind again that UK research on partnership by Knell (1999) and by Guest and Peccei (2001) extends to non-union firms, a series of positive outcomes of partnership for employees are also identified. These include high levels of satisfaction and strong identification with firms' objectives and values (Knell 1999: 28-30), a positive 'psychological contract', a positive contribution of ideas and suggestions for innovation and higher organizational commitment (Guest and Peccei 2001: 226 and 229-30). Black et al. (2004), drawing on US establishment-level data, show that HPWPs are associated with higher wage levels, especially in unionized establishments. The pattern with respect to trends in employment in establishments, however, is less clear-cut. Selfmanaged teams and profit-sharing are associated with large reductions in employment (amounting to 20 per cent or greater), whereas the proportion of workers involved in job rotation is negatively associated with such largescale reductions (Black et al. 2004: 20). The effect of 'employee voice' on job cuts is shown to be mediated by unionization, 'high voice' establishments that are unionized having a lower incidence of large-scale employment reductions. HPWPs are also found to increase wage inequality in establishments between production and non-production (managerial and professional) workers, but the effects of specific HPWPs are found to vary in complex ways between unionized and non-union establishments (Black et al. 2004: 19).

\section{Trade union outcomes}

Some advocates of partnership identify a series of outcomes favouring unions. Prominent here again are Kochan and his colleagues who advocate union involvement in partnership as one means of promoting union renewal and of extending employee participation (Kochan and Osterman 1994; Osterman et al. 2001: ch. 4; Rubinstein and Kochan 2001). This view is 
supported by research by Freeman and Rogers (1999), which shows that workers in the US want greater involvement in their work and more involvement by their representatives in organizational decision-making, but prefer unions working in co-operation with management. These findings echo the views of researchers like Heckscher (1988) that adversarial union representation narrows the scope of representation and leads to a perception among members that unions are remote and bureaucratic. In the UK, Ackers and Payne (1998) have advocated partnership as a channel through which unions can regain the 'institutional centrality' they once enjoyed in workplaces. Based largely on a conceptual analysis of partnership and a priori reasoning, they advocate partnership as a means through which 'unions can regain the initiative and work to rebuild their institutional presence' (Ackers and Payne 1998: 545).

\section{'Win win' outcomes}

Through addressing the effects of 'high performance work systems' (HPWSs), comprising participatory work practices and complimentary human resource practices, in unionized and non-union firms, research by Appelbaum et al. (2000) provides strong and explicit advocacy for some partnership-related practices, concluding that they 'pay off for firms and employees. In steel, apparel and medical electronic instruments, a variety of positive performance outcomes are found to be associated with the scope for work participation, defined as a composite of worker autonomy, degree of communication among frontline workers, work in self-directed teams and participation in problem-solving teams (Appelbaum et al. 2000: 103-4 and ch. 7). Positive effects are also found for such complementary human resource practices as employment security, and pay related to group or company performance. Synergies between both sets of practices are also confirmed in their higher combined than discrete effects on performance (Appelbaum et al. 2000: ch. 8). Positive effects of work participation and related HR practices are also found for a variety of work-related outcomes, including trust in management, organizational commitment (apparel being an exception), job satisfaction (in steel only) and earnings. No evidence is found that HPWSs are associated with higher levels of stress or work intensification; on balance the evidence suggests that they are associated with more positive work experiences (Appelbaum et al. 2000: ch. 9). The study concludes that high performance work systems in manufacturing lead to 'win win' outcomes for plants and workers (Appelbaum et al. 2000: 115). Appelbaum and her colleagues devote little attention to whether unions mediate the effects of HPWSs, confining their examination of unions to the discrete effects of unionization on firm and worker outcomes. 


\section{Dual commitment}

A final theme that merits discussion concerns the possible link between partnership and commitment to both employing organizations and trade unions. 'Dual commitment' in the context of voluntary partnership can be seen as an influence that might mediate the achievement of mutual gains. Employer objectives like higher productivity and better organizational performance appear more likely to be realized if partnership arrangements result in organizational commitment. The institutional security and representative capacity of unions are also likely to be copper-fastened if partnership can also deliver commitment to trade unions. Positive employee outcomes, like better pay and conditions and more secure employment also seem more likely where both types of commitment and a better climate of employment relations are fostered.

US research during the 1980s provided what might be described as 'proto advocacy' for partnership by concluding that dual commitment arose in contexts marked by job autonomy and a positive industrial relations climate. A series of studies in road and air passenger transport, newspaper distribution and of union members at branch level found that different facets of job autonomy and influence, perceptions of a positive climate of industrial and supervisory relations and positive assessments of joint co-operative programmes, were associated with both organizational and union commitment (Fukami and Larson 1984; Angle and Perry 1986; Magenau et al. 1988; Sherer and Morishima 1989).

While research and commentary in other Anglo-Saxon countries during the 1990s more explicitly related the theme of dual commitment to cooperative industrial relations arrangements, a series of empirical findings failed to replicate the US results of a decade earlier (Barling et al. 1990; Fullagar and Barling 1991; Guest and Dewe 1991; Deery et al. 1994; Guest 1995).

Following Guest (1995), it remains a pertinent question whether formal partnership arrangements may be particularly effective in fostering dual commitment (see Guest 1995). Partnerships usually explicitly seek to foster commitment to companies. In the eyes of advocates they underwrite and enhance the representative capacity of trade unions. Partnerships seek to foster these outcomes through enhanced job autonomy, the involvement of unions in organizational decision-making and the promotion of a positive industrial relations climate.

\section{Critics}

Critics of partnership fall into two distinct camps: those who believe partnership to be beneficial to employers but not to employees or trade unions and those who believe voluntary partnership arrangements to be of little lasting or real advantage to any party. Each position will be considered in turn. 
Good for employers but less so for unions or their members

John Kelly has been the main exponent of the view that voluntary partnership, reflecting what he calls a strategy of 'union moderation', delivers few benefits to unions and their members (Kelly 1996; 1998; 1999; 2004). Kelly originally advanced his argument on the basis of a critique of the wellknown single-union arrangements at Nissan's facility in Sunderland, presenting Nissan as a paradigm case of 'union moderation' (Kelly 1996). Subsequent work however has focused more tellingly on exemplary and other cases of partnership in the UK. This latter research showed that partnership was commonly initiated by employers in a largely coercive manner, unions being presented with de-recognition or the closure of unionized facilities as the alternatives. Employers had also commonly failed to honour commitments in partnership agreements to preserve employment security and maintain competitive wage levels (Kelly 1999). Kelly's subsequent analysis of $22 \mathrm{UK}$ partnership agreements found that the rate of job losses was higher in partnership companies, as compared with a matched sample of non-partnership companies or industry-wide trends. The evidence with respect to pay rises in partnership companies revealed that some had registered relatively high pay rises, whereas others had not (Kelly 2004: 281). Evidence with respect to levels of union influence on company decision-making was sparse and seemed to preclude secure generalization, but evidence existed that the influence of workplace representatives had declined in some cases. Though partnership may have precluded union derecognition or the closure of unionized establishments, trends in union membership arrangements were highly variable under partnership. Kelly seems disposed to assess the evidence as suggesting that unions and their members had gained little from partnership in terms of employment security, wage rises, influence or organization, except in a few cases (Kelly 2004: 281-3).

The variability in the operation and effects of partnership revealed by Kelly's own research and the wider corpus of research, nonetheless leads Kelly to qualify his original position. Kelly postulates a range of partnerships falling along a continuum anchored at one end by what he terms 'employer-dominant' partnerships and at the other by 'labour-parity' arrangements. Employer-dominant arrangements are characterized by a balance of power favourable to employers, partnership agendas reflecting employer interests and an emphasis on union compliance rather than cooperation. Labour-parity arrangements arise where power is more equally balanced; unions are well organized; agendas reflect the interests of both parties; and employers are dependent on labour co-operation (Kelly 2004: 283-9). Besides emerging from different sets of commercial and institutional conditions, these types of partnerships are expected to lead to different outcomes: employer-dominant arrangements favouring employer outcomes and labour-parity arrangements delivering mutual gains. Kelly remains 
pessimistic with respect to the wider diffusion of partnership arrangements, especially of the labour-parity type, in the UK. Product market volatility, union weakness and capital market pressure for short-term results are among the forces seen to weaken the incentives for employers to initiate partnerships on a widespread basis (Kelly 2004: 287-9).

Kelly's analysis of the outcomes and prospects of partnerships in the UK is endorsed by Michael Terry (2003b). For Terry, partnerships in the UK ally unions to the language and priorities of businesses, with local activists commonly suffering displacement and employment security agreements lacking much force. Terry's work also provides a bridge with Wolfgang Streeck's critiques of voluntary co-operative arrangements, to be considered in the next section, in his insistence that co-operation needs to be underpinned by a legal framework if unions and their members are to reverse the decline in their fortunes (Terry 2003b: 470-1).

\section{Weak and ineffective for all parties}

Wolfgang Streeck has presented a critique of voluntary co-operative arrangements that needs to be understood against the background of his corpus of work on German works councils and co-determination (Streeck 1992; 1994; 1995). Streeck's core contention is that strong and durable co-operation must be embedded within 'strong institutional constraints' of the kind provided by the German legal code. In the absence of such constraints, the operation of co-operative arrangements is likely to be contingent on employers' willingness to seek agreement and consent when warranted by market conditions or, more generally, on what Streeck calls unions' willingness to maintain 'good behaviour', or to accept managements' priorities (Streeck 1992). Where markets are seen not to warrant co-operation, or unions are disposed to pursue their own priorities on a co-operative basis, employers, according to Streeck, will be prone to defect from voluntary co-operative arrangements. The net effect of these features of voluntary co-operation is that partnership will be unable to generate deep or durable co-operation, proving instead to be weak in co-operative terms and unstable in institutional terms.

Like Kelly, Streeck has softened his position in the light of the emergence of voluntary co-operative arrangements embedded in strong and secure union organization. While Kelly's qualifications had been prompted by labour-parity partnerships that had arisen in the Anglo-Saxon world, Streeck's reconsideration of voluntary co-operation arose from instances of co-operation beyond the remit of legislation and collective agreements in European countries like Sweden and Italy. While Streeck sees such arrangements as significant, he nevertheless remains convinced of the limitations of voluntary co-operation (Streeck 1995: 330). 


\section{Understanding voluntary partnership}

\section{The breakdown of partnership}

Advocates and critics of partnership generally agree that voluntary partnership arrangements are vulnerable to defection either on the part of employers or unions in the absence of strong, robust institutional constraints (Streeck 1992; 1995; Rubinstein and Kochan 2001). The reasons why either or both parties may consider it appropriate or expedient to defect vary, but the literature has focused on a number of key factors.

\section{Contingent commitment to partnership}

The first reason why employers or unions might defect from partnership arrangements is that the benefits from working in partnership may be shortlived and finite, and, that after a certain period, either or both parties may think it more beneficial to revert to traditional postures. For employers, as the nature of competitive challenges varies, so too may they alter their employment relations strategies. A partnership approach may thus be seen to be advantageous in very particular market circumstances, but less so in other contexts. Some scholars, however, have placed less emphasis on competitive conditions as an important explanatory factor, and have instead emphasized that management may withdraw from partnership arrangements as they come to feel insecure in the face of an enhancement in the voice of employees and unions (Edwards et al. 2002b; Hammer and Stern 1986).

In the same way, unions' calculations of the benefits to be derived from remaining within a partnership agreement may change over time. Trade unions have been seen by some scholars to alternate back and forth between partnership and adversarial postures depending on the perceived advantages of pursuing one approach over another (Hammer and Stern 1986).

\section{Union factionalism and internal strife}

Second, defection is seen to occur as a consequence of tensions generated within unions as decision-making in respect of the nature and structure of partnership arrangements becomes centralized around a small group of union activists (Heckscher 1988: 127; Kelly 1999; Rubinstein and Kochan 2001; Terry 2001; 2003a and b). We referred to this above as the 'displaced activist thesis'. The abandonment of partnership may thus occur where senior union officials succumb to criticisms from union activists and membership that partnership has resulted in a centralization of power within the union and the marginalization and alienation of shopfloor representatives. Where such a dynamic takes hold, the future sustainability of partnership is seen by advocates and critics to be jeopardized. 
The interface between collective bargaining and partnership

The relationship between collective bargaining and partnership arrangements is widely seen in the literature as being a critical factor in explaining the sustainability of partnership in the long term. Views as to whether both processes can or should be kept separate and occupy different spheres, or whether they should eventually merge through, for example, the adoption of mutual gains bargaining, diverge. The latter view, as often expounded by advocates of partnership, is premised on the opinion that the trustful relations which develop within partnership forums are likely to spill over into collective bargaining and recast behavioural relations therein. As outlined earlier, the possibility that spillover effects may flow in the opposite direction and that the adversarial relations which inform collective bargaining may come to colour relations within partnership structures is recognized less frequently in the literature. This, however, must be seen as a possibility, especially in circumstances where trade union members fault partnership for not having provided significant gains.

\section{Reliance on established forms of dispute resolution}

The adoption of so-called alternative dispute resolution procedures has recently been recognized as a critical factor in explaining whether partnership arrangements prosper or break down (Cutcher-Gershenfeld and Verma 1994; Rubinstein and Kochan 2001). The argument here is that established mechanisms of dispute resolution informed by adversarial postures, where the parties go head-to-head in pressing the merits of their respective positions, are inappropriate in a partnership context. To continue with such resolution procedures risks destabilizing and undermining partnership arrangements. The argument thus advanced by Rubinstein and Kochan (2001) is that, if partnership is to prosper, the parties need to give early consideration to how they might recast their dispute resolution procedures in line with the principles and values which underpin their partnership agreement.

\section{Management and union succession}

Finally, there is the issue of the vulnerability of partnership arrangements in the face of management and union succession. This brings us to the heart of the critics' case, certainly as proposed by Streeck, that, in the absence of legislative or other institutional constraints, employers, in particular, retain considerable freedom of manoeuvre in deciding whether to maintain or abandon a partnership approach. Management and union succession or transition might thus be seen as a 'pivotal event' in the sense described above. Advocates of partnership have argued that such problems of succession may be handled successfully where companies adapt their HR policies to complement the 


\section{Understanding voluntary partnership}

principles underlying partnership. Our attention is thus drawn to the level of congruence that may or may not exist between, for example, performance management systems, job descriptions and promotion criteria and the aims and values underpinning the partnership arrangement. Where HR policies are thus recast and the management of managers is informed by partnership principles, the future viability of partnership is seen by advocates to be made more secure.

In summary, it is possible to identify competing theoretical positions within the literature as to whether voluntary partnership arrangements between employers and trade unions are viable in the long term. For critics, such as Streeck, in the absence of 'hard' institutional supports, voluntary cooperation is unlikely to be sustainable, principally because both parties are able to defect for strategic or opportunistic reasons. As defection remains an option for either side, unions' and employers' commitment to working in partnership with each other is likely to be half-hearted, tentative and guarded. For Streeck, then, voluntary partnership arrangements are inherently vulnerable because neither party can be trusted or required to cooperate in the long term. Voluntary workplace partnership is thus seen to be endangered by an inherent and chronic 'co-operation deficit'.

Kelly's critique of partnership agreements has focused on the grossly unequal gains which workers derive from their unions' co-operation with employers. Although he does not specify an explicit link between the manner in which such arrangements disadvantage workers and the breakdown of partnership, he does imply that there is such a connection. He also draws our attention to the possibility of competing factions developing within unions as partnership arrangements privilege the role of union officers over lay representatives. Breakdown may thus be seen to occur as a consequence of the displacement of shopfloor union activists and the internal strife and conflict which this generates.

The other theoretical position, as proposed by advocates of partnership, is that partnership arrangements can be made viable where senior management constructs the requisite institutional supports. There are a number of levels at which this is seen to be necessary. At the strategic level, the viability of partnership is seen to depend on the adoption of competitive strategies which assign priority to security of employment, and good wages and conditions of employment. Also seen to be critical is the vertical alignment and integration of representative structures, such as steering groups, with team-based or other direct participation initiatives. Advocates also lay stress on the need to recast industrial relations and HR policies so that they are better aligned with the values and objectives of partnership, principally in areas such as performance management, promotion and dispute resolution. The interface between collective bargaining and partnership is also seen to require careful management. The thrust of the advocates' case is that partnership arrangements can be made effective for both parties and be made durable where mutually reinforcing policies and practices at a series of levels are introduced. 


\section{Conclusion}

Voluntary partnership arrangements of various kinds have become a feature of employment relations in Anglo-Saxon countries, yet little research has been devoted to their features, antecedents, effects, and factors leading to their breakdown. A review of approaches to the study of partnership reveals considerable variation across partnership arrangements with respect to a series of features: the legitimacy accorded to unions and their involvement in decision-making; the scope and influence of joint decision-making, employment practices and relationships between co-operative channels and collective bargaining. A series of influences on the operation of partnership arrangements have been identified in the literature, and these may be expected to mediate the outcomes of partnership in ways that remain in need of rigorous examination. These include competitive strategy, governance and the degree of fluidity of organizational boundaries; the postures of senior and middle managers; the dispositions of union HQs and of union activists. Aspects of how partnership arrangements are configured also influence their operation. Significant here are levels of vertical alignment between direct and representative involvement; the existence of compatible employment practices; the way partnership is aligned with collective bargaining channels and the balance of advantage seen to inhere in the functioning and outcomes of partnership. Pivotal events may critically influence partnership. Depending on how these are handled, they may either accelerate the institutionalization of partnership, or acutely destabilize cooperation.

Two approaches to identifying the antecedents of partnership have been distinguished. The first of these links the emergence of co-operative arrangements with relatively high competitive intensity, aspects of the economics of firms making co-operation a low-risk activity and some features of firms' industrial relations. The second approach relates the emergence of partnership arrangements to configurations or clusters of market and organizational features and sometimes puts greater emphasis on partnership as an outcome of discontinuous commercial change, interacting with unusual sets of organizational features.

Approaches to the effects of partnership are also polarized between 'advocates' and 'critics'. The advocates draw from research showing that partnership-type arrangements can lead to positive outcomes for all stakeholders. Critics argue that partnerships commonly favour employers, or deliver few benefits for any party. There are signs that the gap between advocates and critics may be closing due to the acceptance by critics that partnership arrangements may be highly variable in their operation and outcomes in ways that have yet to be subjected to empirical examination.

The themes examined in this chapter will be considered empirically in the chapters reporting our research on partnership in the Irish Airports Authority. 


\section{The case and research methods}

This chapter outlines the logic behind the choice of Aer Rianta for intensive study and the general significance of the lessons that may be learned from the experiences of management, unions and employees in the Aer Rianta partnership. The chapter also describes the fieldwork and research methods employed in the study of partnership in the company.

\section{The case}

Only an outline of the major features of the company will be provided here, with a view to locating the case in research context. A profile of the business and industrial relations features and contexts of Aer Rianta will be presented in subsequent chapters of the study. Until it was replaced by the stateowned Dublin Airport Authority in late 2004, Aer Rianta was the stateowned commercial company whose main activity involved the management of the main Irish airports at Dublin, Cork and Shannon. The company employed about 3,300 people, 2,400 of which worked in the airports. At the outset of fieldwork in 1997, the numbers employed in the airports and related activities were marginally fewer at 2,100. A subsidiary of Aer Rianta, Aer Rianta International, managed duty-free outlets in a number of overseas airports. The company also held stakes in several airports in the UK and Germany. A second Aer Rianta subsidiary, Great Southern Hotels, owned and operated a hotel chain within Ireland. The focus of the study is on Aer Rianta's core operations in the Irish airports, as partnership in the company was largely confined to this part of the business.

Aer Rianta represents a significant case for the study of voluntary partnership for four main reasons. First, as will be outlined in the next chapter, it offers an important example of a genuine attempt to undertake a radical and sophisticated partnership initiative, combining direct and indirect participation, covering in principle all areas of the business and extending across all levels of the organization, from the shopfloor, to business unit and company levels. This makes Aer Rianta the most radical and significant partnership initiative undertaken in Ireland. Moreover, the authors are not aware of any other initiative of comparable breadth and depth in the UK, and few compara- 
ble initiatives have been undertaken in the Anglo-Saxon countries, outside the exemplary North American cases that have dominated the literature. In recognition of the significance of the case, the Joint Union Company Group at the helm of the Aer Rianta partnership received an award from the Involvement and Participation Association in 2000. Second, and related, such a major initiative in voluntary partnership provides a rich setting in which to study the influences, antecedents and effects of partnership outlined in the theoretical and research literatures, especially in the context of a longitudinal research design spanning some six years. In particular, as the case involved a multilevel and multi-stranded partnership initiative, underpinned by considerable management and union support, it can be used to examine the issues at stake in the dispute between 'advocates' and 'critics' of partnership. Third, although the company was publicly owned and a monopoly service provider at Ireland's main airports, it had always been highly commercial and entrepreneurial in character, as evidenced by its track record in the pioneering of duty-free sales and by its international operations. Furthermore, as will be outlined in later chapters, Aer Rianta experienced very diverse commercial and labour market pressures during the period covered by the research. These included strong financial pressures arising from a burgeoning capital investment programme; disjunctive commercial change arising from the loss of duty-free sales; a radical turnaround in its local labour market, involving a shift from high unemployment to virtual full employment; changes in its regulatory environment arising from the appointment of an airports' regulator; ongoing threats to its monopoly status; and the prospect of a break-up into three separate publicly owned airport authorities in the second half of 2003. Hence the case company cannot reasonably be viewed as a sheltered or 'sleepy monopoly', providing lessons of limited generalizability beyond the public sector, or beyond Ireland. Partnership in Aer Rianta functioned, rather, in the context of commercial pressures of a kind that in the main favour the generalizability of the findings beyond the public sector and beyond Ireland. Finally, the authors enjoyed complete access to personnel, documentation, committees and groups and were able to conduct a major survey of the Aer Rianta workforce, as well as undertake secondary analysis of earlier surveys conducted within the company. Such a level of access remains unusual in studies of partnership, particularly as access spanned a period of six years.

The authors were originally commissioned by the Irish Department of Public Enterprise to examine the development and functioning of partnership, or what was known as constructive participation (CP), in Aer Rianta. Fieldwork spanned the period from 1997 to 2002, with the main phase of intensive fieldwork concentrated in the period 1998-2000 and a second phase of intensive fieldwork during late 2002. In between these intensive fieldwork phases, the authors kept in close touch with developments in Aer Rianta, conducted updating interviews with the principals involved, and closely followed coverage of developments in the company in the business and industrial relations press and media. 


\section{Methods of research}

Complete access was permitted to all CP activities and to all those involved in the operation of CP: company management, union officials and activists and the workforce. An invitation to join the joint steering group responsible for overseeing the partnership, the Joint Union Company Group (JUCG), and to contribute as ordinary members, was accepted. The authors and wider research team also joined a number of other groups, including those dealing with personnel and industrial relations policies and corporate strategy. Finally, in the autumn of 2002 the JUCG asked the authors to prepare a consultative document that might assist in the revitalization of the partnership, by then effectively wound down. Their report was delivered to management and unions in early 2003. In these ways the research involved a significant element of participant observation. From 1997 to 1998, as CP was rolled out across the company, the project's senior research officer spent a lot of time at Dublin Airport and other locations observing the progress of partnership and attending meetings connected in different ways with CP. All internal files, documentation and research relating to $\mathrm{CP}$ were accessible to the research team. The research team and the authors provided feedback on the research and discussed their findings with key figures in management and the unions at various points during the period covered by the research. In particular, in the second half of 2002, formal presentations were made to senior management and the JUCG at the request of both groups. During these the authors discussed their findings and their interpretation of these with senior managers and the JUCG.

Throughout the period of the research, business and industrial relations developments at Aer Rianta received extensive coverage in the national print and broadcast media, as well as in the specialist weekly industrial relations publication, Industrial Relations News. Relevant coverage from these sources and information from the company's annual reports have been drawn on where relevant.

Intensive interviews were conducted with senior managers, middle managers, full-time union officials and activists across the three airports and in other divisions of the company. A number of these interviews were conducted in the context of periodic updates during the course of the period spanned by the research. Most of the interviews were concentrated into the two intensive fieldwork phases, the first phase occurring during 1998-99, and the second in late 2002. The details of the intensive interviews are as follows:

First intensive fieldwork phase 1998-99: 16 senior managers interviewed; 16 trade union officials and activists interviewed; 15 middle managers interviewed.

Second intensive fieldwork phase 2002: five senior managers interviewed; five trade union officials interviewed. Worker directors interviewed. 
The union representatives interviewed were selected from all the main unions represented at Aer Rianta including the Services, Industrial, Professional and Technical Union (SIPTU), the Technical, Engineering and Electrical Union (TEEU) and the public-sector union for employees in retailing MANDATE, as well as the middle management staff association, the Irish Aviation Executive Staff Association (IAESA), which transferred to another public-sector union, IMPACT, during the period covered by the research.

The professional union officials interviewed included those who were centrally involved in the design and implementation of $\mathrm{CP}$ and a small number who had an arm's-length relationship with the initiative. The involved activists' occupied a variety of lay representative positions ranging from shop steward to chair of Section Committee, to chair of Group of Unions. In each case they had assumed a formal role, either through their membership of the JUCG or as 'facilitators' or 'mentors', in the development of CP. These union officers and 'involved activists' were identified as key informants.

The senior managers interviewed included two chief executives, top-level executives at company level, airport general managers and executives in charge of line and staff divisions at company and airport levels. These divisions included duty-free sales/retailing, cleaning, personnel, planning, security and other functions. Also included in the interviews were senior managers centrally involved in the genesis and development of the $\mathrm{CP}$ initiative.

The middle managers interviewed were selected from departments that had some contact with and experience of the $\mathrm{CP}$ process across the three airports, Superintendents from the Airport Police and Fire Service were included among the interviewees. Four interviewees were from this division, three were from finance, four from commercial departments, three from airport maintenance and one from the airports car parks division.

A survey of a sample of the Aer Rianta workforce was conducted between October 1998 and July 1999. Survey fieldwork was undertaken at a time when, as will be outlined in subsequent chapters, CP initiatives were in operation at a number of levels. In particular, they had become integral to company and union responses to the imminent loss of duty-free sales and the future status of Aer Rianta. Relatedly, the survey was undertaken during a period of considerable, indeed, at the time, unprecedented change and uncertainty for the workforce. Among other issues, the survey sought to explore levels of participation and involvement in work tasks and wider aspects of decision-making and governance; engagement with CP; perceptions of the effectiveness of $\mathrm{CP}$; and commitment to the company and to trade unions.

The survey sample was drawn from the register of employees working for Aer Rianta in 1998 (excluding seasonal workers). The effective sample, when non-available respondents were deleted from the target sample, comprised 1,184 employees. Initially, the survey fieldwork was conducted by means of a postal questionnaire sent to respondents at their work address, 
accompanied by a return envelope addressed to the research team. Later, in order to increase the response rate for some categories and locations, the questionnaire was administered through direct contact with respondents. The survey achieved a response rate of 52 per cent. A disproportionate stratified probability sampling procedure was employed. The objectives of the sampling strategy were twofold. First, there was a concern to ensure that the overall pattern of replies was representative of workforce attitudes. Second, sampling was undertaken so as to obtain reliable data on the views of categories like senior managers and supervisors, present in the workforce in relatively modest numbers. To this end, the total population of managers/supervisors was selected and one in two of the nonmanagerial/supervisory population was selected. To adjust for this and for category-specific differences in response rates, the response sample of 612 employees was re-weighted to restore the numbers of respondents in these categories to their proper respective proportions in the workforce. The resulting weighted sample size is 643 . Table 2.1 contains details of the sample, response rates and weighting. Unless otherwise specified, the data to be reported in the book and used as a basis for multivariate analysis comprise the re-weighted data.

Finally, access was granted to two earlier surveys conducted for management and unions in Aer Rianta in 1988 and 1995 by the Economic and Social Research Institute (ESRI). These surveys were designed by managers and union officials centrally involved in promoting partnership, drawing on technical assistance and advice from the ESRI. The objectives of the surveys were to establish levels of interest among employees in participation and involvement, to examine attitudes to existing levels of involvement, and to discover the levels of involvement and participation thought to be appropriate by staff. The surveys employed probability sampling and respondents were assured of anonymity to ensure that the replies received were a valid reflection of their views and opinions. The 1988 survey generated 702 responses, representing a response rate of 73 per cent. The 1998 survey was repeated in 1995 against the background of the emergence of a formal partnership agreement (the Compact). The 1995 survey attracted 664 responses, representing a response rate of 66 per cent. Data from the surveys are subjected to secondary analysis in the study, primarily to examine the climate towards involvement and participation prior to the formalization and roll-out of partnership arrangements.

\section{Conclusion}

Aer Rianta was selected for study because it was viewed as a radical and sophisticated partnership initiative, which could illuminate a series of issues covered in the theoretical and research literature: in particular influences on the operation of partnership; the antecedents of partnership; and the outcomes or effects of partnership. At a more general level, the case seemed 


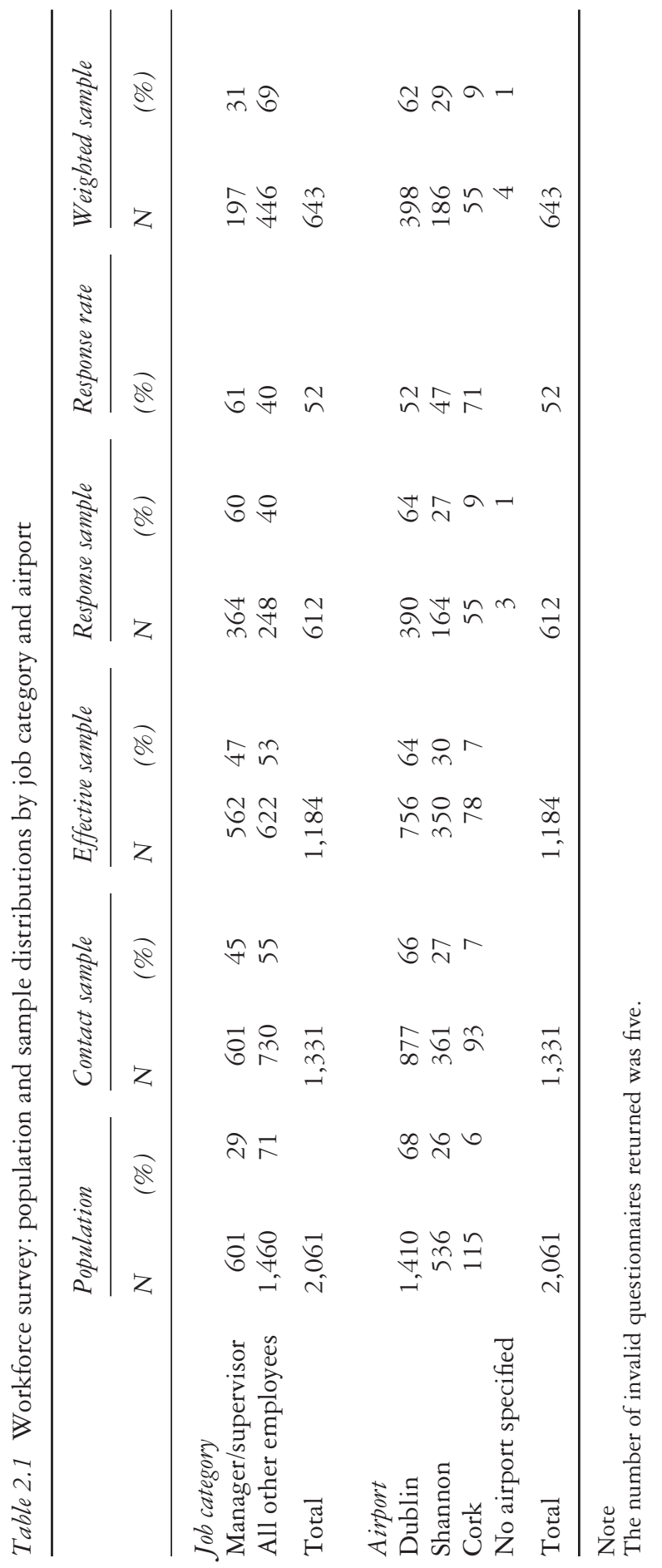




\section{Case and research methods}

particularly apposite for an examination of the issues at stake between the 'advocates' and 'critics' of partnership. Though the company was publicly owned, it experienced chronic commercial pressures and discontinuous change during the period covered by the fieldwork, culminating in a government declaration in the middle of 2003 that the company would be broken up into three separate publicly owned airport authorities. Apart from providing an opportunity to study a major partnership initiative in a context marked by substantial commercial change, the authors also enjoyed an unusual level of access and co-operation from the main parties involved over a period of some six years. This ranged from participation in major partnership committees and groups, access to all internal documentation, intensive interviews with managers at various levels and with union officials and activists. Finally, a survey of the Aer Rianta workforce was conducted in 1998-99 to examine attitudes to partnership and the effects of partnership on employees and union members. To this survey could be added data from two previous surveys of attitudes to involvement and participation, conducted in Aer Rianta in 1988 and 1995. Few previous studies of partnership have been able to draw on such an extensive empirical base, covering a period marked by major and discontinuous commercial change. 


\section{The emergence and development of partnership}

This chapter examines the emergence and evolution of workplace partnership in Aer Rianta from the mid 1980s until the late 1990s. Under the rubric of what came to be known as 'constructive participation' (CP), Aer Rianta management and unions set about establishing a series of arrangements which were to provide employees and their representatives with a say in decision-making processes at all levels of the organization from work groups, departments, business units (airports) to the making of corporate strategy at corporate level. The origins of CP are traced to the mid 1980s when the unions in Aer Rianta gave early consideration to the manner in which the company might respond to and transpose into practice legislation designed to allow for worker participation in state-owned companies. The development of partnership in Aer Rianta went far beyond that envisaged in the legislation and is among the most significant voluntary initiatives of its type in the English-speaking world.

This chapter sets the scene for subsequent chapters in the book by documenting the influences that shaped the approach and contours of partnership, the evolution of $\mathrm{CP}$, including its underlying principles and features both designed a priori and improvized en route, the effects of $\mathrm{CP}$, and the challenges and obstacles encountered as partnership bedded into the company. The chapter gives particular attention to the manner in which the industrial relations context within Aer Rianta and the commercial pressures facing the company influenced the development of CP.

The chapter concludes by highlighting key themes that come to light from our review of the emergence, development and effects of CP. This is an outline review. These issues receive more extensive treatment in later chapters. The chapter begins by providing a brief summary of the antecedents of partnership as outlined in Chapter 1.

\section{Antecedents of partnership}

Chapter 1 presented a detailed discussion of two theoretical perspectives linking antecedents with the emergence and development of voluntary workplace partnership arrangements. The first, which we termed the normal 


\section{Emergence and development of partnership}

competition thesis, is premised on the existence of more or less linear relationships between certain influences and employers' decision to adopt a cooperative industrial relations strategy. The model is associated in particular with the work of William Cooke (1990). The key influences are identified as competitive threats and cost-control pressures. These are 'normal' pressures or constraints and are seen as exercising discrete influences over employers' perceptions of the advantages and disadvantages of pursuing a partnership approach. These influences are also seen to be additive: the more intense these commercial pressures, the greater the probability that employers will seek to develop more advanced forms of partnership.

The alternative theoretical perspective emphasizes how a configuration of influences may constitute necessary antecedents to partnership arrangements. Here, too, commercial pressures are seen to be important, particularly those of an acute or disjunctive form, but of themselves are insufficient to prompt employers to establish collaborative relations with unions. But where such economic circumstances combine with the presence of strong unions, a high level of union awareness among workforces, visionary management and union officials, and influential HR departments, the antecedents are seen to exist for partnership arrangements to emerge and possibly subsume conventional industrial relations structures and processes. A number of scholars, including Cutcher-Gershenfeld and Verma (1994), Kochan et al. (1986) and Appelbaum and Batt (1994), have argued that clusters of factors such as those here listed are the decisive influence, and are critical in determining whether the parties could opt to depart from pre-existing industrial relations traditions. Others, most notably Roche and Turner (1998), have examined whether particular types of partnership arrangements develop from particular configurations of antecedents or clusters of influences. They make the case, for example, that pre-existing traditions of industrial relations are an important mediating influence. Thus, where an impending commercial crisis and supportive pre-existing management and union postures coincide with a well-established trade union and a strong tradition of union activism, partnership of a joint governance form is more likely to develop. But where such features interact with weak unions and low 'unionateness', partnership arrangements based on joint consultative principles are more likely to emerge.

We now turn to examine the origins and development of CP in Aer Rianta and to locate its evolution in the context of the company's industrial relations and commercial environment. In examining the antecedents to $\mathrm{CP}$ we will appraise whether the 'normal competition thesis' or the 'configuration thesis' provides a better explanatory purchase on the evolution and shape of partnership in Aer Rianta.

\section{Getting to 'jointness'}

The genesis of workplace partnership can be traced back to 1984 when, in anticipation of the enactment of the Worker Participation (State Enter- 
prises) Act (1988), a union study group was established to examine the likely consequences of the legislation for employee participation in Aer Rianta. There were two elements to the Act. First, the statute provided for the election of three worker directors - elected by the workforce from candidates nominated by the trade unions, who in turn comprised one-third of board members - to the Board of Aer Rianta. The transposition of this segment of the legislation into company practice was relatively straightforward. The second element, which made provision for the introduction of sub-board participative arrangements, allowed management and unions' representatives to devise mutually acceptable forms of employee participation. A variety of arrangements were permitted under the Act, including direct and indirect participative mechanisms, as well as relatively informal and highly structured arrangements.

The union study group subsequently evolved into a new body called the Industrial Democracy Council (IDC). The IDC was comprised of representatives of all the trade unions in Aer Rianta. Following early deliberations between the IDC and management, it was agreed that the development of participatory structures within the company should be approached on a joint basis, involving management and union representatives from the company's three airports. A joint working group (JWG) was duly established in 1986.

The JWG set itself four objectives: to issue a joint statement on participation; to establish employees' views and preferences in respect of current and future participative mechanisms; to research existing examples of employee participation; and to prepare a report and make recommendations to the management and unions at Aer Rianta. A series of discussion meetings were convened by the JWG across the three airports to communicate to employees and management how the group proposed to move forward and to ascertain in a preliminary manner their views of participation. Subsequently, in 1988, a random sample of the Aer Rianta workforce was surveyed with the help of the Economic and Social Research Institute (ESRI), an independent research body in Dublin. The survey produced a response rate of 73 per cent, 702 employees in all. The results of the study indicated a substantial participation gap: the information which Aer Rianta employees sought in respect of the affairs of the company was significantly less than that afforded them by management; and their level of involvement in respect of decisions which affected their work was also seen to have been inadequate.

With the help of the Irish Productivity Centre, the JWG identified and arranged study visits to a number of exemplar organizations in the United States and Sweden. The choice of countries was deliberate. The former was chosen because of the absence of state legislative support for employee participation in organizational decision-making, in contrast to the latter, where there is a rich heritage of participation reflecting a wider context of institutional supports. In the US, the group visited three companies to examine a variety of initiatives: in Ford, they looked at a training and development 
initiative jointly sponsored by Ford management and the UAW; in General Motors, they were particularly interested in the Saturn project, and at Royal Oak City Authority, they examined the introduction of quality circles. The JWG's report of their visit to the US highlighted a number of factors which gave rise to, and were seen to be crucial to, the successful implementation of partnership activities. These included: significant competitive threats, visionary leadership, and the manner in which change was jointly initiated and managed with the support of senior management and union representatives. In Sweden, meetings were convened with representatives of the employers' organization, SAF, and the LO, the blue-collar union confederation. Site visits were arranged to two Siemens' plants and to the Uddevalla shipyard. Notwithstanding the different legislative context, the group also tried to identify the critical factors promoting employee participation in Sweden. In their report, emphasis was placed on the need for comprehensive agreements, mutual security, effective union organization, mutual respect, and full disclosure of information.

Following four years of research and deliberation, the JWG had acquired a complex and sensitive understanding of different models of participation and of Aer Rianta employees' and management's attitudes to employee participation. In its report it recommended that the company's unions should be extended significant levels of influence over organizational decisionmaking. The JWG, for example, identified the company's business strategies, service quality, training and employment creation as areas over which unions' influence should come to bear. In so doing, the JWG recognized that their understanding and ambitions for participation went 'beyond the provisions of the legislation for employee participation within public sector organisations' and that their overall objective was to produce 'proposals for cultural change in Aer Rianta which would be supported by structures for "jointness" in the organisation' (JUCG 1993). It thus bears emphasis that the JWG envisaged Aer Rianta's unions acquiring significantly more influence over management decision-making than that conceived of in the 1988 Act.

In its report, the JWG was very clear in its delineation of ground rules if a partnership model was to be pursued. Four such understandings or reassurances were highlighted (JWG 1990: 1). They were outlined thus. First, employee participation is more likely to succeed where there is a strong management and a strong trade union. This was identified as a 'prerequisite and an on-going requirement'. If participation were to be used by either party to weaken or undermine the other 'side', it would 'be self-defeating'. Second, partnership and collective bargaining would exist in parallel. It was made plain that the objective was not to 'syphon-off issues from collective bargaining and to place them in a partnership arena. Third, where partnership and collective bargaining co-exist, members of management and union representatives would be required to perform twin roles. Finally, where persons work solely in the partnership arena, it would be incumbent upon 
them to work closely with their colleagues in industrial relations, to have their support and to establish clear terms of reference.

When it came to making recommendations, however, as to the precise shape of the participation arrangements to be adopted, agreement among JWG members proved elusive. The impasse centred on competing conceptions of participation as well as the desirability or otherwise of adopting a partnership approach in preference to traditional representative structures and, in respect of the former, whether representatives might be elected or nominated. Views of JWG members did not divide neatly along management/union lines. While leading trade union representatives tended to favour the development of what came to be known as 'jointness' - meaning joint decision-making between management and unions and direct participation of employees at the point of work, shop stewards were more equivocal as to how to proceed. Some favoured 'jointness' while others preferred a traditional representational model. Upon receiving the JWG's report, senior management chose not to endorse one form of participation over another. Instead, management agreed to accept whichever model the unions might eventually come to agree upon. Essentially, therefore, the matter came to rest with the unions in Aer Rianta as to whether and how they wished to take the process forward.

\section{The formation of the Joint Union Company Group}

The impasse continued for a further year. The shop stewards who made up the IDC decided to refer the matter to the full-time union officials in the Aer Rianta Group of Unions. In 1991, they decided to give the initiative fresh impetus by establishing a Joint Union Company Group (JUCG), which was charged with revisiting how participation might be defined in an Aer Rianta context. The JUCG was composed of equal numbers of senior managers and senior full-time union representatives, together with an external consultant. Their deliberations lasted for another three years. Further study visits to other organizations were arranged, in-depth interviews with management at various levels and shop stewards were conducted by outside consultants, and the employee survey of 1988 was replicated in 1995 to identify any significant changes in employees' views. Weekend seminars and workshops involving experts in airport economics were organized to explore the competitive threats faced by Aer Rianta.

In 1992 the composition of the JUCG was altered to permit the admission of two lay union representatives. In turn management were allowed two further members. To facilitate an open and frank exchange of views, members of the JUCG were required to relinquish their traditional representative roles - to 'leave their hats outside the door' as they were often reminded - and to adopt a non-representational role. From the outset, participation in the JUCG required adherence to the principles of a joint problem-solving approach: all participants were made to endeavour to see 
how other interest groups might view an issue, and in turn to try to find mutually acceptable solutions. The JUCG was cast thus as a non-representational body, independent of both management and unions. Members' primary responsibility was to contribute their expertise to the development of partnership and to bring their influence to bear in a general sense to promote partnership within the company.

The group's deliberations came to be informed and influenced to a significant degree by personal construct psychology (PCP) as developed by the American psychologist George Kelly (1991). PCP provided the group with a philosophy and methodology for understanding how people see the world about them, how their fears might be addressed and aspirations realized and, in turn, how people might be animated to pursue change. PCP places emphasis on empowering the 'client' (in the case of Aer Rianta, the employee), who is viewed as 'the expert' in respect of the nature and influences acting on their working life. The 'therapist' (i.e. the workplace facilitator) is to act as a catalyst for the client's own development. Central to the approach is the idea that an individual can re-fashion their own 'life-worlds' and it behoves the facilitator to view the world as the employee sees it and to suspend or block their own values and prejudices (see Kelly 1991; Fransella 1995). Consultants versed in PCP played a significant role in the early development of CP in Aer Rianta, providing advice, research and preparing training materials.

The influence of PCP was evident particularly in the JUCG's advocacy of the adoption of a non-directive approach to the establishment of pilot work groups and to the so-called 'research phase', wherein group members identified issues or problems they wished to tackle as well as the form participation might assume within the groups. Six such groups were formed across the three airports in mid 1992 (Corporate Finance, Passenger Services at Dublin, Shannon's Building and Maintenance and Cork Airport Police and Fire Service - involving 181 employees in total). The main functions of the groups were: to examine methods for establishing participatory structures; to explore employees' perceptions of participation; to highlight potential obstacles; and finally, to assist employees develop problem-solving skills. It was intended that these groups would operate for a defined period and would be disbanded following the completion of their respective tasks. The procedure for establishing pilot groups and the provision and sequence of support followed a set pattern. (These would also come to be replicated with later 'mainstream' participation initiatives.) First, the JUCG would make a presentation on its aims to staff. Interested groups were then invited to become involved where they had the requisite management and staff support. Second, a research phase would commence, as outlined, to examine employees' views of participation, to identify suitable subject matters and to address training and facilitation needs. In addition, it was clearly stipulated in advance that industrial relations procedures and processes would remain separate from the participation process. In this context, the issues addressed 
by the pilot groups would be agreed with the JUCG and their recommendations for future courses of action would also be put to the JUCG.

The pilot groups met with limited and uneven success. The principal obstacles as identified by the groups themselves included a lack of senior management support, limited union engagement, differences of view as to the purpose of participation between line management and shop stewards, inadequate financial resources and the intrusion of festering industrial relations difficulties. Most groups were disbanded in 1993 but one or two continued for a few more years. The experiment had, however, fulfilled its purpose for the JUCG. It was not simply a question of whether the pilot groups succeeded or failed, but rather what lessons might be usefully gleaned from the experiment so that participants in future initiatives might be better positioned to foresee and resolve potential problems. The following aspects were highlighted. First, work groups had existed as islands of innovation and to have survived in the long term would have required the development of a broader participative framework; second, while it was difficult to draw neat clinical lines between participation and industrial relations, the issue deserved greater consideration; and finally, there had to be greater investment in training.

By this time, in any case, the JUCG had become increasingly preoccupied with securing the requisite financial resources to further develop and implement participation within Aer Rianta. The early portents were not encouraging. In 1994 when the JUCG estimated it would need an annual budget of IR $£ 200,000$ ( $€ 254,000)$ for the coming year, the company reduced its annual funding from IR£75,000 (€95,000) to IR£50,000 (€63,000). A two-year campaign to obtain additional and more secure funding began, with the JUCG also seeking the active support of senior figures within and outside the company. In May 1994, Peter Cassells, the then General Secretary of the Irish Congress of Trade Unions, endorsed the JUCG's efforts. A formal expression of support from Aer Rianta's CEO came somewhat later in early 1995. Shortly thereafter, a JUCG request for funding from Aer Rianta's parent government department was successful, subject to the establishment of agreed milestones; departmental representation on the JUCG; and regular reviews of the project including an independent external evaluation. The latter stipulation was identified as being particularly important so that the lessons of $\mathrm{CP}$ might be recorded, analysed and made available to other public organizations facing similar commercial pressures as a consequence of the liberalization of markets in the state sector. The funding provision made available to the JUCG was substantial. A request for IR£97,000 (€125,000) for the 'promulgation phase' and IR£457,000 $(€ 580,000)$ for the first year (1996) and somewhat less for the following two years (1997 and 1998) was met without demur. The JUCG was given sole responsibility for the distribution of the funds.

The acquisition of such significant funds represented a watershed in the development of partnership in Aer Rianta. The JUCG was now in a position 


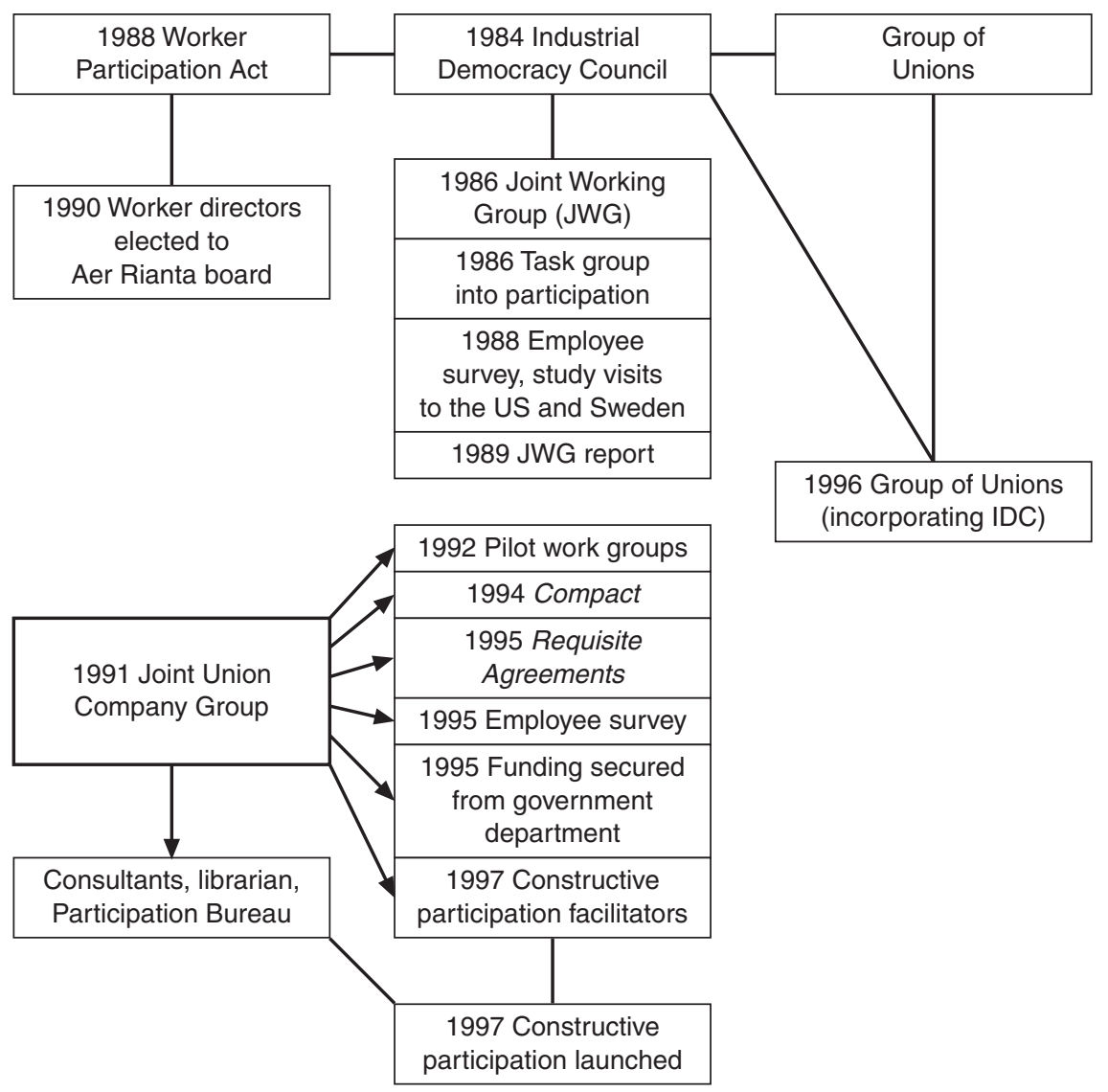

Figure 3.1 The development of constructive participation in Aer Rianta, 1984-87.

to resource its plans and crucially, from its perspective, it had secured financial independence from the company. A senior full-time trade union official seconded to the project and a key senior management champion became the main animators of partnership. Other Aer Rianta staff were seconded to the project in the role of full-time 'facilitators' and others still acted as 'mentors', supporting partnership in various parts of the organization. A 'Participation Bureau' was also established to resource and oversee the administration of partnership activities. Secretarial staff and a librarian were recruited for this and related purposes. Figure 3.1 summarizes the development of $\mathrm{CP}$ in Aer Rianta. 


\section{The contours of $\mathrm{CP}$}

By 1995, the JUCG had finally settled on the development of a 'joint approach' to participation. There was unanimous agreement within the group that the preservation of traditional representational roles and adversarial postures would not serve the company well. 'Root and branch transformation' was called for:

(t)he transformation process would of necessity have to be comprehensive, detailed and radical... The participants (of the JUCG) concluded that any attempt at transformation would have a possibility of succeeding only if the traditional adversarial postures were abandoned. It was clear that the owner, management and unions would have to adopt a constructive alternative to the traditional approach in dealing with the threats and opportunities they faced.

(JUCG 1999: 1-2)

The influence of one senior management participant and two senior union representatives was decisive. Together they were a vital force in conceiving of a joint approach and in articulating its benefits for employees and the company. In this crucial sense, and from its earliest inception, the critical design and conception decisions were taken by an 'elite' grouping and were transposed in a top-down direction.

The JUCG proposals for the development of partnership in Aer Rianta were outlined in two key documents, known as The Compact and The Requisite Arrangements. The Compact set out a series of principles aimed at rebuilding employee-management and union-management relations in Aer Rianta along partnership lines. The Requisite Arrangements identified a series of structures and measures to be put in place to facilitate the realization of partnership. The main proposals in these documents, which provided the framework for what came to be known in Aer Rianta as 'Constructive Participation', are summarized in Table 3.1.

The word 'compact' was chosen for a clear purpose. According to the JUCG (1993):

A contract is essentially adversarial in nature, representing compromise between the separate interests of each party to the agreement.... In contrast, a 'compact' is fundamentally a co-operative document, providing for a mutual vision and a joint system for achieving common goals that foster the general well-being of all stakeholders in a given endeavour.

CP envisaged multi-level and multi-stranded partnership arrangements in which employees and unions would be accorded a role in decisionmaking, spanning task participation, department and business-unit strategy 


\section{Emergence and development of partnership}

Table 3.1 Workplace partnership in Aer Rianta: principles and arrangements

Principles of constructive participation (The Compact)

Both parties accept their joint responsibility to work together in order to improve the economic performance of each constituent part of the organization.

Both parties reject competing on the basis of a low-wage policy but will do all possible to improve company performance and living standards for employees through the conscientious application of best systems and practice at all times.

Both parties will share their objectives and strategic plans in regard to Aer Rianta.

Both parties accept their obligation to work together to serve the interests of customers, staff and stakeholders.

Both parties accept the right of employees to share in the financial success of the enterprise.

Both parties accept the principle of employees shareholding as a legitimate objective in certain circumstances.

Both parties will commit to mutual disclosure of information and will respect confidentiality where necessary.

Both parties will share their perception of future developments, will ensure an awareness of market realities and will anticipate the implications for the enterprise and employment.

Both parties undertake to jointly pursue a policy of equal opportunities and the elimination of discriminatory practices and policies.

Aer Rianta management accept that trade unions have a legitimate and central role in strategic decisions and policy making in addition to their role in day-to-day relationships between management and staff.

Aer Rianta will encourage its employees to support and engage actively in trade union affairs and will not discriminate against union members or representatives.

Aer Rianta management accept employment security as a major policy objective that will figure as importantly in the strategic planning process as does finance, marketing, customer service, etc.

Requisite Arrangements

\section{Regular work groups}

There should be an opportunity for everyone to participate fully at departmental level. The participants will include management, trade union representatives and staff members. Participation at departmental level can be designed around the normal managing process, including departmental subjects and timetable of events. The group should meet four to six times per annum and the agenda is likely to include: review the work of regular work groups; review departmental financial and operational performance; discuss any difficulties, problems or threats to the department, departmental objectives, financial and operational plans and 
relationships with clients or other company departments. The JUCG will agree on the membership of departmental groups. In addition to receiving the training outlined above for regular work groups, training will probably be needed in trade union policies and procedures, and in the company's organisational systems, budgeting, departmental strategy, etc.

\section{Business-unit arrangements}

Business-unit participation should have a strong input into the annual strategic plans and financial plans of the individual airports. These groups should give full consideration to all aspects of the business unit's objectives with regard to its operational activities, marketing activities, capital investment programmes and business development. It will be important for the participation group to include managers, executives, supervisors and general staff. The JUCG will have the task of ensuring that there is a fair spread of membership and that both the management and union position are safeguarded. Training will require an introduction into airport economics, pricing policies, aviation standards and other subjects which must be taken into consideration if the airport is to meet its statutory obligations and act within commercially acceptable parameters.

\section{Significant issue groups}

From time to time particular topics will need to be addressed which transcend the activities of the various groups or which require a particular combination of personnel and skills, e.g. loss of duty free, change of status, etc. In such a case a significant issue group will be nominated to deal effectively with seeking a joint solution to the difficulty.

\section{Corporate arrangements}

The arrangements for CP at corporate level will involve nominees of the JUCG as well as the most senior executives in the company and membership from the various levels and activities throughout the organization. The JUCG will be obliged to determine an appropriate spread of membership. This group will review the growth of the company and its financial and investment performance as well as matters such as the creation of employment, the growth of the business and the policies as articulated in the company's strategic planning document. Training will be needed in company strategic planning, policy formulation and corporate finances.

\section{Board of directors}

Three members of the board are elected by the employees. The executive has no board member. The chief executive attends board meetings in his executive capacity only. The JUCG would consider it appropriate and indicative of real commitment if both worker directors and executive directors had seats on the board of the company.

Source: Abridged and adapted from Towards Constructive Participation: A Positive Approach to Management/Union Relationships (1994) and Requisite Arrangements: Towards Constructive Participation (1995), Aer Rianta Joint Union Company Group on CP. 


\section{Emergence and development of partnership}

and competitive strategy for the company as a whole. To support joint decision-making, the unions received guarantees of institutional security; employees were assured of employment security (the preservation of employment levels would be an agreed parameter of commercial strategy); and financial participation was espoused. The company in turn gained assurances from the unions that they would assist in improving the economic performance of each of its constituent units. The parties pledged that Aer Rianta would seek to compete on the basis of service quality and workforce skill rather than on the basis of cost minimization and low pay. There was also a pledge to provide training covering all aspects of engagement with CP.

The formal roll-out of CP began with the JUCG's communication to all staff of the principles and objectives of CP. Staff seminars were convened in the three airports in 1997. Later a magazine, entitled Compact News, was produced and distributed company-wide. In April 1998, a CP exhibition was organized to coincide with the official launch of Compact News and was opened by the Minister for Public Enterprise, and by the chief executive in Shannon. Staff were invited to attend. Facilitators and strategy group (SG) and regular work group (RWG) members were on hand to discuss CP with those who attended. Facilitators also made presentations on the Compact as part of all staff induction programmes. A 'participation intranet' was developed where staff were provided with direct access to up-to-date information on CP. Subsequently, the RWGs in Dublin maintenance developed their own intranet site within which group members communicated with one another and individuals were permitted to develop their own personal pages to store information and access their own personal calendar.

Upon communicating the principles of $\mathrm{CP}$ across the company, the practical implementation of CP began in 1997. This task fell increasingly upon the Participation Bureau. It became pivotal, acting as steering group and trouble-shooter for the process. Increasingly, too, it was drawn into the handling of operational problems. These included the reluctance of some managers to engage; attempts by others to use $\mathrm{CP}$ to push through changes on a unilateral basis; allegations that unions sometimes sought to use partnership to stall management proposals; and more generalized uncertainty and ambiguity concerning the relationship between partnership and established industrial relations processes.

As the Bureau assumed this central role, so the involvement and significance of the JUCG progressively waned. The frequency of JUCG meetings declined noticeably from 1997 onwards, as well as membership attendance. In the process, the profile and responsibilities of the senior union official who was seconded to the project on a full-time basis, together with a key senior management champion, increased. In being the main animators of partnership and having become intimately involved in the day-to-day implementation process, decision-making authority became increasingly concentrated around these two individuals.

Originally it had been planned to develop departmental work groups 
(DWGs) and regular work groups (RWGs) (see Table 3.1) by first establishing steering groups. These were to be the focus for intensive training in the principles of jointness and were to identify the issues around which DWGs and RWGs would come into being and the logistics surrounding their operations. In time DWGs were expected to network around higher-level participative structures. Participants soon complained that they found this preparatory training too abstract and that the pace of progress threatened to turn participative forums into 'talking shops'. There was a general impatience among those involved to address concrete problems and issues. This resulted in the creation of so-called strategy groups (SGs). SGs focused on single issues, such as the future viability of maintenance operations at Shannon Airport, problems with the provision of the cleaning service at Dublin Airport, and the future of Dublin duty-free shops. For instance, the cleaning department's SG in Dublin examined a range of issues including pricing, non-revenue-earning services, organizational structures and work practices. The group also researched passengers' opinions on the standards and performance of the cleaning services. They also benchmarked their services against similar operations in other airports. They used 'breakthrough thinking' to envisage how their department might operate in the future. During 1997-98 some seven SGs were established at Dublin and Shannon. All SGs addressed issues of service cost, efficiency, viability and development in the context of the strategic commercial priorities outlined in the Compact, including employment security.

A DWG following the intended trajectory became established in the Dublin maintenance department. Participation was confined, however, to skilled craftspeople as the semi-skilled employees had earlier voted not to participate in CP structures or initiatives. This DWG was the first of its kind in Aer Rianta. The group's activities included making submissions to the department's budgeting process and the formulation of a business plan for the future of the department.

To these structures was added during 1997-98 a series of significant issues groups (SIGs), as provided for under the Requisite Arrangements (see Table 3.1). SIGs developed to address two distinct types of issues. First, a number addressed cross-company commercial issues and challenges, such as the likely disappearance of duty-free sales from the summer of 1999 and an imminent change in the status of Aer Rianta under which the company was to be assigned full control over its assets, becoming liable in the process for corporation tax and rates. In 1998, the brief of this group was broadened to address the critical question of the future of the company in the light of the government's rolling programme of partial or full privatization of stateowned commercial companies. Second, a number of SIGs addressed key issues linked with the progress of $\mathrm{CP}$, such as the revision of personnel and industrial relations policies, including reward systems and future training requirements. In all, six SIGs came into operation during 1997-98. All SGs and SIGs were expected to address issues on a joint basis, based on the 
collection, examination and validation of relevant data. Following such a joint process, proposals were to be presented to management and unions. There was no requirement that a common position be arrived at. Some discussion papers indeed articulated an agreed common position on the issues addressed, whereas others simply summarized the points of view that had arisen in the groups' deliberations. Also, in line with the approach adopted under $\mathrm{CP}$, discussion papers were presented to management and unions for evaluation, feedback and possible implementation or negotiation. Crucially, the prerogative as to whether and on what terms a paper's recommendations might be implemented remained with the union and the company.

Two SIGs in particular came to occupy a pivotal role in the partnership process during 1998-2000. The Duty-Free Group produced a paper on how the imminent disappearance of duty-free sales on the instigation of the EU might be handled, and this became the basis on which management and unions subsequently addressed post-duty-free retailing at the airports. The Corporate Strategy Group arrived at a joint vision of the future of Aer Rianta, which supported the partial privatization of the company as the most viable means of meeting its burgeoning capital requirements and pursuing its competitive strategy. The group favoured an Initial Public Offering (IPO), with shareholdings capped at 5 per cent and advocated the creation of an ESOP. The sell-off of the Great Southern Hotel subsidiary was also agreed, to allow the company henceforth to focus on its core business: the management and operation of airport facilities and services. The Corporate Strategy Group's report became the basis for a common front between the Aer Rianta board and management and the Group of Unions, to the degree that on this issue, more than any other, partnership effectively subsumed or displaced collective bargaining and traditional industrial relations channels within the company. Thus, the SGs and SIGs were among the most significant partnership structures to be developed in Aer Rianta.

Given the welter of activity involved in the creation and operation of SGs and SIGs, progress on the establishment of RWGs was very limited. These became established in the maintenance department of Dublin Airport (11 groups), and less extensively in the finance department at Shannon (two groups). The former became involved in equipment selection, training, health and safety, workload allocation and work scheduling. In assuming the role and agenda originally envisaged for RWGs, the SGs came to involve, directly that is, a modest number of employees. The consequence of limited activity at RWG level was that the principle that all employees should be able to 'participate fully at the[ir] immediate place of work in their regular work groups' (Requisite Arrangements 1995: 7), was realized to a much more limited degree than intended.

Furthermore, the level of support needed, and in many cases demanded by employees, to sustain participative structures proved in excess of what the JUCG and Participation Bureau were able to deliver. Additionally, the demand from ever more departments to become involved in CP as well as dealing with ongoing resistance to partnership further stretched the 
Bureau's resources and diluted its efforts. This was of evident concern to the JUCG (1999: 13).

The requirement to respond to facilitation demands from unit strategy groups as well as providing services to the significant issue groups and the time spent in dealing with opposition to the participation programme has overstretched our resource.

The penetration of partnership arrangements was uneven across airports, departments and issues. Dublin Airport was most heavily engaged, followed by Shannon. By late 1998, active groups (including SGs, SIGs, steering groups and RWGs) at Dublin and Shannon covered the majority of staff. Cork was the least engaged due to the rejection of CP by the airport's general manager and problems between local and national officials in one of the main unions. The airport's general manager retired in 1998 and was succeeded by a manager who had participated strongly in the JUCG. The retailing department in Cork did become actively involved in discussions on the likely consequences of the loss of duty-free sales, and some progress was made with the establishment of an SG in the finance department. Thereafter, however, little or no advancement was made. As business-unit structures had not been established, airport-level commercial strategy planning fell outside the scope of partnership, except insofar as it was affected by cross-company SIGs that addressed the duty-free issue and corporate strategy. Areas like property management and physical planning for airports also fell outside the scope of partnership. Department-wise, Dublin and Shannon maintenance departments were heavily engaged, as was Dublin cleaning. The duty-free shops also became involved on an intensive basis and there was some considerable involvement by the Airport Police and Fire Service.

The set of participative structures that evolved following agreement on the Compact and Requisite Arrangements are outlined in Figure 3.2.

\section{Partnership and the industrial relations context in Aer Rianta}

Aer Rianta was highly unionized, with an overall union density level of over 90 per cent. The main unions during the period covered by the research were MANDATE, which organized workers in airport retailing (formerly duty-free) shops, SIPTU, which represented ancillary staff grades, airport police and fire services, operatives and clerical staff, IAESA (now a branch of the public-sector union MANDATE), for middle management, and a number of craft unions, prominent among them, the TEEU, for maintenance craft workers. The unions negotiated together on company-wide issues under the aegis of the Aer Rianta Group of Unions. Since 1987, pay adjustment had been based on the awards set down in the national tripartite programmes. Aer Rianta had a tradition of positive and progressive industrial 


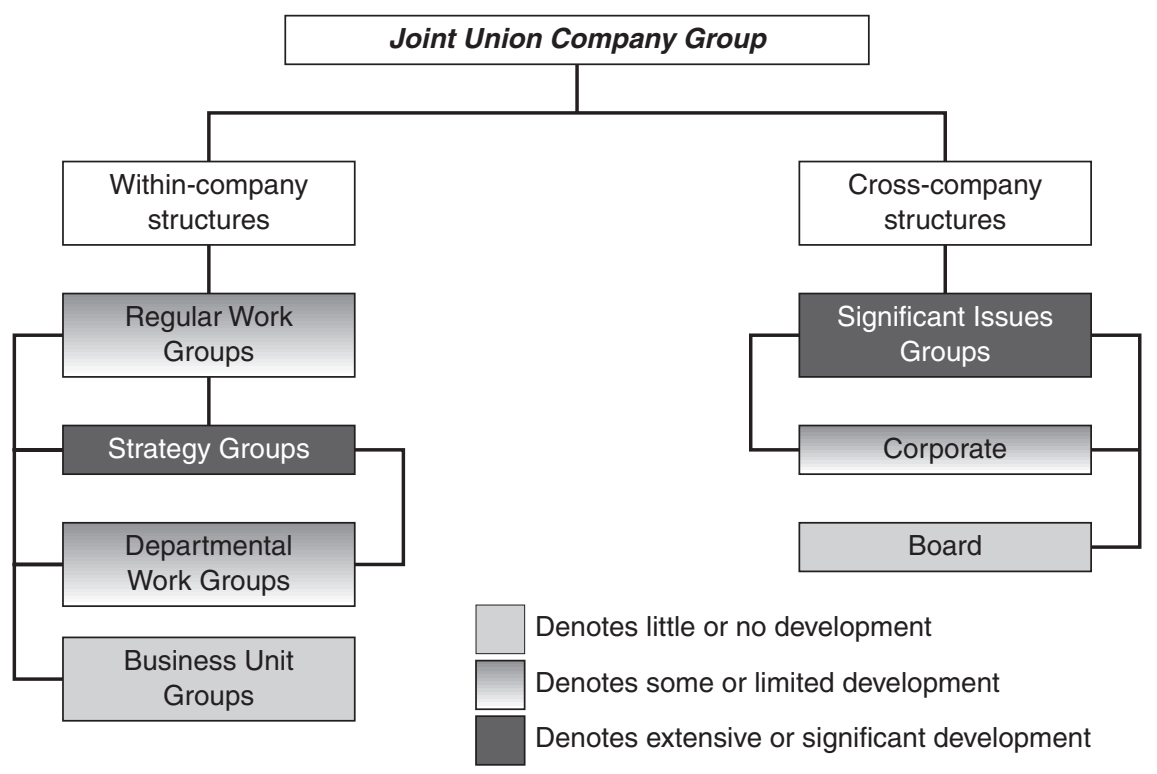

Figure 3.2 The evolution of partnership arrangements in Aer Rianta, 1995-2000.

Note

Strategy Groups overlapped the activities originally envisaged for Departmental Work Groups in areas like duty-free sales, cleaning and maintenance, while Significant Issues Groups addressed the duty-free issue at a company level and corporate strategy which overlapped activities envisaged for a corporate-level partnership structure.

relations and personnel management and was a pioneer of progressive policies in areas such as work-sharing and quality of working life. The incidence, level of participation and number of working days lost due to strikes in the company, adjusted for workforce size, had been significantly below the profile for the rest of the public sector and also compare very favourably with the strike record of the private sector (Strikes Datafile, Department of Industrial Relations and Human Resources, University College Dublin).

The main unions in the company, operating under the aegis of the Aer Rianta Group of Unions, supported CP. The exception was the union representing middle managers, the Irish Aviation Executive Staff Association (IAESA), which was subsequently to merge with the public-sector union, IMPACT. IAESA had not participated in the development of partnership and saw itself as effectively excluded from the process. The JUCG's insistence that all its members act in a non-representational capacity grated with IAESA representatives and ostensibly, at least, became the reason for their refusal to join the JUCG.

The unions viewed $\mathrm{CP}$ as a possible means for emancipating workers from traditional, autocratic and regressive forms of work organization. Teamworking, for example, was presented as a means of enhancing employees' working lives and giving team members a greater say in how their work 
might be organized. But partnership was also presented as an imperative in the face of increasing competitive pressures, tighter budgetary controls, demands for greater efficiency of services, and the likelihood of the deregulation and dismantling of monopoly markets. Traditional collective bargaining, by contrast, was portrayed as disabling union influence. The case was made with some force that partnership offered unions the opportunity to extend their influence over management decision-making and in a way which ensured their institutional security.

The unions' perspective was informed to a considerable degree by what they had witnessed on their study visits to the US. Their communication materials to the rank and file, for example, were frequently illustrated with US case examples and the findings of American research. Still, an uneasy relationship existed within the unions and its constituent structures as between the merits of traditional forms of worker representation and the merits of pursuing a partnership approach.

Relations between the worker directors and the JUCG were difficult and tense. The roots of this unease can be traced back to early deliberations on participation within and between the various union representative structures. As outlined, the basis for union involvement in participation had initially been considered by the IDC. This body subsequently divested itself of responsibility for framing an agreement with management on participation to the JWG, and later the JUCG. Notwithstanding this, there were protracted and on-going negotiations and disagreements between the IDC and the Group of Unions as to the appropriate body for dealing with participation in the company. The latter were largely sympathetic to the JUCG's approach and ambition, but the IDC were perceived, by the JUCG at least, as not having come fully 'on-side' with respect to the manner in which CP was being conceived. It was interpreted by some that the IDC's unease was due to its once dominant hold on employee participation within the company having been captured by another body, i.e. the JUCG (JUCG 1992: 1). The IDC's engagement with participation had been largely through the function performed by the worker directors. The latter reported to the IDC. The rivalry between the two structures centred essentially on whether CP would marginalize worker directors and reduce the influence of the IDC. The appointment of two lay representatives, both of whom were IDC members, to the JUCG in 1992 was an attempt by the Group of Unions to appease the IDC.

Tensions remained, however. Contacts between the IDC and the JUCG continued for a further four years in an effort to define and clarify the bodies' respective roles. It was not until May 1996 that significant progress was made, with the formal incorporation of the IDC into the Group of Unions. A new constitution was drawn up for this purpose. Despite this, internal differences remained in respect of approaches to participation, especially between worker directors and other union activists and full-time union officials, as well as intra-union differences at different airports, and variable levels of commitment to CP amongst shop stewards. These tensions were to 
prove significant impediments in the face of the JUCG's efforts to diffuse partnership across the company.

From the outset, CP envisaged a clear-cut division of roles between partnership structures and established industrial relations channels. Both systems were to co-exist in parallel realms. Individual work groups and departments were free to choose through which route they might advance their interests or address problems and difficulties. The Compact did not proclaim a priori that certain issues should be addressed within partnership forums and that other items could be dealt with via established industrial relations channels. The parties involved in partnership structures were not enjoined to arrive at a single common position with respect to any problem or agenda. Even if they did, it was understood that management and unions retained their established rights under collective agreements, and that either party, or both, could dissent if they chose. Thus, partnership neither incorporated nor displaced established collective bargaining and industrial relations channels. Issues could be handled on a partnership basis, in which case it was ultimately open to unions and employers to accept or reject any proposals put forward. Alternatively, issues could be handled through established industrial relations channels.

The basis for this formal separation of channels was the perception that this was the best way to proceed when $\mathrm{CP}$ was in its developmental stage. To have ordained at the outset that partnership could have or might have led to the recasting of existing collective agreements, or that it might have subsumed collective bargaining would, according to its champions, have alarmed and worried shop stewards and union officials. It would also, it was claimed, have overstretched the joint understanding reached by the parties.

Pragmatism thus prevailed in an effort to reassure management and unions that their established prerogatives and rights would not be endangered or undermined by CP. But as CP became embedded in Aer Rianta in the late 1990s, and as it came to address significant commercial challenges, like the loss of EU duty-free sales and the future ownership of the company, and as the confidence of a wider network of people in partnership arrangements grew, the erstwhile domain of collective bargaining began to shrink. With respect to these two pivotal issues, collective bargaining was effectively subsumed by joint governance arrangements. In this sense, the good relations generated through the Compact provided the foundations for partnership to 'spill over' into addressing issues which otherwise would have been handled within traditional managerial channels and collective bargaining and may also - by most senior managers' and union officials' assessment - have led to adversarial industrial relations. But the spillover dynamic did not operate in only one direction and nor, as later events would reveal (see Chapter 10), did partnership disable collective bargaining. The bypassing and marginalization of worker directors, as outlined, had its own spillover effect with its particular dynamic in leading them to question and launch a sortie against partnership (see Chapters 7 and 10). 


\section{Partnership and the business context at Aer Rianta}

Partnership had developed in a largely benign commercial and labourmarket context. Passenger volumes grew steadily and the duty-free business was highly profitable. Commercial pressures emanated in the main from the deregulation of the airline industry which resulted in strong downward pressure on landing and handling charges. Charges were heavily discounted, especially for low-cost operators like Ryanair, and otherwise tightly regulated by government in the interest of promoting tourism. From about 1998-99, however, the company experienced change of a more disjunctive character: the sharp relative decline in its aviation revenues (from 41 per cent of the total revenue in 1986 to 19 per cent of total revenue in 1997); the loss of duty-free revenues for passengers travelling within the EU (which contributed IR£30 million (€38 million) to company profits, which in 1998 were IR£48 million (€61 million). Dublin Airport lost 75 per cent of its duty-free sales, while Shannon, whose passengers were mainly going to and from the US, lost 20 per cent); increasing passenger numbers caused serious congestion in airport facilities, especially in Dublin; powerful external lobby groups sought the sell-off of Aer Rianta, while others, including Ryanair, lobbied for the building of a terminal at Dublin Airport that would compete with Aer Rianta; the part or wholesale privatization of Aer Rianta looked increasingly likely in the near future; and an airport regulator was established to vet proposed increases in charges. Meanwhile, the Irish labour market continued to tighten to near-zero levels of unemployment; and finally, at a time when its most profitable business line was disappearing and airport charges remained tightly regulated, the company faced an acute need for access to capital to permit further physical and commercial development. It was around discontinuous change, involving these new pressures, that partnership took shape in the late 1990s.

Despite having been adopted as official policy by the company and Group of Unions, CP, as will be examined in Chapters 5 and 6, encountered significant obstacles within management. Senior management was divided on the merits of the approach. A minority supported CP - most of these occupied staff rather than line management roles. Most senior managers were sceptics and doubted whether 'bottom-line' benefits had or would accrue; the rest were overtly opposed. The chief executive in office up to 1998 supported the Compact, but managers who opposed CP were not sanctioned. A new CEO appointed at the implementation stage provided more active support and altered the balance in favour of $\mathrm{CP}$ at a time when the process began to engage major commercial issues. Many middle managers were apprehensive and insecure, a posture that hardened into formal opposition when their union instructed them at the implementation stage not to co-operate with $\mathrm{CP}$. The postures of middle managers were also influenced by their perception of senior management division and ambivalence. Prevailing formal organizational structures and control systems remained substantially 


\section{2}

Emergence and development of partnership

unaltered - CP was expected, in effect, to colonize prevailing modes of decision-making and change them from within. Human resource and industrial relations policies were expected to change, but progress in these areas in joint bodies remained slow. In consequence, prevailing reward systems provided little incentive for either management or staff to engage with $\mathrm{CP}$.

The largely benign commercial conditions of the 1980s and much of the 1990s favoured deliberation and planning in the development of CP. The same conditions also favoured inertia in prevailing structures and modes of decision-making. From about 1998 commercial conditions provided more fertile ground. The acute challenge represented by the EU's abolition of duty-free sales and the fundamental challenge posed by the review of the company, provided opportunities for supporters of $\mathrm{CP}$ to demonstrate the potential of partnership - while in the process tackling senior and middle management scepticism and opposition. The dramatic growth in traffic volumes and a tightening in labour markets from the mid 1990s, as the Irish economy grew by about 9 per cent annually, allowed scope for absorbing the loss of duty-free sales while observing the employment security injunction set down in the Compact.

\section{Conclusion}

This chapter has traced the origins and development of CP in Aer Rianta. The roots of the experiment lay in an attempt by the state to legislate for employee participation in state-owned companies. The legislation was not prescriptive however, and allowed employers and unions significant freedom to devise arrangements which would best suit their specific circumstances and preferences. Most other state-owned companies' initiatives remained largely within the realm of traditional representative structures, and resided within precast adversarial structures and processes (cf. Hastings 2003; Kelly and Hourihan 1994). The significance of the Aer Rianta case is that management and unions attempted to go beyond the requirements of the legislation and to develop voluntarily an ambitious partnership approach to the management of workplace change.

In the context of the theoretical review outlined at the beginning of this chapter and in Chapter 1, the following themes deserve amplification in this concluding section. First, CP had a long gestation, and advanced and developed in a slow and prolonged manner. The protracted nature of the initiative and the slow speed of decision-making and diffusion was a reflection of the inertial forces within the organization in combination with the absence - certainly until the ending of duty-free sales in 1999 - of any major external or internal stimulus for change. From about 1998-99, however, Aer Rianta experienced change of a more disjunctive nature culminating in an acute commercial crisis. It lost a very significant and profitable revenue stream with the abolition of intra-EU duty-free sales and its ability to raise capital to accommodate significant increases in passenger numbers 
either from increasing landing fees or borrowing money was severely constrained. As well as these 'normal' competitive pressures, there was also the prospect that the government would soon act to privatize Aer Rianta in part or whole, and that its monopoly in the provision of airport services, in Dublin Airport at least, was unlikely to last indefinitely. It is commercial pressures of this magnitude that are often identified in the literature as antecedents of partnership. There is no doubting that they were certainly influential contingencies in spurring management and unions to institutionalize CP in Aer Rianta.

Of their own, however, these commercial pressures were insufficient to ensure the adoption and development of CP. Other influences were also important. In particular, the conception, design and steering of $\mathrm{CP}$ was critically dependent on the energy and vision of one senior manager and a small number of senior union officials. Together, they came to the view that established industrial relations arrangements were no longer viable and that the adoption of a co-operative approach provided the best means for handling the pressures emanating from the commercial circumstances facing the company. Thus the postures of unions and management within Aer Rianta were important influences. All the major unions, with the exception of the middle management staff association, were prepared to engage in joint deliberations as to the shape and role of CP. Senior national officials, including the General Secretary of ICTU, endorsed CP and lent their support to its introduction. On the management side, the company's CEO supported the adoption of CP as official company policy. The appointment of a new CEO coincided with the implementation of $\mathrm{CP}$ and his active involvement in supporting CP was critically important in convincing his colleagues of its merits. The significance of the backing garnered from senior civil servants and successive government ministers was of obvious importance, both in giving legitimacy to $\mathrm{CP}$ in the face of wavering and ambivalent support from senior management and in providing the financial 'space' and independence for the champions of CP to develop the initiative. Crucially, too, it endorsed a very particular business strategy and employment system, wherein priority was accorded to quality-based competitive strategies, the involvement of employees, and the enhancement of their skills as well as making provision for the security of their employment.

Pre-existing relations between management and unions in Aer Rianta had also been good and were based on a strong bargaining relationship; instances of overt conflict were rare. Union membership was high and, although there was a multiplicity of unions, inter-union organization and policy formulation were effectively co-ordinated; links with external union officers were also well developed.

Thus, the evidence in respect of Aer Rianta illustrates how a confluence of influences brought CP to fruition and in time led to its integration into the mainstream of strategic decision-making within the company. In its early guise, CP emerged as a consultation-based model of partnership and 
operated in parallel to senior management decision-making. Subsequently, however, with the catalyst provided by the prospect of significant commercial changes and the appointment of a new CEO, CP began to engage directly with major strategic issues and assumed the form of a joint governance model to the extent that in respect of two major business issues - the loss of duty-free sales and the future strategic direction of the company partnership arrangements effectively subsumed conventional management decision-making and collective bargaining processes. In these instances, as will be discussed in detail in Chapter 4, CP came to fuse with the formulation of business strategy.

Elsewhere, too, the internal design and structure of $\mathrm{CP}$ was intended to alter significantly employees' role in decision-making processes and to enhance their influence. Champions of $\mathrm{CP}$ appreciated the importance of having a multi-level model of partnership of the type envisaged by Kochan and Osterman (1994), whereby both direct and indirect mechanisms of participation would be introduced in tandem to engage employees and their representatives in decision-making at workplace and strategic levels. In practice, however, the development of $\mathrm{CP}$ was concentrated at the peak of the organization, first, with the formation of the JUCG and subsequently with CP's involvement in various strategy and significant issue groups. The development of $\mathrm{CP}$ at other levels, for example, at business-unit level, corporate level, and particularly at teamworking level was limited or nonexistent. Thus, for large sections of the company's workforce, CP remained a distant activity divorced from their daily work routines. The bespoke modalities for achieving vertical integration were thus poorly realized in practice and, in this critical respect, the interlocking arrangements identified by advocates of partnership to be crucial for its successful operation were absent in Aer Rianta. But, in general, the shape and reach of CP varied across the company. In some cases, $\mathrm{CP}$ transplanted collective bargaining, in others it existed in parallel, and in yet other instances $\mathrm{CP}$ made very little if any inroads. What is striking, therefore, about the Aer Rianta case is the variability and diversity of decision-making processes which emerged across the company, and also that the shape of $\mathrm{CP}$, where it took root, altered and assumed different functions and had diverse consequences over the period in which it was the accepted policy of Aer Rianta management and unions. One of the key factors influencing the dynamics of partnership was the way in which key groupings responded. This brings us to the key issue of resistance to CP.

CP's reach was uneven and its import contested in various quarters. It met significant resistance from both within management and the trade unions. While CP was primarily management-driven, its conception and development was critically dependent on the energy and vision of a small group of champions. But it was manifestly not line management driven hence management's (senior and middle) residing indifference and scepticism. CP thus came to be seen by many, but particularly by management, as 
aloof and remote, as will be examined in detail in Chapters 5 and 6. The decision by the middle management's staff association to remain formally detached from the process because its representatives were not permitted formal representation on the JUCG amplified its members' misgivings about CP. Clearly, too, the JUCG had, through its attempts to resource CP through its own budget, offices and staff, 'ghettoized' the initiative and fashioned something of a rod with which to beat itself. Further, the language of participation, drawing directly as it did from personal construct psychology, as deployed by champions of $\mathrm{CP}$, was criticized for being abstract and having limited congruence with 'hard' business realities. And while the champions of partnership in Aer Rianta bridled against the charge that many of the problems were of their own making, they saw themselves as operating within a company which was deeply wedded to an adversarial industrial relations tradition. The overlap of 'old' and 'new' agendas was there from the outset, evident, for example, in tensions between the IDC and the JUCG; the intrusion of IR issues on pilot groups' activities; teamworking and the role of middle management; and critically, the uneasy articulation between CP and the role of worker directors. The exclusion of worker directors from the planning and operation of $\mathrm{CP}$ resulted in the 'uncoupling' of different strands of participation. This created significant problems ultimately to the detriment of CP. These issues are discussed in detail in Chapters 7 and 10. 


\section{Partnership and commercial strategy}

This chapter is the first of two that will examine a series of interlinked themes concerning the relationship between partnership and business decision-making in Aer Rianta. This chapter develops a key theme outlined in Chapter 1, by examining the linkages that developed between $\mathrm{CP}$ and strategic decision-making in Aer Rianta, as CP was introduced across the company's airports and departments at a time when commercial challenges of an unprecedented nature arose within the company. The next chapter examines in more detail the evolution of senior managers' postures towards partnership and the forces that shaped management postures.

As outlined in Chapter 1, there is much emphasis in the literature on the importance of strategic integration for the harnessing, effectiveness and sustainability of innovative approaches to HRM and industrial relations. Notwithstanding the significance of this theme, little research has been done on the mechanisms and dynamics through which strategic integration is pursued, particularly in the context of voluntary partnership. In The Mutual Gains Enterprise, Kochan and Osterman state that they know of 'no studies that systematically analyze the effects of integrating human resource considerations into strategic managerial decision-making'. On this issue, as they put it, the 'rhetoric and aspirations of human resource executives and worker representatives continue to be far ahead of organizational reality' (1994: 74-5). Kochan's subsequent study of the Saturn partnership (Rubinstein and Kochan 2001) addresses the area to some degree, but still little is known about the interface between partnership and commercial strategy, or of the dynamics that arise at this critical interface.

The evolution of $\mathrm{CP}$ in Aer Rianta provides an opportunity to examine at first hand the ways in which high-level decision-making may be linked with a distinctive approach to industrial relations based on mutual gains principles. The challenges and setbacks in the process of strategic integration also emerge clearly, as do their implications for the design and management of the partnership process.

As discussed in the last chapter, the Compact was predicated on the principle that commercial decision-making would assign priority to service 
quality rather than simply emphasizing cost. The implications of market and regulatory trends for this posture are considered in this chapter. The chapter begins by examining the concept of strategic integration. It then considers the idea that mutual gains-type innovations and associated practices may generally depend on the development and sustainability of certain types of competitive strategies. These themes provide the focus for the chapter's examination of the experience in Aer Rianta during the high tide of partnership over the period from 1998-2000.

A variety of models and views of innovative human resource and industrial relations practices emphasize that their effectiveness and sustainability depends on the degree to which they have been integrated into strategiclevel decision-making in organizations (Wood and Albanese 1995; Huselid et al. 1997; Roche 1999). In Kochan and Osterman's influential 'mutual gains' model, 'an effective voice for human resources in strategy making and governance' is presented as a key 'strategic-level requirement' for mutual gains industrial relations (Kochan and Osterman 1994: ch. 3).

The rationale behind these views is straightforward. If human resource practices aimed at involvement, commitment and management-union cooperation are to survive, operate effectively and be harnessed to competitive objectives, these practices need to be taken into account in major strategic decisions. The implications of strategic options for employment practices and partnership arrangements can then be considered systematically. At the same time, human resource strengths can point towards strategic opportunities and influence the options decided upon (Dyer et al. 1985; Kochan and Osterman 1994; Pfeffer 1994).

The wider HRM literature understands strategic integration in terms of a series of features of overall corporate 'architecture' that incorporate the ways in which human resource issues are aligned with competitive strategy (Wood and Albanese 1995; Huselid et al. 1997). These include:

- the involvement of the HR department in the firm's strategic planning process;

- the existence of a clear strategic mission that is well understood and communicated at every level throughout the firm;

- a high degree of alignment of business and HR strategies.

The HRM literature seldom considers the role of unions, or of joint management-union partnership initiatives, in the context of strategic integration. In part, this may reflect the paucity of exemplary cases of strategic joint decision-making in countries with a history of voluntary partnership (see Kochan and Osterman 1994; Cutcher-Gershenfeld and Verma 1994; Strauss 1998b; Verma and Chaykowski 1999). Where the issue has been considered directly in the literature on mutual gains industrial relations, the following channels or forms of strategic integration have been identified: 
- board-level representation for key union advocates of partnership initiatives;

- works councils and consultative forums at enterprise and establishment levels;

- executive directorships held by top-level human resource executives, who then become the advocates for, and custodians of, human resource and industrial relations innovations and the opportunities to which they give rise;

- strategic-level joint forums, operating at the apex of partnership arrangements;

- informal channels and mechanisms for ensuring that senior executives and boards take account of and comply with the priorities and practices agreed in joint forums (e.g. periodic review meetings between top management and key union officials, strong informal relationships and channels of communication between key animators of innovation and senior management).

Kochan and Osterman, in particular, suggest that these alternative arrangements for strategic integration could be equally effective in the context of a mutual gains approach (Kochan and Osterman 1994: 55-8). At the same time, the possibility should also be recognized that alternative channels could give rise to tensions and impose strains on strategic integration. To the degree that different channels are used to articulate different priorities, and reflect different vested interests at different levels, such an outcome is likely to result.

As outlined in Chapter 1, commentators are in agreement that competitive strategies focused on 'quality enhancement', 'differentiation' or 'innovation' are best supported by innovative HRM practices and mutual gains industrial relations (Schuler and Jackson 1987; Arthur 1992; Kochan and Osterman 1994: ch. 3). A stronger version of the same view is that high commitment human resource practices and mutual gains industrial relations may be prerequisites for competing effectively on the basis of quality, product difference and innovation. Looked at in another way, the literature is clear that these types of competitive strategies provide the most secure basis for viable high-commitment human resource and industrial relations strategies. Commentary is more divided on whether competitive strategies emphasizing cost minimization or cost containment can also be supported by highcommitment human practices and mutual gains industrial relations (Walton 1985; Pfeffer 1994). Theory aside, research findings suggest that the adoption of high-commitment and mutual gains practices may not commonly be associated with any particular type of competitive posture, possibly because no clear-cut competitive posture pivoting on the cost-quality axis has been articulated (Locke et al. 1995; Wood and Albanese 1995; Cappelli 1999; Guest et al. 2003). Other research suggests that the effectiveness of highcommitment human resource strategies may not in practice be dependent on the type of competitive strategy in being (Huselid 1995; Guest et al. 2003). 
Kochan and Osterman (1994) provide the most direct treatment of what they see as the necessary link between the type of competitive strategy being pursued and the viability and effectiveness of mutual gains industrial relations. They are quite categoric on the question of the strategic underpinnings of mutual gains practices (1994: 55):

It is essential that the firm not depend solely on low costs, especially on low wages, salaries and benefit levels, but rather on such sources of competitive advantage as affordable quality, innovation, flexibility, speed and customer service.

The rationale behind this view is again straightforward. High employee commitment is seen to be impossible to sustain over time unless a company has adopted a competitive strategy that actively requires the commitment, loyalty and motivation of employees to succeed (Kochan and Osterman 1994: 56).

To the degree that a competitive strategy is built to a considerable extent around the guiding principle of service quality, as is the case in Aer Rianta, questions remain, however, regarding the viability of mutual gains industrial relations. As is well understood, the development and implementation of commercial strategy are complex, open-ended and iterative processes (see Purcell 1999). Ambiguities and differences of view regarding the implications of strategic objectives for employment practices can still occur and give rise to difficulties at an operational and even strategic level. An international review of changing industrial relations and human resource practices found that firms commonly pursue competitive strategies combining aspects of quality enhancement and cost containment. This occurs in spite of injunctions in the normative strategy literature about the perils of being 'stuck in the middle' between strategic poles rather than accepting the rigours associated with either posture (Locke et al. 1995). The consequence is that 'hybrid' human resource and industrial relations practices might develop, combining elements of traditional 'control' and innovative commitment or mutual gains models. In such situations competitive postures might also oscillate between a primary focus on cost and on quality enhancement, depending on immediate or short-term commercial pressures (Colling 1995). Oscillation of this type, perhaps dictated by attempts to deliver quality within sustainable price or cost constraints, can obviously introduce tensions into commitment and mutual gains-oriented employment practices.

A related question that arises is whether, in an increasingly competitive and deregulated market, a strategy focused on service quality may remain a viable competitive option. British Airways (BA) provides a paradigm case of a company that espoused service quality and high-commitment human resource principles but was nevertheless pulled by competitive forces down a road in which cost minimization became the dominant force driving the 
business. In the BA case, pressure on costs, pay and work practices became so intense that they seriously damaged the human resource and industrial relations strategies originally favoured by the company (Colling 1995).

These issues go to the heart of the link between partnership, strategy and governance in firms. They will be considered in the remainder of this chapter in the context of the evolution of the link between CP, strategy and governance in Aer Rianta during the period 1998-2000.

\section{Parallel processes: $\mathrm{CP}$, corporate and business unit decision-making}

The Compact and Requisite Arrangements documents sought to institute a strategic-level partnership in the company, backed by participative arrangements at multiple levels, and geared to a commercial posture best suited both to reaping the potential benefits of mutual gains principles and, more basically, to their preservation in a competitive environment. These documents provided then a basic constitution for CP in Aer Rianta. Apart from setting down the procedural principle of joint decision-making at strategic levels, the main $\mathrm{CP}$ documents also articulated a set of substantive parameters for commercial strategy. In ratifying the Compact as company policy, Aer Rianta underscored the pursuit of a commercial posture oriented to competing on the basis of skill and quality, rather than that of cost and price, and geared to the preservation of good employment conditions and employment security.

So from the beginning, CP set down the basic procedural and substantive 'architecture' for strategic integration. But the key CP documents were also abstract and general and provided few details of the mechanisms through which strategic integration would be achieved. Strategic-level decisionmaking in Aer Rianta was soon to open out to hard choices that needed to be made in the light of concrete pressures and opportunities in an increasingly competitive and complex commercial environment. The remainder of this chapter examines the manner in which partnership principles and arrangements related to strategic decision-making, particularly as Aer Rianta faced discontinuous commercial change in the period from 1998-2000.

For a good deal of the time from the inception of partnership until about 1998, CP and strategic decision-making activities can be viewed effectively as parallel processes. Mainstream management processes carried on virtually unchanged and the Compact represented in reality a form of 'shadow' or 'would-be' strategic decision-making. This was in part attributable to the balance of opinion towards $\mathrm{CP}$ within senior management, to be explored in detail in the next chapter. Most senior managers remained sceptical of $\mathrm{CP}$. While top-level management supported partnership, non-compliance with the processes involved among sections of senior management was not sanctioned. The Compact's avoidance of tightly prescriptive participative 
machinery, like works councils or other consultative forums, backed by detailed rules of operation and formulae for representation, meant that staff and union engagement in strategic decision-making was far from automatic. It also meant that senior management's lack of engagement with the Compact's objectives did not surface immediately or directly in clashes over the role, agendas and operation of participative forums. The actual shape of the participative process was evolving in any event, as outlined in the previous chapter, reflecting the demands of staff and the pressures facing different business units, leaving considerable latitude for non-engagement or pseudo-engagement by mainstream decision-makers grappling with strategic issues.

Some of those interviewed at senior management level felt that CP was viewed at board level in the main as a sub-board issue - part of operational industrial relations and human resource policy. There was seen to be a basic convergence of views as between the commercial parameters set down for competitive strategy in $\mathrm{CP}$ and the views of the board and top management as to the proper commercial orientation for the company. The balance of opinion among worker directors towards the Compact was perceived to be negative by supporters of CP. Given this set of factors, the board was unlikely to promote a tight integration of commercial decisionmaking and Compact processes and practices within the company.

For some, the main impact of the Compact on the decision-making activity of senior managers was negative: preventing senior executives from making decisions or pursuing options likely to stir controversy. Positive engagement and a change in the modus of managers responsible for business units or the entire company, towards more inclusive dialogue with staff and unions, remained uncommon.

It was not uncommon for senior managers to view a range of Compact forums as mere 'talking shops', with little real impact on their day-to-day decisions and operations. As one manager put it, offering a generalized portrayal of CP, even as it had begun to engage critical issues like duty-free sales and the future of Shannon Airport: 'it's seen as being a talking shop ... there's that world and there is the world of business, and the view would be that the two don't overlap'. Another manager, reflecting on the conduct of senior management decision-making at airport level, could see little evidence either of real engagement:

I would say that the amount (sic) of times we've devoted items on the agenda to the Compact ... is certainly less than you could count on the fingers of one hand in the last two to three years. That doesn't mean that they're against it, or neutral to it. It doesn't seem to get addressed specifically by the airport senior group.

As one senior manager, who supported $\mathrm{CP}$, put it, while reflecting on the situation company-wide up to late 1997: 


\section{Partnership and commercial strategy}

there was a twin track thing. I think that we, sitting around at management meetings ... or preparing for board meetings, or actually sitting through board meetings - that we would only have been aware of the fact that the Compact is working 'down there'.... So I think that at the time ... we hadn't married the two together. It hadn't happened.

This remained the case in spite of the fact that strategy was by this time viewed as a very real and vital process in the company in the light of internationalization, deregulation of the airline industry and other significant commercial changes. Major strategic issues were now routinely debated and fought out at senior management level, and strategic planning was no longer a periodic process of producing and revising formal plans and documents.

As airports and other business units continued to run largely along traditional lines, the major mechanism for promoting strategic integration at business-unit and corporate level was provided by regular weekly meetings of senior managers. At this forum, attempts to bring the Compact to bear on decision-making took the form of advocacy by the main management champion of CP. Others, however, appear to have been reluctant to give much attention to the case being argued:

We'd say ... 'there are more important things that I want to talk about actually than that'.... So the Compact was a bit of a pain, if it came up, because it was slowing down getting decisions and debate on what we thought was a much more important issue, which might be safety on the ramp, or it might be a better profit margin in the duty-free shops.

Even 'supporters' of the Compact saw the limitations of this form of advocacy as a mechanism for bringing $\mathrm{CP}$ to bear on strategic decision-making:

[The CP advocate] would regularly say: 'wait a minute! You guys can't be deciding these things anymore. There's another whole process to reach [decisions on] these things'. And then we'd kind of say: 'yeah, yeah, we know, we know, but just put that aside for the moment. We really have to resolve this issue now and we've got to finish this argument'. So there was a twin-track, and at that point the tracks hadn't met.

Against such a background, $\mathrm{CP}$ had failed to impact on a range of areas of strategic decision-making at the company, including the deployment of physical assets:

Where we're deciding to use land for public car parking as opposed to warehousing and as opposed to apron development for aircraft parking. Are those things the Compact should be involved in? ... The 'master plan' is another perfect example. We're updating the master plan, which 
will drive the physical development of the airport for fifteen to twenty years: a new runway; more passenger terminal developments; a second passenger terminal. But there's no Compact involved.

Management budgets were also seen to be determined in isolation from CP:

Does [a senior manager] worry about the participative process when he's doing up the budgets for the organization? ... The last thing in the world he probably wants is the participative group to come up and tell him their view of what the budget should be.

Business-unit engagement of $\mathrm{CP}$ around strategic decision-making was also to remain limited, with higher degrees of engagement in the case of the Shannon maintenance review and the maintenance division of Dublin Airport. As will be outlined below, it was primarily cross-company issues, like the threat to duty-free sales and a government-initiated review of the future of the company, that were to draw senior management at businessunit level into more active engagement with CP.

The JUCG appeared largely powerless in the face of the prevalence of traditional management decision-making channels. At business-unit level, the JUCG sought to play a role as both umpire and guarantor of the Compact process in circumstances where either managers or unions complained that the process was being used incorrectly. Thus the JUCG sought to mediate in a dispute over the application of CP principles to a review of cleaning operations in Dublin Airport and principals on both sides intervened in a review of maintenance operations in Shannon amid claims that the parties involved had not consistently engaged with the process.

\section{Converging processes: $\mathrm{CP}$ and major corporate challenges}

Virtually all shades of management opinion towards CP acknowledge that the Compact and strategic processes in Aer Rianta began to fuse around the threat to duty-free sales, the change in the status of the company and the company strategic review, initiated by the government in 1998. These issues represented the most significant challenges in Aer Rianta's history up to that period.

The impending loss of duty-free sales in the summer of 1999 was handled within the Compact by a strategy group. This comprised sub-groups drawn from the commercial divisions at the three airports. The joint groups involved developed a detailed analysis of the likely commercial outcome of the loss of duty-free sales and identified a range of options for responding to the new commercial circumstances. Senior managers felt that for the first time the Compact was a major force and had fused with the formulation of strategic options by the company. 
It's absolutely integrated. Absolutely. ... You've a lot of staff involved, you have a lot of people working on it, and it has enormous implications for the company.... There are certain things we will not be doing post July 1st 1999, and what those things are is being addressed by the joint working groups and the detailed line-by-line analysis which my people could not possibly do without involving these people in a different way. The way they're doing it is much better than me going and asking them questions and probing them.

Here senior management worked within the Compact review process, satisfied to allow the review groups to play an active role in the process of commercial adjustment.

I can see that 98 per cent of the decisions will be channelled through [the airport-level duty-free significant issues group] and coming from there. ... Now, in fact, I won't make decisions without at least discussion with the group.

While the various groups did their work, the company and the union group continued to lobby Brussels for the retention of duty-free sales, but with little real expectation that the lobbying process would this time bear fruit. Duty-free was abolished on sales of goods for passengers on flights within the European Union on 1 July 1999. The loss of margin on what had been a highly profitable business for Aer Rianta had significant implications for the future finances and status of the company, as well as for work practices in airport retail shops as will be discussed below and in later chapters.

As government policy towards the semi-state sector evolved in favour of external investment or privatization, the future status of Aer Rianta became a live issue of public policy. Before the long-term future of the company could be decided, it was necessary to change the status of Aer Rianta from a public agency to that of a fully fledged commercial, semi-state company. This involved amending the legislation under which the company had been established. As important commercial and staff-related issues were involved, and there was a perception that the change in status might be a prelude to privatization, the JUCG established a significant issues group to consider the change in status.

The group met and discussed the issues involved - some technical, such as the profit implications of liability for the payment of rates on airport facilities, dividend payments to the government and liability for corporation tax. Preferred policy with respect to treatment of the company's assets was also covered, as were the implications of the company's new status for the staff pension scheme. The Change of Status SIG also considered the implications for the $\mathrm{CP}$ process of stipulations in the Amending Bill concerning prohibition of unauthorized disclosure of confidential information. Disappointment was expressed at the failure of the Bill to make provision for an 
employee shareholding scheme. The view was also articulated that, whereas ESOPs had recently been established to compensate staff in other semi-state companies facing rationalization programmes, in the case of Aer Rianta corporate change was being undertaken voluntarily by staff through $\mathrm{CP}$. The Change of Status SIG urged that the company should not be penalized for its success by any future attempt to tie the offer of an ESOP to expected job losses. The SIG also sought to have the chief executive made a member of the company's board. His exclusion from board membership was seen as not 'entirely appropriate to a company which intends to make constructive participation a significant feature of its strategy'.

The SIG prepared a joint 'discussion paper' on these and other issues. Issues on which it had not proved possible to put forward a common view, for example, the role of the government as both shareholder and regulator, were also covered. The discussion paper was sent, in accordance with procedure, to the 'sponsors' of CP, including the minister. Simultaneously with the deliberations of the Compact group, company senior management and the Group of Unions also addressed these issues and along broadly consistent lines.

A number of key issues broached by the Change of Status SIG arose again, and very soon, when in the summer of 1998, the Minister for Public Enterprise requested that the board of Aer Rianta should undertake a strategic review of the future of the company. The chief executive and board chairman resolved that the review, formally the responsibility of the board, should connect with the CP process. The brief of the Change of Status SIG had been broadened in June 1998 to encompass company strategy in its entirety, as provided for in the Compact. This group now became the main vehicle through which the Compact process would contribute to the review of Aer Rianta's long-term strategy and future corporate status. To underscore his commitment to a joint review of the future of Aer Rianta, the chief executive attended an early meeting of the group. At this meeting, he gave his views on the options the company might face and invited views and comments from the union, management and external members of the group. The first meeting of the 'Corporate Strategy' SIG, held in the shadow of the review, attracted probably the largest turnout of senior managers yet witnessed at a CP initiative. At the meeting, the CEO indicated that, consistent with CP philosophy, the financial consultant engaged by management and the board to advise the company on the review had been briefed to treat all 'stakeholders' within the company as their 'clients', and not solely the board and management.

The Corporate Strategy SIG set to work on its strategic review. The management participants included the chief executive and all senior managers at airport and corporate levels. The union participants included the national officials of all the major Aer Rianta unions, including IAESA, the chairman of the Aer Rianta Group of Unions and SIPTU's economic advisor. A number of external experts with backgrounds in the airports industry, 
capital markets and financing and industrial relations also participated in the work of the group. In all, six meetings were held, and a 20-page discussion document was submitted to the 'sponsors' of constructive participation. The group was concerned to emphasize that, while the ministerial review had 'given a sharper focus and added emphasis' to its work, its establishment and deliberations reflected the commitment in the Compact to extending participation to corporate strategy. The discussion document sought to synthesize what was described as a 'rich debate on the company's future strategic direction' (Corporate Strategy SIG Discussion Document 1999: 4). In line with the approach adopted under $\mathrm{CP}$, members were not viewed as representatives, but as contributors with distinct bodies of expertise. It was understood that no party could be held accountable for their contribution to the discussion. A series of papers by participants summarizing their views on the positions in the debate within the SIG were appended to the discussion document, without attribution to any party. The discussion document was explicit as to the group's status under the principles of CP: seeing its role in terms of identifying options but not binding any of the parties to a particular course of action:

The ... discussion paper may also be useful in the formulation of a joint strategy policy paper. However, the question of formulating a joint strategy paper does not come within the remit of a 'significant issues group'. It is a separate matter and would require the specific agreement of unions and management.

(Corporate Strategy SIG Discussion Document 1999: 4)

The discussion paper advocated that Aer Rianta should develop as an Irish-owned multinational airport management company, with core strengths in airport operations and retailing. Through $\mathrm{CP}$, it aimed to promote an approach to change that secured benefits and advances for all the major stakeholders. Change that 'advanced the cause of one stakeholder at the expense of another' was portrayed as 'inevitably divisive and destructive' (Corporate Strategy SIG Discussion Document 1999: 5). The document advocated the retention within the company of all three airports, reflecting external debate that the three airports be set up as separate businesses to engender competition. On this principle there was 'joint consensus' within the group. The group also believed that the logic of promoting a twoairports or two-terminals strategy at Dublin Airport, where a second airport or terminal would be privately owned and operated, was flawed and failed to comprehend the damaging consequences of such approaches in other airports internationally. It was noted that airport charges in Aer Rianta were among the lowest in the industry in Europe, and that whether this was sustainable was a highly significant issue for the company's future. The document supported the appointment of an independent regulator to regulate charges and pricing. The report noted that it was necessary to depart from existing per- 
sonnel structures and work practices; to promote flatter company structures; and to foster continuous learning and competency development. Such 'organizational and personnel transformation and renewal' was being conducted with the commitment of management and unions under the principles of 'jointness and participation'.

The group believed that the issue of how the future growth of Aer Rianta might be funded was a critical strategic issue. Of the various options available, some members of the group 'strongly argued' that the state should fund further investment, and that this could be advocated on purely commercial grounds. It was also recognized, however, that the state seemed determined not to invest in Aer Rianta, consistent with its policy of withdrawing from involvement in commercial semi-state activities to the greatest possible extent. It was questioned whether, in the light of the state's poor track-record of investment in semi-state companies, it made sense to leave Aer Rianta in full state ownership and thus vulnerable in the future to 'policy shifts by different governments'. The option of expanding through increased borrowings was currently hindered by a legislative cap on borrowings. Irrespective of such a limit, reliance on borrowings posed the risk of leaving the company vulnerable to future pressure to sell off assets. The existing capital programme was also of such magnitude as to call such an option into question. The option of an initial public offering (IPO), involving the offer of shares on the stock exchange was considered. Those on the group advocating further state investment as a preferred option favoured an IPO as a second choice, provided that certain conditions were met. The conditions were that the state would maintain a majority shareholding in the company; that a new set of rules for the commercial operation of the company would be agreed by government; that the maximum shareholding of any entity in the company, with the exception of employees, should not exceed 5 per cent, and that an employee share ownership plan (ESOP) should be agreed on acceptable terms prior to flotation. The document noted that the Compact explicitly endorsed the principle of employee shareholding, and that ESOP holdings of 5 per cent or more were now commonplace in commercial semi-states that had undergone major programmes or changes in ownership status.

The document agreed that the option of a strategic alliance held few advantages, as the company's need was for finance not expertise; Aer Rianta was already internationally respected for its expertise in the industry. The option of an asset sale was also seen to present little advantage and it was agreed that the company should seek to retain all assets relevant to its core business. The group did not address the future of the Great Southern Hotels, noting that a review was also underway in that specific area. It noted that there were, nevertheless, 'strong views that hotel ownership was not part of the core business of Aer Rianta' (Corporate Strategy SIG Discussion Document 1999: 12). No support existed for a 'trade sale' in which the company would simply be sold off to another company, probably the highest bidder. Such an 
option was seen as tantamount to a hostile take-over. The option of a 'private/public partnership' was also seen to carry little advantage, except possibly in the context of other forms of funding.

The new centrality of CP strategic decision-making in Aer Rianta can be attributed to a combination of a new chief executive's active support for the process and, critically, a disjuncture in the commercial situation of the company towards the end of the 1990s. Aer Rianta had experienced a sharp acceleration in the pace of commercial change from the 1980s into the 1990 s, arising from the deregulation of the airline industry, pressure on landing charges and discounting and sharply growing passenger numbers. These changes, however, were largely accommodated within established management structures, and were insufficient in themselves to propel CP into mainstream management decision-making. The impending loss of duty-free sales at a time when the company became liable for the payment of corporation tax and rates, while at the same time facing the heavy borrowing required to fund infrastructural expansion at the airports, confronted Aer Rianta with quite unprecedented commercial challenges.

These challenges provided the catalyst for the ministerial decision to seek a fundamental review of the company's future. They also forced hard decisions on Aer Rianta, with major implications for staff and trade unions. Decisions of this order could only have been taken within traditional management and board channels with a major risk of industrial relations dislocation. That similar decisions had given rise to serious industrial relations turmoil in Aer Rianta's near neighbours at Dublin Airport, Aer Lingus and the aircraft maintenance company, TEAM, was not lost on senior management. The existence of CP channels - albeit at that point faltering for lack of senior management engagement - provided a means of broaching fundamental commercial decisions without provoking an acute industrial relations crisis. At the same time, the commercial success and position of the company allowed the parties the time and space in which to consider all options available for responding to commercial challenges. Unlike Aer Lingus, in which virtual bankruptcy provoked a sharp focus on cost cutting and headcount reduction, and TEAM, where headcount reductions became a prerequisite for attracting external investment, Aer Rianta's underlying performance was strong. The company enjoyed growing passenger numbers and could envisage absorbing job losses from duty-free retailing through redeployment of staff within the company.

The coupling of CP with the handling of the duty-free issue and, simultaneously, with the conduct of the strategic review, breathed new life into the Compact at a point when even its staunchest supporters began to fear that it might be on the point of collapse.

The company is looking at change being forced on it through competition, deregulation, financial issues and wanting to grow itself. So the Compact was suddenly seen in another light. It's no longer just a big 
training, development and educational thing. It's a vehicle through which you try to become more competitive; try to become a more competent organization; you try to become an organization with less layers and [within which] communications flow a lot better.

Even sceptics, still harbouring considerable doubts regarding the effectiveness of the process, felt that CP had become a more central force in company activities. As one manager put it, 'on a scale of one to ten in terms of its impact, I'd say its hovering around the eight mark now and I'd say in the last twelve months [1997-98] it's moved from three or four to eight'.

\section{The interface with management decision-making}

If $\mathrm{CP}$ assumed more central importance in the context of the company's attempt to confront major commercial issues and decisions, it was also tested by the closer alignment with strategic decision-making. Tensions became apparent with respect to the carefully orchestrated separation of roles and responsibilities envisaged in the Requisite Arrangements. First, some senior managers believed that it was in practice difficult for them to step outside their formal management roles when engaging staff and unions in joint forums. The implications of options discussed, positions articulated and, as they saw it, expectations created, for day-to-day operations and processes were difficult not to bear in mind in Compact forums. In short, for some at least, the avoidance of postures strongly conditioned by formal management roles and accountabilities remained problematic even under the separation of channels, roles and responsibilities envisaged in the operation of CP. Supporters of CP tended to attribute this to reluctant engagement with partnership, or to closed 'mindsets' in some circles. Other managers worried that commercially sensitive market information made available under CP processes would be particularly welcome to competitors and opponents of Aer Rianta.

More important still, given the ambition of the Compact to transform decision-making in Aer Rianta by infusing participation into strategy development, the effective separation or uncoupling of strategy formulation from gaining closure or agreement on strategy - the latter being regarded as the business of management and the unions - created considerable uncertainty among sections of senior management. What was uncertain above all in their eyes was their capacity to act once issues had been addressed in strategic forums. An example was provided by the experience of one management group at airport level in the aftermath of the work of the SIG dealing with the imminent loss of duty-free sales:

The business unit was asked to respond and set up a small group to prepare a response. .. . Our brief was literally to take the Compact report, to embellish it in any way we felt relevant and to come back with a 
conclusion and recommendation in terms of a response. That is being seen very negatively: 'there's the management again going off behind closed doors, their own little cliques putting together a report and not involving anybody'.

Even managers who were on the whole supportive of $\mathrm{CP}$, questioned how strategic decision-making was actually occurring, given the parallel channels that now formally existed:

A very real fear that a lot of people would share [is] are we really driving the strategy? Or is it outside consultants that drive it? Is it the board that is really driving it? Or is it senior management that are really driving it?

Authority and accountability were also seen as problems in the context of CP:

I've asked the question a number of times: 'is it me [who is expected] to drive this within my own department?' And the answer is no, that it should be a joint process and we have to go through that, and I understand that. But at the end of the day then who is accountable for actually getting results? It's one thing to produce papers and to have discussion and to say that this is a joint approach. What you really need is action.

The formal separation of roles and processes was also seen to lead to sharp changes in postures across different forums within the company.

You can have unofficial conversations and official [conversations] within the Compact; conversations where you talk about radical things. As soon as it tends to become normal again it's 'oh hang on, this is an industrial relations arena; it's not a Compact arena', and there's shifting sands all the time as to whether you're in one mode or another.

\section{The interface with collective bargaining}

The formal separation of CP forums and collective bargaining was both a reflection of the philosophy of partnership underlying $\mathrm{CP}$ and pragmatism rooted in realpolitik. The methodology of joint discussion was intended to allow for the identification and fact-based examination of options and the acknowledgement of differences of views where these persisted following joint discussion. There was no requirement that participants in review groups reach a definitive joint position with clear and jointly agreed implications for action. Reports produced by joint groups were conveyed via the JUCG to the 'sponsors' of CP: the ICTU general secretary, who was 
regarded formally as the conduit to the Aer Rianta Group of Unions, the CEO, regarded as the conduit to management and the board, and the Secretary General of the Department of Public Service, the conduit to the minister and government. The process allowed these parties to dissent from or support the conclusions of joint reviews, as they saw fit.

This philosophy had important consequences. It led to intensive research throughout the organization on perceptions of participation and views on issues seen to warrant participation. It inclined the main champions of partnership towards a highly non-prescriptive approach and made them opposed to setting down fixed agendas for participation at any level. The perspective championed by the major animators and supporters of $\mathrm{CP}$ also predisposed them against the establishment under the Compact of councils or structures with consultative or decision rights tightly defined, for example, by issue, subject or representative constituency. Even active supporters of CP in senior management were clear that they would not welcome the establishment of works councils or similar mechanisms in Aer Rianta.

Pragmatism, however, had also influenced the ground-rules for CP. CP could not conceivably have developed without assurances to the parties that existing rights and arrangements, not least those established under collective agreements, would be respected and preserved. Champions of CP felt that, irrespective of the preferred methodology, it would have been inadvisable in the early stages to encourage joint forums and groups to produce precise proposals because, as one person put it, 'if they were shot down, then everybody would say: there, what did I tell you? This thing is only a sham'.

The formal separation between strategy formulation within the Compact and pre-existing channels of management-union accommodation was also reflected in the strategic review of Aer Rianta. The chairman and chief executive sought to link the strategic review with CP through the work of the Corporate Strategy SIG, and, as discussed, consultants were briefed that the company had multiple stakeholders. Nevertheless the formal strategic review was managed by a sub-committee of the board, working with senior management, assisted by the consultants. This group worked independently of the Compact SIG, though management members of each group overlapped, and did not meet with the Compact group. The Compact SIG report was issued to the sponsors in March 1999 and the Aer Rianta strategic review document was published the following month. An unattributed paper appended to the discussion document published by the Compact SIG, expressed the concerns of a member arising from the formal separation of strategic reviews:

I would like to remind the Corporate Strategy Group that the minister has not chosen to directly involve this Group in her review and it would be useful and reassuring to know how the Corporate Strategy Group's deliberations will be reflected in the final document sent to the minister by the board.

(Corporate Strategy SIG Submission on Company Review, n.d.) 


\section{Partnership and commercial strategy}

Notwithstanding the formal separation of strategic processes under the review and attendant anxieties, there emerged in practice a high degree of overlap or commonality in the positions reached under the parallel strategic reviews, and in the resulting positions of management and unions as to the issues at stake. The company review made explicit reference to the fact that 'other stakeholders, under the Compact for Constructive Participation, have evolved ... conclusions [regarding the future of the company], which are substantially in agreement with those of the board and management' (Future Strategic Direction: A Report to the Minister for Public Enterprise, April 1999: 7). Like the Compact discussion paper, in which the IPO strategy was seen in effect as the most beneficial practical option, the Aer Rianta review document endorsed an IPO as the best way forward for the company. The desirability of instituting an ESOP was accepted. Partnership was identified as one of the 'core values' of the company, critical to the maintenance of its competitive advantage in the future. While one clear strand of opinion in the Compact review was that shareholding by any outside party should be capped, this was not formally endorsed or proposed in the company review. Here the issue was simply considered in respect of the impact it might have on the valuation of the company for flotation (Future Strategic Direction: A Report to the Minister for Public Enterprise, April 1999: Appendix, iv.).

Subsequent to receiving the Aer Rianta strategic review, the minister appointed a further group of consultants to evaluate the report and consider its recommendations on the wider canvas of other options that had been mooted by third parties for the future of the airports. The ministerial review involved contact with Aer Rianta management, but no contact with any Compact forums, or with the unions. The report substantially endorsed Aer Rianta's proposed strategy, with its emphasis on the company remaining an international airports group, with core competencies in airport operations and retailing, and on raising the capital required to expand through an IPO (Report to the Minister for Public Enterprise and the Minister for Finance: Review of Strategic Options for the Future of Aer Rianta, December 1999).

Following the publication of the various review documents, the Aer Rianta Group of Unions met to formulate its position on the future of Aer Rianta. The union group favoured the option of further investment in the company by the existing shareholder. It recognized that this was unlikely to occur and, as such, concluded that an IPO provided the best fall-back strategy for the company. The group favoured the capping of outside shareholdings at 5 per cent and sought an ESOP. The unions had taken the discussion document produced by the Compact SIG and used it as a basis for developing its policy, discussing the proposals with senior management in the hope of gaining agreement on a common position (Report of senior union official to Meeting of the Corporate Strategy Group, 25 February 2000).

Management, meanwhile, also sought to win support within the company and in the department for the preferred options outlined in the strategic 
review, favouring an IPO floating a significant minority interest in Aer Rianta. The Corporate Strategy Group was reconvened in early 2000 to consider the situation that then existed and to advise on moving forward with the IPO and other changes sought. By that time, the positions of the internal stakeholders were close. Management, the board and the unions agreed that the challenge was to retain control of the company and its strategy, while obtaining the funds necessary to finance its capital programme and medium-term plans for expansion. The parties' views were also broadly consistent on the need to cap shareholding and on the establishment of an ESOP.

Manifestly, in the light of these developments, a considerable degree of spillover had occurred between both the processes and strategic deliberations of forums under the Compact and the formal positions and strategic decisions adopted by the board, management and the unions. Though these processes and strategic forums were separate under the Compact, mutual gains-type principles influenced the approaches taken on both sides following deliberations in Compact forums and facilitated speedy accommodation between them. Discussions of strategic options in Compact forums had also shaped decisions with respect to strategy and action in the case of both management and unions. The observation of a key animator of the Compact that, as the process became more sophisticated, management and unions might not have to 'operate in that mandate' in traditional ways seemed to reflect the evolution of relations around the strategic review.

Confidence in the new centrality and effectiveness of CP fostered new aspirations among key animators. The formal separation of $\mathrm{CP}$ and established decision channels had been dictated in part by pragmatism, and pragmatism also now prompted some to envisage radical changes in the basic institutional architecture of the process. Supporters of the Compact began to articulate a long-term perspective in which the processes inherent in $\mathrm{CP}$ might subsume formal deliberations between the agents of the 'sponsors': 'I think that you make it more and more sophisticated so that people who are management [or] union are actually not required to operate in that mandate a lot'.

The Compact process even began to be seen as a prelude to the emergence of a form of organization in which co-operative joint decision-making would become the very fabric of management-staff interaction at strategic and operational levels, facilitated by a flatter structure, team-based working and genuine staff empowerment at all levels. Such a vision remained highly abstract, however, and had not emerged or been articulated through the $\mathrm{CP}$ process itself, except briefly in the discussion document of the Corporate Strategy SIG.

Duty-free sales for intra-European passengers ceased at the end of June 1999. The main animators of the Compact and Compact facilitators on the ground then sought to ensure that the process of adjusting to the new situation in the shops would be informed by both CP principles and the 


\section{Partnership and commercial strategy}

substantive options outlined in the reports of the strategic issues groups. In a tense and uncertain situation, they now feared that management might seek to act unilaterally at the same time as the main union involved might seek assurances on behalf of its members. Such traditional postures might interact to engender crisis and bring to the fore actors either opposed to the Compact, or poorly conversant with the principles involved. It was, as one key animator put it, a case of the 'old culture ... always trying to take over'. Reflecting on the situation immediately after the disappearance of duty-free sales, a Compact supporter pointed to the potential for crisis:

This is the dangerous thing. This is a particularly dangerous point because if [people on the union side] who haven't been involved meet [a manager] who is not involved at all, they would agree that 'this is our agenda now, crisis, staff being let go', and they would just have their blinkers on.

Another key animator of $\mathrm{CP}$ saw a need for a fundamental reassessment of the ground-rules of constructive participation. In this climate the approach taking shape in the minds of champions of $\mathrm{CP}$ involved achieving closure on issues in Compact joint forums, precluding the need for issues handled in such forums to be referred back to established channels of managementunion engagement for final decision or accommodation. Ideas began to develop on changes that would involve ending the separation of processes, roles and structures as between joint decision-making and established industrial relations channels, as enshrined under the Compact. A single channel for joint decision-making was envisaged, based on 'mutual gains bargaining', backed by an internal arbitration process incorporating alternative dispute resolution principles. Compact supporters began to examine examples of arrangements of this kind outside Aer Rianta.

Strains between the Compact and established industrial relations channels also emerged following the completion of the strategic reviews. Although the strategic review SIG, the board, management and the Aer Rianta Group of Unions all endorsed a future strategic direction involving the flotation of part of the company through an IPO, worker directors now came out strongly against this position, denouncing these plans as a form of privatization. The Aer Rianta Group of Unions sought to respond by pressing worker directors to accept the policies articulated by the group. These tensions and their effects will be examined in detail in Chapter 10 .

\section{The sustainability of competitive priorities and Compact assurances}

The strategic reviews and their implications for the future ownership status and commercial strategy of Aer Rianta also throw into sharp relief the issue of the sustainability of the competitive posture underpinning both the 
Compact processes and its associated assurances on pay and conditions of employment. Two intertwined sets of issues arose here. The first was the sustainability in the light of market trends of the upstream or quality-focused commercial posture informing Aer Rianta's support for CP. The second concerned the implications of possible changes in corporate governance and associated changes in the regulatory environment of the company for the processes and assurances involved in CP.

Concurrent with the conduct of the strategic reviews of the company's future, senior management held differing views of the implications of market trends for a quality-focused competitive posture. The dominant view was that Aer Rianta could continue to pursue a strategy in the home airports wherein the quality of the service provided to airport customers would remain a major consideration. The implication was that the skill, commitment, flexibility and attitudes of the staff would remain an important commercial asset. A senior executive articulated his position with regard to both domestic and international airport businesses:

I always felt that there wasn't any other intelligent way for us to proceed except that basis [i.e. the Compact's commercial parameters] because I never felt that we could compete internationally through using a low-cost strategy. I just didn't think that was a runner. I didn't think that we would be able to win anything on that basis; that we could only win internationally on the basis of quality, on being what we are and adding unique flavours. We're not big enough and we have no tradition of working as a low-cost supplier of services. And if you were to try to become a low-cost supplier of services it would mean such a dismantling of everything that you've ever been that you would lose your whole brand by doing it.

Other executives were equally determined that Aer Rianta would continue to compete on the basis of high quality rather than seeking to emulate what was described as the 'Ryanair model': 'follow the Ryanair model, as one executive put it, and you'll drag the whole airport down as well'. With the exception of continuous criticism of Aer Rianta's landing charges by Ryanair and to a lesser degree Aer Lingus, most criticism of the service was seen to have focused on quality issues and facilities rather than on cost. As a number of managers saw it, Aer Rianta's costs were well in line with other operators; productivity had risen very sharply as a result of high passenger growth combined with only modest employment growth; the market was set to continue growing significantly and a range of new facilities was set to come on stream in Dublin and the other airports. The employment effects of the loss of duty-free sales could, as they saw it, largely be neutralized in such a context through staff redeployment. The Compact assurance of employment security to permanent retailing staff had been respected, and, less than one year on from the loss of duty-free sales, the overall level of employment in Aer Rianta was higher than in June 1999. 
Dublin and the other domestic Aer Rianta locations had one airport only and, unlike many airports in Europe and the US, they did not have to contend with direct competition from neighbouring low-cost airports. They also appeared unlikely to face such competition in the future. Low-cost, nofrills operators might be accommodated in suitable facilities, without the entire service getting 'dragged down to its absolute base minimum'. 'Network carriers', prioritizing customer service, would remain a major customer of all airports. In such a context, intensifying competition between airlines and between airports would not translate into irresistible pressure on costs, necessitating a major commercial repositioning away from quality and service towards cost, and requiring the abandonment of Compact assurances on pay, skill development and employment security.

Other managers, however, interpreted medium-term to long-term market trends in a different way.

The industry, as I understand it, has very little tradition of people surviving for long on a quality basis.... We would have had first-hand knowledge here that as soon as somebody comes along with a low price - a lower price in this environment - people will flock to it absolutely and there'll be little loyalty to higher service, or, as they call it, a fullservice airline.

In this scenario, the posture towards Aer Rianta of low-fare operators like Ryanair represented the thin end of a wedge that might be expected, on certain assumptions, to corrode service quality priorities from the competitive mix of the company. Ryanair had sought a cheap, 'no-frills' terminal facility ('a shed', as one executive described it) at Dublin Airport. Aer Rianta responded by providing a cost-differentiated service in Pier A, with further capacity of this type in the pipeline. In the event of a downturn in the aviation industry, one senior executive believed that all carriers would seek to use such low-cost facilities. The possible advent of a privately run terminal would add further pressure to costs and prioritize 'operational flexibility' over the human resource attributes underpinning the Compact. Other executives approached the competitive sustainability of Compact commercial parameters on the basis of the circumstances of the different airports. If the assumptions underpinning the Compact might be viable for Dublin Airport, other airports were seen to require a level of numerical flexibility inconsistent with the Compact to allow them to respond to highly seasonal traffic patterns. Higher levels of contract employment, and more scope to match staffing levels to business volume, were seen to be the main competitive imperatives here, and were seen to go directly against the grain of the Compact. At its most radical, this airport-level scenario pointed to the possibility of 'three or four different types of operation' within the company.

It was equally, clear, however, that alternative competitive scenarios also depended on assumptions regarding the future of the company and regula- 
tion of competition in the sector within Ireland. Thus the sustainability of the Compact's commercial parameters depended also on issues of ownership, corporate governance and regulation. These issues were central to the various strategic reviews, but they also opened out into public policy and politics beyond the direct reach of the parties to CP.

While management and unions in Aer Rianta were clear that their preferred competitive posture was predicated on an appropriate form of corporate governance, they were also well aware that the future of the company had become subject to intensive lobbying. Aer Rianta was seen as a gilt-edge acquisition or investment, and various interests lobbied in favour of different options. These were seen to include wholesale privatization and the break-up of the company through selling off each of the airports separately. For some time, lobbying had also been underway to permit the building of a privately financed terminal at Dublin Airport and the development of a passenger airline capacity at the existing military airport at Baldonnel. While all the strategic reviews reported unfavourably on most of these options, politics would determine the ultimate fate of the company.

The establishment of an independent aviation regulator, viewed in all the reviews as a precondition for change in the status of the company, also posed challenges to Aer Rianta's commercial strategy and associated Compact assurances. The reviews dealing with the nature and structure of regulation advocated a method of regulation known as 'price cap' or 'RPI plus or minus $\mathrm{X}$ '. In the report for the government, the consultants elaborated this principle further and advocated so-called 'single till, price cap regulation'. This type of regulation involved fixing increases in airport charges across all operational areas, aeronautical and non-aeronautical, on the principle of allowing for increases in the retail price index minus (or plus) a so-called ' $\mathrm{X}$ factor' designed to promote improvements in efficiency and productivity on an ongoing basis. The calculation and evolution of the ' $\mathrm{X}$ factor' could, of course, take into account the service quality objectives of the company, ensuring that service standards were not driven below the requisite quality levels in pursuit of crude efficiency improvements. In this way, external regulation could operate in a manner that was compatible with the priorities assigned to quality and service in the company's commercial strategy and the Compact, and could even conceivably drive those priorities and associated working practices in a positive way.

At the same time, the advent of regulation manifestly reduced the scope of the company to position and price its services in accordance with its own conception of quality and service. These service attributes and their relationship to price and charges in the product mix now become subject to mediation and negotiation with an independent regulator. In consequence, a regulator would have to be convinced that the commercial parameters underpinning the Compact, as well as the work practices and organizational principles it enshrined, were consistent with meeting competitive principles, and did not entail prices out of line with economic cost. Again this 
was new territory with respect to the link between company strategy, Compact assurances and modes of working favoured by CP.

\section{Conclusion}

$\mathrm{CP}$ provides an opportunity to examine in depth the links between strategy, governance and partnership. CP formally encompassed staff and union involvement in strategic decision-making in business units and at corporate level. The Compact also set down clear parameters for commercial decisionmaking: Aer Rianta was enjoined to compete on the basis of service quality and the skills of its workforce and not to promote business options that entailed lower pay and poor working conditions. This commercial strategy appeared both viable to the parties and consistent with the Compact; shortterm cost or market pressures posed few problems for longer-term commercial priorities, and none of the challenges that arose appeared to warrant a shift in strategic priorities.

Formal arrangements for integrating partnership with strategic decisionmaking appeared strong. The board had endorsed $\mathrm{CP}$; champions of $\mathrm{CP}$ could be found among senior managers and the CEO supported the approach. The board included three worker directors. The shareholder or minister responsible for Aer Rianta and the parent department were supportive of partnership. Great effort was devoted to establishing and facilitating a range of structures to integrate $\mathrm{CP}$ and strategic decision-making at department and business-unit levels.

But the formal position disguises the complex and variable processes that determined the degree to which partnership meshed with strategic decisionmaking in Aer Rianta. In general it can be said that Compact processes and actual management decision-making processes focused around strategic issues occupied parallel channels until the late 1990s. Senior managers had failed to engage Compact processes to any significant degree at business-unit level or cross-company level. Advocacy by supporters of constructive participation was of very limited effectiveness, even though they had the ear of top management. The JUCG's main brief was to orchestrate the variety of Compact structures and initiatives underway, but it also intervened in circumstances where it believed the Compact was under threat or was being inappropriately applied.

While the board had endorsed the Compact, it had done so in the spirit of regarding the approach involved as a positive approach to industrial relations: as an essentially sub-board concern. The board's awareness of the commercial parameters set down in the Compact was of a general character. Compact processes and commercial principles can thus be viewed as having been 'loosely coupled' with board-level strategic decision-making. The board understood that an affinity existed between Compact objectives and the commercial traditions of the company. The chief executive supported the Compact, as did the minister who had made appointments to the board. 
This did not, however, amount to Compact objectives guiding commercial decision-making at the top in any active or vigorous manner, or involve an active concern to assess strategic options open to the company in the context of Compact processes and assurances. The worker directors on the board were seen by champions of $\mathrm{CP}$, if not by themselves, in the main as opponents of CP.

Parallel strategic and CP decision processes changed when a new CEO was appointed and largely incremental commercial change gave way to change of a disjunctive nature in 1998-99. These two developments interacted. The new chief executive was faced with the handling of major and potentially contentious issues and he had to handle them quickly. He opted to link the company's response with the Compact, and tied senior management into more active engagement with $\mathrm{CP}$ on these issues. The duty-free problem and the strategic review breathed new life into constructive participation and led to a convergence between strategic decision-making and Compact structures and processes. The state facilitated strategic integration by favouring the involvement of the partnership initiative in the strategic review of Aer Rianta's future.

Though still formally separate, management's strategic decision processes and Compact strategic forums were now in reality fused in important ways, and evolved a largely common response to major strategic challenges. Moreover, now the process of engagement between $\mathrm{CP}$ and strategic decisionmaking actually went further than formally allowed for in the Compact and Requisite Arrangements. Two distinct 'spillover' effects could be identified. First, the open, fact-based and constructive process of joint dialogue underpinning the work of Compact forums spread to dealings between management and the trade union group in collective bargaining, as attempts were made to find common ground based on the work of the SIG involved in the strategic review. Second, Compact forums were expected only to identify and review strategic options, leaving the board, management and unions free to make whatever decisions they deemed necessary. Under the strategic-review process, however, these lines of 'demarcation' became blurred. The formulation and adoption of strategy encompassed formal management structures and Compact structures in a kind of seamless web of dialogue based on overlapping membership and shared concerns.

As strategic engagement based on partnership emerged in earnest, questions also arose about the formal modalities for strategic-level decisionmaking as set down in the Compact. Supporters of CP saw how Compact processes might, at it appeared to them, productively displace adversarial industrial relations. The question for them then became whether $\mathrm{CP}$ could take over important functions and areas originally intended to remain within the sphere of established industrial relations channels. If extending the frontier of participation now became an option in their eyes, the risks inherent in the existing formal separation of the processes also became clearer. Paramount in their eyes was the danger that adversarial industrial 
relations postures might become amplified in the process of adjusting to the loss of duty-free sales. A new and even more radical vision of partnership that would require fundamental changes to the architecture of CP began to form in their minds.

Few in the company believed that market trends alone would force Aer Rianta to reposition downstream, prioritizing cost over service and quality and thereby rendering the Compact unsustainable and possibly redundant. But market forces alone would not determine the continued viability of $\mathrm{CP}$, or even the continued existence of the company. Under the aegis of $\mathrm{CP}$, the board, management and the unions had worked out a common vision of the company's future. This was to be secured through the flotation of a sizeable minority holding through an IPO, share-capping and the creation of an ESOP.

In short, Aer Rianta and its unions proposed to move forward through an agreed change in the 'organization's boundaries' which could preserve the key priorities of commercial strategy and retain partnership. Whether this might be realized, however, was beyond the powers of the company or its unions to determine and dependent ultimately on the posture of government. For now the political climate was positive. There appeared to be little prospect that political considerations might result in the derailment of the new corporate and organizational form jointly endorsed by the company and its unions; less still that the state might seek fundamentally to redraw the organizational boundaries of the company without reference to the board, management or unions. The appointment of an aviation regulator meant that in future Aer Rianta would need to negotiate key parameters of the company's commercial strategy with a powerful and independent external agent. In this process, quality and service standards were likely to be more highly formalized, and their cost and price implications would come under closer scrutiny. This opened up uncharted ground for the Compact.

Even at the high tide of partnership in Aer Rianta, some perceptions and some developments struck an ominous note. Champions of CP had formed the view that, if partnership was to be preserved, it had to be extended into operational aspects of industrial relations, so as to preclude the emergence of adversarial industrial relations postures in the immediate aftermath of the abolition of duty-free sales. As will be seen in Chapter 10, fears of the emergence or re-emergence of adversarialism proved to be prescient, if not perceptions as to the likely dynamic through which adversarial postures might develop. The joint agreement on the partial privatization of the company soon provoked opposition from worker directors. Finally, although the government for now appeared to favour the parties' own blueprint for redrawing organizational boundaries and changing corporate governance arrangements in ways that preserved and even strengthened partnership, very soon politics and partnership were to become disaligned, as first stalemate developed over the future of Aer Rianta and then proposals emerged for the break-up of the company. 


\section{Senior managers}

This chapter examines the attitudes of senior managers to $\mathrm{CP}$ and considers in more depth their role in the evolution and operation of partnership in Aer Rianta up to the high tide of partnership in 2000. Senior management, in the sense understood here, comprises executives at company level, general managers at airport level and executives in charge of line and staff divisions at company and airport levels, including duty-free retailing, cleaning, personnel and planning, among other functions. Also included are top-level managers and the senior executives centrally involved in the genesis and management of the constructive participation initiative.

The discussion focuses on the influence of corporate values on management postures, as well as on the priority accorded to partnership by the company's board. The effects on senior management postures of support provided for partnership during the high tide by the shareholder and senior civil servants is also examined. The chapter also considers differences in postures towards partnership within the senior management group. The advantages and disadvantages inherent in the process from their vantage point are explored, as are the dynamics surrounding top management succession at a time when partnership was in peril of coming unstuck in the face of widespread management scepticism and indifference.

\section{Corporate values}

US studies in particular have stressed the role of corporate values, ethos or culture in sustaining innovations in human resource management and industrial relations. Reflecting a wider literature on variations between companies in corporate values and their human resource effects, Osterman (1994) shows that companies committed to 'helping to increase the wellbeing of employees with respect to their persons or family situations' are more likely to have adopted innovative forms of work organization. The role of 'humanistic values' in the choice companies make between alternative employment systems is also addressed by Kochan and Osterman (1994). As firms facing similar market conditions enjoy some latitude regarding their choice of employment practices, corporate values may be significant in 


\section{Senior managers}

shaping the choices made (Kochan and Osterman 1994: 97-8). Corporate values commonly reflect the original vision and priorities of company founders, and may also obviously reflect national institutional traditions (Kochan and Osterman 1994; Lincoln and Kalleberg 1990).

In the UK, the role of 'paternalist' corporate values has been examined in the context of the employment practices of companies, such as M\&S, committed to co-operative employment relations (Turnbull and Wass 1998). Here it has been argued, however, that the 'sophisticated human relations' underpinning M\&S employment practices had eroded in the face of intensified competition and no longer provided 'signposts for management action' (Turnbull and Wass 1998: 108). As outlined in Chapter 1, Guest and Peccei's (1998; 2001) studies of 'partnership companies' in the UK also found that a broadly common set of values or principles underpinned partnership practices. The EPOC study of innovative forms of work organization in enterprises in Europe also established a link between the incidence of direct involvement practices and management values. Here it was found that the most commonly reported motive for introducing forms of direct involvement was the belief that employees could capably and substantively contribute to the improvement of organizational performance through their input (EPOC 1997).

In a public-sector context, the ethos of senior managers is likely to be influenced by the posture of the shareholder and senior civil servants. Although senior executives within state companies and their boards of management enjoy considerable discretion with respect to both strategic and operational aspects of decision-making, senior civil servants and their ministers also play an important role, and, in some degree at least, can be considered part of the management system. The minister is the shareholder, and senior civil servants are the agents of the shareholder. The posture of the minister and civil servants towards both competitive strategy and employment practices thus becomes another parameter bearing on decision-making at senior executive levels within state companies. Taking account of the positions of ministers and senior civil servants is important not only because these parties are capable of directly influencing company plans and operations. It is also important because of the well-documented tendency in state companies for management and unions to seek to build support for their positions and actions, or to block plans and actions by the other side, through direct and indirect dealings with civil servants and politicians (Ferner 1988; Hastings 1994; 2003). This means that strategy is made or unmade in public companies through both senior executive decisions and those of boards of directors as well as through complex political brokerage activity above the level of the company. What the minister, departmental secretary general, assistant secretary and other senior public servants wish to achieve, and more particularly how they wish their objectives to be achieved, thus becomes another major force bearing on levels of senior management support for such practices and the sustainability of innovative employment and industrial relations practices. 


\section{Senior line managers and innovation}

Senior line managers assume particular importance in the literature on human resource management innovation. One of the defining features of contemporary human resource management, it is often argued, is the degree to which line managers are the key drivers and sponsors of human resource and industrial relations practices. No longer do personnel departments follow their own agendas regarding the best or most effective means to shape or implement employment practices. Their more appropriate role, according to current ideas of best practice, is to act as technical specialists, conversant with commercial pressures and their implication, with the capability to act as 'internal consultants' to line managers. The latter must be viewed categorically as the key human resource managers, at all levels, from general and senior line management to first-line supervisory management (Guest 1987; Storey 1992: ch. 2). One of the key factors influencing such new normative thinking on the appropriate roles and relationships between personnel and line managers is the observation that it has frequently been line managers who have driven major initiatives in change and restructuring in their attempt better to align employment practices with commercial pressures and opportunities (Storey 1992). As Storey (1992: 194) has suggested: 'Line managers have come to the fore in this regard not only as the crucial delivery mechanism for new approaches in employee relations ... but, more assertively, as themselves the designers and drivers of the new ways'.

Storey's (1992: 194) evidence from major UK companies that personnel managers were not infrequently 'foot-draggers rather than . . . active change agents', is consistent with US evidence that line managers commonly championed change and innovation in response to commercial pressures, while industrial relations and human resource specialists were slow to change (Kochan et al. 1986).

Overlapping the literature on line managers as primary drivers of transformation in employment practices, is the literature considered earlier on the external drivers of partnership. Both of the main perspectives identified on the origins of partnership arrangements, in common with the literature on line managers as agents of change, emphasize the role of intensified competition and attendant commercial pressures and setbacks on the adoption of human resource and industrial relations innovation. In the change model at the core of HRM and theories of industrial relations transformation, external commercial drivers provoke senior line managers into radical and innovative responses, which involve a realignment of roles between line and personnel management with respect to leadership and 'ownership' concerning human resource and industrial relations policies. The resulting new centrality of employment practices to senior line managers' commercial agendas is seen as the key to real change of a deep and lasting character within companies. 


\section{Senior managers}

\section{Top-level management}

One of the stock themes, indeed almost clichés, of the literatures on industrial relations and human resource management innovation, is the degree to which significant and lasting change is predicated on senior management support for change programmes. Without support from the top, ultimately from the chief executive, it is commonly argued, change programmes are unlikely to build up sufficient momentum to overcome inertia and vested interests, or to ride out setbacks (Kochan and Osterman 1994: 55-8). The more radical the change programme, the greater the degree to which it threatens the status quo and, commensurately, the more urgent the need for support from the top of the organization. Normative change models generally assign primacy to top-level executives in articulating and communicating the vision underpinning innovation. Senior executives also send 'signals' to managers at lower levels regarding the kinds of priorities and behaviours favoured by the organization, and ultimately hold the power to reward and sanction executives in relation to those priorities. Given the importance of senior management support for innovation and mutual gains industrial relations, the issue of succession at the top becomes a critical one for sustaining innovation once it has begun. It is critical not least because some of the benefits expected to accrue from change are likely to become evident only over the long term. The handling of the succession issue involves both perils for existing innovations and an opportunity to underscore them through the appointment to senior management positions of executives sympathetic to the aims and methods involved.

Each of these themes is examined in the rest of the chapter, drawing on intensive interviews with senior managers conducted during the high tide of partnership, as well as on documentary data. A final section draws the themes together to consider their combined import for the development and impact of CP in Aer Rianta.

\section{Corporate values and senior managers in Aer Rianta}

As a semi-state company with a record of progressive personnel policy, and with government as the shareholder, corporate values and corporate governance might be expected to be favourable for the development of partnership. Aer Rianta had a history of progressive personnel policy in such areas as job-sharing, child-care, consultative arrangements, gain-sharing and organizational development. These developments reflected an underlying ethos in many ways typical of a long-running tradition in Irish commercial semi-state companies prior to EU-instigated deregulation. A senior personnel practitioner characterized the ethos as that of a 'caring, sharing . . paternalistic company'. For senior executives in general, the emergence of the Compact reflected such a long-running strand in the company's approach to dealing with staff issues. 
A number of key senior executives had worked in the personnel department during their careers in Aer Rianta, including the two chief executives in office during the $\mathrm{CP}$ initiative and the main champion of the Compact among senior management.

Given the underlying ethos towards staff issues and the prominence at senior management level of executives who had worked in personnel, it is hardly surprising that, as one executive put it, 'human resources always figured prominently in a positive way' in the affairs of the company. Sections within senior line management, however, also criticized these values for being 'soft' and contrasted Aer Rianta's ethos with what they understood to be the hard-nosed commercial values that had animated successful Irish companies. In the eyes of one senior executive, there had always been a 'struggle in Aer Rianta' between executives espousing alternative value systems. Executives who had worked in personnel were likely to champion the idea of achieving commercial success through commitment by people over those favouring 'kicking ass' and managing on the basis of a 'good hard dose of reality'.

While the Compact thus drew on pre-existing values favouring concern for staff, good pay and conditions and positive industrial relations, the limits imposed on innovation by a traditional paternalist ethos and the company's largely orthodox approach to personnel management also bear emphasis. Though, by definition, paternalism embraces or entails people-centred values, its conception of the role of personnel concerns in commercial success is qualitatively different to that underpinning value systems associated with radical innovations in employment practices and radically changed modes of decision-making of the type entailed by the Compact. The more conservative or constraining aspects of the traditional approach to personnel management in Aer Rianta emerges, in particular, in three interrelated aspects of the company's operations: the virtual monopoly of authority and expertise in people management long enjoyed by the personnel department; the subsidiary role of human resources in line management; and the posture of the board towards personnel issues. The Compact challenged all of these aspects of the traditional approach to personnel management in Aer Rianta. The effect on CP of the traditional personnel ethos and approach and that of the subsidiary role of HRM in line management will be considered in the next section. The section after this will consider the ethos and posture of the board towards personnel issues and their effects on CP.

\section{The postures of personnel and line management}

One clear indicator of the organizational stature of the personnel department, as described above, was the success of former members in gaining senior line and general management positions in Aer Rianta. In the day-today operations of Aer Rianta, personnel enjoyed a high degree of control over the determination of pay, employment conditions and working 
practices. One senior executive was emphatic that in the past the "personnel department ran Aer Rianta':

I remember as a young fellow [in the personnel department] going to meetings with what would have been senior middle-aged managers, and really I'd be calling the shots and they'd be only too glad to allow that to happen; to the extent that I'd say to myself if I ever move into a line job, I won't let one of those [expletive] from industrial relations near me.

In the 1970s, in particular, when industrial relations activity was intense in Aer Rianta as in semi-state companies generally, a line manager 'only at his peril dealt with personnel issues'. During the 1980s the company engaged in a programme of decentralizing management systems in general. Major business units like the three airports could now develop their own specialist management functions, including personnel. While devolution was supported by the corporate-level personnel function, and envisaged personnel specialists acting in support of line and general management, in practice things changed only to a limited or variable extent. In one airport, as a senior manager put it, the "practice was to let the personnel manager get the heart attack'.

Notwithstanding the sequence of organizational development (OD) initiatives in which the personnel department had engaged, the fulcrum of personnel philosophy and activity involved the handling of industrial relations claims and the regulation of terms and conditions of employment. A senior executive pointed towards the degree to which OD-type initiatives were marginalized in the operation of the function.

An OD unit was founded, and we did, I thought, very good work. But when I left and went back to a line department ... and came back the next time I found that the OD unit was gone. It had turned into a job evaluation unit, and there was nothing but the old IR job evaluation 'recruit them, retire them, and in the middle wring what you can out of them' sort of things.

Against such a background, it was hardly surprising that the Compact originated outside the personnel department. The department in its turn, while formally supportive of $\mathrm{CP}$, remained cautious about the development of the process. Champions of the process too remained cautious about the perils of allowing the process to be subsumed to the prevailing approach to personnel and industrial relations management. One consequence of this was a separation of the Compact and the personnel function. Personnel specialists joined the JUCG and participated in a series of Compact groups and initiatives. The prevailing approach to good practice in the wider profession now also converged to some degree at least on the principles informing CP. 
However, in the eyes of champions of $\mathrm{CP}$, the outlook of the department remained distinct in major respects from that of the Compact. As one champion of CP remarked: 'On Significant Issues Groups on wages and union agreements [there was] a hell of a job trying to shake them off simply updating or rewriting what they have; trying to get them into a new mode of thinking'.

As the Compact gained momentum, this divergence of approach was compounded by anxiety about the implications that the Compact might have for the future role of the department and even for its continuation. Some within the function now felt that it should have had more involvement in the process at the initial stages. Senior executives admitted that much 'confusion' had arisen about roles in the personnel department. Personnel specialists at airport level took their cue from general managers, and these were often lukewarm towards or opposed to CP. Not surprisingly, as the Compact was rolled out across the company in 1998 and 1999, what some called the 'separateness of personnel and the Compact' came to be seen by supporters of the Compact as a problem that required resolution.

Next we consider the effects of personnel's dominance of people management expertise and authority for line management practice and the implications for CP. An active and custodial personnel department and a largely passive and reactive line management approach to personnel issues were, of course, mutually dependent features of company decision-making. All senior executives interviewed agreed that some line managers were naturally good people managers and took the personnel challenges arising from their roles seriously. With decentralization during the 1980s, some line and general managers were seen to have engaged with personnel issues more directly. But no systemic change had occurred in the degree to which human resource management had become integral to line management practice. Line managers in general were not viewed as particularly 'proactive' with respect to the management of human resources. Things like the conduct of performance appraisal were very uneven and depended on the inclination of individual line managers. In handling recruitment, line managers were heavily dependent on personnel. No bonus or performance-related reward system existed based on line management assessment of the performance of subordinates. In the words of a senior line manager, line managers in general were 'traditionalists'.

So an ethos and approach to people management, which was in broad terms 'progressive' in its willingness to experiment with new initiatives, and which was portrayed by Aer Rianta managers themselves as 'paternalist' in its concern to treat staff well and offer good terms and conditions of employment, went hand in hand with a largely traditional, custodial style of personnel management and an approach to line management in which the proactive handling of people issues was not a recognized priority. Values concerning how people should be treated established parameters to management decision-making and predisposed personnel specialists to experiment 
with a range of progressive policies. At the same time, people-focused values were not seen by line managers in general as integral to business success, or to carry clear and specific implications for how they should work with staff under their control. This underlines the extent to which the principles underlying the Compact, through resonating with aspects of the pre-existing ethos towards people in Aer Rianta, also represented in important respects a discontinuity with past values and postures. From now on, the approach to personnel management to be favoured by the company involved breaking many of the rules in the traditional personnel textbook. Its success would ultimately depend not only on active engagement of human resource issues by line managers but also on a kind of engagement in which managers were expected to involve staff in accordance with the principles of the Compact. Both the level and type of line engagement involved were without precedent in the company.

\section{The posture of the board}

The values espoused in the Compact found support at board level, but the nature of support at this level is important to appreciate. Senior executives interviewed were of the view that the board had little real or deep awareness of the values underpinning the Compact, or even of the implications of Compact assurances for commercial priorities. In part this was attributed to the affinity perceived between the Compact approach, the traditional ethos in the company, and to the joint affinity of these with the commercial focus and operation of the company. Reporting to the board were successive chief executives and senior managers who believed that the approach and commitments set out in the Compact were consonant with the company's prior commercial focus, and further believed that the 'upstream' commercial posture underpinning the Compact was an advisable - if not the only advisable - course to follow. Aer Rianta senior executives were also disposed towards what one key executive described as a 'non-ideological' approach to the future of the company. Whatever worked was seen to be the 'sensible' policy to adopt.

Another senior executive was more pointed. In his opinion the 'board wouldn't give a cobblers about the Compact'. He saw the board as properly totally focused on business issues, and the Compact was viewed as no different to any other issues within the ambit of personnel management like health, safety or welfare. The board-level constituency most concerned with the Compact was seen to be the worker directors. They, however, had been excluded from the Compact process.

\section{The shareholder and senior management}

The postures of senior managers and the position of the board with respect to $\mathrm{CP}$ was also likely to have been influenced by the position of the 'shareholder' and of the senior civil servants charged with developing policy towards the Airports Authority. Developments at these levels during the 
high tide of $\mathrm{CP}$ were to tilt the balance in favour of more active senior management engagement. During the second half of the 1990s, a close affinity developed between the approach to change management enshrined in the Compact and Aer Rianta's parent department's concern with the process of managing liberalization and intensifying commercial pressure in state companies. The process of liberalizing the hitherto highly regulated markets of many state companies had become a central concern of senior public servants and of governments since the 1980s. Given the strategic economic significance of these companies, their high levels of unionization, and not infrequently their turbulent industrial relations histories, the handling of liberalization and its attendant effects on employment conditions and industrial relations became of considerable concern. Partnership-based approaches had been attempted in the electricity utility, ESB and the then communications utility, Telecom Eireann. On the whole, the outcomes in each case were seen as successful. Industrial relations strife had been sparked by acute commercial crises in Aer Lingus and the state-owned aircraft maintenance company, Team Aer Lingus, where partnership approaches had not been possible. This seemed further to underline the advantages of promoting partnership in Aer Rianta, and determining thereby whether the approach developed there might have wider applicability to other semi-state organizations faced with deregulation and growing commercial pressures. Some senior managers in Aer Rianta emphasized their belief that the department's endorsement of the Compact was largely instrumental'. According to this view, partnership was regarded as a more effective way to handle a change process that might ultimately require significant job reductions - an end result that contradicted one of the parameters of $\mathrm{CP}$.

At a more general level still, the Compact was gaining momentum at a time when a 'mandarin revolution' was in progress in the Irish public service, involving high-level training for a rising cadre of senior public servants in business and strategic management and a growing determination on their part to implement aspects of 'new public management' in the Irish public sector. This shift in management ethos within the public service was tempered by a growing realization that new management principles and approaches might only prove viable and effective if they meshed with institutional and political realities and constraints.

These forces resulted in departmental support for CP at the highest levels from the mid 1990s until the early 2000s, and in a willingness to underwrite the costs of the initiative by allowing Aer Rianta to withhold a portion of the annual dividend paid to the government. This allowed funding for the project to be 'ring-fenced' and to be administered by the JUCG. This was a highly significant development in the eyes of supporters of the Compact, as it precluded hostility towards the Compact within sections of senior management finding expression in pressure to contain or cut the budget available to fund CP initiatives.

But of far greater significance than direct financial support, was the 
adoption of a policy stance which underscored the Compact as the government's and department's preferred or expected line of response from the company to handling the commercial challenges which it faced. Until mid 2002, successive ministers pledged their support for CP, and key senior civil servants took an on-going interest in the progress of the Compact process. As outlined in the last chapter, departmental and ministerial support for the Compact were to assume particular importance when the company prepared for the loss of its duty-free business and almost simultaneously addressed whether its future should lie in continuing within the public sector, in some form of strategic alliance, in a partial flotation on the stock market, or in wholesale privatization. The stimulus for the 'strategic review' of the company had been a wider policy of reforming public enterprises in the light of EU-instigated liberalization and more positive political attitudes towards privatization and private investment in state companies. But support for the Compact within the parent department copper-fastened the attempts of champions of CP within Aer Rianta management to ensure that the review would be conducted to a significant degree under the processes and principles of constructive participation. Thus, as was discussed in the last chapter, departmental sponsorship of the Compact helped ensure that the process was 'mainstreamed' into strategic decision-making at a time when it might otherwise have been bypassed or sidelined by the pace and urgency of events and the scale of the commercial decisions facing Aer Rianta.

The department's posture reflected more than on-going support for CP in Aer Rianta and its cumulative experience of change management in the semi-state sector. The first two ministers to hold office during the life of CP provided general support and agreed to act as 'sponsors' of the initiative. However, the incumbent minister during the high-tide phase was probably more conversant with the principles underpinning $\mathrm{CP}$ and more politically committed to them than her predecessors. As a former Minister of State at the Department of Enterprise and Employment, she had first-hand experience of handling industrial relations difficulties and emerged as a more active supporter of partnership. The posture of the minister and her civil servants also reflected the salience of enterprise and workplace partnership under the national-level tripartite social partnership agreement, Partnership 2000. This national agreement, in force from 1997-2000, contained a framework agreement intended to foster partnership in firms and workplaces as well as enshrining partnership as a prevailing mode of political, economic and social governance.

Support for the Compact at departmental and ministerial level served to tie senior line management more closely into CP. Support at these levels was important in leading senior managers to the view that, whatever they might personally think of CP, the process could no longer be ignored. Supporters of $\mathrm{CP}$ were not slow to emphasize departmental support as a factor that brought wavering or opposed managers into line. 
It was very useful to be able to say: 'look, the Minister has said and the Department has said and the Government has said that this is the way they want to see it going'. We used that as a stick to beat people who didn't want to move with it.

Sceptics of $\mathrm{CP}$ also recognized that the department's stance carried significant implications. 'A lot of communications from the Department would be enshrined in this new language called "jointness" or participation, or whatever, and that would have instilled in people the need to treat it more significantly'.

External endorsement of this kind had not featured in previous organizational development-type initiatives within Aer Rianta. Outside interest in and support for the Compact was seen, as one sceptical senior manager put it: to 'give gravitas to the thing'. Public service endorsement was also seen by some to have brought some discipline into the process, because civil servants were required to 'report on these things, and they have to see results'.

\section{Contrasting postures among senior managers}

This section looks at the closely intertwined themes of top-level and senior line management attitudes towards $\mathrm{CP}$ up to the high-water mark of partnership. It draws heavily on intensive interviews with senior executives conducted during 1998. The Compact, as outlined in Chapter 3, originated in a debate over sub-board level participation in the company. Senior managers generally had not been central to, or interested in, that debate. The Compact, therefore, was not part of a package of changes pressed by senior line or top-level managers in the light of acute commercial pressures faced by the company. Given the origins of $\mathrm{CP}$, it is not surprising that senior line management opinion was mainly sceptical towards or opposed to the Compact. CP also had supporters, of course, but these tended in the main to be managers in staff positions and departments. The most active and vociferous opponents, on the other hand, occupied key senior line management positions. Between the active supporters and the outright opponents were a group best described, perhaps, as 'sceptics'. The sceptics were probably closer in outlook to the views of the opponents than they were to the supporters.

Canvassing senior line management opinions of the Compact confronts the problem that executives could posture support for the process on grounds of expediency - something that was flatly admitted by some, and that probably became more pronounced as $\mathrm{CP}$ gathered force in the company in the late 1990s. Thus there was a general recognition, in the words of one senior manager, of the advisability of 'bowing to the totem'. Or, as another put it 'posturing support became the order of the day'. In the climate that prevailed during this period, a good number of managers were seen to be 'sitting on the fence and playing it each and every way'. 


\section{Senior managers}

\section{Supporters}

The supporters and sponsors of CP within management had little doubt from the start of the challenge they faced in convincing their colleagues of the merits of partnership. Shortly after the unions had agreed to opt for a 'comprehensive approach to participation' rather than arrangements that minimally conformed with legislation on sub-board participation, senior management was briefed on the implications. At that stage supporters of CP 'found out', as one put it, 'that we didn't have a great deal of management support'. Supporters feared that some opponents were manipulating middle management views and seeking to undermine the Compact by complaining about having to release staff to attend meetings; by criticizing the expenditure involved and by complaining that the Compact was wasting their staffs time. Supporters looked to support from chief executives, ring-fenced funding for the Compact and elicited the 'sponsorship' of the Department of Public Enterprise as ways of copper-fastening CP. Once the Compact had become the formal policy of Aer Rianta, supporters could seek on occasions to sanction recalcitrant managers, sometimes with support from the unions. Active support from the new chief executive appointed in 1997, support from the 'shareholder' and a quickening of the pace of commercial change towards the end of the 1990s, also strengthened the cause of the supporters. Thus, even though the supporters of constructive participation failed to command anything approaching numerical superiority among senior line managers, during the high tide of partnership they increasingly came to command the support of the most powerful managerial figures within the company, combined with support from senior civil servants and ministers in the parent state department.

\section{Opponents}

Opponents warned supporters from the start that there were many 'people nodding and agreeing' who were, in fact, opposed to CP. Opponents sometimes claimed, as did some sceptics, that the Compact was skewed towards the interests of 'union activists'. Opponents ranged from managers who felt that the achievement of 'positive industrial relations' along largely traditional lines was sufficient for the company's needs, to managers who rejected the Compact approach as without substance. The strongest and most strident opposition involved rejecting the Compact out of hand.

It's not for real. If I'm doing something it has to be for real. This is mirrors put up for the Department because they like it and it sounds good. ... The final benefits are not coming from it.

Management decentralization within Aer Rianta during the 1980s meant that initiatives seen as impositions by the corporate level on business units 
and airports were treated with suspicion. Territory granted under the new management structures was protected, and this increased both the inclination and the capacity of managers to oppose centrally driven initiatives, even where they had become formal company policy and enjoyed support from top-level management. Local autonomy could also be a matter of pride: 'The head office [believed that they] had all the best ideas - what I called the "metropolitan fog"!'

As discussed earlier, personnel specialists at airport level also took their cues from general managers at that level with respect to their attitude to $\mathrm{CP}$. By the late 1990s, the Compact had gained such a degree of support and had become so central to the handling of significant issues and challenges that outright opposition had become unusual. Opposition now more commonly emerged as resistance to a CP-based approach to a specific issue, or a difference of view as to what the Compact might entail that was articulated nevertheless as support for $\mathrm{CP}$ in principle.

\section{The sceptics}

The largest group of senior managers appeared to be sceptics. Though some within this camp were closer in attitude to active supporters of the Compact than to opponents, most, as outlined above, were probably closer in attitude to opponents, tilting the overall balance of senior managerial opinion against $\mathrm{CP}$, especially in the early and roll-out stages of the Compact process. The sceptics avowed an intellectual understanding of the benefits of participation and staff involvement and claimed to recognize that this was the way the 'world was going' both inside Aer Rianta and outside. Their avowed stance was one of broad agreement in principle with the approach. This was combined, however, with considerable scepticism as to the practical functioning of CP, as well as of the benefits that had accrued when set against the costs and disadvantages. The latter were very salient to senior managers in this camp.

One aspect of the sceptics' disposition was the view that CP simply had to be better than their experience of traditional adversarial industrial relations in the company.

I can remember a time when every day you went from industrial relations meeting to industrial relations meeting. Everything was an industrial relations issue. In and out of the Labour Court; in and out of conciliation; in and out of Rights' Commissioner hearings. ... You felt as if you were in a war situation practically.... I would submit very strongly to the principle of participation because to me it's the only real way to go.

The sceptics also averred to the growing support for the Compact by toplevel management and the parent state department, necessitating a more 


\section{Senior managers}

active level of engagement with the process than might initially have been seen to be necessary. While the sceptics thus avowed either principled support or pragmatic engagement, or both, they were also far from convinced that the Compact process had proved effective in delivering better decision-making and concrete benefits for the company. Scepticism arose from a series of overlapping doubts. Many managers questioned what they regarded as the prolonged and open-ended nature of the Compact process.

You have to have something; some answer, and nobody will wait while people debate about self-improvement, and issues, and maybe this and maybe that. Somebody has to call it.

Where is it that the process is supposed to be leading other than in [the] very broad terms [of] whatever is written in the document? But, you know, what type of company is it trying to deliver? What type of parameters? What type of benchmarks? What type of standards? Those things don't figure in the discussions.

There is confusion about what all the different processes are at the moment. ... What's a strategy group? What's a working group? What's a natural work group and whatever? What's a steering group? And there is confusion among people as to where they are and where they're leading and whether they fit this into this process and nobody really knows where it's going.

Linked with concern about open-endedness and direction was criticism with respect to the speed of decision-making when issues were subject to deliberations under CP.

There's a trade off between speed and deliberation involving a lot of people, and there are times when I feel extremely anxious about the speed aspect.

I think that deadlines are terribly important in this. There are real deadlines.

It's trundling along and I also think that what we need are strict deadlines that we want to meet.

Sceptics doubted whether major concrete or bottom-line business achievements had arisen from CP.

It has established good relationships; it has established openness; it has established a certain amount of trust. These things are not to be underestimated. But to get into the making of hard-nosed business decisions ... it's beyond the scope of experience for a lot of players. ... 
I know that it is the only way forward actually, and if I try to go and beat it, I'm not going to beat it. There's no way I can do that so I've got to embrace it. But I have seen no results out of it.

I'd like to ask someone the question: show me what it has achieved and show me what we have put into it? ... I'd like to see, if you like, the balance sheet and I don't mean in financial terms, but I'd like to see it drawn up and to see where we are and what we have got.

On balance the existence of a forum within which serious issues can be deliberated upon is of value. It has to be of value because the alternative is imposition and decisions by others. But whether the Compact can assist in meeting the demonstrated needs of the outside influences is a question because of the structure of the Compact, the sheer scale of the Compact and the time frame of the Compact. I don't know.

Sceptics were also critical of what they saw as unclear procedures for taking decisions and unclear lines of authority for executing positions arrived at in joint initiatives and working groups.

There's a lot of different reviews going on at different departments like the cleaning and maintenance departments, and then there are the significant issues groups. I'm on a number of them, and it seems to me that a lot of work is done and a lot of research is done; a lot of presentation, but they seem to be very inconclusive. Nothing seems to come out of them in forming hard recommendations.

The question I had was who makes the decision to push the button? How can I say 'let's go with this'? 'We're doing it'?

Some senior managers also felt that the Compact had diluted their authority, capacity or even inclination to make decisions.

There would also be a view: 'well look you really don't do anything in case you upset the participative climate', as such, and that really there would be a certain frustration with line managers that 'ah sure, there's nothing to be managed. That'll all be looked after from the Compact'. Whether it will or won't is not really the issue.

I think that what management has lost, particularly the line management group, when it [comes to] day-to-day or slightly more longerterm issues; what they have lost is the capacity to make that decision. So, in a way, and I've seen and experienced [it], is, you know, it's almost a stick to beat a manager who tries to initiate a change that is perceived to impact negatively on staff. 
For some the Compact process was seen to have worked with respect to issues where a manifest common threat existed, but it was also regarded as ill suited to the handling of management concerns in general.

I'd see it as functioning well where there's a commonality of interest and maybe where there is mutual dependence in terms of the issues.... Where I would be critical is where you get down into the more microtype issues and there's the old classic conflict. For example, where a manager ... sees an issue in terms that would have a negative impact, or a perceived negative impact on staff, or any particular group of staff. I don't think the participation process is, having experienced it, capable of handling those issues.

Others pointed towards what they perceived as 'cherry picking' by unions, adept at using the Compact in a largely instrumental or tactical manner.

If they [unions] are confronted with an issue that's too hot to handle from their point of view, that it does have, or could have, a negative impact on staffing or individual staff members, or whatever, they will gladly kick it into the Compact process in the sure and certain knowledge that it's going to sit there for an extended period of time....

For some of the sceptics, Aer Rianta's experience during a 1998 strike over union recognition at Ryanair, represented something of a litmus test for the effects on staff behaviour of CP. A number of baggage handlers working for Ryanair at Dublin Airport pressed for recognition for SIPTU - an important union in neighbouring Aer Rianta. The resulting stoppage spread to Aer Rianta and closed Dublin Airport over two days for the first time in its history. A number of senior managers believed that union and staff postures in Aer Rianta during the Ryanair strike demonstrated that the Compact had little impact on behaviour or loyalty towards the company. They pointed, in contrast, to the role played by middle managers - then outside and in dispute with the Compact - in attempting to keep the airport open and services in operation:

For all the input that was put into fostering relationships and participation and all the rest, here was an issue where there was another organization in dispute and staff followed, I suppose, a union agenda in breach of all industrial relations. And ... if you were being ultra critical you would say [that] part and parcel of the problem was that the company's identity has been weakened.

Key members of the JUCG had anticipated just such a reaction. During the Aer Rianta work stoppage JUCG personnel sought to play a role as mediators between unions and management within Aer Rianta. Their role in obtaining a return to work won credit from some managers. 


\section{Perceived advantages and disadvantages of CP}

This section examines the advantages or benefits and disadvantages or costs associated with $\mathrm{CP}$ in the eyes of senior managers. Virtually all the advantages identified during the high tide of partnership could be portrayed as process advantages. That is, they related to improvements of various kinds in processes of decision-making or related aspects of company operations. That these advantages were salient for senior managers generally indicates that they were viewed as significant in helping them to do their jobs more effectively and in making Aer Rianta operate more effectively. At the same time, few pointed to concrete or 'bottom-line' advantages such as cost reduction, quality improvement, increased job satisfaction or service innovations. It is, of course, reasonable to suppose that benefits such as these are long-term in nature and would have taken some considerable time to have emerged from changes in decision-making processes. The disadvantages identified by senior managers, on the other hand, related both to process and concrete or bottom-line effects attributed to CP.

To a considerable degree the postures of senior managers towards $\mathrm{CP}$, as outlined in the last section, reflected their assessments of the overall 'balance sheet' regarding the net effect of the Compact in Aer Rianta. At the same time, managers' personal philosophies and predispositions towards the principles involved in $\mathrm{CP}$ also conditioned their perceptions and assessments of the overall impact of partnership on the company. As management postures towards $\mathrm{CP}$ thus overlapped assessments of concrete advantages and disadvantages, this section highlights key themes not covered in the discussion in the last section of management postures.

Table 5.1 outlines the main process and concrete advantages and disadvantages associated with $\mathrm{CP}$ in the eyes of senior managers. A number of senior executives believed that Compact forums allowed management access to a range and depth of expertise and knowledge not hitherto available because employees now opted to share their understanding of work processes with management.

Having the people intimately involved in the business, putting their heads together, giving it their best shot to come up with a good analysis, even as a challenge to the management team to take and try to move beyond that point - it's a huge advantage and an example of where jointness actually does contribute.

Some executives believed that external consultants, using traditional methods of analysis, would not have been capable of acquiring such a level of intimate knowledge of work processes and commercial procedures. There was also a perception that the Compact had fostered a disposition on the part of staff to 'ask business questions' and had encouraged a better awareness of the business challenges facing the company. For some 
Table 5.1 Advantages and disadvantages of constructive participation as seen by senior managers

Advantages of constructive participation $\quad \begin{aligned} & \text { Disadvantages of constructive } \\ & \text { participation }\end{aligned}$

Process advantages

- Wider range and deeper levels of knowledge and expertise brought to bear in decision-making.

- Understanding of business issues promoted.

- Specific discussion papers have been beneficial.

- Adversarial industrial relations processes have declined.

- Critical issues no longer generate adversarial postures and processes.

- Trust and openness enhanced and key issues can now be dealt with constructively.

\section{Bottom-line advantages}

- Modest changes in work practices.
Process disadvantages

- Slows down decision-making.

- Authority and procedure for action post-deliberation in partnership forums now unclear.

- Reduces managers' predisposition to tackle (potentially) contentious issues.

- Corporately developed structures for constructive participation are inflexible to local arrangements and traditions.

- 'Dual channels' for pursuing issues tactically exploited by unions.

- Raised expectations carried forward into adversarial industrial relations forums.

\section{Bottom-line disadvantages}

- Direct cost of CP.

- Cost of staff time off to attend meetings and of time senior management devote to meetings.

managers, the CP facilitators, in particular, had acquired a very good knowledge of business issues - though this was sometimes seen to leave them vulnerable to isolation from their work colleagues. Most senior managers believed that the documents emanating from the Duty-free and Change of Status SIGs had proved to be very beneficial, though some felt that the position arrived at in these Compact forums was close to managers' own views of the challenges involved.

There was a general perception that as the Compact had gathered momentum, issues that had hitherto sparked traditional industrial relations activity, or that had ended up in industrial relations processes, no longer proceeded through these channels to the same extent. Managers spoke of the 'absence of the knock on the door with every little tittle-tattle', and how a 'lot of issues that may have landed on my desk in the past are not landing there'. The short-circuiting of traditional industrial relations processes was seen to be of particular importance in the context of big or critical issues like 
the loss of duty-free sales and the review of Aer Rianta's future status. In the context of the ministerial request during August 1998 that the board undertake a major review of the future of Aer Rianta, one executive observed:

I reckon that if that had happened maybe three years ago, two years ago, I would have been inundated with trade union requests for meetings to explain what was actually happening and there would have been a lot of unrest on the ground in relation to people's perception of what was happening to the company. Now that didn't happen, and it didn't happen because there were meetings held; there were representatives from all the trade unions; there were observers from the staff; there was a lot of documentation issues. At the end of it every staff member got a copy of the discussion paper and the thing passed without a murmur, and really what could have been an issue wasn't an issue.

Another manager provided a detailed account of the manner in which the breaking news was handled through the Compact process.

There was a meeting with the CEO and the facilitators because the facilitators said: 'people are asking us; people are saying what's going on?' So the CEO met them and talked to them about it. They asked a lot of questions and they were happy going out onto the streets that they could answer all the questions. ... The press got hold of it and a number of the press got onto the trade unions and said: 'we believe the Minister is going to talk on the radio tomorrow morning about Aer Rianta and privatization et cetera and what have you got to say?' A number of them had been to our first strategic issues group and I had calls from three of them who said: 'the press have told us about this; we were at the strategic issues group'. So I was able to tell them what that was about and what the Minister was actually saying and we're going to have another meeting [of the Corporate Strategy SIG]. So they went back - SIPTU in particular - and issued a press statement, saying: 'we're already in discussion on the strategy and the future of Aer Rianta and this is nothing new or surprising'.

In reflecting on the manner in which these major issues were handled in Aer Rianta, managers were commonly mindful of the highly adversarial ways in which acute commercial problems had been handled in Aer Lingus and its aircraft maintenance subsidiary, TEAM - both close neighbours at Dublin Airport and both organized by some of the Aer Rianta unions.

Some managers, however, coupled their observations on the short-circuiting of adversarial industrial relations postures and processes with somewhat darker observations on the underlying dynamics of this trend. In some managers' eyes, the Compact had 'softened' union officials: 'union officials have been sorted; they've been taken on promotional trips'. In the same way, 
some pointed to how management too had been 'compromised', [made] less willing now to tackle contentious issues for fear of being seen as opposed to the Compact. Management was also seen to have pulled their punches: '[confrontation] is much less, provided that the manager bites his tongue and stands back from confrontation'.

A number of senior managers believed that the Compact had enhanced trust and openness, allowing issues to be handled in a constructive manner. 'Hot heads' now had to submit to a process that tempered militancy and promoted dialogue.

Though these advantages were clearly perceived by many to be of particular significance, few were inclined to point towards clear-cut concrete, 'bottom-line' gains from the Compact process. For some the only perceptible benefits, during the high tide of partnership were process-related benefits. Other senior executives pointed to benefits on minor, or what they termed 'bread and butter', issues - modest changes in working practices stimulated by Compact forums. A near constant theme of the commentaries of sceptics, in particular, was the perceived need for CP to deliver more concrete 'hits', 'big eggs' or successes if senior managers were to show more active support.

The perceived disadvantages associated with constructive participation are outlined in the righthand column of Table 5.1. In summary, Compact processes were commonly seen to have slowed down decision-making; to have increased decision-making cycles; to have reduced the resolve of some managers to tackle contentious issues; and to have led to uncertainty concerning what action could be taken by managers subsequent to issues being discussed with staff through CP. There was a perception that the structures of the Compact were configured to suit the requirements of a large and differentiated workplace-site like Dublin Airport. Some managers, as has already been discussed, believed that unions had become adept at exploiting Compact processes and established industrial relations channels on tactical grounds. Others felt that discussions in Compact forums covering issues like pay and conditions, performance bonuses and ESOPs might build up staff expectations that would spill over into established industrial relations forums.

While senior managers had not emphasized bottom-line benefits, bottom-line disadvantages were identified by many, irrespective of whether they could be portrayed as 'supporters', 'sceptics' or 'opponents'. Apart from the actual direct costs associated with the $\mathrm{CP}$ in the company, senior line managers were very aware of the costs associated with releasing staff to attend meetings, particularly at busy times, and of the time input into $\mathrm{CP}$ forums required of themselves.

\section{Top-level management and the pivotal impact of succession}

When agreement had been reached on the Compact and Requisite Arrangements with the Aer Rianta unions, the $\mathrm{CEO}$ voiced his support for $\mathrm{CP}$, mindful 
that a sizeable section of his senior management either harboured deep scepticism or opposed the initiative. During a key early meeting of senior managers at which the Compact was discussed and outright opposition voiced by some individuals, the CEO was seen to have made his position clear. 'When all that wound up [he] said to them - I think he surprised them because he said - "this is the way the future is going to be, so you'd better change your tunes..." . Following this intervention, as seen by one sceptic of CP, it was a case of the Compact having become 'compulsory for managers but optional for unions'.

It remained the case, however, that senior managers choosing to ignore the Compact faced little real sanction. In the words of one senior manager, 'nobody ever got rapped about it'. Senior managers were subject to an appraisals scheme linked with performance-related bonuses. The CEO now introduced familiarity with participation and the practice of a participative approach to management as an objective to be encompassed within the annual objective setting in the performance management system. In the eyes of supporters of the Compact this had little effect on management behaviour. Understanding and skill in the area of CP did not become a key or missioncritical objective and at best had only a loose and tenuous connection to performance awards. Opponents and sceptics remained willing to court disfavour and calculated that little other than generalized support for the Compact would emanate from top management, now increasingly preoccupied by major commercial challenges.

Against such a background, senior managers, irrespective of their shade of opinion, believed that the Compact was likely to fade away with the imminent retirement in 1998 of its chief management champion. Opponents and sceptics were satisfied to bide their time. Even those most closely involved in the long-term evolution of $\mathrm{CP}$ sensed that the initiative might soon run out of steam.

The surprise retirement of the CEO and his replacement by a new CEO seen to be a supporter of the Compact brought about an immediate change. The company's most senior executive espoused the philosophy underlying the Compact, as his predecessor had done, but also undertook a series of concrete initiatives that altered the formal status of CP processes and forums in company decision-making. As top-management support became active and insistent, the Compact seemed destined to grow in influence in company affairs. Among the concrete measures now undertaken in support of the Compact, the following were the most significant. First, the recently retired champion of the Compact soon agreed to return to the company on contract to remain the main management linchpin in CP. Second, a change in reporting relationships at senior management level at Dublin Airport was seen to be important in bolstering support for the Compact. The airport general manager in Dublin now reverted to reporting directly to the CEO, rather than to an assistant CEO. As the new CEO actively espoused the principles of the Compact, the influence of $\mathrm{CP}$ was seen to have been copper-fastened, 


\section{Senior managers}

not only in Dublin but throughout the organization. Third, job advertisements and the appointments process for new senior management positions now formally identified as key selection attributes a willingness and ability to work in a manner consistent with the Compact. Several senior appointments that followed were seen to be in line with the new practice. At Cork, a long-standing member of the JUCG took up the post of airport general manager, which had been occupied by a strident opponent of CP. Fourth, the training function in Aer Rianta was reconfigured as a corporate-level function, and an executive closely involved in the training effort associated with $\mathrm{CP}$ was promoted in moves which sought to integrate the philosophy of $\mathrm{CP}$ into training activity in general in Aer Rianta. Fifth, the new CEO attended meetings of key Compact forums, a move interpreted by senior management as a clear signal that they too were expected to engage with the process actively. Sixth, subsequent to his remaining on at Aer Rianta to handle $\mathrm{CP}$, the main champion of the process in senior management took up the post of general manager of Dublin Airport. There followed a management reshuffle at the airport, which was seen to have bolstered CP at this key workplace. Finally, and more generally, the new CEO was seen to have engaged in a process of centralizing management decision-making, and promoting corporate priorities over the immediate priorities of the airports and business units. His approach was to promote the identity of the company over the identity of its units, and to end competition within the company, particularly between the airports.

The new CEO saw his active support for $\mathrm{CP}$ both as a matter of personal managerial philosophy and in terms of responding pragmatically to the challenges that he faced on taking up his post. He had told senior managers that he needed to make many changes, and that he had to make them quickly, and if the Compact had not been in place he would have had to invent it himself. Others had heard him remark that, if the main champion of the Compact had proceeded with his plans for retirement, the CEO would himself have taken charge of $\mathrm{CP}$.

To the degree that decentralization had led senior managers to harbour suspicion of the Compact as a corporate-level intrusion onto their 'turf, a renewed corporate focus on commercial and operational matters generally favoured a company-wide initiative like CP. The centralization of decisionmaking on key issues of strategy and direction, also allowed for a more coherent and effective top-management impetus behind the Compact process. In this sense, the assertion of hierarchical power in support of CP buttressed the process in the absence of senior and line management support rooted in commercial challenges.

\section{Conclusion}

Aer Rianta had long been viewed and viewed itself as a progressive company, willing to engage in innovation with respect to personnel and 
industrial relations. This, combined with the embeddedness of the company in a public-sector tradition wherein personnel priorities of a broadly "paternalist' character informed management postures, both encouraged and constrained the development of CP. The Compact resonated with a tradition of experimentation and innovation that attributed priority to people-focused values. In this sense it was nothing strange or alien, and had grown organically out of the company's history and traditions. At the same time, the prevailing corporate ethos had not been forged in the cauldron of intense competition, and, by some at least, was increasingly seen as being inconsistent with the imperatives of competing in a changing industry. Thus, the prevailing corporate ethos or value system in Aer Rianta, while receptive to the values underpinning the Compact, was quite different to corporate value systems in which, to use Kochan and Osterman's terms, 'humanistic values' reflect hard-nosed corporate choices about how best to compete, made in the context of intensely competitive markets. It is mainly value systems like these, possibly of a business-defining character, that provide the focus for the US literature on the importance of management ethos for mutual gains practices. Value systems of this type also have the greatest capacity to bind senior managers, especially those occupying line positions, to HR innovations, as the latter are seen to have emerged out of commercial conditions and priorities.

What must in contrast be recognized about paternalism of the kind prevalent in Aer Rianta was its inherent conservatism and tendency to shy away from radical innovations in employment practices and modes of decision-making of the type entailed by partnership. The Compact envisioned a changed role for the personnel department, a realignment of roles and responsibilities between personnel and line managers, new roles for managers generally and new relations between management and employees and between employees and unions. Little sanction for these types of changes could be found in the company's paternalist values and traditions.

The support and 'sponsorship' of senior civil servants and of the 'shareholder' were important in underwriting CP, particularly in the light of considerable senior management scepticism and opposition. Major change was on the agenda for Aer Rianta as for other state-owned companies during the 1990s. The Compact provided a means whereby radical change might be handled without the extreme unrest or turbulence that had ensued in a number of state-owned companies. Perceived ministerial support for CP became pivotal at the time of the strategic review in 1998-99, buttressing the attempts of top management and supporters of the Compact to align the strategic review with CP. Relatedly, senior management sceptics and opponents of CP were also mindful of the department's on-going support. Support by the departmental 'sponsor' helped to ensure that CP became part of mainstream corporate decision-making at a time when it might otherwise have been sidelined by the pace of events and by the scale and nature of the challenges facing the company. 


\section{Senior managers}

While homage had to be paid to CP by senior managers, considerable scope existed for managers to manage as they saw fit. Personnel and industrial relations problems were by tradition absorbed mainly by the personnel department. Line managers had seen personnel and organizational development initiatives come and go, without significantly changing their ways of working. The Compact sought to institute a fundamentally new way of working, but for some time it was thought that this too would go the way of previous initiatives. The change process in Aer Rianta was thus quite different to what might be regarded as the standard pattern identified in the literature. The standard pattern was for deep and lasting changes in practices to originate in the attempts of senior line managers to realign employment and working practices to changed external market pressures. In the case of Aer Rianta, a new approach to management, based on staff and union involvement, had originated among visionary figures in management and unions sceptical of pre-existing methods of promoting worker participation and intent on moving beyond adversarial industrial relations. The management sponsors of CP were faced with the task of 'selling' the concepts involved to a largely disinterested, sceptical or straightforwardly hostile management group. Early on, the main management supporters of CP tended to be executives working in service functions. The main opposition, or the deepest levels of scepticism, came, however, from senior executives in line positions, especially at airport level. The capacity of managers at airport level to resist $\mathrm{CP}$ was buttressed by a move to decentralized management structure during the 1980s.

Senior managers on the whole were willing to identify advantages arising from CP. Most of the advantages identified were however 'process advantages', and few believed that substantive, bottom-line advantages had arisen yet in such areas as cost reduction, service quality improvement or operational processes and practices. Alongside such advantages, many senior managers identified what they saw as both process and bottom-line disadvantages arising out of CP. For most, the overall balance between advantages and disadvantages was such as to confirm them in their scepticism towards partnership.

The slow pace of development of CP reflected to a major degree line management disinterest and opposition, and this in turn was sustained by the slow pace or incremental nature of change in the domestic business context over much of the period covered by the Compact. By the late 1990s the pattern and pace of change had altered. Landing charges had remained unchanged for some years and heavily discounted charges remained in place for major customer airlines. Low and static landing charges, combined with the imminent disappearance of duty-free sales and changes rendering the company liable for the payment of rates and corporation tax, threatened to undermine the company's commercial success and even viability. At the same time, rapid economic growth resulted in escalating passenger numbers and airport congestion, especially in Dublin, and the need to finance an 
expensive programme of capital development of runway facilities, airport buildings and other facilities. In this context, the government signalled its intention of moving forward with changes in the status of Aer Rianta, raising the prospect of a partial or complete sell-off.

When commercial changes of a more 'disjunctive' nature began to bite in the closing years of the 1990s, the Compact was just about surviving and provided a ready-made vehicle through which they might be addressed. Yet $\mathrm{CP}$ might still not have survived or become a key channel for change management were it not for the succession of a new CEO who had been a supporter of the Compact. With change at the top came new appointments and revised reporting arrangements that strengthened $\mathrm{CP}$ for a time. A general process of centralization, involving a greater emphasis on corporate priorities, also strengthened $\mathrm{CP}$, which from the beginning had been a corporate-level initiative. In these ways, hierarchical power for the first time underwrote a process that represented the very antithesis of decision-making authority based on formal positions in a hierarchy. The effects of management succession at Aer Rianta finally provide an illustration of how a 'pivotal event', emanating from a 'generic challenge', can accelerate the institutionalization of partnership. 


\title{
6 Middle managers
}

\author{
With Alastair McPherson
}

As outlined in Chapter 1, middle managers have long occupied a relatively unambiguous role in the literature on employee involvement and partnership. They have been viewed in the main and in simple terms as opponents of innovative approaches to work organization and joint decision-making. The classical themes in the literature concern the threats posed by involvement and partnership to middle managers' authority and established ways of working; the tensions that arise between new decision-making processes and established accountability for the attainment of hard business objectives; and ultimately, the fear that innovation may entail or lead to delayering, the loss of promotional ladders and even of jobs. In one way or another these themes have informed nearly all studies of middle managers' reactions to employee involvement and associated innovations in work organization and decisionmaking (for reviews see Cooke 1990: 8-9; Hyman and Mason 1995: ch. 8; Fenton-O'Creevy 1998; 2001; for an exception see Storey 1992: chs 7-8). Only recently has this view begun to be modified in significant respects. While not doubting that middle managers frequently resist employee involvement and workplace partnership in defence of sectional or self-interest, several researchers have sought to locate middle management reactions to work innovations on the wider canvas of organizational systems and processes. In this perspective, middle managers' and supervisors' reactions are understood to a significant degree as a reflection of the extent to which senior management supports work innovations, both directly and through multiple organizational systems for which they bear ultimate responsibility. This approach will inform our analysis of middle management attitudes in Aer Rianta, where, for much of the period from the genesis to the high tide of partnership in the late 1990s, considerable tension and at times outright conflict characterized the relationship between middle managers, their union and $\mathrm{CP}$. 


\section{Middle managers in organizational context}

\section{Splits in the management bierarchy}

Marchington (1995: 296-90) anticipates such a broader perspective in his wide-ranging discussion of how managerial actions or inaction can reduce the impact of employee involvement initiatives, or cause them to function in ways not intended by their champions. Marchington's analysis identifies resistance from first-line managers as one barrier to success. While he relates this to self-interest and threats of a familiar kind to the position and prospects of first-line managers, he suggests that first-line resistance also needs to be understood in the context of 'splits and discontinuities between different levels in the management hierarchy' (Marchington 1995: 289). First-line managers may view employee involvement initiatives, for example, as little more than 'soft' management, or as 'idealists at corporate headquarters' pandering to the workforce (Marchington 1995: 289).

\section{Incomplete coverage of involvement initiatives}

Other shortcomings in management and organizational systems may compound these problems. Significant gaps may exist between formal policy statements and senior managers' beliefs and the real level of penetration of involvement initiatives at workplace level. This may in particular represent a problem where involvement is voluntary, as is often the case. Some involvement-based groups may meet infrequently or only exist in a formal sense. Incomplete coverage might in turn reflect operational pressures and difficulties, such as tight production or service schedules, or the dispersion of the workforce over multiple sites and logistical problems in bringing people together for participative activities (Marchington 1995: 286-7).

\section{Competing initiatives and contradictory rationales}

Marchington suggests that in large establishments it may not be unusual for a series of different employee involvement techniques to operate at the same time. The multiplicity of techniques may result in particular techniques competing with, or even contradicting, each other, especially where they are championed by different management functions or departments. Techniques could sometimes be introduced promising empowerment, while employees also find themselves being subjected to tighter control (Marchington 1995: 287-8).

\section{Practical difficulties}

First-line managers may experience work overload and find it difficult to set aside the time to consult with or brief subordinates, particularly if they are 


\section{Middle managers}

not explicitly rewarded for such activities, or their performance is judged against something other than narrowly defined production or service criteria. Training in the implementation of involvement initiatives may also be inadequate (Marchington 1995: 289-90).

Marchington's analysis points in major degree to problems in organizational hierarchies and systems as a way of accounting for the commonplace failure of involvement initiatives to live up to their promise. Splits and discontinuities in the management hierarchy, both vertical and lateral or crossfunctional; contradictions between avowed policy and operational pressures and priorities; a failure to align rewards and performance management systems with the goals of involvement and training difficulties, may all accompany first-line management resistance as barriers to success. Significantly, some of these forces are also seen to interact with and intensify first-line management resistance.

\section{Congruence with organizational subsystems}

The postulate that middle management resistance needs to be understood as more than simply a reflection of sectional interest is more explicitly developed by Fenton-O'Creevy (1998; 2001). Like other writers, FentonO'Creevy identifies sectional interest, rooted in the standard fears and anxieties, as a significant source of middle management resistance to employee involvement. He emphasizes, however, that middle managers need to be seen as simultaneously pursuing their own interests and responding as members of an organization that has selected and socialized them for a particular role and that reinforces particular types of behaviour through multiple organizational systems and signals (Fenton-O'Creevy 1998: 70). Drawing on an empirical study of employee involvement initiatives in a sample of 114 UK enterprises across a diverse range of industries, he identifies a series of organizational systems that influence the reactions of middle managers to employee involvement. The degree to which senior managers show clear personal commitment to change influences middle management reaction. So also does the extent to which organizational systems like rewards and performance management systems reinforce middle management co-operation with change. Middle management capability to function under involvement arrangements is also identified as an important force, and this is shaped by such things as the degree to which they can access information and control resources and exert influence over change. Capability is also shaped by training and development activities (Fenton-O'Creevy 1998: 70-2). Echoing a theme also developed by Marchington, Fenton-O'Creevy (1998: 72) suggests that 'role strain', engendered by high short-run performance pressures, may also engender fatigue and resistance to change.

Such a 'systemic explanation' of middle management resistance, which highlights how middle managers may be treated as 'scapegoats' for organizational failures, is seen as providing a more adequate explanation of middle 
management behaviour in the context of involvement initiatives than classical notions of the middle manager as self-interested 'saboteur' (FentonO'Creevy 2001).

\section{Middle managers in Aer Rianta}

This chapter examines the attitudes of middle managers and first-line managers such as supervisors and superintendents to the development and implementation of workplace partnership at Aer Rianta. The analysis is based in the main on in-depth, semi-structured interviews with middle managers. It also draws on internal research on middle managers' attitudes to $\mathrm{CP}$, conducted by consultants working for the JUCG. It is important to note that the interviews were conducted with middle managers from departments that had some contact with the participation process and across all the airports. However, the level of contact varied in intensity across different departments and also across individual managers within departments. Chapters 7 and 8 will report survey data on the attitudes and responses of middle managers to $\mathrm{CP}$.

Before discussing the findings from the in-depth interviews and other sources in the context of the theoretical framework outlined above, we first examine middle management attitudes towards a series of aspects of $\mathrm{CP}$.

\section{Attitudes towards participative approaches to management}

Middle managers' involvement in the early development of CP in Aer Rianta was very limited. As reviewed in earlier chapters, participative principles and arrangements had been developed largely by champions within senior management, with support from key trade union officials. Middle management was not directly involved in the foundation-laying work of the Joint Working Group on Participation between 1986 and 1990. Although middle managers' comments were elicited through an employee survey and through internal communications exercises, held with mixed groups of employees, there had been no direct representation of middle management views within the main participation forum. This situation was maintained when the Joint Working Group was reincarnated as the JUCG in 1991. Thus, there was little direct representation of middle management views at the top table during a period when the conceptual and practical approaches to participation were advancing steadily, for example, through the development of the Compact and Requisite Arrangements.

Middle managers were however becoming engaged with the developing participation effort in a number of other ways. Certain groups of middle managers became involved in pilot groups, and a more general introduction to the issues came through a further employee survey along with continuing internal communications and research exercises. The pilot groups, running from late 1992 and gradually declining in activity after late 1993, exposed a 
small section of middle management to a concrete example of participation in action. However, the tentative and experimental nature of the pilot groups did not result in many tangible benefits at departmental levels. Rather, from the middle managers' viewpoint, these early efforts presented participation in a relatively limited, poorly articulated and frustrating guise.

Clear indications of substantial middle management concern regarding CP emerged in two research studies conducted as part of the internal research programme associated with the initiative. In 1996 and 1997 studies of middle management attitudes were undertaken in Dublin and Shannon. In Dublin a random sample of 20 middle managers was interviewed. Some 41 per cent were reported as believing that middle managers had most to lose in the participation process, and the main concerns were reported to revolve around the erosion of the middle management role, loss of power and slower decision-making. These views were held in spite of a general perception that participation could be beneficial for both management and staff. Middle managers saw their role in clear-cut terms as involving 'control of the situation and making decisions'. Participation was perceived to be about consultation and allowing people to voice decisions at all levels. Only five of those interviewed anticipated that participation would involve staff sharing directly in the decision-making process (The Anticipated Effect of Participation on the Role of the Middle Manager, n.d.).

Forty middle managers were interviewed in Shannon in June and July 1997. Here the research reported that, overall, CP was seen as having more negative than positive implications for middle management as a group. There were 'consistent concerns that increased levels of participation would lead to the erosion of role for the middle manager'. Some 42 per cent of those interviewed defined their role as being about decision-making and control of information. Many feared that $\mathrm{CP}$ could result in job cuts at the airport. Perceived lack of senior management commitment to the process emerged as a major theme, as did a belief that senior managers' expectations of middle managers revolved around getting the job done and achieving results. CP might heighten the expectation of staff, imposing new demands on middle managers. It was concluded that middle management did not have 'as ambitious an understanding of participation as is stated in the Compact'. Throughout the research exercise, the researcher had encountered what was described as a 'strong demand for an explanation of the perceived exclusion of middle management from the process to date' (Report on the Middle Management Group in Shannon Airport, December 1997).

After 1996 then, as the participation process shifted from development to implementation, middle managers came to the process from a relatively uninformed and uninvolved position, but with considerable anxiety or scepticism towards the extension of participation. Throughout 1997-98 a wide range of managers encountered a burgeoning series of participation initiatives within their departments. The material presented below captures the 
response of middle management to these new developments. The findings reflect attitudes during a period of sustained activity in the development of participation within the everyday work contexts of middle managers. So the period was one in which the existing attitudes and beliefs of middle managers were being tested against what, for many, were radically new concepts and ways of working.

What emerges from the interviews conducted in association with this study, as from the earlier internal research, is that many managers claimed to support some form of partnership within management-employee relations. In particular, there was a strong avowal of the value of workplace partnership for the competitive posture of Aer Rianta. This was reflected in a series of comments across a number of departments:

Eventually it will just be the way we do our business ... if we're not going to change we'll just get left behind.

(commercial manager)

I think it's the only way any organisation can proceed now.

(finance manager)

As a principle I think it's the way forward ... the only way to make things happen is to bring people along.

(commercial manager)

This us and them, this sort of turn of the century sort of stand-offish structure ... anything that breaks down these historical suspicions and gets people more involved [is welcome].

(finance manager)

I would say [it is a] fundamental mechanism through which we can make our business better.

(maintenance manager)

It is a very positive way to do business.

(maintenance manager)

I think it is essential if we are to move forward.

(commercial manager)

I was initially sceptical because I would come from the hierarchical sort of background.... Very quickly after maybe three or four education programmes ... particularly thought it was an initiative that we could do with and was very much something that we would work here if it was supported and used properly. 


\section{Middle managers}

However, such views were not universal. In the eyes of a manager from the Airport Police and Fire Service:

Basically the way I looked at CP at the very start, my own feeling on it, was that it was really another wing of the union.

Another manager from the same department shared this view:

Instead of the dog shaking the tail, it was going to be the tail shaking the dog.

In significant degree, attitudes were conditioned by the degree to which middle managers had engaged with the process. As one middle manager in maintenance commented:

You can virtually see a gradation of belief if you like between people who are heavily involved ... to people who ... believe that there is something in it, but they are not quite sure what yet, to the people ... who write it off as just another gimmick.

Many middle managers felt that they already worked in a participative way, and often that they had been doing so for some time. For example, one commercial manager commented:

I think really to be quite honest about it this airport has always kind of worked in that kind of way. People are always involved in things. I mean there is never [any] kind of 'them and us'. I mean, okay, there are industrial relations problems that come up, but that's different. But we've always, all the staff, have always been involved in what goes on around the place.

A manager from the finance department also claimed that participation had been routine there for some time:

I suppose to some extent we have been doing that anyway (participation). In our area, we would have constant contact with one another every day. Maybe not in a total group sense but certainly in ones or twos and threes, so that has worked pretty well.

If participation was commonly understood as a way of relating to colleagues, in the Airport Police and Fire Service a more formalized method was said to have been common.

I'm here since 1964 and we've had committees and I've been involved in all of those committees right through. The 1971 agreement is one of the 
top ones that we have and is still being used to resolve disputes or arguments. CP, I would see as just a follow-up from that in our department. Now other departments wouldn't use that but we've always been very constructive in our approach.

Middle managers appear to have conceived of participation largely in terms of downward communication. Thus, most managers saw informationsharing as a key issue in partnership. In the words of a maintenance manager:

It is the sharing of information where before it was perceived by people that decisions were secret... Now that still applies, let's be honest about it, particularly from the point of view of industrial relations problems, you know like staffing levels or salaries, or even to a degree, budgets. But in general where it involves the people on the floor, the approach would be that it is more open.

Another comment typical of middle managers' views came from a finance manager.

The staff levels are staying the same. I am finding it difficult to cope. Now I am not sure if CP will solve that problem, I don't know. But what it could do perhaps is maybe help identify what is critical in terms of information needs and what isn't. And not just in a departmental level, but more so at a company level.

As indicated, middle managers saw this type of activity as part of their existing routines. Thus, for many managers, CP meant building upon existing practices to inform staff about plans, either through regular structured techniques, or quite often, via informal or non-routinized channels. Problemsolving activities that involved employees were not so apparent in middle managers' understanding of what partnership entailed. There did not appear to be a clear understanding that structured processes for employee involvement, such as quality circles, suggestion schemes, or attitude surveys, might be entailed by partnership. Some of these mechanisms had previously been used in a number of departments, for example the Airport Police and Fire Service.

At the moment I'm getting information back through the committees that have been set up so it seems to be working. But we're lucky I suppose in our section that we've always had committees and we've always worked through committees.

Problem-solving activity was associated by middle managers in the main with committees or working groups, such as the various SIGs and related 


\section{Middle managers}

$\mathrm{CP}$ initiatives that had come into being. However, the degree to which middle managers were integrated within these structures was highly variable and middle managers held mixed views on the merits of these approaches as effective forms of partnership. The attitude of middle managers to the joint forums is discussed in more detail below. Certainly, the forums were not seen to be middle management-inspired or led, at least at the department level.

Nor did middle managers in general associate partnership with task participation or changes in work organization. However, the link between partnership and work organization was more salient in departments where teamworking had previously been pursued. For example, awareness of task participation possibilities was greater in maintenance departments, although, as discussed below, negative connotations were also associated with teamworking.

\section{Attitudes to Compact forums}

While the majority of middle managers declared themselves to be supportive of increased levels of partnership, it appeared that middle managers fell into two general camps with respect to their detailed attitudes towards partnership. For the majority of middle managers interviewed, partnership was viewed in the relatively limited terms of direct employee involvement, focused primarily around downward communication. For a smaller group, with a greater degree of involvement with $\mathrm{CP}$, joint arrangements were seen as having a greater role to play, although middle managers viewed their own relationship to these structures as uncertain. This was partly due to the problems of middle management integration within $\mathrm{CP}$. While some managers saw positive outcomes from Compact forums, many others viewed these as either unproven, or as intrinsically flawed.

Some managers looked positively on Compact forums, when they saw tangible results being produced. As a commercial manager put it:

For me really getting involved with the duty free strategy group was the one [event] that made me realise that there is ... benefit in this.... I suppose when we were involved in that process a lot of the staff got involved in it and they were involved in the decision-making the same as I was. So on that project ... looking to our future and how we're going to handle the future, it definitely would have been handled differently.... Some of the groups have actually had some very good results. I mean I know one or two of the groups ... and they have come up with very good reports ... and it has been the union and staff working together. Now I mean whether you get it to work in all areas I don't know.

Managers also identified as an advantage of the Compact forums the manner in which they had allowed employees to contribute their knowledge and 
skills in a much more productive way than previously. As one maintenance manager commented:

It has given a certain amount of support in working the way I have always worked but which from time to time has been against the normal pattern of how Aer Rianta works. ... It has given me the opportunity to use people's knowledge and brain in the way that they don't feel intimidated, or that they are going to be abused. ... So the very fact that we meet people we wouldn't normally meet - the hierarchical structure before would have kept many people in the background, we wouldn't have met them. ... So I think it is a two-way stream here. I call that the fizzy drink situation where you suddenly let the top off the bottle and you get this effervescence coming out, of ideas, and a lot of what is coming out is only gas but there is genuine ideas in there which have never been released before.

However, other managers saw Compact forums as of limited value. A further influence on negative middle managers' attitudes was uncertainty over the direction and shape of evolving structures. The non-prescriptive nature of $\mathrm{CP}$ precluded a clear picture of an end goal for middle managers. As noted by a commercial manager:

The principle I'm happy with it but the methodology of implementing it and pursuing it I wouldn't be too happy with.... I'm not quite sure that the way we're doing it is the right way to do it ... because it seems to me to be very secretive or biased against my particular grouping.

\section{Views on the role of trade unions}

Rather than viewing partnership as a means of undermining trade unionism and worker solidarity, middle managers equated $\mathrm{CP}$ with a strong and even dominant role for union representatives, rooted in the Compact forums. However, it appeared less clear to middle managers whether joint committees or joint working groups might be channels for increased trade union influence, or merely another channel in which to address issues.

On the whole, middle managers perceived the role of $\mathrm{CP}$ as a potential route for overcoming past adversarial attitudes, which they associated with trade unions: 'We have a number of union representatives down here. They come in and they talk to you and they keep you informed. It has changed people'. There was little sense that $\mathrm{CP}$ might diminish the role of trade unions. However, given the limited interaction of middle managers with $\mathrm{CP}$, it was difficult to identify if they had considered how the relationship with trade unions might evolve. In the context of the Compact forums, it was not clear to what extent the middle managers involved were prepared 


\section{Middle managers}

actively to engage in partnership with unions and staff. However, there was some evidence of intent in this respect. A maintenance manager stated that:

I also see the unions getting so involved in it instead of the traditional conflict role. ... To me this is a milestone. ... The unions are very much committed to this and I think that is a good thing and that certainly would sway my attitude towards the whole thing.

Another manager in maintenance commented:

So do they [staff and unions] then have a part to play in the overall level of control, in the strategy of the department? Yes they do. ... Given that there are still things that have to remain confidential there is no reason why we can't be more open about the way things work.

Some managers believed that the balance of advantage arising from CP favoured unions. Referring to the posture of shop stewards, a commercial manager reflected:

I'd say they'd be a lot more sympathetic to CP than, say, middle managers would, because they would see from their own point of view that they're going to have a bigger say in the workings of the departments or decision-making and the whole lot. That's the way they'd see it.

A number of managers believed that Compact forums were likely to give way to adversarial patterns as soon as greater demands were made from employees. In the words of a manager from the Airport Fire and Police Service:

There's a lot of involvement when it comes to being able to do something for them from my side. But when it comes to something out of my remit then we have to go somewhere else and then it becomes an industrial relations issue ... that once you're saying no and you give a good reason for saying no then it becomes an industrial relations issue.

\section{Middle managers' views of employee attitudes}

The middle managers interviewed considered employees to be divided into two main groups: a largely ambivalent or sceptical group without much contact with CP, and a more enthusiastic group that had experienced participation in Compact forums. A commonplace position was reflected by this comment from a maintenance manager:

There are sceptics. We seem to manufacture sceptics here, but that may be because of the way things were handled in the past. ... It's getting 
better by the day. I would say we are around the half-way mark at the moment.

A finance manager was marginally more positive:

Generally there is a positive buzz about it. People are still in the 'I'm not quite sure about how this is going to affect me' mode to some extent. I wouldn't call it scepticism, not as strong as that, but you know a question mark, because I suppose people come out of these meetings and they go back to their work and there really isn't a lot of time to go and discuss the thing.

However, middle managers felt that the continued interest of the sceptics was conditional on positive gains from the forums. As one maintenance manager put it, with reference to limited employee enthusiasm:

Well it will only change if there are results.... There is no point in making a talking shop out of it ... and if I am totally honest again I suppose to some degree it is at the minute ... so until they see action and see results, I would say that will stay as it is.

Some managers felt that the process had been one-sided in advantaging employees. Where a potential cost arose for employees as a result of Compact deliberations, they believed that the process might unravel. Others were concerned that employees would increasingly associate their work roles with the business of Compact forums and that their 'everyday' work would suffer as a consequence. A maintenance manager based this view on previous experience of teamworking, which he felt had affected employees in a way that had been detrimental to productivity:

I think some of the problems with teams are going to be some of the problems with participation. Where people are no longer satisfied with their lot ... we were losing all our workmen because they were all becoming professors you know ... there are a lot of people who would use the developing situation to do less and less.

An associated problem was seen as being the removal of 'teeth' from supervisors and the insulation of staff against criticism.

Middle managers pointed commonly to the influence of employee age and career stage in determining attitudes to workplace partnership. Almost universally, managers saw older staff in general as an impediment to change. A typical explanation was that given by a manager in the Airport Police and Fire Service: 


\section{Middle managers}

'We've seen it before' is their attitudes. Some of them would be for it. Most of the older officers would look upon it as another committee.... The older staff don't trust it. ...

This perspective was in part informed by the established work practices of long-serving employees. In addition, those nearing retirement were viewed as having little incentive to invest time and effort in learning new ways of working. In contrast, younger employees were seen not only as 'clean slates' but as being more in tune with a partnership ethos. A commercial manager remarked:

there's a younger group of staff coming in there now so those are the ones that you really need to get at. You know. I suppose if you have a group of older staff, a lot of older staff in a department I think you could have a problem there because older people then I suppose maybe they're not as open and they fear change, you know. Younger people are a lot more open-minded. .. . It seems to be more staff at the junior level that seem to feel the benefit of it because they would never have been involved in decision-making before and for them it is an opportunity.

Perceptions of staff attitudes to participation are also coloured by a lack of management engagement in the process. One commercial manager declared with respect to employee attitudes to participation:

I wouldn't have personally gone out and even asked that question. I wouldn't have even my ear tuned in to even try and get a vibe for it, you know. I'm more concerned with the day-to-day running of the business. . . .

\section{Middle management attitudes in organizational context}

\section{Defence of sectional interest}

From the discussion above, a number of reasons were apparent as to why middle managers had engaged to a limited degree with CP, in spite of their commonly avowed support for the underlying approach involved. Concerns for their own interests emerged as an important factor in the internal research, reported earlier, and were also reflected in the research reported here. But the direct role of opposition rooted in the defence of middle managers' interests was underscored in the interviews to a surprisingly limited and muted degree.

A concern to defend the position of middle managers against encroachment under CP had been evident in the dispute between IAESA and the JUCG. The proximate cause of the dispute had been the JUCG's insistence that members could not occupy a representative role. However, the underlying dynamics of the dispute seemed to have been driven mainly by the 
concern of the middle managers' union with the implications of $\mathrm{CP}$ for the status and security of middle managers as a group. Several finance and commercial managers interviewed linked the IAESA debacle directly to fears about the future of the middle management role:

That organization needs to be taken seriously ... because middle management are very much the ham in the sandwich anyway ... there is a train of thought that says that this is the layer we can take out much more easily, that it's a blockage anyway. Maybe there is a certain feeling of being threatened.

There was an in-built bias against IAESA from the unions and the company turned around and said 'Okay we'll go with the union guys, our pals, on this thing and exclude the IAESA guy'.... It's saying to the middle managers, 'Look, you're going to be the meat in the sandwich here. In this process that's going on it's going to be tougher and tougher and tougher for you to do your job because at the end of the day now you're going to have a whole lot of people who have a whole lot of opinions on how you should do it, rather than the person that you're reporting to'.

Evidence from in-depth interviews with middle managers made it clear how the dispute between IAESA and the Joint Union Company Group impacted directly on the $\mathrm{CP}$ process. The call from IAESA for their members to boycott $\mathrm{CP}$ had been a major impediment to middle management engagement.

But the evidence also indicated that IAESA's defence of the interests of middle managers was less strident or forceful than it might have been because many middle managers were ambivalent about their loyalty to the union and their role as managers in Aer Rianta. Despite the official action of the union, some managers felt obliged to preserve a relationship with $\mathrm{CP}$. This could mean involvement at arm's length, for example providing relevant information for $\mathrm{CP}$ meetings, or facilitating staff release for attendance at meetings. Others took a more direct role in $\mathrm{CP}$, feeling that to abstain would involve a dereliction of their job. A commercial manager explained:

I mean I was involved even though I shouldn't have been involved. But simply because I was in a position that I was responsible for ... I felt it was my job. But it was a very awkward situation. I mean you were getting letters from the union telling you not to be involved. If you didn't become involved you weren't doing your job.

Not all middle managers belonged to IAESA, and so some felt relatively insulated from the effects of the IAESA boycott. In addition, the bargaining strength of the organization was perceived to be relatively weak, compared 
with other trade unions, as was the solidarity and militancy of members. Middle managers as a group identified closely with the interests of the company, as was evidenced by their ultimate unwillingness to put the dispute between their association and the JUCG ahead of job commitments.

Nonetheless, while many middle managers kept an eye on CP developments, and often facilitated them, there was a strong sense of grievance with the participation process and a widespread perception that middle management had been excluded from the development of workplace partnership. Frustration about this was evident, and was articulated by a commercial manager in the following terms.

Well I think it came about, from the little I know about it, I think it came about simply because IAESA weren't allowed to become involved as full members [of the JUCG]. I mean ... I think basically ... that middle management in the company felt that they were being excluded from the process and I mean if they're not going to be totally involved in it you might as well forget about it.

This feeling was compounded by the dilemma of whether to follow the staff association action or to engage with developments in their respective departments. As one finance manager commented:

So we had a conflict here. You either let your job go to pot by failing to participate in different things, or you take a directive not to participate, or you just ignore all that, a bit more of a dilemma because at the end of the day you are going to protect your job first. There were a number of people here who were hoping to get involved on a sort of secondment basis with the Compact. Each one of them pulled out. They were very keen on this and then they pulled out for career reasons.

The reasons given for middle management non-involvement were twofold. First, personal differences between IAESA and the JUCG leaders were seen as having made it difficult to establish effective relations between both bodies. Second, the problematic nature of defining a middle management role in joint arrangements that was independent of, and distinct from, that of senior management was also seen to have caused problems. In the words of a manager from a maintenance department:

The real problem is that we don't fit into either group. We don't fit into the senior group and we don't fit into the pure trade union group. That is the real problem. Therefore we weren't considered ... when the JUCG was being put together ... therefore people have not got the confidence in the JUCG to be making the right decisions or even to be putting forward the right policies that represent middle managers as well. 
A further factor, highlighted to a lesser degree, was trade union opposition to the involvement of IAESA. On the whole, middle managers felt uncertain as to the real underlying rationale for non-involvement. As discussed below, this uncertainty occasionally manifested itself in suspicions about hidden agendas aimed at 'delayering' the management hierarchy.

The theoretical framework outlined earlier in the chapter allows for an exploration of how middle managers' attitudes also reflected the wider context in which $\mathrm{CP}$ was introduced in the company. A series of dimensions of the wider organizational context are relevant in understanding the attitudes and postures of middle managers, and will be discussed in the following sections.

\section{Coverage}

As outlined earlier in Chapter 3, coverage of $\mathrm{CP}$ was limited and uneven across airports and business units or departments. While all the middle managers interviewed came from departments having some contact with $\mathrm{CP}$, their level of exposure to partnership varied considerably. In addition, middle managers had not been subjected to a systematic training programme centred on CP, as had other staff categories and union representatives.

Further, the IAESA dispute had restricted the extent to which middle managers engaged in the more general training exercises focused on the functioning of Compact forums. Thus the exposure of middle managers to the ideas embodied in CP was restricted. For many, exposure was limited to attendance at large-scale employee gatherings aimed at providing an introductory overview to $\mathrm{CP}$, or was sometimes restricted to independent study of $\mathrm{CP}$ documents.

An important factor in the slow spread of $\mathrm{CP}$ ideas amongst middle managers appeared to be the relatively weak lateral communication between departments, and particularly between middle managers from different departments. Peer communication of this character about the workings of $\mathrm{CP}$, and especially about benefits stemming from some of the joint working groups, seemed highly restricted in the case of middle managers. Most middle managers interviewed had very limited awareness of events in other departments at their own airport, and even less about developments at other airports. The weakness of lateral co-ordination between middle management groups had the further effect of increasing the influence of negative signals about CP, originating from either IAESA or within sections of senior management. 


\section{Middle managers}

\section{Earlier initiatives and contradictory rationales}

Various involvement initiatives had been undertaken in the past, and the legacy of these had informed middle management attitudes to new programmes for organizational change. Comments from two managers in finance point towards the continuing influence of experience with past initiatives.

We have had a load of different other initiatives over the years ... like the 'Human Factor' ... and the 'Kilkenny Experience', and there have been all sorts of things at other stages along the development of the culture of the company.

Initially a lot of people had some reservations about it, and perhaps felt 'Well, oh sure they tried it before. It didn't work'.

Thus, what was perceived as the transient and ineffective nature of former initiatives had left middle managers somewhat sceptical about the potential or 'staying power' of CP. Such a state of mind probably reduced the time and resources middle managers were willing to invest in CP.

More significant, in terms of impact, was a perception of contradictory rationales arising from the business and participative aims of departments. In both the internal research conducted for $\mathrm{CP}$ and the research reported here, middle managers had a strong sense of being pulled in two directions. They were pulled one way by what many proclaimed to be the welcome goal of establishing inclusive and participative structures. They were pulled in another direction by what they perceived as the need to resolve, often quickly, important business decisions. Many managers cited CP as a real or potential impediment to the speed and quality of business decisions. A worry was expressed that $\mathrm{CP}$ both slowed down decision-making and led to decisions based on compromise rather than to best solutions, as seen by them.

Similarly, an important question for many managers was whether outputbased objectives should assume priority over workplace partnership in the event of conflicting objectives arising. Most middle managers seemed to think that the bottom line in the eyes of senior managers was about meeting hard-nosed business objectives. They certainly felt themselves to be judged, at the end of the day, by their immediate business objectives or service criteria. Part of the problem here was that middle managers did not perceive any explicit reward to exist for developing workplace partnership, but they did see themselves as being strongly judged on the basis of their short-term contribution to the business. 


\section{Division in the management bierarchy}

Another issue impairing commitment to partnership was the relationship between middle managers and senior managers. Both the internal $\mathrm{CP}$ research and interviews with middle managers revealed that the 'signals' being received by middle managers from their superiors were often noncommittal or unclear. A common feeling was that many senior managers only paid lip service to $\mathrm{CP}$ and that they were not fundamentally in support of the approach. Comments from two managers in different departments are typical of thoughts generally on this issue.

The senior management layer above me would all 'salute the flag'.... That's as far as it goes. Nobody has ever sat down with me and said 'look, this is what participation is all about, the Compact is all about'. There'd be a kind of formal approval and that's it.

I would say that they're [senior management] not enthusiastic. That's about the nearest I can go to it ... I'm being diplomatic ... and it's the same I think in most of the departments until we can prove that this is good for Aer Rianta and it's good for the whole of Aer Rianta, both management and staff, then it's an uphill battle.

It is not enough for the Chief Executive, or any of the board members, to say they support participation ... you have to see evidence that they support us. Why don't they roll up their sleeves some day and get involved. Now I know the Chief Executive is involved in a number of groups, which is good for a busy man, but there is a hell of a lot of people who aren't as busy as him who aren't involved.

In some settings, senior management opposition had been overt. In most other cases, there was a pervasive sense that only a small group of senior managers was fully committed to CP. One manager explained:

I believe there are a handful of people who feel that this is an extremely wonderful thing. There is a big band who don't care really one way or the other.... I think there is a lot of, at management level more so than at staff level, there is much more 'what's it all about anyway?', 'I have to say it is a good thing because I've been told I must'. There is a touch of that I think.

It is harder to assess the direct impact of senior managers' attitudes on middle managers' behaviour in general, but the dominance of the 'sceptics' among senior management, as outlined in the last chapter, may well have made many middle managers think twice about committing themselves to a process about which their superiors where known to harbour considerable doubt. 


\section{Middle managers}

A related aspect of the role of senior management was the perception of middle managers of their superiors' management style. Quite often this style was seen to be authoritarian, indeed more so than the dominant style of middle managers themselves. In consequence, some middle managers thought many senior management figures were unlikely advocates of a participative approach. For example, one manager stated:

I think in the corporate level ... you have very hierarchical structures. There is a touch of ... 'I am up here and you are way down there'... . There are old styles. Now there are some who are very, very good on this; have a very good style... But those who don't are not really conducive to suddenly changing from being authoritative to being participative.

As with their perceptions of other employees, middle managers viewed many established senior managers as set in their adversarial and hierarchical ways.

\section{Practical problems}

We have already highlighted middle management concern about the impact of $\mathrm{CP}$ on the speed and quality of decision-making. Many managers interviewed believed that decision-making would be impeded in such as way as to interfere with the effective running of departmental business. A maintenance manager's comment was typical of such concerns:

I still think that at the end of the day we will need managers to manage.... I don't believe that this department can run on the basis of group decisions on an ongoing basis, but that polices and directions and issues such as grass-cutting or issues such as budget maintenance ... can be thrashed out in a bigger forum and $\mathrm{CP}$ does give us that opportunity.

A related concern was the amount of time available for middle managers to engage effectively in the development and operation of workplace partnership in a departmental context. Practical difficulties of this kind were echoed by a finance manager:

Our biggest problem is workload versus numbers.... It is difficult when you put a lot of time into something and you want to get involved in these things to find that you are handcuffed, because you are so busy with other things.

A further concern for middle managers was their avowed inability to point to many concrete outputs from $\mathrm{CP}$. While they were aware that the process was relatively new, they nonetheless saw a pressing need for results. As a maintenance manager commented: 
If it doesn't achieve things, and I mean achieve things within ... say six months to twelve months, then it will just be written off as a talking shop by a lot of people.

\section{Conclusion}

Middle management involvement in the development of $\mathrm{CP}$ was very limited. Participative practices and arrangements had been championed by sections of senior management, with support from the major trade unions. Some middle managers had experience of $\mathrm{CP}$ at the early development stage through their exposure to pilot groups and communications exercises. When the initiative began to impact significantly on decision-making in the late 1990s, few middle managers had extensive contact with the process and its guiding principles. Internal research provided clear indications that middle managers viewed CP as a threat, and, at least in the case of Shannon, as involving more negative than positive implications for the group. The main concerns articulated were the possible erosion of the middle management role and more diffuse fears over job security. Yet many of those interviewed nevertheless avowed support for partnership as an approach to running the company. A posture in which generalized support for participation by middle managers and recognition of its benefits by middle managers went hand in hand with concern about its likely effects on their specific interests has been underlined in the wider literature (cf. Klein 1984), and was apparent in Aer Rianta.

A dispute between the middle managers' union, IAESA, and the JUCG, ostensibly over the nature and purpose of membership of the JUCG, led the union formally to withdraw from $\mathrm{CP}$ as the initiative entered a critical developmental phase. The underlying dynamics of the dispute, however, seemed to reflect considerable concern within IAESA and among many middle managers regarding the implications of the partnership process for the status and security of the group as a whole. While the posture of middle management towards CP thus harboured concerns rooted in the sectional interests of the group, the union's stridency and effectiveness in defending its members' interests was limited by the ambivalence many members felt with respect to their loyalty to the union and their role as managers within Aer Rianta. Many members continued to involve themselves in CP initiatives against the policy of their union, though resenting the dilemma in which they were placed. The next chapter will examine middle managers' attitudes to their union and permit an assessment of whether the union's opposition to $\mathrm{CP}$ delivered any organizational premium.

It was clear that partnership was understood by middle managers primarily as a means of providing opportunities for employees to 'voice' their opinions and also as a mode of downward communication and information provision. Few middle managers saw $\mathrm{CP}$ as encompassing shared decisionmaking or work task restructuring. Their core understanding of the middle 
management role, indeed, involved middle managers bearing responsibility for controlling information and making decisions. Partnership was seen more as a buttress to union influence than as a channel for bypassing unions. Middle managers perceived employees as being divided between those who were sceptical and ambivalent and 'enthusiasts' who had more experience of CP. Many middle managers interviewed voiced doubts about the concrete benefits of $\mathrm{CP}$, some believing that the future of the process was predicated on the achievement of more tangible results.

While concerns rooted in the defence of their own interests account in part for the posture of middle managers towards $\mathrm{CP}$, the evidence shows that middle managers' attitudes were also shaped by the wider organizational systems in which both they and $\mathrm{CP}$ were embedded. Middle managers had not been systematically engaged in the development of partnership, nor had they been the recipients of systematic training as to the nature and effects of $\mathrm{CP}$. The group had witnessed programmes for organizational change come and go in the past, and were disposed to believe that $\mathrm{CP}$ might go the way of previous initiatives of a similar kind. Middle managers articulated what they saw as the contradictory demands arising from the process objectives of partnership and the hard-nosed business objectives for which they were above all held accountable by their superiors. This dilemma was heightened by the absence of organizational systems like performance management or reward practices that might have sought to balance performance across 'soft' and 'hard' aspects of managers' roles. While the need to revise such organizational systems to provide support for $\mathrm{CP}$ had been explicitly recognized, the systems developed before the advent of $\mathrm{CP}$ largely remained in place in the company. Though employment security was an explicit feature of $\mathrm{CP}$, this was not perceived by middle managers as providing them with a guarantee of security in their existing job roles. The dilemma of responding to contradictory pressures was heightened too by pressures on time and staffing levels, which were seen to have left little scope for participative decision-making. Perceived divisions within the management hierarchy were also an important factor conditioning the attitudes of middle managers. Middle managers had not been convinced of the support of senior managers for $\mathrm{CP}$ and stated that 'mixed signals' had been received concerning senior management support and commitment. This was in turn compounded by the view, expressed by some, that senior managers appeared unlikely advocates of participative approaches to working with staff.

The interviews explored the attitudes and postures of middle managers during the high tide of partnership, when they were viewed by champions of the Compact as the category most opposed to $\mathrm{CP}$, and when their union's stance involved formally boycotting the initiative. The union's stance was to soften in 1998-99, when the newly appointed CEO invited the middle managers' union, IAESA, to join the SIG dealing with the company's future. This move responded to the major objection by IAESA that it had not been involved as a representative body in overseeing the operation of the Compact. 
The new CEO's support for $\mathrm{CP}$, as reported in the last chapter; the significance of the SIG in question for middle managers' future prospects; and the subsequent transfer of IAESA to the major public sector union, IMPACT, were important in bringing middle managers formally into $\mathrm{CP}$ in spite of the attitudes and tensions revealed in the research. 


\section{Trade unions}

This chapter builds on the analysis of union involvement in the development of CP in Chapter 3 by examining the role of unions in the operation of workplace partnership in Aer Rianta, and the effects of partnership on unions and their members. As outlined in Chapter 1, the academic literature on unions and workplace partnership is sharply polarized between the positions of 'advocates' and 'critics'. These rival groups present different views as to the nature of trade union engagement with workplace partnership and as to the effects of partnership on unions, union activists and union members. Cross-cutting the debate between advocates and critics is a second keen debate focusing on the effects of workplace partnership on relations within unions between full-time officials and senior shop stewards on the one hand and union activists and rank-and-file members on the other. These two themes provide the analytical focus for this chapter and will be considered in the next two sections.

\section{Advocates, critics and union involvement in partnership}

Amongst the most noted advocates of workplace partnership is Thomas Kochan who, together with colleagues, has advocated the development of partnership arrangements as a means of union renewal and of extending employee participation (Kochan and Osterman 1994; Kochan 1995; Rubinstein and Kochan 2001). Kochan's arguments are set against the failures, as he sees them, of the New Deal system of industrial relations in the US. The New Deal's principal failing is that, in restricting the opportunity for unions and employees to influence management decision-making, it has perpetuated a low-trust spiral, from which both parties find it difficult to extricate themselves. Kochan is not unmindful of the challenges that such a departure poses for unions, in particular the fear that management might use employee participation to undermine the union's position. Running against such concerns, however, is the important issue of what workers themselves want. Drawing on research conducted by Freeman and Rogers (1999), Kochan argues that workers are acutely aware of the existence of a participation/representation gap; that they want greater involvement in 
their work and more involvement by their representatives in the formulation of business strategies. Workers were also seen to have little patience for adversarial industrial relations and demonstrated a clear preference for their union leaders to work in co-operation with management.

The challenge for employers and unions, Kochan (1995) contends, is to find innovative ways of accommodating and meeting employees' request for more 'voice' and influence. While Kochan and Osterman (1994) ideally favour the introduction of structures that seek integrative, joint gains solutions, accompanied by bundles of human resource practices emphasizing mutual gains and quality-focused competitive strategies, this need not result, they argue, in the abandonment of collective bargaining. Implicit in their argument is a call for an institutional separation of collective bargaining (an adversarial and distributive process) from joint consultation (an integrative/consensus-orientated process), which echoes Storey and Sisson's (1993) work in the UK. The benefits - and concerns - are seen to be broadly similar. With joint consultation, unions are allowed scope to influence management decision-making. Unease exists that this may provide the semblance but not the substance of influence. Without the power of veto, unions may compromise their independence by involving themselves too deeply in company decisions.

John Kelly advances a critique of partnership and of what he calls the associated strategy of union 'moderation' based largely on UK experience (Kelly 1996; 1998; 1999; 2004). His critique has two major strands. First, drawing from a wide range of empirical evidence, Kelly seeks to demonstrate that UK employers have grown increasingly hostile to trade unions and collective bargaining (Kelly 1996: 88-92). Kelly concludes - not unreasonably - from such aggregate trends that the outlook for partnership in the UK is bleak, and that unions would be better served by the adoption of more militant postures in relations with employers. The second strand of Kelly's critique focuses on an assessment of the features and outcomes of the strategy of trade union 'moderation', which he believes to be at the core of workplace partnership. Kelly's original choice of a paradigm case is curiously Nissan's facility in Sunderland. From this case a general model of 'partnership' is developed, based on a template of single-union recognition agreements, full flexibility arrangements and company-sponsored and controlled works councils. Such a test of 'partnership' cannot be taken as an adequate examination of the concept. Arguably such instances of union moderation fall outside the remit of partnership altogether and are best conceived as straightforward cases of employer-dominated modes of cooperation based on pseudo-participation. Later research by Kelly (1999; 2004) does set out to examine a number of other cases of partnership in the UK. The findings are again on the whole bleak, with 'partnership' companies threatening to derecognize unions, or engaging in derecognition, as well as failing to honour collective agreements which pledged to maintain employees' employment security and competitive wages. A study of 22 
partnership companies concludes that the rate of job losses is found to be higher in partnership companies than in other comparable firms. Wage rises are variable in partnership companies as contrasted with other comparable firms. Trends in union density and influence also vary among partnership firms (Kelly 2004). Again, however, the case needs to be made that the companies chosen for examination by Kelly appear to be skewed towards instances where partnerships emerged from companies in extremis, or forced to implement major restructuring programmes, and include few instances where partnership arrangements emerged in less turbulent commercial circumstances; or were jointly designed by employers and unions and embraced multi-level and multi-stranded forms of participation and involvement closer to what Kelly himself describes as partnership based on 'labour parity' (Kelly 2004). In such cases, Kelly believes that a more even balance of power between employers and unions, higher levels of union organization and security and dependence by employers on union co-operation may lead to different outcomes and a higher probability of mutual gains, including gains for unions (Kelly 2004).

Michael Terry (2003a and b) underscores Kelly's analysis with respect to the balance of advantage in partnership arrangements commonly favouring employers. Terry's resulting emphasis on the need for a legislative basis for partnership to bring about a more even balance of power between employers, employees and unions provides a bridge between Kelly and Wolfgang Streeck. Wolfgang Streeck's arguments against the effectiveness and viability of 'voluntary' forms of union-management co-operation are set against his wider corpus of writings on German works councils and co-determination (Streeck 1992; 1994; 1995). In contrast to works councils, voluntary partnership arrangements are seen to be inherently unstable and unlikely to prosper in the long term. Streeck's objections to voluntary partnership are based, first, on a deep asymmetry of power between management and organized labour. Second, union interests are seen to be accorded legitimacy by management only to the extent that they serve particular market functions. Third, for Streeck the only way unions can ensure continued influence over management actions in voluntary partnership arrangements is by, as he puts it, maintaining 'good behaviour' (Streeck 1992: 326). Thus, the key feature of Streeck's critique is that 'hard' institutional constraints of the kind provided by the German labour code, are necessary conditions if anything other than a parody of strong and effective co-operative industrial relations is to emerge.

In a later work, a softening in Streeck's position is discernible with the recognition that new forms of management-union co-operation in some European countries, most notably in Italy and Sweden, had developed outside pre-existing works councils and beyond the remit of legislation and centralized collective agreements (Streeck 1995). It is to the voluntary nature of such arrangements, then, that Streeck draws our attention. The reasons why such voluntary forms of co-operation developed are explained in terms of wider institutional conditions in which unions 'were firmly established in 
their positions' and 'felt safe enough to offer themselves as agents of workplace participation without fear of losing their representational status and capacity' (Streeck 1995: 329). While Streeck (1995: 330) recognizes that these voluntary forms of co-operation are of no small significance, he nevertheless retains his earlier doubts and reservations concerning the limitations of 'voluntarism'.

Streeck's argument rests on the assumption that legislation supporting employee voice is a necessary basis for securing effective and long-lasting forms of union-management co-operation. The issue is presented in terms of a simple dichotomy between stable arrangements, backed by strong legal rights, on the German model, and voluntary and thus less effective and unstable arrangements. Even a priori, this position seems too crude. In the light of empirical research on German works councils alone (cf. Royle 1998; Thelen 1991), it appears more convincing to think in terms of a continuum of effectiveness and stability along which co-operative arrangements might fall: marked at one extreme by legally regulated and institutionally rooted cooperation and neither legally regulated nor institutionally rooted arrangements at the other extreme. Streeck's admission, reluctant though it might be, that other institutional forces and sets of circumstances may induce unions and management to co-operate provides a bridge to a recurring theme in the theoretical literature advocating partnership arrangements. Advocates argue that the viability of workplace partnership is dependent upon the presence of supportive HR practices, together with the promotion of 'strategic integration' between HR/IR concerns and strategic management. The question then arises as to whether the existence of such practices and constraints might come to act as 'functional equivalents' to the powers of the legal code which underpins German co-operative arrangements. If this is indeed the case - and such a matter must be considered empirically - voluntary partnership arrangements may be capable of operating effectively and durably for both management and unions where conditions are conducive.

Given the main issues in contention in the theoretical dispute between the advocates and critics, in examining the empirical data below, we focus on the following set of research questions.

1 Given that partnership in Aer Rianta involved, as discussed in Chapter 3 , a quality-focused competitive strategy, commitment to a bundle of human resource and industrial relations practices promoting mutual gains, strong unions and distinct collective bargaining channels, did unions feel sufficiently secure and confident to represent workers' interests in partnership forums? Further, were they unimpeded by concerns about incorporation, potential damage to terms and conditions, or doubts regarding management's bona fides and the durability of partnership?

2 How did union officers and activists assess the consequences of partnership? Did partnership operate to the advantage of unions and extend 


\section{Trade unions}

their reach into management decision-making, or were unions co-opted and disadvantaged through their involvement in partnership?

3 Was the operation of partnership associated with union members holding positive or negative perceptions of union effectiveness and influence?

4 To the degree that union members may have been differentially involved in, or affected by, partnership arrangements, did a positive or negative association exist between variations in members' involvement in partnership, their attitudes to union influence and effectiveness and their level of commitment to unions?

5 Where a union opposed partnership, as arose in Aer Rianta in the case of the middle managers' union, IAESA, was opposition associated with higher levels of commitment from members, or with lower levels?

\section{Relations between officials, shop stewards, activists and members}

Cross-cutting the debate between advocates and critics is a second prominent debate focused on the effects of union involvement in workplace partnership on relations between full-time union officials (FTOs) and senior shop stewards and rank-and-file trade union activists and members. Kochan (1995) hails the case of partnership at GM's Saturn plant as a learning template. Although the Saturn local is explicitly identified as a 'new American style of enterprise union', Kochan is keenly aware that the workplace union's long-run success - and that of workplace partnership - is dependent on an 'affiliation with a national [union] organisation that can provide the right type of resources and leadership' (Kochan and Osterman 1994: 151, 163) and support when confronted by pressures to compete by driving down wages and other labour standards (Rubinstein and Kochan 2001). Nonetheless, it is clear where the emphasis is to lie: 'unions of the future may need to be highly autonomous and decentralized in order to be close to their members'. Thus an important thrust of Kochan's argument is that, for partnership to prosper, national union officers must loosen their control over local unions' operations and permit local representatives more discretion in their dealings with employers. Rubinstein and Kochan (2001) are equally awake to the danger nonetheless of the local union organization becoming centralized and isolated from the membership. To guard against this, they place considerable emphasis on leadership accountability, the establishment of dense communication networks and the preservation of competitive elections to representative positions.

Although John Kelly, like critics of partnership more generally, has given less explicit treatment than have advocates to the implications of partnership for trade union organization and intra-union relations, the following arguments can be discerned. For Kelly (1999), it would seem that the cooptation of unions is led by FTOs beguiled by management's promise of an 
increased say in decision-making. In turn, FTOs are seen to assume the 'managerial' task of demobilizing rank-and-file resistance. In effect, union organization becomes hierarchical and decision-making centralized around a small privileged group. Thus, with management sponsorship, FTOs develop separate 'institutional interests' from the membership.

A striking feature of the literature to date is the paucity of empirical studies that have examined the consequences of partnership for intra-union relations (Taylor and Ramsay 1998: 118; Rubinstein 2001). Nonetheless, a small number of in-depth case studies of partnership initiatives exist and provide important clues as to the conditions that generate particular patterns of intra-union relations

These case studies point to partnership being associated with significant intra-union tensions, but the implications for activists' influence and the future viability of partnership vary significantly between the different organizations studied. Partnerships at Saskatoon Chemicals (Clarke and Haiven 1999) and at United Distillers (UD) and Allied Distillers Limited (ADL) (Marks et al. 1998) emerged against similar backgrounds: brownfield locations, significant union strength and adversarial industrial relations. The achievements of partnership at Saskatoon Chemicals were, in the authors' judgement, quite extraordinary, both in respect of the inclusion of union representatives in joint governance arrangements and of the gains won for employees (Clarke and Haiven 1999: 178, 188). Nevertheless, considerable tensions existed within the union as to the manner in which decisionmaking influence had become concentrated around a small elite and the accountability of officers to the membership. These tensions spilt over into intra-union conflict and factionalism, and the initiative floundered.

In contrast to Saskatoon, partnerships at UD and ADL were imposed upon wary union representatives and a sceptical workforce. Management set about privileging the role and influence of FTOs who, in turn, were given the task of winning over the support and co-operation of shop stewards and the membership. The consequences for union representation were at once beneficial and detrimental. FTOs were the main beneficiaries as industrial relations considerations came to form an important element in business strategy formulation. At plant and shopfloor level, however, the outcomes were not so benign. In some UD plants the number of stewards was reduced and steward management committees were replaced by plant-wide and sectional consultative committees, comprised of union and non-union members. As FTOs redirected their energies towards company-level decision-making, a representative vacuum was left in their wake. Shop stewards were not only poorly prepared to respond to the decentralization of decision-making authority within management structures, but they were also poorly equipped to counter line management's newly exhibited assertiveness.

A third well-reported case, that at Saturn, is a greenfield site facility. In contrast to the other case-study companies, partnership was introduced 


\section{Trade unions}

without any undue pressure from management. From the outset, GM and UAW representatives set about jointly developing a form of organizational governance based on stakeholding principles. Nonetheless, similar difficulties emerged in respect of union decision-making and the legitimacy it enjoyed amongst the membership. Management and union officers responded by deepening and extending the partnership process: developing so-called 'on-line co-management by the union'. This was a key factor in winning employees' and representatives' endorsement for management-union cooperation (Rubinstein 2001; Rubinstein and Kochan 2001: chs. 2 and 4). Critically, then, and in contrast to arrangements at UD and ADL, the conduct of partnership was decentralized to the level of production modules, where considerable influence was permitted to workplace union activists.

There were other tensions in respect of union organization and representative capacity. First, there were allegations that the selection of worker representatives to line positions by management and union leaders had created 'a new privileged class' within the union, which had become distant and removed from the membership (Rubinstein 2001: 182, 188). Eventually these tensions gave way to the ousting of the union's leading officers. The new leadership moved quickly to restore membership confidence in the partnership initiative, and the union's role therein, by increasing shopfloor input to the selection of worker representatives. Second, tensions existed between workplace representatives and senior national UAW officers. The latter exhibited considerable ambivalence towards the Saturn project: principally as some of its innovations departed from, and in time, it was feared, might come to undermine, the system of national standards and pattern bargaining and unleash a whipsawing dynamic within the wider car industry. The local union's authority to initiate changes to Saturn's contract without first having the UAW's approval was revoked. Saturn, then, is a story of the creation and dismantling of a representative elite which had become sandwiched between an alienated rank and file and a national leadership feeling that it had lost control over a wayward offspring. It bears emphasis, however, that the membership's suspicions concerning their employee representatives did not spill over into disillusionment with partnership or indeed with trade unionism.

In the case studies examined, the centralization of decision-making gave rise to a series of intra-union tensions, in most cases of a grave nature, but which in turn had different consequences for the role and influence of activists, union cohesion and for the future viability of partnership. As to the mechanisms which link the centralization of union influence with discontent among workplace activists, the following warrant particular emphasis. First, there is the manner in which change is introduced and its consequences for the representative capacity of stewards. Consider again the example of UD and ADL. Partnership was imposed on the workplace union (albeit with the participation of FTOs) and the structures of workplace governance and consultation were significantly reshaped. Shop stewards lost their strategic 
coherence and became disoriented. And while workers acquiesced to partnership, there was considerable disquiet and concern as to management's motivations. Their perceptions of partnership and its benefits were thus cast in ambiguity and doubt. Second, there is the issue of participation. In the cases examined here, employees' and activists' fears were aggravated where there was little attempt by union officers to engage in consultation. Saskatoon and Saturn were found to reveal contrasting tales here. Third, whether such tensions or discontent result in intra-union conflict and resistance to partnership, would seem to depend on the perceived possibility of maintaining traditional bargaining postures and the perception of a firm's competitive position in the marketplace. The differences between UD and ADL and Saturn and Saskatoon could not be more marked. In the former two companies, there seemed little alternative but to work with management's proposals, whereas in Saskatoon and Saturn, where pro- and anti-partnership factions developed, the option of resistance and a resort to traditional bargaining postures appeared feasible.

From this review of the positions in the debate regarding the effects of partnership on intra-union relations, we pose a second series of questions that will guide our analysis below of data from Aer Rianta.

6 Did partnership again in this case involve centralized power and control within participating unions and did this result in a redistribution of power away from shop stewards and activists?

7 What were the consequences for intra-union relations and did conflict and factionalism result?

8 Did partnership result in the emergence of an alienated and disaffected cadre of shop stewards and activists, characterized by distinctive and negative attitudes towards their unions' level of power and influence and towards $\mathrm{CP}$ ?

\section{Trade unions' assessments of the effects of CP}

This section begins by looking at union officials' and activists' attitudes towards CP. We turn then to examine representatives' views of the implications of partnership for the institutional position and representative capacity of unions in Aer Rianta (AR). In doing so, we begin by considering two of the research questions posed above. First, we consider whether on balance representatives believed unions at AR were advantaged or disadvantaged by their participation in CP. Second, we look at the possible effects of perceived management ambivalence on union attitudes to partnership and its durability.

\section{Proponents, sceptics and opponents}

The intensive interviews conducted with union officials, shop stewards and activists during the first intensive fieldwork phase revealed three contrasting 
shades of opinion among union representatives towards CP. The "proponents' comprised in the main the small group closely connected with the development and implementation of CP. They believed partnership was operating to the benefit of unions and their members, and that union influence had been extended into new areas of organizational decision-making. The 'sceptics' were active supporters of $\mathrm{CP}$ and represented the vast majority of those interviewed. They also acknowledged that partnership had the potential to extend the reach of union influence into management decisionmaking, but they feared that it faced significant obstacles, principally that management was seen to be ambivalent and, at times, openly hostile, and that it might not succeed over the long term.

Finally, for much of the period up to the late 1990s, the main 'opponents' comprised the middle management staff association, IAESA; and at least some worker directors were opposed to the substantive proposals emerging from $\mathrm{CP}$ and to the use of $\mathrm{CP}$ to address pay and conditions, as the Compact began to engage major strategic and operational issues from the late 1990s. Partnership accorded the worker directors little formal role or status, instead establishing alternative channels of participation. IAESA's objections had focused on the manner in which the JUCG was constituted, its membership, the insistence that members of the group act in a non-representational capacity, and on the perception that IAESA had been excluded from participating in the JUCG. Once IAESA agreed to join the JUCG in January 1999 , its public posture towards CP was one of active engagement and support. IAESA representatives' views were closer, however, to the predominant sceptical pattern of other union representatives.

\section{Perceived advantages and disadvantages}

Virtually all those union officials and activists interviewed felt that CP had resulted in significant benefits for unions. Specifically, they highlighted the significant improvement that had occurred in the climate of management-union relations; the enhancement of employee and union influence at the level of work tasks, at department, business-unit and company levels; and generally stressed the increased attention management now accorded to hearing employees' views and establishing effective twoway communication channels. The following remarks from representatives highlight the ways in which partnership was seen to have advantaged unions and their members:

Traditionally management decided what the problem was: 'you're the problem, there's too many of you, we have to get rid of some of you'. Whereas the union would say, 'this manager is useless'. They would see him as the problem. So they weren't talking about the same problem at all. We insist that they start with identifying what is the problem. That is the precondition. 
This way (via the Compact) we are more likely to reach a consensus that benefits both unions and management, rather than an accommodation that benefits nobody.

As we are now involved in management decision-making the goal posts on business strategy cannot be moved.

People are now empowered on the ground to be involved in the decision-making process in their own department. That's something that never happened before.

Other attendant benefits were identified: employees' knowledge of the company's market position and competitive context was seen to have improved; workers were believed to have become more willing to contribute voluntarily to the success of the company in ways that had been absent in the past; employees' skills were seen to have been enhanced to the extent that they had acquired a greater confidence in their own abilities and were increasingly competent in participating in joint decision-making processes; and a better quality of working life was also seen to have come into being, with an assurance of good pay and employment security.

Union officials drew further sharp distinctions between the negative consequences of traditional adversarial industrial relations processes and the positive benefits of partnership. In contrast to the former, which was seen to have inhibited employees' participation in union activities, partnership was identified as having acted as a catalyst in 'radicalizing' the rank and file, encouraging union members to question and criticize union decisionmaking and thereby according them greater influence over the definition and representation of their interests. In turn, shop stewards who sought sanctuary in a lax and lazy representation of employee interests were seen to have been exposed and compelled to go beyond simple oppositional postures and to identify solutions to difficulties. Adversarialism, it was believed, had provided an easy and ready-made fall-back position for at least some shop stewards:

Some of my own shop stewards who would have been of an antagonistic and adversarial mind-set are now much better able to think things through logically and better able to identify solutions, rather than merely digging in their heels.

(senior union official)

Partnership also had the benefit of distinguishing qualitative issues from quantitative concerns. Once qualitative issues were sorted and placed in what was regarded as their 'proper place', they could then be resolved without the appendage of financial wrangles. Issues of pay and rewards could subsequently be taken up in collective bargaining, where traditional 
postures might be deployed. The important point, then, is that the institutional separation of collective bargaining from joint decision-making processes did not result in the 'decommissioning' of the power of collective bargaining, or that 'effort bargaining' had ceased. As one union representative remarked: 'Collective bargaining hasn't stopped because we are involved in participation and no one has ever suggested that it should stop. A lot more change issues, however, are being developed through participation'.

Turning to the important issue of union incorporation, the most striking aspect of officials' and activists' views was how rarely it was remarked upon. When asked, interviewees were generally bemused by the question; it was seen as an unlikely prospect. This accords with research conducted for the JUCG examining shop stewards' views at Shannon Airport. This found that the majority of stewards were 'very positive' in their response to $\mathrm{CP}$, with only one in ten believing that there was a danger of unions 'colluding with management' and of 'shooting [themselves] in the foot' (Offer 1998).

That there was little concern about the risk of incorporation does not mean, however, that union officials, especially the most senior among them, were not awake to the possibility. They believed that guarantees had been secured to guard against such an eventuality, principally through the adoption of the Compact and the Requisite Arrangements. The following elements were pointed to: first, management had pledged to preserve the unions' representative position and to involve representatives in any business adjustment process; second, management was committed to competing on the basis of service quality and the provision of good and secure conditions of employment; and finally, the right to resort to traditional industrial relations processes was preserved. These provisions were seen to offer considerable comfort and security. One union official put it thus: (the Compact is a) 'well balanced document that allows us (unions) to buy into a process of change but gives a lot of protection as to how we do that'.

The perceived disadvantages of CP included the complexities and difficulties that came with the co-existence of 'old' and 'new' industrial relations processes. Certain sections of the workforce had not entered CP either because they had not agreed to work in partnership with management or they had not received the requisite training. This led to some sections of the workforce coming to define themselves as being either pro- or anti-Compact which, in some situations, was seen to have created new rivalries, usually between departmental boundaries. Union representatives, in turn, were compelled to inhabit the realms of two different forms of employee representation. The most unsettling aspect of this chameleon existence was that both proponents and opponents of CP 'had still to be brought behind the SIPTU banner', as one union official put it, and reassured that, whichever approach they sought to pursue, they would receive the necessary support from their union. The same official quipped: 'It would be very useful if one was schizophrenic in this job'. There was also the additional complication that the co-existence of two systems allowed some employees, as one union official put it, to 'manipulate' 
either process to advance claims and grievances. The length of time it took to develop and diffuse partnership structures had also made it difficult for supporters to demonstrate to sceptics and opponents that partnership could work to unions' advantage. Obviously, this difficulty was compounded by a prevailing scepticism towards management's bona fides.

The following conclusions with respect to questions 1 and 2, posed at the outset, seem warranted by the evidence. First, officials and activists were broadly positive in their assessments of partnership. Unions' institutional security was assured, their representative capacity was enhanced and their influence over the formulation of business strategy was consolidated. These provisions were sufficient to guard against union co-optation and any risk that conditions of employment might be undermined. Second, and notwithstanding this positive endorsement, union representatives remained cautious and sceptical when evaluating the future prospects of partnership. The equivocal support from management was identified as a significant obstacle. Considerable doubt remained, therefore, as to the future durability of partnership. On balance, then, the weight of evidence as presented thus far, principally that union representatives were largely in favour of partnership and could point to appreciable benefits, tilts the argument in favour of the advocates with respect to our answers to research questions 1 and 2 .

\section{Union effectiveness and bargaining power}

In this section we focus on the relationship between partnership and members' attitudes to unions, and attempt to answer research questions 3-5 posed above. Ninety-one per cent of those responding to the survey conducted in 1998-99 were trade union members. Table 7.1 examines members' views as to the effectiveness of unions in representing employees' interests and as to whether unions' influence over management had increased over the three-year period preceding the survey. A considerable spread of opinion existed as to the effectiveness of Aer Rianta unions. Only 38 per cent of all employees endorsed unions as either 'fairly good' or 'very good', and a further 23 per cent stated that they were unsure how effective unions have been. A spread of opinion was again evident on the issue of unions' bargaining influence. Only a minority of union members ( 15.3 per cent) took the view that union bargaining influence over management had increased, compared with nearly 40 per cent who believed that union bargaining influence had declined.

Overall, in answer to question 3, partnership can be said neither to have been associated in AR with a predominant view that unions had been highly effective and had increased their influence over management, or with the converse view that they were ineffective and had lost influence. Positive and negative attitudes on the former issue were almost equally divided. On the issue of changes in union influence, negative attitudes were more than twice as prevalent as positive attitudes, but were still outweighed by positive and non-committal views combined. 
Table 7.1 Attitudes to the effectiveness of unions in representing employees and to change in their bargaining influence

All union members

(\%)

$\begin{array}{lr}\text { How good have Aer Rianta unions or staff } & \\ \text { associations been in representing your interests } & \\ \text { over the last three years? } & 5.5 \\ \text { Very good } & 32.6 \\ \text { Fairly good } & 23.4 \\ \text { Unsure } & 22.3 \\ \text { Fairly bad } & 15.2 \\ \text { Very bad } & 619 \\ \text { N } & \\ \text { Over the last three years, do you think union or staff } & \\ \text { association influence over management has } & 2.0 \\ \text { Increased greatly? } & 13.3 \\ \text { Increased somewhat? } & 45.4 \\ \text { Stayed much the same? } & 18.4 \\ \text { Decreased somewhat? } & 20.8 \\ \text { Decreased greatly? } & 586 \\ \text { N } & \end{array}$

Note

Results are based on weighted data.

As outlined in Chapter 3, the penetration of partnership arrangements varied substantially across airports, departments and groups of employees. It is important therefore to examine question 4 outlined above: whether members' exposure to and involvement in partnership influenced their assessments of the situation of unions in the company, and whether it influenced their commitment to unions. In order to examine these issues, a series of scales were used to measure levels of involvement in partnership activities and to measure commitment to unions. Table A1 in the Appendix presents details of the scales used to measure varying levels of contact, familiarity with and involvement in different aspects of $\mathrm{CP}$, and displays summary and scale reliability statistics. The first scale measures variations in the level of membership of formal CP groups and committees, as well as occupancy of support roles. This scale allows for an examination of the impact on attitudes and practices of union members' involvement in the formal arrangements set in place by CP initiatives. A second scale measures variations in more general engagement with CP. This scale is heavily focused around the exchange of information, feedback and discussion concerning CP issues and concerns.

A third scale focuses on communicative involvement through the receipt of information regarding the deliberations of formal decision-making structures in the company. This scale measures the degree to which information 
on the activities of established formal aspects of company decision-making had been made available to staff - the sharing of valid information with staff being an important principle of CP. Finally, a work participation scale seeks to measure the degree to which employees experience scope for participation and autonomy at work. This is captured by sets of items describing variations in how work tasks are conducted and the character of management and supervisory styles. In a sense, this scale measures the very bedrock of CP. The various formal structures and roles established under CP and the various channels for wider engagement, discussion and feedback were all intended to be part of a systematic attempt to encourage management and employees to change the character of day-to-day work and decision-making in the company. The greater the degree to which this had been achieved, the more employees should have directly experienced the principles underlying CP in their day-to-day work. But what must here be recognized also, in the light of Chapter 3's examination of progress with respect to CP structures and arrangements, and especially the creation of regular work groups, around the time of the survey, is that variations in work participation cannot be viewed in any strict sense as a reflection solely of partnership. While CP initiatives and the philosophy underlying CP influenced people's work roles and relationships, other factors may also have been important: for example, preexisting differences between departments and areas in work organization and management style, and indeed employees' own concerns to seek autonomy in their day-to-day work.

To test the influence of experience with partnership on attitudes to union representation and bargaining influence, replies to the questions outlined in Table 7.1 were converted into two scales. The first scale measures attitudes to union effectiveness in representing members' interests. On a 1-5 scale attitudes are scored from 1, where unions are seen to be 'very bad' at representing members' interests, to 5, where they are seen to be 'very good'. A second scale measures attitudes towards changes in union bargaining power over management. Again responses are scored on a scale from 1, where union bargaining power is seen to have 'decreased greatly' to 5 , where it is seen to have 'increased greatly'. The critical issue here is whether members' attitudes are more positive the more involved they have been in partnership, as the advocates would imply, or more negative, as the critics would imply. Table 7.2 presents the results of regression models examining the association between the various facets of union members' experience of partnership and their attitudes to union representation and bargaining influence. A series of control variables is also entered into the regressions. The underlying attitudes to unions of different categories of staff are controlled through dummy variables for senior managers, middle managers and supervisors. Possible differences in attitudes by gender and age groups are also controlled through dummy variables (under 35 s versus older age groups), as are differences specific to airport locations (Cork and Shannon airports relative to Dublin). For economy the results for the control variables are not shown in the table. 


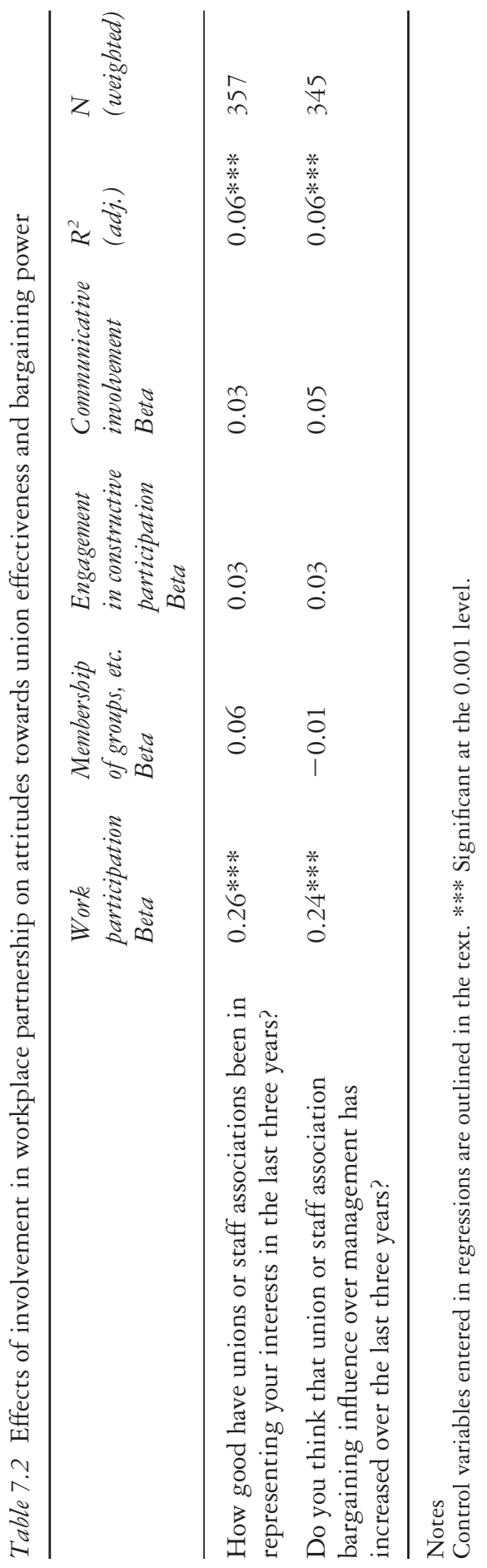


What emerges from the results in Table 7.2 is that only work participation influences the attitudes examined, and in a positive direction. The more scope union members enjoy to make decisions about the conduct of their jobs, the more positively they view union representation and the more likely they are to believe that unions have increased their bargaining power over management. The evidence thus provides modest support for the proponents of union engagement with partnership - modest because most attributes of partnership appear to have no effect and because work participation explains little of the variance in the attitudes to unions examined.

\section{Commitment to unions}

We move now to examine whether experience with partnership in AR affects members' commitment to their unions. Union commitment is measured using the 12-item version of the scale developed by Gordon et al. (1980). Individual scale items, associated descriptive statistics and scale reliability statistics, are outlined in Table A2. The composite scale is expected to comprise four underlying dimensions: 'loyalty to the union', 'belief in the union', 'responsibility to the union' and 'willingness to work for the union' (Gordon et al. 1980). The existence of these underlying dimensions was confirmed through factor analysis. Sub-scales measuring the four discrete aspects of union commitment and associated items are thus also presented in Table A2. Table 7.3 examines the effects of experiences with CP on the composite measure of union commitment and on each discrete aspect or mode of commitment. The control variables outlined above are again entered into all regressions reported. A variable measuring perceptions of the industrial relations climate, sometimes found to influence union commitment (see Deery et al. 1994), is also entered as a control variable (and is insignificant in all equations). Results for the underlying attitudes of different staff categories are presented in Table 7.3 and these will be discussed in the next section.

The results show that engagement with $\mathrm{CP}$ is positively associated with union commitment. This holds both for the composite measure of union commitment and for two of its discrete dimensions: belief in the union and willingness to work for the union.

So the evidence is that the more union members had been informed and informed themselves of participative activities and the greater the degree to which they had debated and discussed what had occurred under the rubric of $\mathrm{CP}$, the more committed they were to their unions. This finding is consistent with the claims of the advocates. Because the data are cross-sectional, however, the possibility that members more highly committed to their unions may have engaged with CP cannot be ruled out. Nor can it be ruled out that these results might be attributable to reciprocal causation. The various other modes of involvement appear to have had no effect on union commitment or on any of its discrete dimensions. Unions seem not to have 


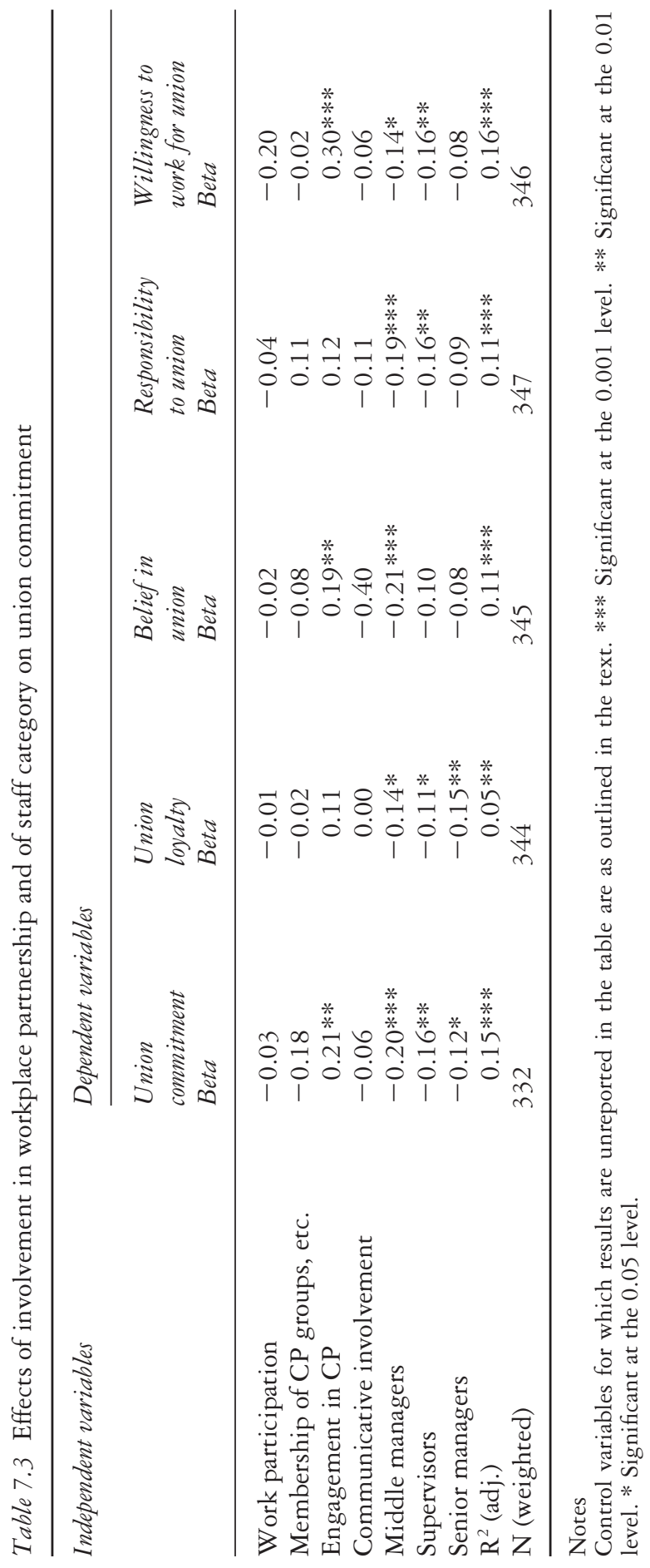


benefited in commitment terms from work participation, membership of formal partnership groups and committees, or from communicative involvement with respect to the formal decision-making structures of the company.

\section{Middle management opposition to CP and union commitment}

In this section we seek to answer research question 5 posed at the outset: whether a union that opposes partnership benefits in respect of a higher level of union commitment relative to other unions, or may be penalized by a lower level of commitment. As reported in Chapter 6, the Aer Rianta middle managers' union, IAESA, was a strong critic of CP in the period preceding the survey. We examine, therefore, whether the union's opposition to partnership was associated - as might be consistent with the claims of critics - with a higher level of commitment on the part of its members. The results outlined in Table 7.3 provide little support for this view. The table reports the relative commitment levels of middle managers, supervisors and senior managers, as compared with the 'other employees' group. All managerial and supervisory groups show lower levels of commitment to unions on some or all dimensions of commitment than non-managerial and non-supervisory employees. What stands out, however, is that middle managers show the lowest relative level of commitment of all groups. This might be attributable in part to the apparent ambivalence of IAESA members towards their union's injunction against co-operation with $\mathrm{CP}$, as reported in Chapter 6, and what seems to have sometimes been overt or covert defiance of the official union line. Whatever the explanation, the survey evidence appears inconsistent with the view that IAESA's opposition to CP (until the late 1990s) might have garnered credit among members of the union in general.

\section{Partnership, centralized decision-making and its effects}

We turn next to an examination of questions 6-8 above regarding the possible effects of union involvement in workplace partnership on intra-union relations. As in the case of the empirical studies of partnership reviewed above, CP in Aer Rianta was associated at the outset with centralized decision-making and influence, focused around a small group of FTOs, and subsequently around a small group comprised of union and management representatives. There were two main reasons why this came to pass. First, increased influence was conceded to this small group of FTOs at the behest of lay activists and other FTOs when discussions within Aer Rianta reached an impasse with respect to how the legislative provisions of the 1988 Worker Participation Act might be transposed into practice. The legislation was not prescriptive but allowed employers, unions and employees to devise their own preferred form of participation. Opinions within Aer Rianta did not divide neatly along union-management lines; views differed within both groupings. In an attempt to overcome this stalemate, a joint 
management-union body was established to consider how participation might be defined and operationalized. Critically, union activists within AR reasoned that, as a number of FTOs had prior experience of translating the legislation into practice in other state-owned companies and, as they were better informed of debates with respect to different models of participation, it would be more appropriate to hand responsibility for the discussions over to them. Subsequently, a close affinity developed between these FTOs and one senior manager and (although there were some changes in personnel on the union side) they were to become the key drivers in shaping the $\mathrm{CP}$ process. Second, as CP took shape, decision-making remained centralized around this key group within the JUCG, principally to ensure, as they reasoned, that the initiative would be protected from those opposed to its development. CP's key animators thus saw themselves performing an important protective and nurturing function.

We review here the views of FTOs and 'involved activists' as they relate to the centralized nature of decision-making within the JUCG. The other important issue of whether, as commonly reported in the literature, partnership resulted in a redistribution of power in favour of FTOs and away from activists within participating unions is also assessed. For evidence we rely on in-depth interviews and a variety of other measures and institutional indicators. To the degree that partnership involved centralized decision-making around a closed circle within the JUCG and a redistribution of power within unions more generally, the analytical task is to understand the consequences for shop stewards' and activists' support for and attitudes towards partnership and trade unionism.

As outlined above, the interviews revealed three groups with distinctive attitudes towards CP: 'proponents', 'sceptics' and 'opponents'. The proponents reported little concern with centralized decision-making and saw few problems arising with respect to relations between those actively involved in central partnership arrangements and union representatives and activists in general. We review here, therefore, the views of the sceptics and the opponents as they relate to centralized decision-making within the JUCG and unions, and the consequences for intra-union relations and for partnership.

A principal concern of the sceptics was that CP had become too closely associated with, and controlled by, a small group. Significantly, this view was shared both by activists and by those FTOs who were not part of this small union management group. As one such FTO described the situation:

The concept of partnership is exactly what we [unions] need. But I have some reservations about how it functions. The fundamental difficulty I have is that so much of it resides with the [key management and union animators]. I have to use the word 'control' rather than 'guiding'.

Critics also complained that the JUCG as an institution had been relegated to a 'talking shop'. As such it had assumed a largely ineffective role as an 
initiator and developer of policies but provided a basis for the exercise of influence by a small cadre of FTOs and managers. Otherwise, the JUCG acted largely as a secretariat for the $\mathrm{CP}$ initiative.

Frustration with centralized decision-making showed itself in a number of ways. One was the difficulty of establishing departmental autonomy over the development of work groups or departmental groups, as indicated in one of the quotations above. Another was the practice of dissuading SIGs and SGs from making firm recommendations in discussion documents. In respect, for example, of the report on the company's Change of Status, which had been prepared for the government minister responsible for Aer Rianta, a compilation of differing views was presented, without any preferred position being identified and articulated.

The outcome of the Change of Status Group was very much a wasted exercise. It was a collection of opinions which neither had any focus nor any thrust to it. Every point that was ever raised was listed and left. Once again they [the group's participants] were told what exactly they were about and they were not allowed to develop it [the report] beyond that. If an agreed position had been put to the Minister by the unions and the company, think of how much influence that would have had. It would certainly have been greater than a ... list of points.

The central figures did not dismiss the charge that they 'controlled' SIGs' and SGs' activities, but in their defence argued that this was necessary to guarantee managerial and union rights to dissent if they sought fit. Their argument centred on protecting CP: if groups were permitted a free hand, there was the danger that they and $\mathrm{CP}$ would be seen to challenge management and union powers, and to displace established industrial relations procedures. One key animator of $\mathrm{CP}$ explained it thus:

We have never asked the unions or management to give over any of their prerogatives to us. And that does a number of things. It leaves the group free to explore things in a non-threatening way because the unions and management can deny anything that comes out of it.

It was also clear from our observations of JUCG meetings that decisionmaking had indeed become centralized within the JUCG in the manner portrayed by our interviewees. First, CP's key animators acted as a 'clearing house' for all CP documents, materials and proposals; second, they closely scrutinized and sought to determine the pace of development of partnership activities in the various departments; third, they appointed CP facilitators and mentors across the three airports; fourth, they devised training programmes for activists and facilitators which were deliberately conceived as integrative devices; and finally, as indicated above, they discouraged discussion groups from prescribing preferred courses of action in their reports. 


\section{Trade unions}

Thus the concerns expressed by interviewees with the manner in which decision-making had become centralized within the JUCG parallel those identified in other investigations of workplace partnership. There are important points of contrast, however. In Aer Rianta, decision-making in respect of the development of $\mathrm{CP}$ resided within a small management-union caucus, but only a small number of FTOs formed part of this group. As a consequence, both activists and some FTOs were unhappy with the manner in which control had been exercised over CP's activities. In other studies of partnership, decision-making was also centralized but it was the preserve of FTOs and excluded shopfloor activists. This is an important difference. There are two other contrasting points which are of more significance, especially in respect of understanding the contingencies which have a bearing on explaining whether or not partnership gives rise to factionalism and intraunion conflict. First, while arrangements for the development and implementation of partnership in AR were indeed centralized around a small group, as documented above, partnership did not result in the 'centralization' of power within participating unions per se. Centralized decisionmaking within the JUCG did not lead to power being wrested away from shop stewards and activists. There was no indication from our interviews or from other sources that, prior to partnership, shop stewards and activists had exercised more influence within unions and that CP had somehow resulted in power being redistributed in favour of FTOs to the detriment of shopfloor representatives. The decision as to whether to operate 'under the Compact' or to continue with traditional adversarial approaches was taken at section level by employees and their representatives, although such decisions were then notified as a matter of form to unions' branch secretaries. Where they opted to work under partnership principles, local activists were central to the development of CP, albeit the JUCG core group continued to scrutinize and control these processes from a distance. But more importantly, CP did not result in any major dislocation in activists' roles, such that work practices or existing agreements were altered 'above their heads' in exclusive dealings between FTOs and management, as was the situation in some of the other partnership cases reported in the literature.

Another point of contrast with other studies of partnership was that, while activists and FTOs in Aer Rianta had concerns in respect of the centralized nature of decision-making within the JUCG, this did not culminate in active resistance to CP. Possible indicators of activists' displacement and resistance such as meetings to campaign against partnership, intra-union conflict, and factions opposed to partnership contesting union elections - as witnessed in other studies of partnership - were not observed in Aer Rianta.

Resistance in Aer Rianta came from two other quarters and these represent the opponents to $\mathrm{CP}$. The resistance from the middle management union, IAESA, did in part reflect an objection to centralized decisionmaking within the JUCG and to the 'summit politics' which were seen to be exclusive to other unions' representatives and senior management. But 
IAESA's decision to stand apart from and oppose partnership was rooted also in their anxieties regarding the implications of participative management for the union's members.

Within the ranks of union members and activists, some worker directors became dissatisfied with partnership. They were to voice their objections to $\mathrm{CP}$, principally that joint groups did not have a formal mandate to speak for union members, that the pre-ordained division of spheres between collective bargaining and partnership was being eroded, and also that the proposed privatization of the company did not have the full support of the workforce. Some of these issues were to achieve a greater resonance as CP began to engage with major issues of reorganization and restructuring at departmental level within Aer Rianta. They are discussed in greater depth in Chapter 10.

Thus in response to research questions 6 and 7 posed above, the following conclusions seem warranted. First, partnership in AR, as in other cases reported in the literature, did involve centralized structures and arrangements. In this sense, the development and implementation of partnership was controlled by a closed circle, in which a number of FTOs gained prominence. This was a source of some concern among other FTOs and activists. Second, although $\mathrm{CP}$ involved centralized decision-making within the JUCG, this did not result in a fundamental shift in the balance of power within unions, of the type witnessed in other studies, and involving a redistribution of power and influence in favour of FTOs at the expense of stewards and activists. Nor was any change in activists' role or influence plotted or executed de haut en bas. Finally, whatever objection FTOs and activists had towards the manner in which CP's key animators sought to control decision-making in respect of the design and implementation of partnership, this did not result in intra-union factionalism or in overt resistance to partnership.

\section{Shop stewards' attitudes to partnership}

In this section we examine levels of involvement of shop stewards and activists in $\mathrm{CP}$ and consider, as posed in research question 8 above, whether they display more negative attitudes to partnership than the rank and file, or any otherwise distinctive set of attitudes that might point towards acute disaffection.

The first approach we have adopted involves examining whether the behaviour and attitudes of shop stewards and activists reveal lower levels of involvement in partnership and more negative attitudes towards its effects than union rank-and-file members. This analysis proceeds by examining the signs and significance levels of coefficients on dummy variables for shop stewards and activists in a series of multiple regressions. The regressions incorporate a series of controls for variables that might affect involvement in partnership and attitudes towards its effects. Possible differences by staff 
category are controlled by dummy variables for senior managers, middle managers and supervisors (with other employees as the reference category). Possible differences by gender and age group are also controlled (under 35s versus older age groups). As the climate towards partnership varied across the airports, with Dublin appearing the most receptive and Cork the least receptive, airport dummy variables were also entered as controls (Cork and Shannon, with Dublin as the reference category). For economy of presentation, the results of control variables are again omitted from tables.

Of those sampled in the survey, 8.3 per cent said that they were currently shop stewards and a further 13.5 per cent said that they were 'actively involved in union affairs and business'. The involvement of shop stewards in formal CP groups and committees varied from 55.6 per cent who participated in regular work groups, to 29.5 per cent who were members of SIGs. Activists had lower levels of participation varying from 36.5 per cent (regular work groups) to 20.9 per cent (SIGs). Levels of engagement with $\mathrm{CP}$ were very high in the case of both groups. For example, 69.4 per cent of shop stewards and 70.5 per cent of activists attended CP seminars or training sessions.

Table 7.4 shows that shop stewards and activists were also highly involved in CP relative to the rank and file. This is the case with respect to participation in formal groups and committees (equation 7.4.1), as well as with respect to wider engagement in training, information exchange, discussion and debate (equation 7.4.2). Overall, there is scant evidence here that shop stewards or activists had seceded from or abandoned CP as a consequence of disaffection arising from centralized decision-making.

It is also important to examine shop stewards' and activists' attitudes to union performance under CP relative to rank-and-file members. The key issue is whether shop stewards and activists were even harsher critics of union performance under $\mathrm{CP}$ and less convinced of the effects of $\mathrm{CP}$ than members in general - pointing towards acute disaffection and alienation. This is also examined in the regressions in Table 7.4. Shop stewards emerge as more likely to believe that unions had been effective in representing their members than the body of trade union opinion (equation 7.4.4). Neither shop stewards nor activists were more positive regarding changes in union influence (equation 7.4.5). Attitudes to the effects of partnership on a series of facets of decision-making and on levels of trust between unions and management were measured by combining a series of five questions. Details of scale items and scale reliability statistics are outlined in Table A3. Both shop stewards and activists were more likely to believe that CP had beneficial effects (equation 7.4.6). The issue of whether employees' interests were better represented by $\mathrm{CP}$ is a component of the scale used to measure attitudes to the effects of CP in equation 7.4.6. As this is a key issue, however, we examine it separately and specifically in equation 7.4.7, where it emerges that activists rather than shop stewards were more likely to be of this view.

A limitation of the regression analysis is that it fails to allow for the pos- 


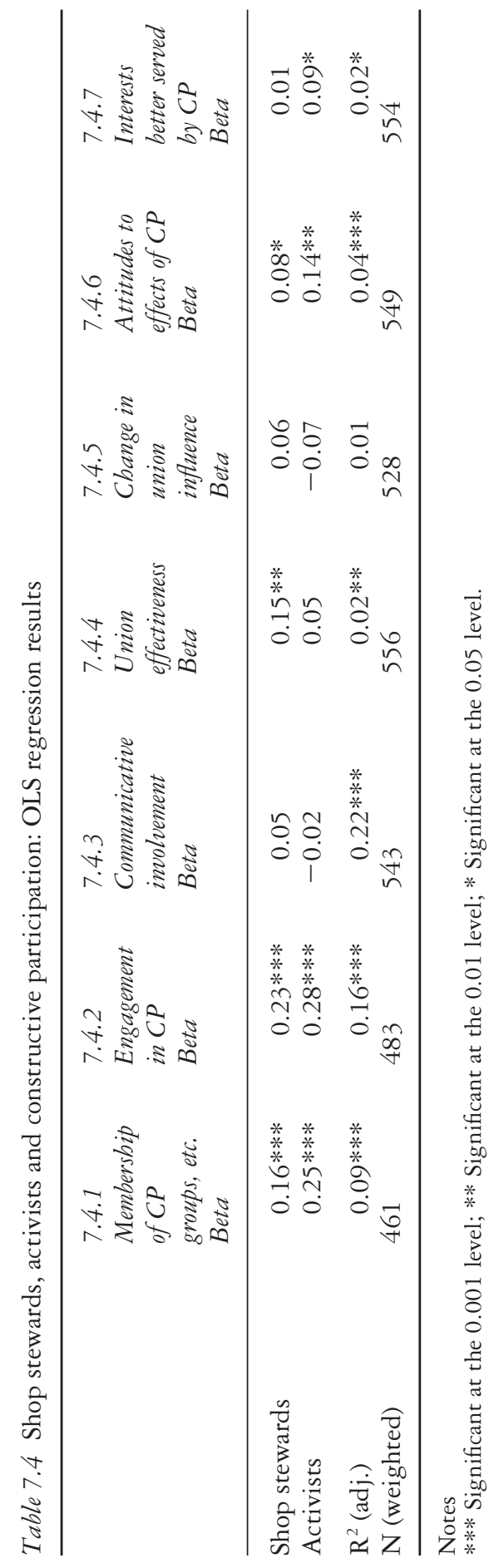




\section{Trade unions}

sibility that groups of union members may exist with distinctive attitudes to union performance and the effects of CP. If this is the case, it will be of interest to examine whether shop stewards and activists might be concentrated among such groups. For example, it might be hypothesized that groups broadly equivalent to advocates for partnership, sceptics of partnership and critics of partnership can be found among the body of union members and that shop stewards and activists might be concentrated among the second such group: less critical and disaffected than some members but still less positive and convinced than others. To test this hypothesis, a series of latent class models was fitted to the three variables measuring attitudes to union effectiveness and influence and attitudes to CP (for an examination of latent class analysis, see Hagenaars and McCutcheon 2002; for details of the software program used here see http://www.latentgold.com).

The results are detailed in Table 7.5. The best-fitting model suggests that four clusters or latent classes are identifiable. Cluster 1 comprises 87 per cent of union members who were either of the view that union influence over management had stayed the same or had decreased somewhat (scale response categories 2 and 3 combined). Cluster 2 is characterized by the view that unions are fairly good in representing members' interests and that their bargaining influence had either not changed or had increased somewhat. Cluster 3's attitude is that unions are very bad at representing their members' interests and that their bargaining influence has decreased greatly. Cluster 4, which represents only 7 per cent of union members, is characterized by the view that unions are fairly good in representing their members' interests, that it is either unclear whether their bargaining influence had changed or increased somewhat, and that CP had beneficial consequences.

The important issue for the displaced activist thesis is how shop stewards and activists are distributed across these clusters. The evidence provided by the beta coefficients for the covariates in Table 7.5 suggests that they are more likely to be in cluster 4 - the most positive overall cluster with respect to partnership and its effects - but that the result is not statistically robust. Overall, therefore, the latent class cluster analysis discounts the view that shop stewards and activists can be viewed in any meaningful sense as critics or sceptics; they are more likely to be found in the sample, if not the survey population, among those with the most positive attitudes towards the effects of partnership, with positive attitudes towards union effectiveness and with neutral to mildly positive views as to changes in union influence.

\section{Conclusions}

A series of research questions was derived from the debate between advocates and critics concerning the effects of voluntary partnership, as well as from the literature on the possible effects of partnership on intra-union relations. The first question considered whether partnership of the type implemented in Aer Rianta provided unions with a basis for active co-operation with 
Table 7.5 Attitudes to unions and to constructive participation: latent class cluster analysis results

Model fit statistics: $L^{2}=364.1 ; d f=342 ; p=0.20$ (testing that additional class(es) required for model fit).

\begin{tabular}{|c|c|c|c|c|c|}
\hline & & Cluster 1 & Cluster 2 & Cluster 3 & Cluster 4 \\
\hline Cluster size & & 0.5297 & 0.2507 & 0.1520 & 0.0675 \\
\hline \multicolumn{6}{|l|}{ Union effectiveness } \\
\hline \multirow[t]{2}{*}{ Very bad } & 1 & 0.0916 & 0.0067 & 0.6095 & 0.0004 \\
\hline & 2 & 0.3316 & 0.0751 & 0.3407 & 0.0109 \\
\hline \multirow[t]{2}{*}{ Unsure } & 3 & 0.2682 & 0.1875 & 0.0426 & 0.0726 \\
\hline & 4 & 0.2942 & 0.6350 & 0.0072 & 0.6540 \\
\hline Very good & 5 & 0.0144 & 0.0956 & 0.0001 & 0.2621 \\
\hline \multicolumn{6}{|l|}{ Change in union influence } \\
\hline \multirow[t]{2}{*}{ Decreased greatly } & 1 & 0.1095 & 0.0004 & 0.9805 & 0.0007 \\
\hline & 2 & 0.3683 & 0.0239 & 0.0194 & 0.0322 \\
\hline \multirow[t]{2}{*}{ Stayed much the same } & 3 & 0.5018 & 0.5459 & 0.0002 & 0.5964 \\
\hline & 4 & 0.0202 & 0.3687 & 0.0000 & 0.3268 \\
\hline Increased greatly & 5 & 0.0002 & 0.0610 & 0.0000 & 0.0439 \\
\hline \multicolumn{6}{|l|}{ Attitudes to effects of $C P^{1}$} \\
\hline \multirow[t]{2}{*}{ Strongly disagree/disagree } & 1 & 0.2491 & 0.1102 & 0.4344 & 0.0002 \\
\hline & 2 & 0.2062 & 0.1405 & 0.2309 & 0.0017 \\
\hline \multirow[t]{2}{*}{ Disagree/can't decide } & 3 & 0.1843 & 0.1712 & 0.1584 & 0.0076 \\
\hline & 4 & 0.2271 & 0.2880 & 0.1344 & 0.0620 \\
\hline \multirow[t]{2}{*}{ Agree } & 5 & 0.1283 & 0.2901 & 0.1419 & 0.9285 \\
\hline & & Beta & Beta & Beta & Beta \\
\hline \multicolumn{6}{|l|}{ Cluster covariates: } \\
\hline \multirow{2}{*}{\multicolumn{2}{|c|}{ Shop stewards ${ }^{2}$}} & -0.9585 & -1.4786 & -1.2840 & 3.7211 \\
\hline & Activists $^{3}$ & -0.4699 & -3.9330 & -1.1842 & 4.5871 \\
\hline
\end{tabular}

Notes

1 For ease of estimation and presentation, the categories of 5-25 scale were reduced to a 5category scale. The resulting descriptive anchors in the table are broadly equivalent to the points ranges involved in the non-grouped categories and reveal a skew towards the lower points ranges, as discussed in the text of the paper.

2 Difference in distribution across clusters: $p=0.51$.

3 Difference in distribution across clusters: $p=0.29$.

management without fears of incorporation, potential damage to terms and conditions of employment, management's bona fides and the durability of partnership. The evidence suggests that the absence of a legislative framework had not precluded the emergence and development of a significant voluntary partnership initiative and that unions' strength and institutional security were, to a significant degree, the key to their willingness to proceed along partnership lines. Unions actively engaged in partnership on several 


\section{Trade unions}

major strategic issues and a range of operational issues. There was little evident fear of incorporation or damage to terms and conditions. Doubts regarding management's bona fides and commitment did not impair the cooperation proferred in any discernible manner. With regard to the second question, which concerned the balance of advantage for unions in partnership arrangements, the evidence suggests that union officials and activists closely involved with partnership assessed its effects on unions' representative capacity and power in positive terms. Considerable benefits accrued: unions' institutional security was guaranteed, unions' organization and cohesion had strengthened; the frontier of worker and union influence was extended into new areas of organizational decision-making; and employees' skills and the quality of their working lives were enhanced. At the same time, collective bargaining had not been displaced, but remained an indispensable adjunct to the development of partnership. Nonetheless, union representatives were aware of the difficulties faced and the tensions generated and harboured continuing doubts regarding management's commitment to partnership and its long-term durability.

Question 3 considered the relationship between unions' involvement in partnership and union members' attitudes to union effectiveness and power. The survey results are neither consistent in a straightforward way with the hopes of the advocates nor with the fears of the critics. Partnership had clearly not proved to be transformative in its overall effects on attitudes in either a positive or negative direction. Positive and negative attitudes towards union effectiveness and influence were equally pronounced. That such a spread of opinion existed probably reflected to some degree the uneven and contested reach of partnership structures and initiatives across different categories of staff and across the three airports.

Interest then turned to question 4 regarding the effects of differential levels of involvement in partnership on members' attitudes to unions. Notwithstanding the conventional reservations regarding the interpretation of cause-and-effect relationships in cross-sectional data, the more workers had engaged with certain aspects of partnership the more positively disposed they were towards unions' effectiveness and the more committed they were to their unions. But their experience of other features of partnership appeared to have had no effect on members' perception and assessment of union influence or rank-and-file commitment to unions. In answer to the final question regarding whether opposition to partnership might reward unions, IAESA's decision to stand apart from and oppose partnership until the late 1990s appears to have garnered the union little credit in the eyes of its members, judged in terms of relative levels of union commitment among middle managers.

At the same time, aspects of the functioning of partnership illustrate some of the concerns expressed by the critics and raise the issue of the longterm survival of CP. Management ambivalence and opposition, as reported in earlier chapters, limited the spread of partnership in Aer Rianta and con- 
ditioned the areas or issues around which it had taken root. Overlying unions' positive responses to partnership was a persistent concern as to whether it would prosper or survive in the face of management attitudes.

In the literature, both advocates and critics of union involvement in workplace partnership present a series of theoretical arguments regarding the potential effects of centralization under partnership arrangements. The most serious effect identified concerns such as the likely displacement of shop stewards and activists resulting in factionalism and conflict within unions. A number of case studies of partnership have confirmed the existence of a series of tensions or conflicts, of varying degrees of seriousness for union cohesion. These arise from the negotiation of 'peak-level' agreements on the shape and import of partnership between FTOs and senior management, and from a centralization of union power under partnership around 'elite' groups.

The issue of centralization and its effects was rehearsed in in-depth interviews with FTOs and activists in AR. Union activists and some officials expressed concerns over the manner in which partnership was associated with centralized decision-making around a small group of union and management representatives. But these reservations apart, shop stewards and activists participated in and supported CP activities. The attitudes of shop stewards and activists did not reveal a hostile or alienated grouping within the ranks of union membership. If anything, workplace representatives appeared more positive in their views than the rank and file. The sternest challenge to partnership in Aer Rianta was to come not from displaced, disaffected and disempowered activists, but from among another group of worker representatives, the worker directors, operating at the apex of decision-making structures in the organization. Critically, then, while some FTOs, shop stewards and activists might have had reservations and concerns over the manner in which a small group of management and union representatives sought to steer and control decision-making in regard to the implementation of $\mathrm{CP}$, they were not sufficiently critical or opposed to move to obstruct the development of partnership, or to damage the standing of unions.

Among the contingencies that distinguish Aer Rianta from other cases reported in the literature and that may also cast light on differences between the reported cases, the following appear to merit emphasis. First, partnership in Aer Rianta originated in a joint union-management commitment to building a new type of industrial relations consistent with the principles of CP. FTOs were permitted to explore such a new model and the resulting partnership arrangements were not seen to have been imposed under duress. No displacement of traditional shop steward or activist roles and representative arrangements occurred and established collective bargaining procedures and processes remained in place in parallel with partnership arrangements. Critically, partnership in Aer Rianta did not involve, as in other cases, a redistribution of power towards FTOs at the expense of 
shopfloor representatives. That this had not occurred would seem to have been an important factor in explaining the absence of opposition and the relatively positive orientation among shopfloor representatives towards partnership. Shop stewards, too, were encouraged to engage with partnership initiatives at multiple levels and training was provided on the union side to cover the new negotiating and representative skills required by CP. Many of these features seem to have been absent in the UD and ADL cases and at Saskatoon Chemicals, where serious intra-union conflict arose.

Second, the context of the partnership initiative in Aer Rianta, as in Saturn, was positive, with joint commitment to partnership as a new model of industrial relations and joint design of partnership arrangements. What distinguishes Saturn from Aer Rianta, however, was the unique radicalism of the former, which entailed the near complete encoding of partnership into mainstream organizational structures and into decision-making processes at all levels. This required intensive involvement by shop stewards and activists and effectively left them with only one model of representation and trade unionism. The partnership initiative in Aer Rianta was, as has been outlined, more variable in its penetration of mainstream decision processes and co-existed with established industrial relations structures. Shop stewards could in this sense 'ride either horse' or even both in their dealings with management. This set of contingencies at Aer Rianta, we would argue, involving less disturbance to traditional roles and structures than observed in UD, ADL or Saskatoon Chemicals, and less radicalism in partnership arrangements than at the unique Saturn experiment, account in major degree for the findings reported in this chapter. The major import of the findings reported here is that the displaced-activist thesis cannot be sustained as a valid generalization with respect to the functioning of partnership. 


\section{Employee attitudes and behaviour}

The effects of voluntary partnership arrangements on attitudes and behaviour at work have yet to be studied to any significant degree. The effects of different aspects of CP on work attitudes and behaviour will be examined systematically in this chapter. The next chapter will examine whether partnership in Aer Rianta led to the emergence of dual commitment. As discussed in Chapter 1, the recent literature on partnership reflects a longrunning interest in the more general theme of the impact of participative arrangements and work reorganization on employees, and the relevant literature on participative arrangements and teamwork in general will first be examined in the next three sections before key issues arising from the more recent literature on the effects of partnership are highlighted. The rest of the chapter will examine the effects of $\mathrm{CP}$ on work-related attitudes and behaviour, as revealed in the survey conducted during 1998-99, as well as in two earlier surveys conducted in association with preparation for the implementation of partnership in Aer Rianta.

\section{Interest in participation}

Research generally confirms that significant numbers of employees wish to exercise a greater say over decisions affecting their jobs and working lives (for reviews of relevant research, cf. Wall and Lischeron 1977; IDE 1981; Drago and Wooden 1991). Employees value good pay and conditions and employment security, but they also value the opportunity to use their abilities, good relations with supervisors and jobs that allow them to use their initiative. Moreover, these work attributes appear to be becoming more important to employees over time, as well as good pay and security (Gallie and White 1993: 13-14). A study of employee attitudes in Saturn and in Chrysler's North Jefferson plants also shows a positive demand for participative arrangements in two plants combining team production with autonomous working arrangements and union involvement in management decision-making. Shaiken et al. (1997: 29-35) interviewed 120 workers split evenly across both plants. They found that workers rated both plants highly, particularly when compared with plants where they had previously worked. 
Workers reported liking their level of involvement and participation in decision-making most about working in the plants.

Some theories of long-running change in employee priorities in advanced economies have posited a 'culture shift', involving, in the world of work, a more emphatic concern for autonomy and 'self-actualization' or the pursuit of challenge and development (Kanter 1978; Rose 1989; Inglehart 1990). This trend has been generalized to trade union members by US commentators (cf. Heckscher 1988). Some commentators have sought to link rising skill with employees' growing propensity to seek greater influence in the workplace, as well as pointing to the negative consequences for commitment and performance if traditional control strategies fail to change in the light of changing employee priorities (Walton 1985; Rose 1989; Gallie et al. 1998).

Reviewing the research literature on employees' interest in involvement and participation, Marchington aptly comments that: 'Employees are attracted to the general concept of involvement and participation; indeed it would be remarkable if they were not, given that the alternative is to argue for autocratic and non-communicative management styles!' (1995: 290-1).

It has been observed that surveys reveal employees as being more interested in a direct say in matters affecting their own work domain (their job, work group, department, etc.) than in joint decision-making powers with management (Blumberg 1968; Wall and Lischeron 1977; Marchington 1995: 291). This position warrants caution, however, for five reasons. First, surveys of employee involvement have seldom been conducted in partnership contexts where multi-level channels of influence are in operation, so reliable data on the priority that employees accord different channels or levels of influence in such contexts have yet to be obtained. Second, employees in practice enjoy least influence over wider aspects of company decision-making (Gallie and White 1993; Gallie et al. 1998: ch. 4; Cully et al. 1999: 151-3). In consequence, they have less experience of the ways in which such influence might be exercised; the possible effects of influence over company decision-making and the implications for their own interests (Drago and Wooden 1991; Wilpert 1998: 59-60). Third, studies commonly report that employees do indeed express interest in more scope for participation in high-level or long-term decisions, as well as in work-based decisions (Wall and Lischeron 1977; IDE 1981; Freeman and Rogers 1999; ICTU 1998; 2001). Some studies report that employees have a preference for forms of involvement based on co-operative relations with management, or based explicitly on partnership (Freeman and Rogers 1999: ch. 3; ICTU 2001). Fourth, employees may at once seek wider involvement in organizational governance while being critical of the degree to which available channels actually allow them to have any meaningful influence, or possibly critical of the manner in which influence can be exercised through existing channels. Thus, the large-scale employee attitude survey undertaken in the UK in 1992 by Gallie and his colleagues shows that, in the minority of workplaces where works councils exist, employees rarely saw them as having significant 
influence. At the same time, the same survey revealed very substantial levels of dissatisfaction with existing levels of participation in organizational change - suggesting a desire for influence that goes well beyond immediate issues affecting the job (Gallie and White 1993: 39; Gallie et al. 1998: 103-4). Fifth, both theory and evidence suggest that employees' attitudes and behaviour may be most strongly influenced by forms of participation and involvement that combine direct and indirect channels or forums. Empirical studies undertaken during the 1970s concluded that direct and indirect participation should be seen as complementary and that the most effective forms of participation were likely to combine both approaches (IDE 1981: 328-9; Wall and Lischeron 1977: 150). This theme was carried forward into the theoretical and empirical partnership literature (Cutcher-Gershenfeld and Verma 1994; Guest and Peccei 2001).

\section{Effects of participation}

In the late 1960s, a classic review of international experiences with various forms of worker participation concluded that they were highly positive in their impact on attitudes and performance (Blumberg 1968). During the 1970s and 1980s, greater scepticism was apparent, as more careful reviews were undertaken of the claims of earlier studies and their supporting methodologies (Wall and Lischeron 1977). The mammoth study of industrial democracy in 134 establishments in 11 European countries and Israel, undertaken during the 1970s, nevertheless presented a broadly positive picture of the relationship between individual-level involvement, representative involvement and worker attitudes (IDE 1981). Data from a sample of nearly 8,000 employees suggested that variations in direct participation at the individual level were associated with variations in individual satisfaction with work and the company (IDE 1981: ch. 8).

Survey-based studies undertaken internationally during the 1990s indicated that employee involvement in decision-making was generally associated with higher levels of commitment and more positive attitudes towards the employer and industrial relations. Lincoln and Kalleberg (1990) report evidence for the US and Japan based on large samples of employees in plants in a range of manufacturing industries. Appelbaum et al. (2000) also report results for the US based on large samples of employees in plants in the steel, clothing and medical electronics industries. Lincoln and Kalleberg's surveys show that a number of features of task participation have positive and substantively significant effects on attitudes. 'Job complexity', levels of 'job autonomy', and 'intrinsic rewards' from work (mainly involving 'meaningful' and 'challenging' work) have positive effects on organizational commitment and job satisfaction in both the US and Japan (Lincoln and Kalleberg 1990: ch. 4). Quality-circle membership is also associated with higher organizational commitment in both countries (Lincoln and Kalleberg 1990: 121-2). Lincoln and Kalleberg summarize their results in unequivocal terms: 
Taken as a whole, the findings suggest that organizational designs and management practices which engender 'responsible autonomy' ... as well as participation, integration, careers and intrinsic rewards foster loyalty and diminish alienation in a workforce.

Freeman and Roger's surveys of employees in the US found that participants in employee involvement programmes reported making more frequent suggestions to management and that management was more likely to act on these. The same study showed that a majority of participants in employee involvement programmes believed that such programmes raised productivity (Freeman and Rogers 1999: 103-5).

Appelbaum and her colleagues' research (2000) established that employee experiences of various forms of involvement and participation in US manufacturing have been positive in the main. In their survey of 4,000 employees, variations in employees' involvement in 'high performance work systems' (HPWSs) are shown to have positive effects on levels of trust in management, intrinsic returns from work, job satisfaction and organizational commitment (Appelbaum et al. 2000: ch. 9). While the detailed pattern of findings with respect to the effects of discrete dimensions of employees' 'opportunity to participate' differs across the industries studied, in general the degree of autonomy over task-level decisions emerges as the most significant and robust influence on employee attitudes. Levels of stress were also found to be inversely related to employees' opportunities to participate (Appelbaum et al. 2000: 198). Again Appelbaum et al. interpret their results as providing a strong endorsement of participative forms of work organization:

Taken as a whole, our results suggest that the core characteristics of HPWSs - having autonomy over task-level decision making, membership in self-directed production and off-line teams and communication with people outside the work group - generally enhance workers' levels of organizational commitment and job satisfaction.

(Appelbaum et al. 2000: 201)

Gallie et al. (1998: chs 4 and 9) found that variations in levels of direct or task participation were associated with more positive attitudes to change; with perceptions that the organization was operating effectively; with positive attitudes to the quality of management-union relations; and with levels of organizational commitment. Levels of 'communicative involvement' comprising the issuing of news of what was happening in the organization, the holding of meetings where such information was imparted and where employees could express their views - were also positively related to perceptions of organizational effectiveness, the quality of management-union relations and organizational commitment. In contrast, indirect representation 
through works councils was found to have had no consistent positive effects on employee attitudes (Gallie et al. 1998: 112-13, 115-16, 253).

\section{Work reorganization and teamwork}

Commentators who advocate 'empowerment' look upon management motivations for introducing participative schemes as congruent with employees' interest in having a greater say over decisions which affect their daily working lives. A series of imperatives, most emanating from the market place, is commonly identified as having compelled employers to consider granting employees greater participation in their work in recent decades. This has led in turn to a number of 'up-beat' accounts, with the declaration that the nature of work and employment regulation had been, or was about to be, transformed. The sharpest presentation of this transformation thesis is Walton's (1985) famous claim that there had been a shift from the 'management of control' to the 'management of commitment'. Participation, principally through teamworking, was seen to have a number of advantages for management. It would lead to lower labour costs by reducing performance-monitoring costs, flattening hierarchical structures, and tapping employees' discretionary efforts and tacit knowledge. Workers were also seen to benefit through the elimination of routinized, boring jobs. Greater job satisfaction would also flow from increased training, enhanced skills and greater autonomy. In the workplace partnership literature, teams are also accredited with considerable influence in helping to create industrial harmony by replacing adversarial forms of 'job control' and work organization (Kochan et al. 1986).

These claims, as well as their managerialist bias, have become the focus of much criticism (cf. Godard and Delaney 2000; Ramsay et al. 2000; Webb 1996). While most commentators are now agreed that the scenario portrayed by those who espoused an 'empowerment' perspective on teamwork is deeply flawed, there is still some considerable debate and disagreement as to what constitutes a more accurate portrayal of the nature and consequences of teamworking. A critical perspective arguing that work reorganization has resulted merely in intensifying work and increasing the exploitation of employees has enjoyed considerable popularity. The consequences of the introduction of new work structures are here seen to be detrimental to employees' welfare, resulting in job losses and effort intensification (Sewell and Wilkinson 1992; Sewell 1998). Hyman and Mason (1995: 191, 193) in their review of employee involvement initiatives argue that: 'basically and critically, empowerment becomes a euphemism for work intensification' and that similar practices are being 'used to disguise workers' growing occupational impoverishment'. In this sense, it is claimed, management's motives are the same as they have always been; all that has changed is the means by which they are pursued. Few benefits are seen to accrue to workers.

The difficulty many observers have with the 'exploitation' thesis is that it 


\section{Employee attitudes and behaviour}

overstates the degree to which management is able, or indeed would wish, to use teamworking more fully to exploit workers. Such determinism is in turn matched by a view of workers who are seen to be readily passive and malleable in the face of new management ideas and, as argued by Barker (1993: 1999), impotent in the face of worker indoctrination (cf. Hales 2000; McCabe 2000; Geary 2003). The fundamental failing of the 'exploitation' perspective is that, by simply inverting the optimism of the empowerment thesis, it ironically shares with it the belief that new work practices actually achieve their stated objectives (Edwards 2001).

Most accounts of teamworking and other employee involvement initiatives now report a more complex picture (Marchington et al. 1994; Wilkinson et al. 1998; Wright and Edwards 1998; Hales 2000; Geary and Dobbins 2001). In their review of the evidence, Edwards et al. (2002a) conclude that management initiatives are 'more limited and controlled than the enthusiasts claim, but more constructive than the critics admit'; essentially that the intentions and consequences of management's actions are more complex and variable than allowed for by either camp. In place then of the 'empowerment' and 'exploitation' theses, is proposed the 're-regulation perspective' (Geary 1995; 2003; Edwards et al. 2002a). The starting point of the reregulation view is that new forms of work organization entail both autonomy and control, and embraced within managerial actions are a series of tensions and ambiguities. The management problem of identifying the apposite balance between exercising control and generating employee consensus remains. Workers may assume greater responsibility for their work and be permitted greater involvement in work organization, but this may not lead to wider empowerment. While there may be a shift away from direct command-and-control mechanisms, this cannot be read as an abandonment of all forms of control. Rather there is often a shift to new means of control, which may, at first sight, seem less constraining. It is the failure to understand this distinction, as Edwards (2001) stresses, which underlies many of the more up-beat managerialist accounts, which contrast traditional supervision with alleged autonomy and empowerment. But the move from traditional authority structures - as incomplete and partial as it may be has resulted in the deployment of a different mix of control structures. In this sense, 'new forms of work organization are a re-regulation of work, not the end of regulation' (Edwards et al. 2002a: 52).

Complementing this perspective is Batt's research on the effects of selfmanaged teams in a former Bell regional telephone company in the US (Batt 2004). Batt notes that the utility studied introduced self-managed teams as part of a partnership programme with the union: a context likely to be most conducive to the delivery of mutual gains through teamwork (Batt 2004: 190-1). The research reveals that, in the case of non-managerial and nonsupervisory workers, self-managed teams were associated with higher levels of discretion, employment security and satisfaction. These results, however, did not generalize to supervisors or middle managers. Supervisors reported 
lower levels of satisfaction, derived mainly from higher job insecurity. Middle managers involved in initiating self-management were somewhat more positive in their attitudes than other managers (Batt 2004: 197-205). Echoing the literature on middle managers and partnership, discussed in Chapter 6, Batt concludes that self-managed teams have differential effects across organizational hierarchies. In the organization studied, the selfmanaged teams programme was thus abandoned 'for political reasons' in spite of pay-offs for the firm, employees and union and their congruence with the joint partnership programme. Both teamwork and the partnership programme eventually collapsed due to the political turbulence created by self-managed teams, the company ultimately shifting to a programme of reengineering and downsizing (Batt 2004: 206-7).

Drawing from the general literature on participation, involvement and teamwork, the following questions can be posed to focus the analysis of data on Aer Rianta.

1 Was there a significant level of interest in more scope for work-level and organizational-level participation in Aer Rianta prior to the establishment of $\mathrm{CP}$, and how was this distributed across grades and categories of staff?

2 Did participation under CP positively affect work-related attitudes and behaviour?

3 What were the effects on attitudes and behaviour of teamwork in the form of the 'regular work groups' instituted by $\mathrm{CP}$ ?

\section{Partnership, attitudes and behaviour}

As discussed in Chapter 1, direct and indirect participation and work reorganization are commonly examined in studies that fail to distinguish between unionized and non-union contexts, or fail to consider union involvement in different forms of participation and work reorganization as a mediating variable affecting attitudes, behaviour and outcomes. Studies that examine participation and work reorganization in the context or under the rubric of 'partnership' also commonly fail to distinguish between union and non-union contexts. Even studies that deal with partnership arrangements that involve unions tend to examine attitudes and behaviour indirectly through management reports of their effects on employees (for example, Cooke 1990); presume that partnership affects attitudes and behaviour in ways that contribute to organizational performance and other outcomes without demonstrating such effects (for example, Cutcher-Gershenfeld and Verma 1994 and Rubinstein and Kochan 2001); or more or less ignore employee attitudes and behaviour altogether, focusing instead on objective outcomes like pay, employment security and union influence (for example, Kelly 2004). An exception is Kelly and Kelly's (1991) examination of the effects on attitudes and behaviour of various 'new industrial relations 


\section{Employee attitudes and behaviour}

practices' (profit-sharing, share ownership, quality circles, autonomous teams), as reported in a number of US and UK studies conducted during the 1980s. This review concludes that such practices had few effects, reporting in particular that employees' perceptions of the state of industrial relations that is, the degree to which there was a perception of 'them and us' - as well as levels of commitment were little affected by experiences of new industrial relations practices (Kelly and Kelly 1991). Some of the research dealing with 'dual commitment', to be examined in Chapter 9, also represents an exception in directly examining attitudes and behaviour, although much of this research preceded the advent of 'new industrial relations' or partnership.

A number of research questions concerning attitudinal and behavioural effects arise from the literature on partnership, and these will provide a focus for the analysis of later sections of the chapter.

4 As partnership often involves the creation of channels for participation at multiple levels and with respect to a range of issues, did the various channels established under $\mathrm{CP}$ each positively affect work-related attitudes and behaviour?

5 Consistent with the claims and findings of a number of theoretical and empirical studies of partnership (Cutcher-Gershenfeld and Verma 1994; Guest and Peccei 2001), did involvement in multiple channels, especially channels combining direct and indirect participation, affect workrelated attitudes and behaviour to a greater degree than participation in single channels in isolation?

6 Did involvement in CP arrangements affect attitudes and behaviour in a manner consistent with the 'mutual gains' principle (Kochan and Osterman 1994; Knell 1999), or the 'unbalanced' or 'constrained mutuality' principle (Osterman 1999; Guest and Peccei 2001)? Critical here is whether CP positively affected organizational commitment and productivity, as well as employees' well-being and satisfaction, or whether its effects on commitment and productivity were more pronounced (Kelly 2004).

\section{Interest in participation in Aer Rianta}

As outlined in Chapter 3, two employee attitude surveys had been carried out in Aer Rianta before the research reported in this study was undertaken. The first survey was conducted in 1988, as figures in management and unions began to consider developing a new approach to participation in the company. The survey was repeated in 1995 against the background of the emergence of the Compact and the formalization of CP. The surveys employed probability sampling; 702 employees responded to the first survey, giving a response rate of 73 per cent, and 664 responded to the 1995 survey, giving a response rate of 66 per cent. In the analysis that follows, data from both surveys have been pooled, unless otherwise specified. 
The 1988 and 1995 surveys contain data on actual levels of participation and involvement in Aer Rianta, as perceived by employees, and on levels of interest in more extensive participation. Using pooled data from both surveys, indicators were constructed of the scale of disparities between actual and preferred levels of participation with respect to aspects of task-level or work participation. For each aspect of participation covered, five categories are defined. These are labelled 'a good deal too little say', 'too little say', 'correct amount of say', 'too much say' and 'a good deal too much say'. As can be seen from Table 8.1, employees in general reported that they were interested in significantly higher levels of influence with respect to work tasks than available to them in the period prior to the formalization of partnership in Aer Rianta. Substantial proportions of the Aer Rianta workforce responded in a manner that indicated that they enjoyed too little, or a great deal too little say in task-based decision-making. Slightly fewer than one in four to one in three suggested that they enjoyed levels of influence commensurate with their wishes, and only small minorities reported having too much influence over aspects of their day-to-day work.

Pooled data from the 1988 and 1995 surveys also provide an indication of employees' views as to the levels of information obtained from a series of decision-making forums in the company. The kind of 'communicative involvement' at issue here is 'downward communication', but the results are broadly consistent with those on task-based participation. Table 8.2 explores the scale of the disparities or gaps reported by employees with respect to the actual information available to them relative to their levels of interest in obtaining information with respect to activities at different levels of the company. It is again clear that a substantial majority of employees obtained too little or a good deal too little information from the levels of decisionmaking examined in the surveys, and broadly in equal measure across the various levels.

The answer to the first part of question 1 above, therefore, is that significant underlying levels of interest in greater scope for participation at

Table 8.1 Disparities between actual and preferred levels of task participation

\begin{tabular}{lcccc}
\hline & $\begin{array}{l}\text { Planning } \\
\text { work } \\
(\%)\end{array}$ & $\begin{array}{l}\text { Improving } \\
\text { work methods } \\
(\%)\end{array}$ & $\begin{array}{l}\text { Setting } \\
\text { targets } \\
(\%)\end{array}$ & $\begin{array}{l}\text { Organizing } \\
\text { workloads } \\
(\%)\end{array}$ \\
\hline A good deal too little say & 13.9 & 23.1 & 30.5 & 25.3 \\
Too little say & 38.9 & 46.1 & 42.9 & 39.4 \\
Correct amount of say & 32.8 & 26.5 & 22.5 & 30.8 \\
Too much say & 4.5 & 4.3 & 3.7 & 4.5 \\
A good deal too much say & 0.3 & 0.1 & 0.4 & 0.0 \\
$\mathrm{~N}$ & 1,359 & 1,357 & 1,350 & 1,352 \\
\hline
\end{tabular}

Source: Pooled Aer Rianta Surveys 1988 and 1995. 
Table 8.2 Disparities between actual and preferred levels of communicative participation in Aer Rianta

\begin{tabular}{lcccc}
\hline & $\begin{array}{l}\text { Board } \\
\text { meetings } \\
(\%)\end{array}$ & $\begin{array}{l}\text { Corporate senior } \\
\text { management } \\
\text { meetings } \\
(\%)\end{array}$ & $\begin{array}{l}\text { Airport senior } \\
\text { management } \\
\text { meetings } \\
(\%)\end{array}$ & $\begin{array}{l}\text { Local } \\
\text { departmental } \\
\text { meetings } \\
(\%)\end{array}$ \\
\hline $\begin{array}{l}\text { A good deal too little } \\
\quad \text { information }\end{array}$ & 27.8 & 29.6 & 34.0 & 34.3 \\
$\begin{array}{l}\text { Too little information } \\
\text { Correct amount of } \\
\text { information }\end{array}$ & 50.3 & 51.1 & 48.1 & 45.6 \\
$\begin{array}{l}\text { Too much information } \\
\text { A good deal too much } \\
\text { information }\end{array}$ & 17.0 & 15.4 & 14.4 & 16.5 \\
$\mathrm{~N}$ & 1,362 & 3.7 & 3.4 & 3.3 \\
\hline
\end{tabular}

Source: Pooled Aer Rianta Surveys 1988 and 1995.

multiple levels existed in Aer Rianta prior to the implementation of CP. In this context it is also of interest to examine the distribution of the demand for higher participation across categories of staff and locations. Data from the 1988 and 1995 surveys are less than ideal for analysing differential levels of interest in more participation across grades because only about 50 per cent of respondents identified their grades in the surveys. Nevertheless, from the data available it is possible to distinguish the postures of middle and supervisory management and other employees and to compare these to senior and executive management. Table 8.3 indicates that interest in greater scope for task-based participation and in communicative involvement is hierarchically ordered: middle managers and supervisors showing greater levels of interest than senior and executive managers and non-managerial, non-supervisory employees showing the highest levels of interest in all aspects of participation and involvement. Levels of interest in scope for further participation appear to be have been lower overall in Cork and Shannon than in Dublin, though the scale of the differences across locations are very modest, as compared with those across grades.

In summary, the 1988 and 1995 survey results were focused on attitudes towards participation in work tasks, wider aspects of supervision and control and downward-information provision. The results indicated high levels of interest among employees in extending the scope available to them for influence on the job, as well as in obtaining more information on the deliberations of decision-making forums than available to them. Comparatively few expressed themselves to be satisfied with the status quo with respect to participation in either area. Those least satisfied with the status quo and showing the highest level of interest in further participation were employees 


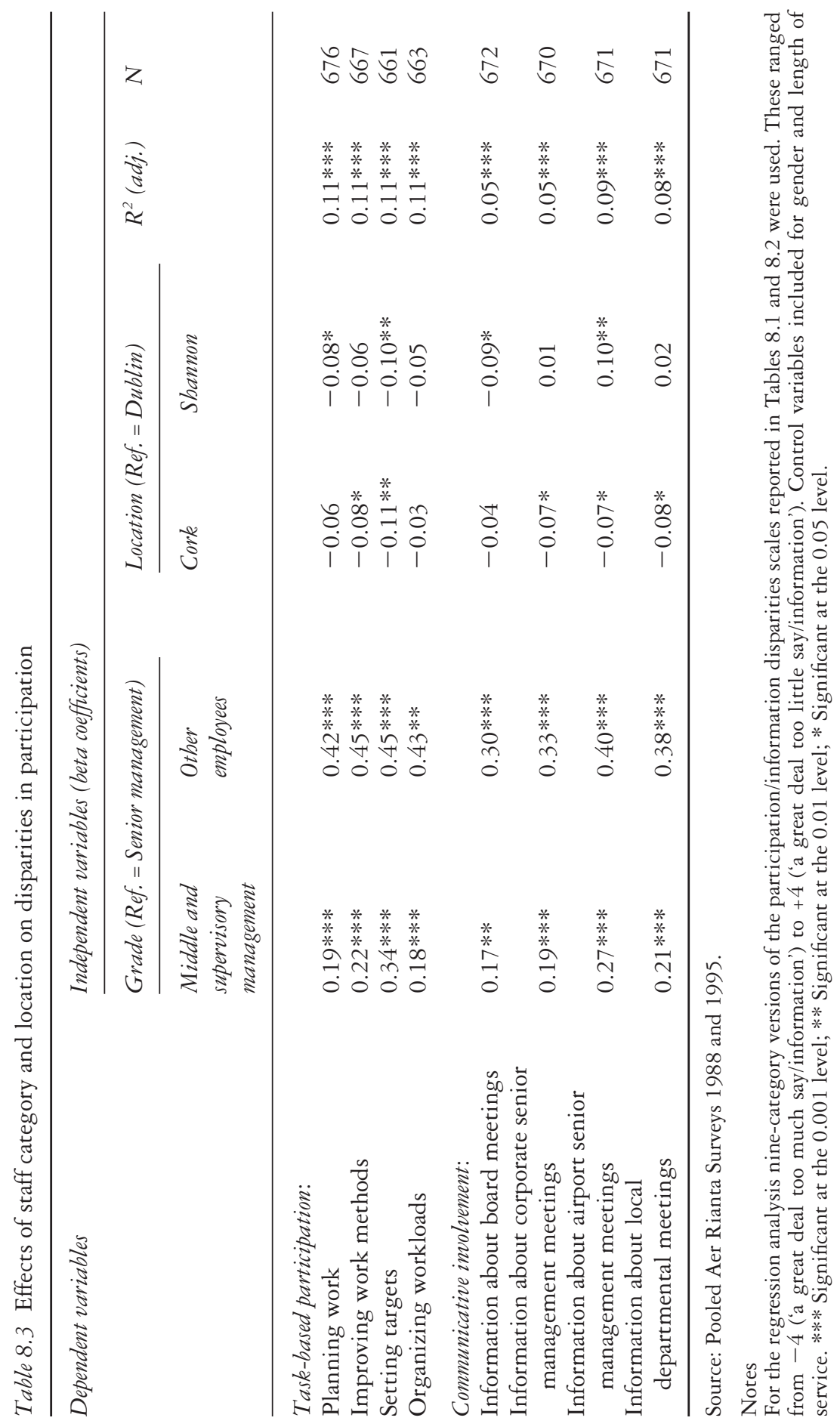




\section{Employee attitudes and behaviour}

located at the base of the organizational hierarchy. While underlying levels of interest in more scope for participation and involvement appeared lower in Cork and Shannon than in Dublin, differences across airports were modest compared with differences across grades. In these respects, the historical evidence on the climate among employees towards participation in Aer Rianta prior to the formalization and roll-out of partnership showed it to have been positive, especially among those enjoying least participation within the prevailing decision-making regime.

\section{$\mathrm{CP}$, attitudes and behaviour}

As is clear from earlier chapters, the level of activity associated with workplace partnership in Aer Rianta rose substantially from 1995, when formal agreement was reached on the Compact and participative arrangements were rolled out consistent with the mechanisms agreed in the Requisite Arrangements. The circumstances of the period from 1995 to 1999 were also different in that employees were now being invited to engage with a more or less well-articulated model of participation, characterized by a distinct set of arrangements designed to foster direct and indirect participation at a series of levels and across a range of issues. Up to the mid 1990s, participation had been espoused by supporters in the company; and alternative approaches to participation had been debated within management and unions. Now a particular model focused action and debate on the issue in Aer Rianta. The $\mathrm{CP}$ model became the focus, in particular, of differences of view among senior managers, as outlined in Chapters 4 to 6 . As the pace of participative activity increased, disputes surrounding $\mathrm{CP}$ also arose, in particular the dispute with the middle managers' union, IAESA. The period 1998-99 marked a further intensification of activity, as $\mathrm{CP}$ engaged key issues like the loss of duty-free sales and the future of the company. Against this backdrop, this section examines levels of involvement in $\mathrm{CP}$; attitudes towards $\mathrm{CP}$; and the effects of participative activities on work-related attitudes and behaviour.

\section{Levels of involvement in CP}

By 1998-99, awareness of CP was almost ubiquitous in Aer Rianta: substantial majorities of over 90 per cent across all categories said that they were either 'very aware' or 'somewhat aware' of the initiative. Table 8.4 presents data on levels of formal membership or involvement in the various organs of CP. Between 20 and 30 per cent of staff stated that they were members of a 'regular work group'. Because, as outlined in Chapter 3, regular work groups, as provided for under $\mathrm{CP}$, had only been established to any major extent in the maintenance department and to a more limited extent in finance, survey responses appear to have exaggerated the incidence of RWG membership - a common problem in surveys dealing with the 
incidence of group and teamwork initiatives. Membership of 'departmental steering or work groups', ranged from between 13 to 24 per cent, and that of 'departmental strategy groups' ranged between 11 and 32 per cent. 'Significant issues' groups involved between 7 per cent (supervisors) and 55 per cent (senior managers) of staff, while 15 to 34 per cent acted as 'observers' at any of the aforementioned groups. Substantially smaller numbers acted as 'participation mentors' within departments, or as 'participation office facilitators'. What stands out from Table 8.4 is that not insubstantial minorities of staff played some role in the formal organs of CP. For categories other than senior managers, some of these roles involved staff selected in effect as representatives of their respective grades. However in line with the canons of $\mathrm{CP}$, those involved in formal participative structures were viewed, and were expected to view themselves, as contributors to a pooling of expertise rather than as representatives in the strict sense or defenders of the interests of their specific grades or categories. The table also reveals the relatively high demands placed by $\mathrm{CP}$ on senior managers. Table 8.5 examines the incidence of involvement in multiple organs of $\mathrm{CP}$. Bearing in mind that there may have been some measurement error with respect to the incidence of RWG membership, up to 33 per cent of the workforce as a whole are revealed to have occupied one or more roles in the main formal groups and committees associated with CP. An estimated 24 per cent of these occupied from one to three roles in CP.

Respondents were also asked to indicate whether they had engaged 'frequently', 'occasionally' or 'never' with a series of broader aspects of CP and related activity. Activities like attendance at departmental and union meetings at which $\mathrm{CP}$ was discussed, the reading of newsletters, attendance at staff seminars and the receipt of feedback on CP from colleagues, are also forms of involvement in or, as they will here be described, 'engagement' with CP. These responses were combined in Chapter 7 into a scale measuring engagement with CP (see Appendix Table A1 for details of scale construction). What emerges from the more detailed examination of different facets of engagement with CP, presented in Table 8.6, is that a substantial majority of staff across all categories had deliberated on $\mathrm{CP}$ through their attendance at departmental meetings at which it had been discussed; through discussing $\mathrm{CP}$ with colleagues; through receiving feedback from colleagues involved in formal organs of $\mathrm{CP}$; through reading newsletters dealing with $\mathrm{CP}$; and through attending seminars devoted to the subject. Attendance at union meetings covering $\mathrm{CP}$ involved only minorities across all categories, as did attendance at exhibitions and use of the CP library.

There is no clear-cut evidence in these tables concerning the extent of middle management alienation from CP. However, some indicators point to a lower level of middle management engagement than might be expected given these managers' central role in operational-level management. For example, a significant gradient in levels of membership of formal structures usually separated senior managers from all other categories, with middle 


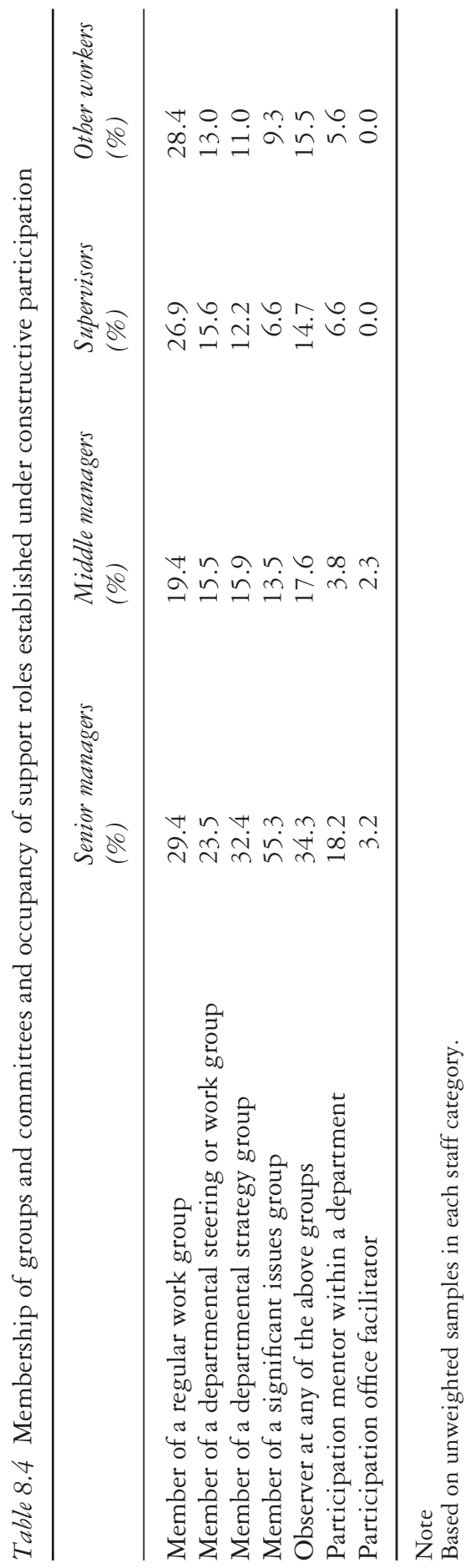


Table 8.5 Multiple membership of groups and committees and occupancy of support roles established under constructive participation

\begin{tabular}{lrr}
\hline & $(\%)$ & $N$ \\
\hline Membership of groups and committees and & & \\
occupancy of support roles & 67.5 & 341 \\
$\quad$ None & 15.1 & 93 \\
One & 5.9 & 30 \\
Two & 3.1 & 16 \\
Three & 2.4 & 12 \\
Four & 2.0 & 10 \\
Five & 0.7 & 3 \\
Six & 0.1 & 1 \\
Seven & & 506 \\
N (weighted) & & \\
\hline
\end{tabular}

Note

Data relate to the seven committees, groups and roles listed in Table 8.4.

managers showing a profile of involvement or non-involvement more similar to other categories than senior managers. The same holds for aspects of wider engagement with CP (Table 8.6), especially with respect to activities that involve, so to speak, 'visible engagement'. Thus sharp gradients separate senior and middle management involvement with respect to attendance at departmental meetings at which CP was discussed; attendance at staff seminars focused on the area; and the receipt of feedback from colleagues involved in CP. At the same time, consistent with the evidence reported in Chapter 6, actual levels of involvement by middle managers indicate that the dispute with the middle managers' union, IAESA, by no means wholly precluded middle management engagement, however reluctant, ambiguous or cautious that engagement might sometimes have been in practice.

A multivariate analysis of membership of CP groups and committees and occupancy of CP roles revealed no significant differences across airports. A similar analysis of levels of engagement with broader aspects of CP revealed significantly lower levels of engagement in Cork across a range of areas, including attendance at CP seminars organized by the JUCG, attendance at union meetings where $\mathrm{CP}$ was discussed and discussions with colleagues about CP. This pattern no doubt reflects the effects of Cork's near secession from CP prior to the retirement of its former general manager, and possibly also the continuing rumblings of the dispute at Cork over the appointment of facilitators. Reflecting the discussion in Chapter 3 of the uneven penetration of $\mathrm{CP}$ across departments, statistical analysis revealed that the members of the maintenance trades were most likely to be formally involved in CP groups and committees in general, followed by people working in retailing and cleaning. Levels of engagement in $\mathrm{CP}$ also followed this pattern, with 
Table 8.6 Levels of engagement with constructive participation

\begin{tabular}{llll}
\hline $\begin{array}{l}\text { Senior managers } \\
(\%)\end{array}$ & $\begin{array}{l}\text { Middle managers } \\
(\%)\end{array}$ & $\begin{array}{l}\text { Supervisors } \\
(\%)\end{array}$ & $\begin{array}{l}\text { Other workers } \\
(\%)\end{array}$ \\
\hline
\end{tabular}

Attendance at departmental meetings or training sessions at which constructive participation was discussed:

$\begin{array}{llrrr}\text { Frequently } & 29.5 & 9.7 & 16.9 & 13.0 \\ \text { Occasionally } & 59.1 & 51.9 & 38.5 & 47.9 \\ \text { Never } & 11.4 & 38.3 & 44.6 & 39.1\end{array}$

Read departmental newsletters on constructive participation:

$\begin{array}{lllll}\text { Frequently } & 54.5 & 20.9 & 24.5 & 19.9 \\ \text { Occasionally } & 29.5 & 51.0 & 50.3 & 51.5 \\ \text { Never } & 15.9 & 28.1 & 25.2 & 28.6\end{array}$

Read company/union newsletters on constructive participation:

$\begin{array}{lrrrr}\text { Frequently } & 55.3 & 27.0 & 23.5 & 22.5 \\ \text { Occasionally } & 36.2 & 60.4 & 59.1 & 53.3 \\ \text { Never } & 8.5 & 12.6 & 17.4 & 24.2\end{array}$

Attendance at any staff seminars on constructive participation arranged by the Joint Union Company Group:

$\begin{array}{lllll}\text { Frequently } & 25.0 & 10.8 & 12.2 & 13.3 \\ \text { Occasionally } & 47.7 & 53.8 & 43.5 & 45.6 \\ \text { Never } & 27.3 & 35.4 & 44.2 & 41.1\end{array}$

Attendance at exhibitions on constructive participation arranged by the Joint Union Company Group:

$\begin{array}{lrrrr}\text { Frequently } & 15.6 & 5.8 & 5.6 & 4.6 \\ \text { Occasionally } & 40.0 & 23.7 & 25.4 & 21.3 \\ \text { Never } & 44.4 & 70.5 & 69.0 & 74.1\end{array}$

Attendance at union meetings where constructive participation was discussed:

$\begin{array}{lrrrr}\text { Frequently } & 10.8 & 3.8 & 7.0 & 9.6 \\ \text { Occasionally } & 13.5 & 33.3 & 21.8 & 24.3 \\ \text { Never } & 75.7 & 62.8 & 71.1 & 66.1\end{array}$

Use of constructive participation library:

$\begin{array}{lrrrr}\text { Frequently } & 8.9 & 1.9 & 3.4 & 2.1 \\ \text { Occasionally } & 17.6 & 7.0 & 6.9 & 6.0 \\ \text { Never } & 73.3 & 91.1 & 89.7 & 91.8\end{array}$

Discussed constructive participation with colleagues:

$\begin{array}{lllll}\text { Frequently } & 40.4 & 27.0 & 23.5 & 25.5 \\ \text { Occasionally } & 48.9 & 53.5 & 55.7 & 58.0 \\ \text { Never } & 10.6 & 19.5 & 20.8 & 16.5\end{array}$

Received feedback from colleagues involved in constructive participation:

$\begin{array}{lllll}\text { Frequently } & 23.9 & 20.8 & 18.1 & 23.2 \\ \text { Occasionally } & 63.0 & 37.7 & 45.0 & 44.3 \\ \text { Never } & 13.0 & 41.5 & 36.9 & 32.5\end{array}$

Note

Based on unweighted samples in each staff category. 
trades very substantially more likely than any other category to have engaged with $\mathrm{CP}$.

\section{Assessments of $C P$}

In examining question 2 above concerning the effects of $\mathrm{CP}$ on attitudes and behaviour, it is relevant to consider assessments of CP and its effects by Aer Rianta staff. Table 8.7 presents the data from a series of questions in which survey respondents were asked the degree to which they either agreed or disagreed with a series of statements concerning the effects of CP. What emerges here is that substantial numbers of employees were negative in their assessments of the achievements or effects of CP. The proportions of employees expressing positive attitudes towards the effects of CP across a range of areas were by no means negligible. However, the only instances in which a majority within any of the four categories expressed clear-cut positive attitudes concerned senior managers' views on the effects of $\mathrm{CP}$ on the representation of employees' interests and on trust and better understanding between management and employees. Otherwise, at best only minorities across all categories delivered a clear-cut positive endorsement of the effects of CP and often this was more than counterbalanced by the proportions of staff expressing negative views with varying degrees of vehemence. Negative assessments predominated with respect to middle managers', supervisors' and other workers' views on whether more was known about what was going on because of $\mathrm{CP}$, and with respect to whether work decisions were accepted more easily because of CP. Negative attitudes, while held by minorities, were more common than positive attitudes across these same staff categories with respect to views on whether the quality of decisions was improved; views as to whether CP slowed down decision-making; and views as to whether understanding and trust resulted from CP. In the case of views as to whether employee interests were better represented by $\mathrm{CP}$, the picture was more positive with 70 per cent of senior managers endorsing CP and substantial numbers, approaching 50 per cent, in most other categories also agreeing. A majority of senior managers alone was of the opinion that $\mathrm{CP}$ slowed down decision-making (57 per cent), one in five senior managers disagreeing that this was the case.

Clear-cut indications of a distinctive pattern of middle management alienation from CP also emerged from the data in Table 8.7. Middle managers were less commonly positive than other categories with respect to all the effects of $\mathrm{CP}$ other than its effects in creating better understanding and more trust between management and employees. They were also more commonly negative than any other category with respect to attitudes across the range of effects. Moreover, among those middle managers expressing positive attitudes, fewer relative to other categories of staff expressed 'strong agreement' across all items, other than to endorse the ease with which decisions were accepted due to $\mathrm{CP}$, and the fact that interests were better 
184 Employee attitudes and behaviour

Table 8.7 Attitudes to constructive participation

\begin{tabular}{lllll}
\hline Attitudes to CP & $\begin{array}{l}\text { Senior managers } \\
(\%)\end{array}$ & $\begin{array}{l}\text { Middle managers } \\
(\%)\end{array}$ & $\begin{array}{l}\text { Supervisors } \\
(\%)\end{array}$ & $\begin{array}{l}\text { Other workers } \\
(\%)\end{array}$ \\
\hline
\end{tabular}

I know more about what is going on because of constructive participation:

$\begin{array}{lllll}\text { Strongly agree } & 10.6 & 3.1 & 5.4 & 4.5\end{array}$

$\begin{array}{lllll}\text { Agree } & 21.3 & 14.5 & 22.1 & 27.5\end{array}$

$\begin{array}{llll}\text { Can't decide } & 21.3 & 15.1 & 20.1\end{array}$

$\begin{array}{lllll}\text { Disagree } & 40.4 & 49.7 & 43.0 & 43.9\end{array}$

$\begin{array}{lllll}\text { Strongly disagree } & 6.4 & 17.6 & 9.4 & 8.6\end{array}$

I accept work decisions more easily because of constructive participation:

$\begin{array}{lllll}\text { Strongly agree } & 6.5 & 1.3 & 0.7 & 2.5\end{array}$

$\begin{array}{lllll}\text { Agree } & 15.2 & 10.1 & 14.9 & 22.7\end{array}$

$\begin{array}{lllll}\text { Can't decide } & 32.6 & 14.6 & 19.6 & 22.3\end{array}$

$\begin{array}{lllll}\text { Disagree } & 41.3 & 55.7 & 56.8 & 44.6\end{array}$

$\begin{array}{lllll}\text { Strongly disagree } & 4.3 & 18.4 & 8.1 & 7.9\end{array}$

The quality of decisions is improved by constructive participation:

$\begin{array}{lllll}\text { Strongly agree } & 8.7 & 3.2 & 4.8 & 3.7\end{array}$

$\begin{array}{lllll}\text { Agree } & 26.1 & 17.8 & 17.7 & 21.2\end{array}$

$\begin{array}{lllll}\text { Can't decide } & 37.0 & 25.5 & 29.3 & 30.6\end{array}$

$\begin{array}{lllll}\text { Disagree } & 26.1 & 33.1 & 37.4 & 34.7\end{array}$

$\begin{array}{lllll}\text { Strongly disagree } & 2.2 & 20.4 & 10.9 & 9.8\end{array}$

Employee interests are better represented by constructive participation:

$\begin{array}{lrrrr}\text { Strongly agree } & 25.5 & 6.3 & 9.5 & 8.3 \\ \text { Agree } & 44.7 & 38.0 & 38.5 & 38.4 \\ \text { Can't decide } & 19.1 & 31.0 & 25.7 & 26.0 \\ \text { Disagree } & 10.6 & 15.2 & 22.3 & 21.5 \\ \text { Strongly disagree } & 0.0 & 9.5 & 4.1 & 5.8\end{array}$

Decision-making is made slower by constructive participation:

$\begin{array}{lrrrr}\text { Strongly agree } & 4.3 & 17.8 & 6.1 & 4.9 \\ \text { Agree } & 53.2 & 27.4 & 23.6 & 29.2 \\ \text { Can't decide } & 21.3 & 38.2 & 45.9 & 39.9 \\ \text { Disagree } & 19.1 & 14.6 & 22.3 & 22.6 \\ \text { Strongly disagree } & 2.1 & 1.9 & 2.0 & 3.3\end{array}$

Better understanding and trust exist between management and employees as a result of constructive participation:

$\begin{array}{lrrrr}\text { Strongly agree } & 17.4 & 3.1 & 2.7 & 3.7 \\ \text { Agree } & 37.0 & 25.2 & 24.5 & 19.3 \\ \text { Can't decide } & 28.3 & 28.9 & 32.7 & 32.9 \\ \text { Disagree } & 13.0 & 32.7 & 32.7 & 35.0 \\ \text { Strongly disagree } & 4.3 & 10.1 & 7.5 & 9.1\end{array}$

Note

Data based on unweighted samples of each staff category. 
represented by $\mathrm{CP}$. More middle managers consistently expressed 'strong disagreement' across all items than members of the other three categories of staff examined. In short, middle managers emerged as distinctive both in less commonly expressing positive attitudes towards the effects of $\mathrm{CP}$ than any other category and in more commonly expressing negative attitudes. Those middle managers who did express positive attitudes were also usually less positive in their endorsement of $\mathrm{CP}$ than other categories and those expressing negative attitudes were more vehement in their views.

In the light of the findings reported above that levels of engagement with $\mathrm{CP}$ were lower in Cork than Shannon and Dublin, an analysis was undertaken examining whether attitudes to the effects of $\mathrm{CP}$ also differed by location. No systematic pattern of variation by location was found, with Shannon rather than Cork showing less favourable attitudes with respect to the effectiveness of $\mathrm{CP}$ in representing worker interests and in fostering better understanding and trust between management and employees.

In summary, on the whole staff at Aer Rianta in 1998-99 were disposed to judge the effects of $\mathrm{CP}$ in negative terms. The pattern of attitudes towards $\mathrm{CP}$ reflected a context with a number of salient features. As was seen from the analysis of surveys conducted in the late 1980s and mid 1990s, most employees wished for higher levels of participation than those available to them in Aer Rianta. Latent in such preferences in all probability were high expectations of what $\mathrm{CP}$ might deliver - expectations in turn probably intensified by the roll-out and development of $\mathrm{CP}$ over the period since the mid 1990s. As reported in earlier chapters, the roll-out itself had to confront divided senior management opinion and for a time, in formal terms at least, the effective secession of the middle managers' union - factors that had affected both the pace of change and the extent to which the principles of the Compact took root in the routine operations of the company. While policy changes designed to reinforce $\mathrm{CP}$ were under joint deliberation through the work of significant issues groups, no major changes in areas like reward systems had occurred. The determination of many groups to telescope the stages of the $\mathrm{CP}$ approach, by proceeding direct to problemsolving activity, had also strained the resources of facilitators and their capacity to support the participative initiatives underway. Finally, CP had been in being for only a period of several years at the time of the survey, and it might be reasonable to suppose that new arrangements might take longer to affect attitudes and behaviour in a major way. Against the backdrop of these factors, successes chalked up by $\mathrm{CP}$, such as the handling of the dutyfree problem and the strategic review, appear to have had insufficient impact on staff attitudes in general to outweigh the effects of the heightened expectations, as well as of the strains and problems encountered by the new approach.

Given the uneven roll-out of $\mathrm{CP}$, it is also of relevance in answering question 2 to examine whether attitudes towards CP varied with levels of involvement in different aspects of the process. Table 8.8 presents the results 
when attitudes to $\mathrm{CP}$ are regressed on scales measuring different aspects of involvement with the process. Membership of $\mathrm{CP}$ groups and committees, levels of engagement with $\mathrm{CP}$, communicative involvement and work participation are measured as outlined in Chapter 7 (for details of scales and scale reliability statistics see Appendix Table A1). With regard to work participation, the caveats introduced when the scale was introduced in Chapter 7 should again be borne in mind. Given that little formal work reorganization occurred in practice under $\mathrm{CP}$, particularly through the establishment of regular work groups, this scale in part measures the effects of whatever work reorganization had occurred under the influence of $\mathrm{CP}$ principles. But it may also have picked up the effects of pre-existing variations in job autonomy, whether instituted by managers or carved out by employees themselves. The dependent variables were scaled in accordance with the response categories presented in Table 8.7, with values ranging from 'strongly disagree' $(=1)$ to strongly agree $(=5)$.

The results show that attitudes towards CP and assessments of its effects were indeed in general more positive the more employees have been involved in the process, whether through higher levels of work participation, membership of formal groups, committees and occupancy of CP roles, or through various forms of broader engagement. The results presented provide further and more rigorous evidence that middle managers were significantly less convinced of the benefits of $\mathrm{CP}$, irrespective of their levels of participation, involvement in or engagement with the process. Given the problem of measurement error with respect to the regular work group facet of the $\mathrm{CP}$ 'groups, committees and roles' scale, the regressions were also undertaken with a version of this scale that excluded the RWG item. The results were materially unaffected.

\section{Attitudinal and behavioural effects of $C P$}

We move now to examine the effects of a range of aspects of participation and involvement under the $\mathrm{CP}$ regime on attitudes to work and workrelated behaviour. As it might be expected that the attitudes and behaviour to be examined will be influenced by staff category - higher categories expressing more positive attitudes towards the company and recording more company-oriented behaviour - all regressions contain control variables for staff category, as well as the other controls identified beneath each of the tables. Table 8.9 examines the effects of participation and involvement on a series of facets of attitudes towards management. These items are commonly viewed collectively as indicators of the 'climate' of industrial relations. All items are scaled on a 1-5 scale ranging from 'strongly disagree' to 'strongly agree'. The results show that work participation or autonomy was consistently associated with substantively important positive effects on employees' attitudes to management. The more scope available to employees to participate in task-level decision-making and the greater their level of task 


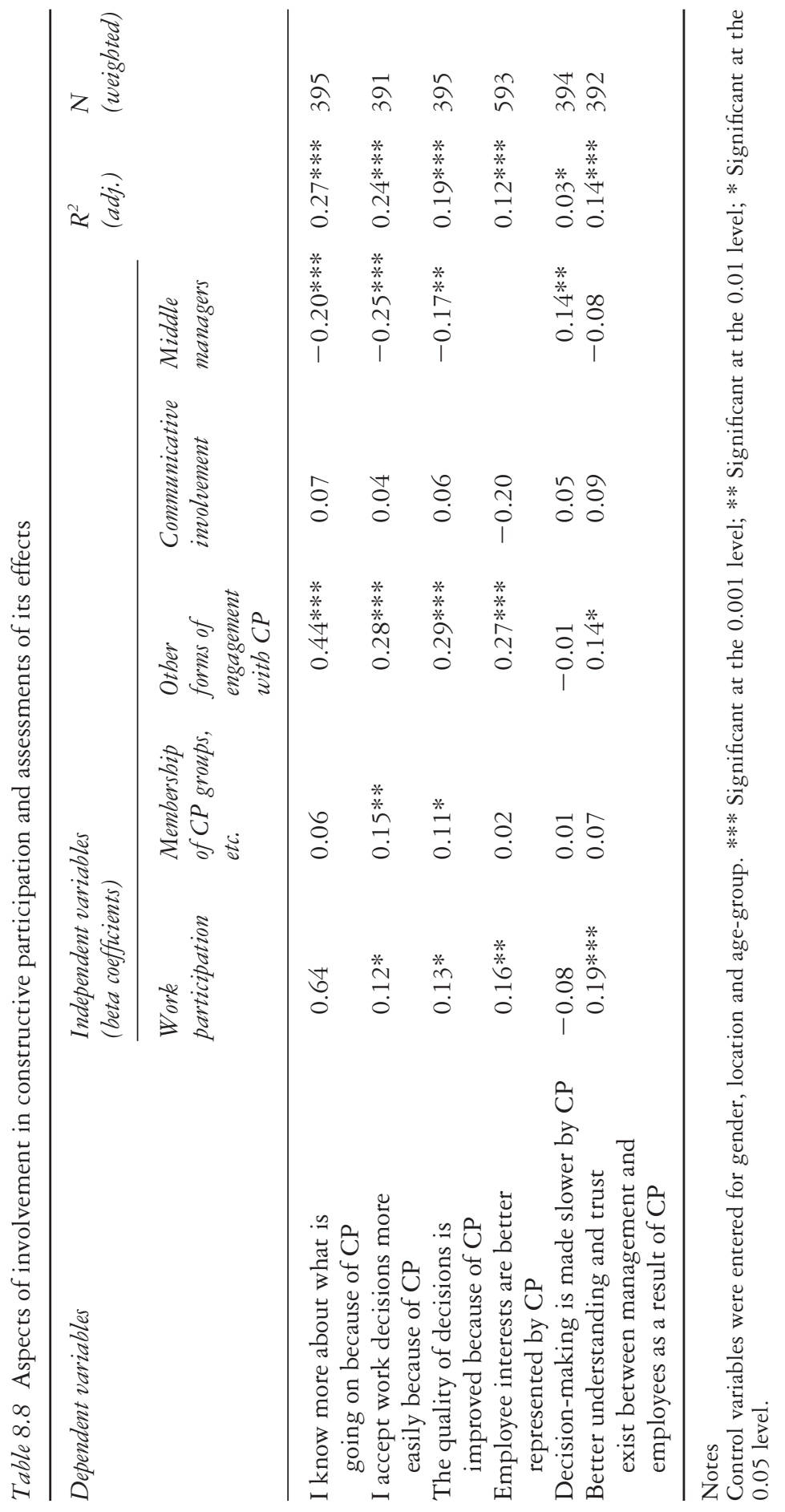


autonomy, the more positively they assessed management attitudes and behaviour. The results also show that the more information employees obtained about the deliberations of formal decision-making bodies, the more favourable their attitudes to management, though communicative involvement had weaker and somewhat less consistent effects on attitudes to management. Engagement with $\mathrm{CP}$, through feedback, discussion, training and information exchange, had no statistically significant effect on attitudes to management, although the coefficients within the sample were negatively signed.

Membership of formal groups and committees and occupancy of support roles were negatively associated with assessments of management in the case of three out of the four items examined: in other words, membership of formal partnership structures and occupancy of support roles were associated with a more critical posture towards management. As noted above, the scale used to measure this aspect of $\mathrm{CP}$ may have incorporated significant measurement error in respect of the incidence of regular work group membership. To test whether the effect of membership of formal CP groups and committees remained robust when direct account is taken of this problem, the regressions reported in Table 8.9 were re-estimated, first by entering a modified version of the scale which omitted the regular work group dimension; and second by entering a control (dummy) variable for staff in the maintenance department. As outlined above and in Chapter 3, regular work groups were established in the main in maintenance. The dummy variable was thus included to allow for the possibility that any effect that might otherwise arise from the regular work group component of the overall scale could mask the posture of members of the maintenance trades, organized by strong and independent craft unions, towards the employer. Neither method of re-estimating the regressions led to materially different results, suggesting that the effects of membership of formal $\mathrm{CP}$ committees and groups, as reported in Table 8.9, were robust and not significantly affected by measurement error with respect to regular work group membership.

The finding that those more actively involved in $\mathrm{CP}$ structures held more critical or negative attitudes towards the employer probably reflected the higher expectations of $\mathrm{CP}$ held by those involved in these forums and roles and their commensurately greater level of frustration with the scale of progress actually achieved by 1998-99. An alternative explanation for this finding is that the causal link ran in the other direction: that is, people more critical of management became more highly involved in CP. Some management critics of $\mathrm{CP}$, as discussed in previous chapters, were disposed to argue that it was 'pro-union' and attracted union activists. There was no evidence to support this viewpoint in the survey. The average level of commitment to unions among those with higher than average levels of membership in CP groups and committees was no higher than the average for the sample as a whole. It seems that those more highly involved in CP groups, committees and roles had adopted a more 'radical' posture with respect to desired change 


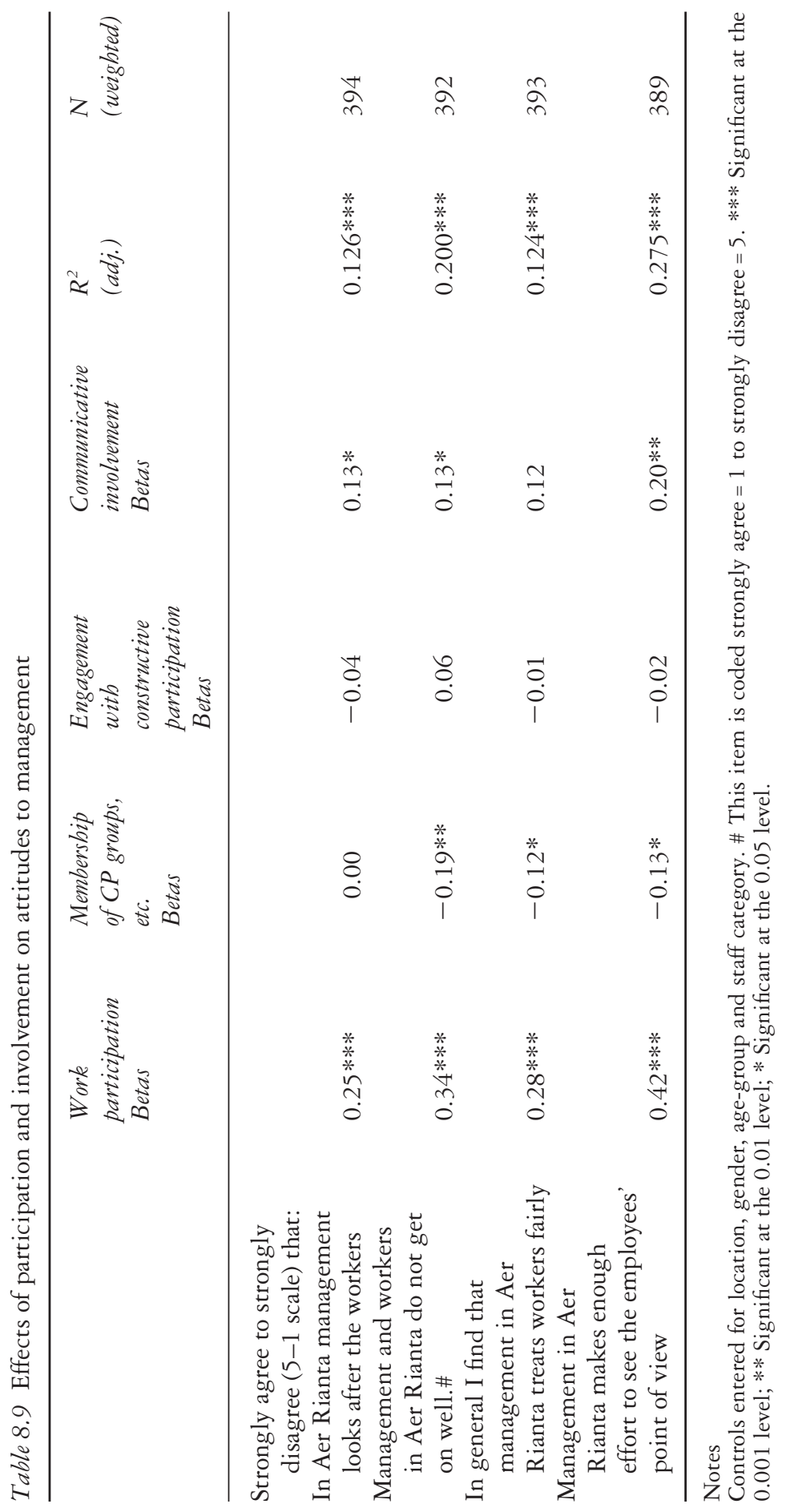


in decision-making and management behaviour in the company and that this accounted for their attitudes to management, as revealed in Table 8.9.

We move next to consider whether the various activities associated with $\mathrm{CP}$ affected levels of organizational commitment within Aer Rianta. Organizational commitment was measured using the scale developed by Porter et al. (1974). Full details of the scale and of scale statistics are outlined in Table A4 in the Appendix. The complete scale provides a composite measure of variations in employees' commitment to the organization. It has been argued in the literature that the Porter Organizational Commitment Scale contains sets of items measuring discrete dimensions or facets of commitment which need to be distinguished and are worthy of study in their own right (cf. O'Reilly and Chatman 1986; Meyer and Allen 1997; Gallie et al. 1998: ch. 9).

Here we follow Gallie et al. (1998: 237-9) in distinguishing between 'effort commitment', 'flexibility commitment' and 'value commitment'. Effort commitment denotes the degree to which employees are willing to show commitment by putting in effort over and above normal expectations and by delivering exemplary performance. Flexibility commitment denotes a willingness to accept any assignment to keep working for the organization. Value commitment denotes a feeling of pride and loyalty towards the organization and a willingness to identify with its values. Though the concepts are derived from Gallie et al., the items used to measure them here are sometimes different to those adopted by Gallie and his colleagues and similar items are slightly differently worded (cf. Gallie et al. 1998: 237-9). Gallie et al. further note (1998: 237) that a number of items commonly used in commitment scales measure a rather passive or inertial dimension of commitment, involving a 'passive attachment or low capacity to leave the organization'. This dimension of commitment is similar to what Meyer and Allen (1997), in a well-known formulation of organizational commitment, describe as 'continuance commitment'. Meyer and Allen, however, associate this concept as much or more with an awareness of the costs of leaving the organization as with simple inertia or passivity (cf. Meyer and Allen 1997: 11-13). Here we will examine influences on continuance commitment, but understood and measured more in the sense of Gallie and his colleagues than Meyer and Allen. While this dimension of commitment might be viewed as of lesser importance for shaping employee performance, in an economic context such as that at Aer Rianta in the late 1990s, where the recruitment and retention of staff had become a major concern, it is of interest to determine whether involvement in CP may have affected employees' intentions to remain in the company.

In examining the effects of involvement with different aspects of $\mathrm{CP}$ on organizational commitment and its sub-components, it is necessary to take account of the commonly reported finding that 'industrial relations climate' may also be an antecedent of organizational commitment (Angle and Perry 1986; Magenau et al. 1988; Deery et al. 1994; Snape and Chan 2000). As 
outlined above, the items included in Table 8.9 are often regarded as indicators of industrial relations climate, and they are also found in this study to scale well $($ Alpha $=0.84)$. Reflecting the findings reported in Table 8.9, perceptions of the overall climate of industrial relations in Aer Rianta were positively influenced by work participation and communicative involvement and negatively influenced by membership of $\mathrm{CP}$ groups and committees and occupancy of CP roles.

Reflecting international research findings, perceptions of the climate of industrial relations were confirmed as an important antecedent of organizational commitment, as shown in Table 8.10. As such, it can be concluded that work participation and communicative involvement indirectly and positively influenced organizational commitment in Aer Rianta, while membership of CP groups and committees indirectly and negatively influenced organizational commitment: each exerting an influence through their effects on perceptions of the industrial relations climate. However, Table 8.10 also reveals that over and above such indirect effects, no aspect of involvement in $\mathrm{CP}$ had a robust direct effect on organizational commitment in its entirety engagement in $\mathrm{CP}$ just about attaining significance at the 0.10 level. The pattern with respect to the different types of commitment differs somewhat, however, where work participation is found to have exerted a direct influence on 'effort commitment' and 'value commitment' over and above the indirect effects operating through perceptions of the climate of industrial relations.

Finally, the survey data allow for an examination of whether a series of work practices were directly affected by involvement in different aspects of CP. Employees were asked to indicate how their work had changed in the three years preceding the survey as compared with before. Substantial majorities reported working harder, more productively and more cooperatively, said they had been willing to take on extra duties and had become more concerned to work for the benefit of the company. Taking account of this pattern, the effects of $\mathrm{CP}$ were assessed by examining the influence of different aspects of CP on the odds that employees reported positive changes in the work practices covered as distinct from reporting either no change ('the same') or change involving them working 'less' hard, less productively or less co-operatively. The results in Table 8.11 suggest that levels of involvement in $\mathrm{CP}$ activities in general had not directly influenced the working practices examined. Table 8.12 presents employees' views on the importance of a series of factors shaping the manner in which they had worked in the three years preceding the survey. What emerges is that changes brought about by $\mathrm{CP}$ had relatively little effect when compared with commercial pressures, concern about job security, management pressure or personal willingness to do a good job.

In summary and in answer to question 2 posed above, CP positively affected attitudes to management, primarily through changes that allowed more scope for participation in work-related decision-making and also 


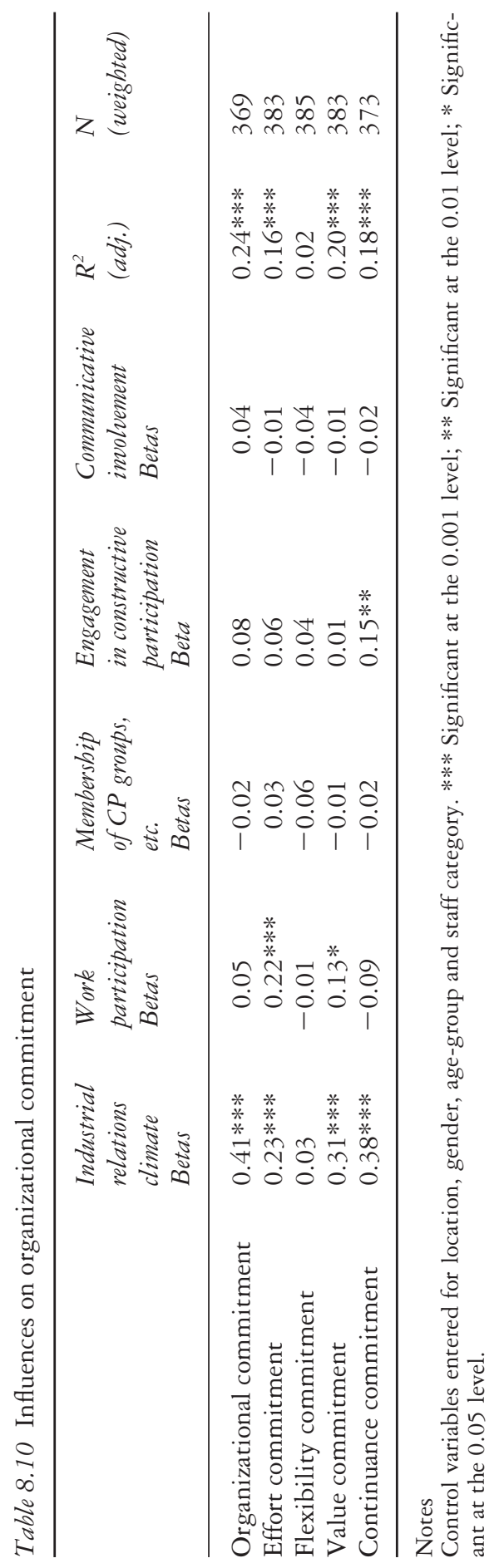




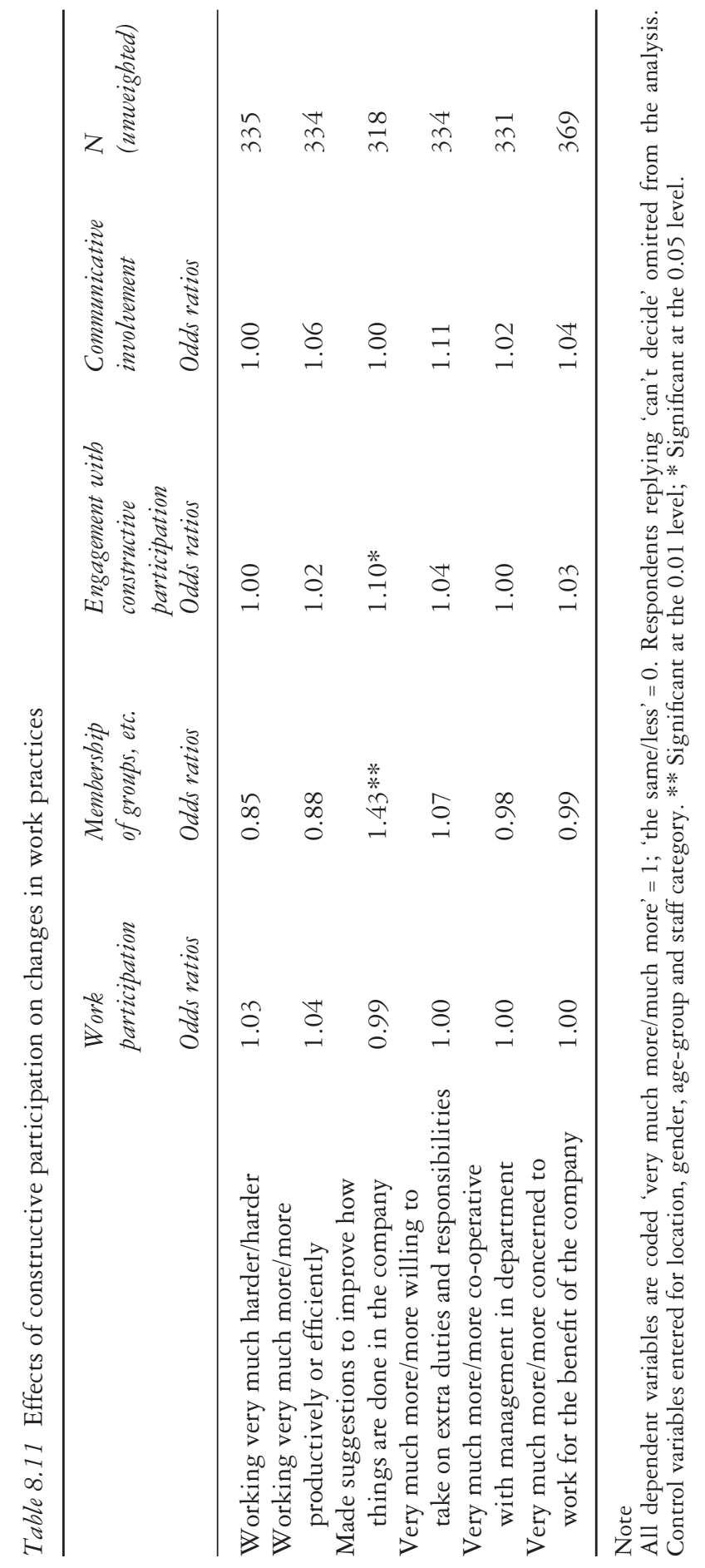




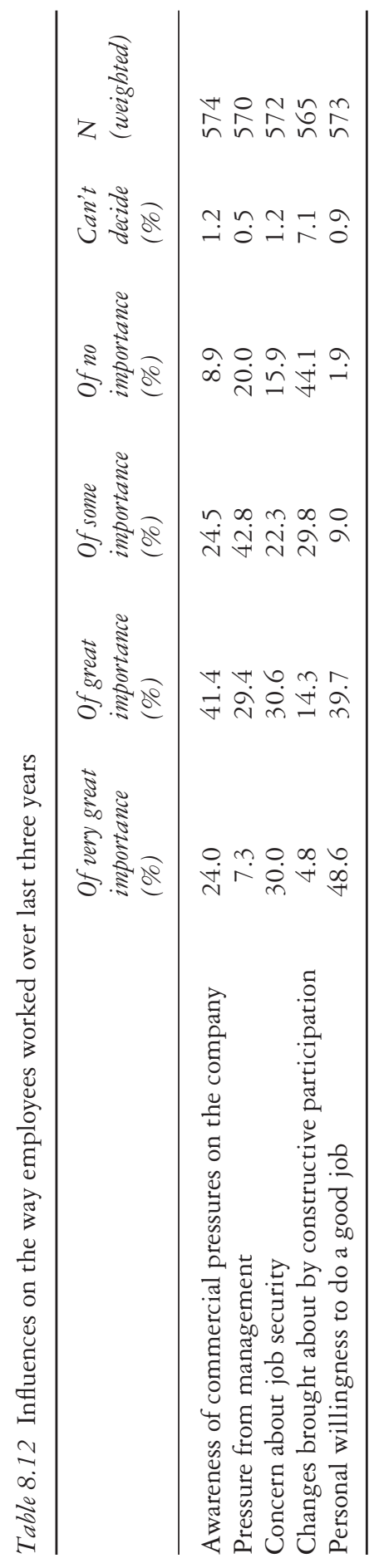


through the provision of more information on activities within the company. Formal involvement in $\mathrm{CP}$, through groups, committees and related roles negatively affected attitudes, probably by radicalizing those involved and increasing their frustration with the level and pace of change that prevailed. CP also indirectly influenced organizational commitment both positively and negatively through the effects of industrial relations climate on commitment to Aer Rianta. Certain aspects of organizational commitment, however, namely 'effort commitment' and 'value commitment' were also influenced directly by CP, through its effects in spreading more scope for work-related participation in the company. It appears that $\mathrm{CP}$ did not significantly affect a series of changes in work practices, those changes reflecting influences of a more conventional character.

\section{Teamwork}

Some 81 per cent of survey respondents indicated that they worked in teams, most ( 55 per cent) stating that their teams had been formally established by management. In interpreting these findings, it has to be borne in mind that Aer Rianta had not organized work on a formal teamwork basis, and that respondents, in the main, may have been describing a work context that involved people on shifts or in departments working with other employees. As outlined in Chapter 3, CP had, however, made provision for instituting formal teamwork throughout the organization, through the creation of 'regular work groups'. While the Requisite Arrangements document suggested that RWGs would engage in significant task-level decisionmaking, no detailed blueprint for the operation of $\mathrm{CP}$ teams had been developed. Furthermore, little progress was made in establishing regular work groups, and formal teams of this kind were confined to skilled trades in maintenance, as well as some areas of finance at Shannon. As a significant proportion of people working in trades were involved in regular work groups (75 per cent), we can examine the effects of RWG membership in trades on levels of work participation and autonomy and also on attitudes and behaviour.

The results reported in the first row of Table 8.13 indicate that members of regular work groups in trades had not experienced more scope for tasklevel participation than other employees in Aer Rianta. It is not surprising, therefore, to discover from the other findings reported in the table that regular work group membership in the department with the greatest level and depth of CP-initiated team activity had no significant effects on attitudes and behaviour more generally.

With respect to the formal work teams linked to partnership in Aer Rianta, it has to be concluded that their effects on autonomy, attitudes and behaviour were neutral. CP-linked teams neither confirmed the optimistic accounts of advocates, nor the pessimistic accounts of critics. What stands out in the case of Aer Rianta was the limited progress recorded in establishing 


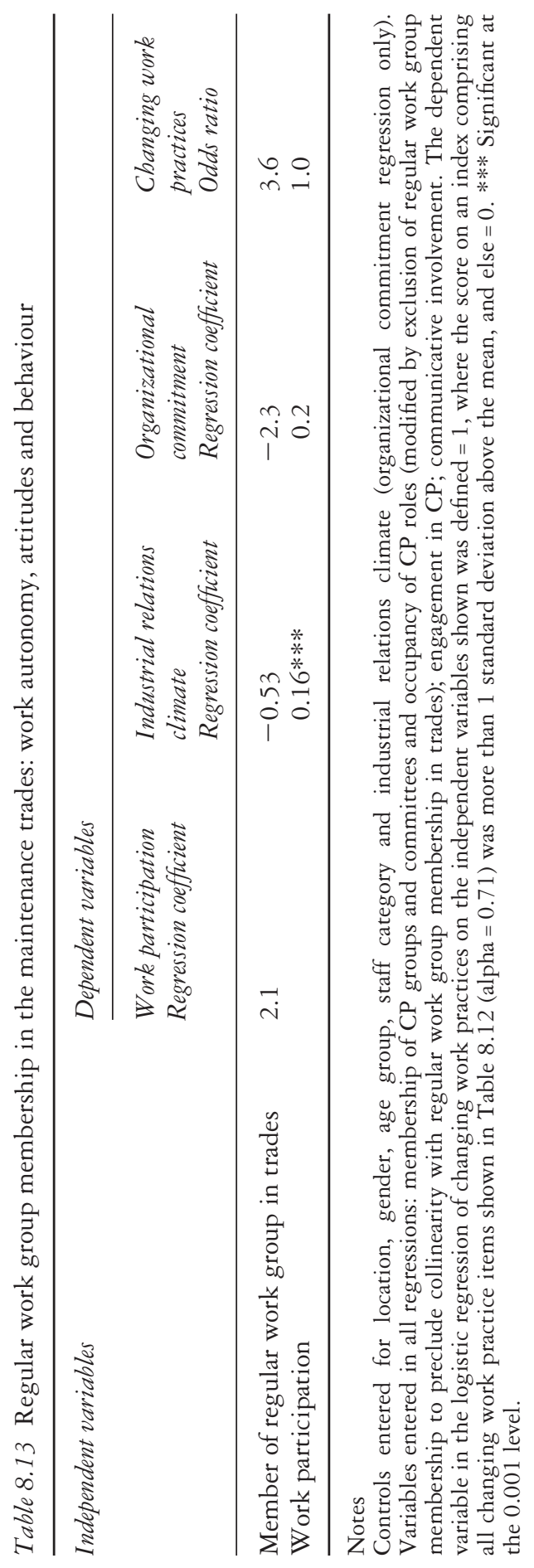


formal work teams, guided by the philosophy of the Compact and, in answer to question 3 above, the limited impact of the teams that were formally established on patterns of working, attitudes and behaviour.

\section{Effects of involvement in multiple CP channels}

Partnership commonly involves the creation of multiple channels or forums for employee and union involvement in decision-making, each channel providing scope for involvement in a different area or at a different level, and all channels expected to influence attitudes to the employer, as well as employee satisfaction and morale in a positive way. In this section we turn to an examination of questions 4 and 5 above, concerning the discrete and combined effects of different aspects of $\mathrm{CP}$ on attitudes and behaviour. The analysis of earlier sections provide an answer to question 4. Consistent with international research findings on involvement and participation in general, they suggest that task-level involvement had the most significant and consistent effects on a range of work-related attitudes and behaviour (but at the same time failed to influence a range of work practices). Other channels appear to have had more selective effects on attitudes and behaviour. For example, communicative involvement appears to have positively affected perceptions of the climate of industrial relations, while membership of $\mathrm{CP}$ groups and committees and occupancy of $\mathrm{CP}$ roles appears to have engendered frustration and negatively affected perceptions of the industrial relations climate. CP-linked formal teamwork, of limited scale or incidence in the company, had no significant effects.

In the case of Aer Rianta, therefore, most of the $\mathrm{CP}$ channels in operation had selective effects on attitudes and behaviour, in ways not clearly envisaged by the partnership literature. The latter seems to operate on the basis of the premise that 'more voice', in the sense of more voice channels, is better with respect to a range of valued outcomes. Judging by the findings in Aer Rianta, this premise appears problematic and different partnership channels can have highly specific and sometimes contrary effects.

The answer to question 5, concerning whether simultaneous involvement in multiple channels exerts a specific effect on attitudes and behaviour over and above the discrete effects of involvement in individual channels, requires further analysis. As outlined in Chapter 1 and earlier in this chapter, this 'vertical integration' premise underpins important contributions to the partnership literature, such as Cutcher-Gershenfeld and Verma's (1994) theoretical argument that a combination of direct/task-level and indirect/representative involvement exerts the greatest level of influence on outcomes valued by firms and employees, and Guest and Peccei's (2001) research finding that partnership firms combining direct and indirect involvement achieve superior performance outcomes.

Two approaches were adopted to examine whether involvement in multiple aspects of $\mathrm{CP}$ and multiple channels, incorporating both direct and 


\section{Employee attitudes and behaviour}

indirect forms of involvement, affected attitudes and behaviour. The first was to identify (using cluster analysis) those who were relatively highly involved across the main areas of $\mathrm{CP}$ examined in this chapter. Consistent with the 'vertical integration' premise in the literature, this group might have been affected in a specific manner through their relatively high level of involvement across multiple partnership channels. To test whether this was the case, a dummy variable representing this cluster was entered in combination with the other $\mathrm{CP}$ variables already examined in a series of regressions in which the various aspects of attitudes and behaviour examined in previous sections were denoted as dependent variables. The results of this analysis are presented in Table 8.14. For the sake of economy, only the results on the dummy variable representing the high $\mathrm{CP}$ involvement cluster are shown in the table. Only in the case of organizational commitment are the findings consistent with the premise that involvement in direct and indirect/ representative partnership channels positively affected attitudes and behaviour more than involvement in either of these types of channels alone.

A second approach was adopted which tested for the effects of paired combinations of different direct and indirect CP areas and channels (by including interaction terms for such effects in regressions). Based on theory, the potentially important effects here are those between scope for involvement in task-level decision-making, as indexed by the work participation scale (minus the unreliable RWG membership item), and either the scales measuring membership of $\mathrm{CP}$ groups, committees and occupancy of $\mathrm{CP}$ roles (minus the RWG membership item), or engagement in CP. The latter represents a somewhat diluted form of indirect participation, but merits consideration nonetheless, given its influence on some aspects of attitudes and behaviour. Other pairs of partnership channels were also examined,

Table 8.14 High constructive participation involvement, attitudes and behaviour

\begin{tabular}{llll}
\hline Independent variable & $\begin{array}{l}\text { Dependent variables } \\
\text { (Regression coefficients/odds ratio) }\end{array}$ & \\
\cline { 2 - 4 } & $\begin{array}{l}\text { Industrial } \\
\text { relations climate }\end{array}$ & $\begin{array}{l}\text { Organizational } \\
\text { commitment }\end{array}$ & $\begin{array}{l}\text { Changing } \\
\text { work practices }\end{array}$ \\
\hline High CP involvement cluster & -0.26 & $2.85^{* *}$ & 1.05 \\
\hline
\end{tabular}

Notes

The High CP Involvement Cluster group, comprising 20 per cent of the sample, emerged in a three cluster solution, employing K Means cluster analysis.

Controls entered for membership of CP groups, committees and occupancy of CP support roles, engagement in $\mathrm{CP}$, communicative involvement, work participation, industrial relations climate (organizational commitment regression only), location, gender, age-group and staff category.

The dependent variable for the changing work practices regression was defined as outlined in the note at the foot of Table 8.13. The coefficient reported is the odds ratio obtained from a logistic regression. ** Significant at the 0.01 level. 
although less well grounded in theory. To facilitate interpretation, all the areas and channels of $\mathrm{CP}$ examined were transformed into binary variables in which values of more than one standard deviation above the means of each $\mathrm{CP}$ scale were coded as 1 and other values as 0 . Interaction terms were based on pair-wise combinations of the $\mathrm{CP}$ variables transformed in this way. All the main dimensions of attitudes and behaviour considered above were examined in regressions that included the interaction terms.

The interaction terms were unsuccessful in demonstrating that high levels of involvement in specific combinations of direct and indirect channels or areas shape attitudes and behaviour. In answer to question 5 above, the overall pattern of evidence for AR with respect to the effects of combinations of partnership channels on attitudes and behaviour appears unimpressive. However, well-understood statistical problems that arise in estimating multiple interaction effects need also to be borne in mind. Also, this conclusion does not indicate that combinations of direct and indirect partnership channels have no effects on partnership outcomes, only that they appear in the case of Aer Rianta to have had no systematic or robust direct effects on the dimensions of individual-level attitudes and behaviour examined here.

\section{Mutual gains?}

The final research question posed earlier in the chapter concerns whether any positive effects of $\mathrm{CP}$ on attitudes and behaviour reflected beneficial effects for both the company and employees. This is important both in the light of the mutual gains premise that underlies the theoretical and prescriptive literature on partnership, and in the light of research in the UK and US which concluded that in practice the expected or actual outcomes from partnership may be skewed towards employers (Osterman 1999; Guest and Peccei 2001; Kelly 2004). A number of facets of attitudes and behaviour, examined above, incorporate areas of relevance to both Aer Rianta and employees: in particular items measuring perceptions of the climate of industrial relations and some items measuring organizational commitment. It is helpful, nonetheless, in considering the degree to which mutual gains accrued from $\mathrm{CP}$ at the level of individual attitudes and behaviour, to focus more directly on specific areas of concern to employees. Two items from the organizational commitment scale provide an index of work satisfaction: 'I am extremely glad that I chose this organization to work for, over others I was considering at the time I joined' and 'for me this is the best of all possible organizations for which to work'. These items combined result in a work satisfaction scale with an alpha coefficient of 0.73 . Two items used to measure the climate of industrial relations can also be combined to form a scale of perceived 'fairness' with respect to management's treatment of employees: 'in general, I find that management in Aer Rianta treats workers fairly' and 'in Aer Rianta, management looks after workers'. These items combined register an alpha coefficient of 0 . 80. One item from the set 
measuring assessments of $\mathrm{CP}$ provides a direct indicator of how employees assess the effects of partnership on their interests: 'employees interests are better represented by Constructive Participation' (scaled from 'strongly agree' $=5$ to 'strongly disagree' $=1$ ). Finally, while there is no direct indicator in the survey of employees' sense of employment security, an item asking employees to assess potential influences on the way they had worked in the three years preceding the survey provides an indirect indicator of perceptions of job security. Respondents were asked to assess whether concerns about job security had influenced the way they had worked, and replies were scaled from 'of very great importance' $=4$ to 'of no importance' $=1$.

The results obtained when these scales and items were regressed on the standard variables measuring different aspects of involvement in partnership are outlined in Table 8.15. They reveal that involvement in CP had mixed but generally positive effects on areas of particular concern to employees. Work satisfaction was positively related to work participation. Perceived fairness was also positively related to work participation and also to the extent of communicative involvement. Employees perceived their interests better served by CP the higher their level of work participation and the higher their level of engagement with CP. Those with higher levels of work participation were less influenced by concerns about job security but those with higher levels of engagement with $\mathrm{CP}$ were more influenced by concerns about job security. It appears that different aspects of $\mathrm{CP}$ thus had contrasting effects: employees with higher levels of work participation feeling less concerned about job security, while those involved in CP groups, committees and roles developed a heightened concern, based perhaps on their assessments of the prospects for Aer Rianta in formal CP forums, like SIGs and strategy groups.

In answer to question 6 posed above, the pattern of the findings overall confirms that mutual gains resulted from $\mathrm{CP}$ in the sense that involvement in different aspects of $\mathrm{CP}$ positively affected attitudes to the company and its relations with staff, as well as areas of specific concern to employees, such as work satisfaction, fairness and effectiveness in representing their interests. Also relevant are the findings from the two earlier Aer Rianta surveys, that employees wished for higher levels of involvement and participation in the company and that $\mathrm{CP}$ provided many of them with opportunities for higher levels of involvement at different levels. At the same time, it also emerged that CP appeared to have had no effect on changes in a variety of specific work practices that might have benefited the company, and that those most heavily involved in formal CP groups, committees and roles were most critical of the company's relations with staff and most concerned about job security.

\section{Conclusion}

The surveys undertaken in Aer Rianta in 1988 and 1995 indicated that employees were in general interested in substantially higher levels of 


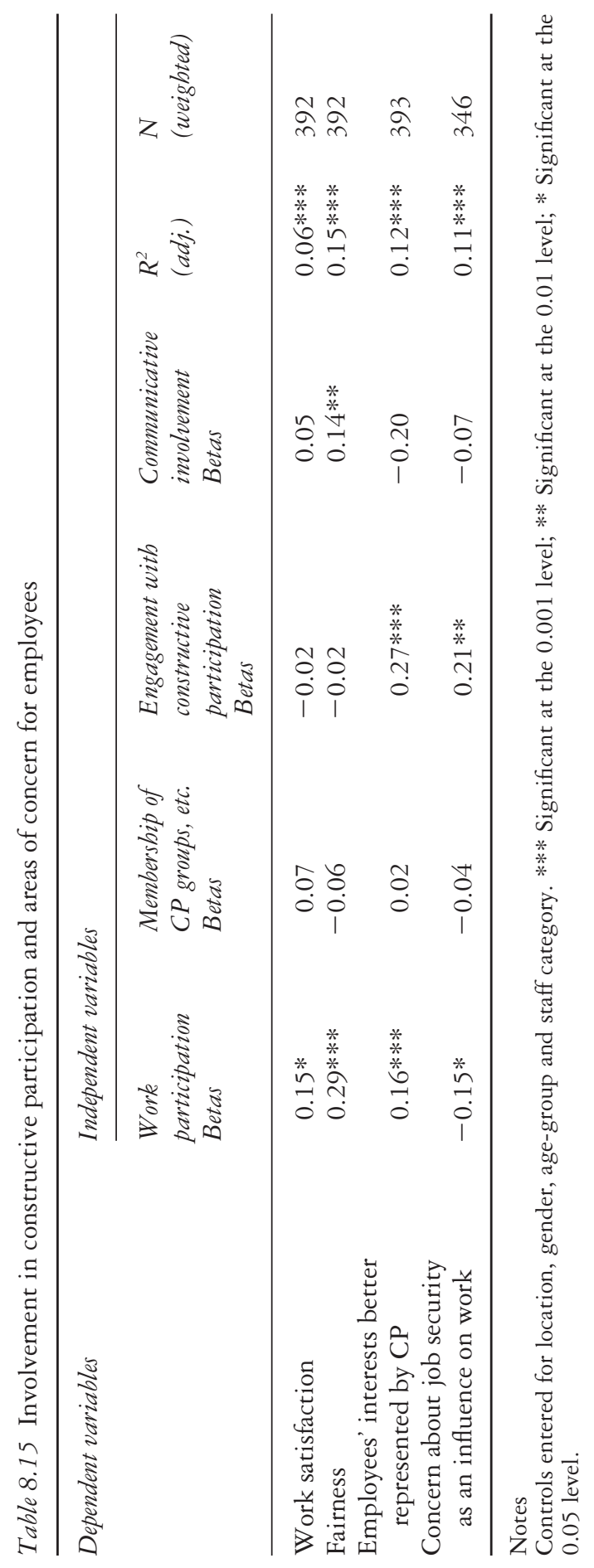


participation and involvement than then available to them. This was particularly so among those at the base of the occupational and grading structures in the company. By the time of the 1998-99 survey, CP had gained momentum and had led to the establishment of a series of structures, committees and support roles, as well as to a series of channels for information exchange, discussion and feedback concerning the workings and effects of participative initiatives. The level of advocacy in support of partnership of various kinds had also increased, as had the vehemence and coherence with which participation and involvement was advocated. $\mathrm{CP}$ was by now the formal policy of Aer Rianta. The build-up of momentum and the establishment of formal structures, arrangements and channels, in all probability led to expectations with respect to involvement and participation increasing commensurately. Sizeable numbers of employees soon participated in groups, committees and support roles established under the $\mathrm{CP}$ regime. Many more engaged the process through a range of channels for discussion, communication and feedback. $\mathrm{CP}$ was now expected to inform the routine conduct of work; to shape communication and decision-making at various levels; and to shape problem-solving initiatives focused on a series of commercial challenges and significant issues facing the company. The evidence suggests that employees in general were negative in their assessments of the effects of $\mathrm{CP}$ on decision-making and interest representation. This can probably be accounted for by rising expectations and doubts as to the scale of concrete achievements under $\mathrm{CP}$. Awareness of senior management divisions on the issue and experience of middle management resistance could also have coloured employees' assessment of CP. Also significant was the uneven penetration of $\mathrm{CP}$ across departments and categories, and, albeit to a lesser degree, across the airports, and the 'top-heavy' nature of the partnership that was realized.

But the various channels for participation and involvement set in train under CP had effects on attitudes to work. The higher the degree of work participation experienced by employees, and the higher their more general engagement with $\mathrm{CP}$, the better their assessment of $\mathrm{CP}$ and the more positive their assessment of its effects across a range of areas. Membership of $\mathrm{CP}$ groups and committees and occupancy of $\mathrm{CP}$ roles had positive effects in fewer areas: the ease with which decisions were made and the quality of decision-making. The higher the degree of work participation experienced by employees, the more positive were their assessments of the climate of industrial relations and the higher their level of organizational commitment. The effect of work participation on organizational commitment overall was mediated by its effect on perceptions of the climate of industrial relations. The more extensive people's involvement in groups, committees and support roles, on the other hand, the less favourable were their assessments of the climate of industrial relations - a finding that can best be accounted for by the radicalism of many of those most heavily involved and their concomitant impatience with the management ambivalence and opposition and the bar- 
riers and obstacles encountered. Though more critical of management, they were no more 'pro-union' in their attitudes than employees generally and no less committed to the organization.

No robust evidence could be found that CP increased the odds that employees had worked harder, more productively, flexibly or co-operatively in the three years preceding the survey. Large majorities of employees claimed that they had been working in more onerous, productive, flexible and co-operative ways in recent years, and they were emphatic that their work over this period was influenced primarily by an awareness of commercial pressures, concern about job security and their personal willingness to do a good job. Compared with these forces, CP was seen to have had only a modest impact. Evidently, external and internal pressures of a more conventional nature were seen by employees as the decisive forces influencing the way they had been working rather than participative principles, practices and arrangements.

The establishment of regular work groups on a widespread basis in the maintenance trades appeared to have had no specific effects on either levels of work participation or on the attitudes and behaviour of work group participants. The chapter also failed to identify compelling and consistent results supporting the argument that simultaneous involvement in direct and indirect partnership channels influenced attitudes and behaviour particularly strongly. However, a better case can be made on the basis of the findings that $\mathrm{CP}$ resulted in gains for both the company and employees in respect of significant aspects of attitudes and behaviour. At the same time, a series of work practices that might have benefited the company appeared not to have been affected by CP, while formal involvement in CP groups and forums had made employees more critical of management and more concerned about job security. 


\section{Dual commitment}

Chapters 7 and 8 revealed that partnership in Aer Rianta was associated neither with widespread opinion that unions were effective, nor with general approbation with respect to the consequences of $\mathrm{CP}$ for decision-making or understanding and trust between management and employees. These chapters also revealed, however, that experiences of aspects of $\mathrm{CP}$ in the main had positive effects on perceptions of the climate of industrial relations and on commitment to both unions and the company. This chapter examines whether significant numbers of employees were committed to both the company and the union: characterized, in other words, by 'dual commitment'. The chapter begins by considering why dual commitment might be found in organizations with formal partnership arrangements, and by reporting international research on dual commitment and industrial relations practices. It then examines conceptual issues and problems that arise in the study of dual commitment. The chapter's main research findings are then reported and interpreted in the concluding section in the context of the discussion of the introduction of CP in Aer Rianta in Chapters 3-6.

\section{Dual commitment and partnership}

As outlined in Chapter 1, dual commitment is a long-established concern of US industrial relations research, where it arose originally around a concern that unions might detract from commitment to the corporation (Deery et al. 1994). During the past two decades, the concept has become more closely tied in the international research literature to the attitudinal and behavioural effects of 'new industrial relations' reforms of various kinds, promoting management-union co-operation (see Guest and Dewe 1991; Deery et al. 1994; Guest 1995).

The relevance of dual commitment to voluntary partnership is clear. New industrial relations initiatives in general and partnership initiatives specifically, seek to promote commitment to the company by involving employees in decision-making both directly and through their trade unions. If commitment to the company comes at the expense of commitment to trade unions, serious short-term or long-term organizational problems might arise for 
unions from their involvement in new industrial relations and partnership arrangements. If, on the other hand, unions could actually strengthen their members' commitment by involving themselves in organizational governance, by engaging management around new agendas beyond adversarial collective bargaining, by representing members in new and co-operative ways, and by encouraging members to engage in various forms of direct participation, they too stand to benefit organizationally from partnership (Freeman and Rogers 1999; Kochan 2000). If such benefits can accrue to trade unions, it follows that they can promote partnership in the confidence that any advantages arising for the company, as well as for their members as employees, will not be at their organizational expense and could, on the contrary, strengthen unions' capacity to represent and mobilize their members.

\section{Research findings}

The international research literature suggests that the proposition that partnership-type arrangements might foster dual commitment is neither fanciful nor universally supported. US research has most commonly reported the existence of dual commitment and has found links between dual commitment, task participation, co-operative industrial relations programmes and positive industrial relations climates. It has also commonly marshalled these results to support arguments that both employers and unions can benefit from new industrial relations and partnership. Angle and Perry (1986), for example, found that employees in municipal bus companies were more committed to their companies and trade unions, the more co-operative they perceived industrial relations to be in their workplaces. Magenau et al. (1988) also found that job satisfaction and perceptions of a positive climate of management-union relations were related to company and union commitment among a sample of union members in a branch in the US midwest.

Studies in other countries have produced more uneven or negative findings. Deery et al. (1994), for example, found no evidence of dual commitment among a sample of Australian white-collar workers. Positive perceptions of the industrial relations climate were shown to be positively associated with commitment to the company but negatively associated with commitment to the union. The implication of this finding for Deery and his colleagues was that union involvement in co-operative programmes might damage members' involvement in trade union affairs (Deery et al. 1994: 592-4). In the case of the UK, Guest and Dewe (1991) found that the level of dual commitment was low among a sample of employees in the electronics and electrical consumer industries. More prevalent was a pattern involving weak commitment to both company and union. Dually committed employees, however, were more satisfied with the scope for involvement in the workplace, including involvement in communication and personal development (Guest and Dewe 1991: 91-4). The same study also reported 
data from a comparative survey suggesting that dual commitment was more common in countries such as Germany, Sweden and Japan, where participative mechanisms - of different types - promoted 'integrative bargaining' and a greater sense of shared identity between organizations and their employees.

By way of a summary of existing findings and their implications, the following conclusions seem reasonable. Many aspects of partnership, like cooperative industrial relations arrangements, job influence or autonomy, positive relations with supervisors, a positive industrial relations climate and perceived union effectiveness, have been shown to be positively associated with organizational commitment or union commitment, or sometimes with both types of commitment. But, on the whole, the pattern of research findings, certainly outside the US, suggests that organizational commitment and union commitment may commonly be rooted in distinctive sets of antecedents. Research also suggests that some antecedents of commitment to employing organizations, for example, perceptions of the climate of industrial relations, could sometimes be negatively associated with commitment to trade unions. It is thus an open and, it would seem, a highly pertinent question whether context may matter, in the sense that positive effects on organizational and union commitment - and thus significant levels of dual commitment - might be more likely to be found where formal partnerships, agreed between management and unions, result in the 'bundling' of many partnership-type arrangements together in the context of joint governance structures, supported by compatible competitive strategies and supportive sets of HR and industrial relations practices (employment security, training and development policies, etc.). Arguably, this may be the major question regarding the possible link between partnership and dual commitment, and it is this question that will be examined empirically in this chapter. First, however, it is necessary to examine conceptual concerns that arise in the study of dual commitment.

\section{Conceptualizing and measuring dual commitment}

To some extent, the contrasting research results, discussed above, may also reflect differences in approaches to conceptualizing and measuring dual commitment. While, as noted earlier, scholars broadly agree as to the nature of commitment to the organization and commitment to the union, the same is not true with respect to dual commitment. Gordon and Ladd (1990) go to the heart of the most important difference of approach arising here in their distinction between 'dimensional' and 'taxonomic' approaches to the study of dual commitment. The dimensional approach involves separately measuring organizational and union commitment and defining dual commitment as a positive association or correlation between employees' scores on scales measuring each construct. Dual commitment is said to exist in instances where a strong positive correlation is found that cannot be attributed to 
chance or sampling error. A problem with this approach is that a positive correlation between variables measuring the constructs only shows that the two measures co-vary but not the extent of high levels of commitment simultaneously to unions and their employing organization (see Gordon and Ladd 1990: 51; Guest and Dewe 1991: 83; Sverke and Sjoberg 1994: 536-7).

The taxonomic approach, on the other hand, identifies the extent of dual commitment in terms of the attributes of individuals by locating them within types or classes of commitment (e.g. dual commitment, union commitment, company commitment and dual non-commitment). This is usually done on the basis of their scores on separate scales of company and union commitment. Critical here is the choice of the scale cut-off points that determine how individuals are allocated to such categories. Researchers have chosen scale cut-off points in various ways. One approach uses absolute scale values to classify individuals. For example, those on average selecting response options expressing 'very high' or 'high' levels of commitment across the items on both the union and company commitment scales might be identified as showing dual commitment. Alternatively, those scoring on average at or above the mid points on both scales are sometimes said to show dual commitment. An objection to this approach is that the choice of cut-off points often appears theoretically arbitrary. If the cut-off point chosen is modest (e.g. scale values representing such response categories as 'agree' or 'neutral'), individuals might be classified as showing dual commitment to union and company, when, in reality, they may be largely indifferent or, at best, moderately positively inclined towards both the company and unions.

A second variant of the taxonomic approach uses the sample distributions of commitment levels - usually mean or median levels within the sample - to determine cut-off points to use in allocating individuals to commitment classes. The objection here is that individuals expressing modest overall levels of commitment to union and company might be classified as showing dual commitment simply because their levels of commitment to both institutions are above average relative to the sample under study. A third variant uses cluster analysis to reveal whether a series of classes of individuals with distinct commitment profiles may be 'latent' within the sample and, where this is shown to be the case, whether some of the latent classes thus identified are characterized by their high scores on company and union commitment scales.

What should be kept in mind, above all, we would suggest is the ultimate substantive concern of recent research on dual commitment in the context of partnership and new industrial relations practices more generally: that is to examine whether such arrangements can engender high levels of commitment to both company and union among a significant proportion of employees and union members. This principle will guide our analysis below of commitment to the company and unions in Aer Rianta. 


\section{In search of dual commitment in Aer Rianta}

In this study, as outlined in Chapter 7 , union commitment is measured using the 12-item version of the scale developed by Gordon et al. (1980). Scale details and associated scale statistics are outlined in Table A2 in the Appendix. Organizational commitment is measured using the 15 -item scale developed by Porter et al. (1974). Details of scale items, descriptive statistics and scale reliability statistics are outlined in Appendix Table A4. As discussed above, the dimensional approach identifies dual commitment in terms of a strong positive association between commitment to the organization and to the union. Dual commitment is said to exist where there is a tendency for levels of commitment to the union and organization to co-vary: those with low commitment to the union displaying low commitment to the organization, those with moderate commitment to the union being moderately committed to the organization and those with high commitment to the union also being highly committed to the organization.

Figure 9.1 presents a scatterplot showing the relationship between union and organizational commitment and displays the correlation coefficient between the variables. The scatterplot suggests that little in the way of a linear relationship exists between the two types of commitment, and this is confirmed by the low and insignificant correlation coefficient $(r=0.028$; $p=0.26$ ). If anything, the scatterplot suggests a 'swarm' of points around the middle of both commitment scales, pointing towards an underlying pattern in which a large proportion of people in Aer Rianta were characterized by moderate or neutral levels of commitment towards both the company and their unions.

The taxonomic approach, discussed above, arguably conceives of dual commitment in an intuitively and theoretically more compelling way by examining whether a significant proportion of employees demonstrate high levels of commitment to both union and organization, irrespective of any

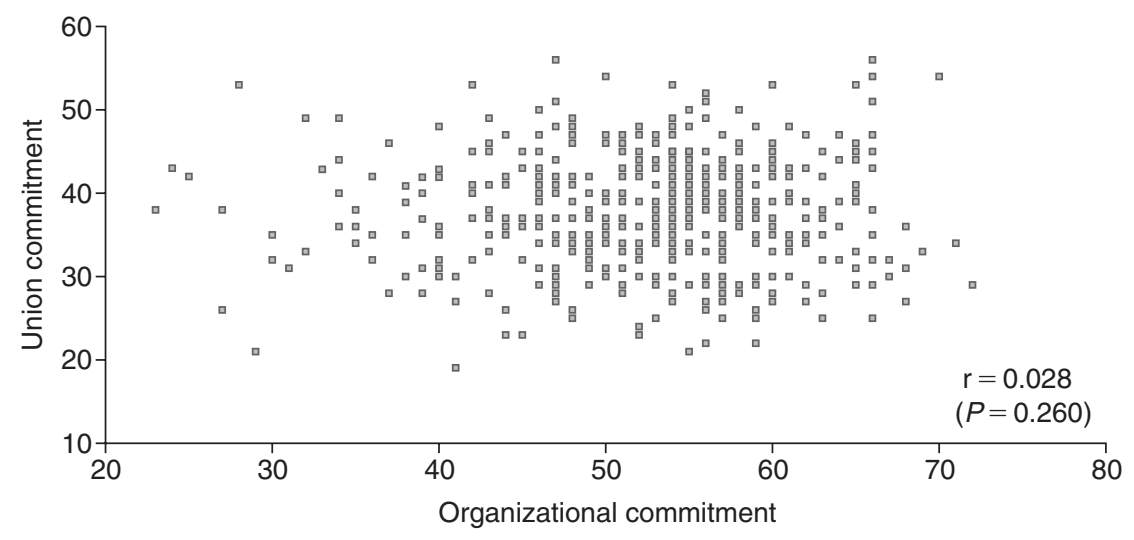

Figure 9.1 Scatterplot of union and organizational commitment. 
pattern of association that may exist between the variables across their entire range of values - the focus of the dimensional approach. The critical issue here though is how 'high' is to be defined. A problem with using median or mean values on each scale to split the sample into four quadrants - "dual committed' (equal to or above the means or medians on both scales); 'union committed' (equal to or above the mean or median on the union scale only); 'company committed' (equal to or above the mean or median on the organizational commitment scale only); and 'dual non-committed' (below the means or medians on both scales) - emerges from inspecting the scatterplot in Figure 9.1. While medians or means can be used to split the sample into four quadrants, most of the actual values in the sample, as discussed above, appear to cluster around the mid points of both scales, suggesting moderate levels of commitment to both unions and the company. The use of median or mean splits, therefore, creates commitment categories by forcing much of the scatter of points around the mid values of both variables into neat but rather artificial quadrants.

It seems preferable to use the scale options presented to those responding to the survey as a basis for identifying 'high' commitment to both unions and the company. This amounts to relying on the actual responses of those surveyed rather than statistically defined distributions within the sample. For each item on the union and company commitment scales, outlined in Tables A2 and A4, respondents were asked to indicate the degree to which they either agreed or disagreed with a statement. The response options, coded 1-5, were 'strongly disagree', 'disagree', 'unsure', 'agree' and 'strongly agree'. Using the pattern of responses to the 15 company commitment items and 12 union commitment items, it is possible to identify as 'highly committed' those whose composite scores on each scale are consistent with an average overall pattern of response within the 'agree' to 'strongly agree' range; to identify as non-committed those with composite scores falling on average within the 'disagree' to 'strongly disagree' range, and to identify as 'neutral' those whose average scores fall between these two intervals. Following this approach and cross-tabulating total points scores on each of the commitment scales, we derive the nine $(3 \times 3)$ descriptive categories of commitment outlined in Table 9.1. What emerges from this analysis is that the underlying level of dual commitment in Aer Rianta - here defined as the proportion affirming positive overall attitudes to the items on each scale was very modest indeed. What emerges is that the bulk of the sample was concentrated in and around the category of neutral towards both the union and management or neutral towards one and committed to the other - a finding also suggested by the scatterplot in Figure 9.1.

To cross-validate these findings, standard cluster analysis was undertaken on the union and organizational commitment scales. The objective was to determine whether distinct groups of cases could be identified and, if they could, to consider what the nature of these groups might be with respect to their profiles on the commitment scales. Four- and nine-cluster solutions 
Table 9.1 Categories of commitment to the union and the company

$(\%)$

High union and high company commitment (dual commitment)

High union and neutral company commitment

High union and low company commitment (union commitment)

Neutral union and high company commitment

Neutral union and neutral company commitment

Neutral union and low company commitment

Low union and high company commitment (company commitment)

Low union and neutral company commitment

Low union and low company commitment (dual non-commitment)

0.2

\section{Notes}

High union commitment $=$ score from 48 to 60 on the 12 -item union commitment scale; neutral commitment $=$ score from $25-47$ on the scale; low commitment $=$ score from $12-24$ on scale.

High company commitment $=$ score of 60 to 75 on the 15 -item organizational commit ment scale; neutral commitment $=$ score of 16 to 59 on the scale; low commitment =score from 15 to 13 on scale.

Results based on weighted sample data.

were specified a priori. The first solution was examined following the premise guiding taxonomic approaches using median and mean scale cut-off levels that four commitment groups might be identifiable: 'dual committed', 'union committed', 'company committed' and 'dual non-committed'. The second solution was examined in line with the nine categories identified in Table 9.1. The results are shown in Table 9.2. It emerges that irrespective of whether a four- or nine-cluster solution is assessed, most clusters group cases around the 'neutral' values ranges on the union and organizational commitment scales.

Finally, a series of latent class models was fitted to the union and company commitment scales. The results are presented in Table 9.3. A model testing the hypothesis that only one class exists in the data provides a baseline by formalizing the hypothesis that the two commitment variables are mutually independent and provide no basis on which to assign people to separate classes or clusters. The $\mathrm{L}^{2}$ for this baseline model indicates that the one class model is supported.

Although Chapters 7 and 8 revealed that aspects of CP inclined employees positively towards the organization and union members towards their unions, the analysis presented in this chapter shows that dual commitment was not a feature of the workforce in AR. This emerges whether a dimensional approach or a taxonomic approach of a defensible kind is adopted towards the study of dual commitment. 
Table 9.2 Cluster analysis of union and organizational commitment scales

\begin{tabular}{|c|c|c|c|}
\hline & \multicolumn{3}{|c|}{ Cluster centroids } \\
\hline & $\begin{array}{l}\text { Union } \\
\text { commitment }\end{array}$ & $\begin{array}{l}\text { Organizational } \\
\text { commitment }\end{array}$ & $\begin{array}{l}\text { Cases in } \\
\text { clusters } \\
(\%)\end{array}$ \\
\hline \multicolumn{4}{|c|}{ Four-cluster solution: } \\
\hline Cluster 1 & 34.45 & 46.64 & 23.5 \\
\hline Cluster 2 & 41.73 & 38.30 & 11.6 \\
\hline Cluster 3 & 44.62 & 55.55 & 38.2 \\
\hline Cluster 4 & 33.08 & 58.45 & 26.9 \\
\hline $\mathrm{N}$ (weighted)* & & & $(510)$ \\
\hline \multicolumn{4}{|c|}{ Nine-cluster solution: } \\
\hline Cluster 1 & 33.47 & 63.37 & 9.3 \\
\hline Cluster 2 & 29.03 & 42.28 & 6.2 \\
\hline Cluster 3 & 37.87 & 47.47 & 17.7 \\
\hline Cluster 4 & 34.60 & 45.23 & 3.4 \\
\hline Cluster 5 & 45.23 & 38.83 & 5.4 \\
\hline Cluster 6 & 46.58 & 61.88 & 8.1 \\
\hline Cluster 7 & 47.31 & 51.62 & 14.7 \\
\hline Cluster 8 & 39.95 & 55.79 & 23.4 \\
\hline Cluster 9 & 29.95 & 54.91 & 12.1 \\
\hline N (weighted)* & & & $(504)$ \\
\hline
\end{tabular}

Notes

Cluster analysis based on the K-Means algorithm. * Percentages are subject to rounding errors.

Table 9.3 Latent class cluster models fitted to union and company commitment scales

\begin{tabular}{lllll}
\hline Latent class models & $L^{2}$ & Df. & P Value & BIC \\
\hline One class & 1,079 & 1,680 & 1.00 & $-9,395$ \\
Two classes & 1,073 & 1,677 & 1.00 & $-9,384$ \\
Three classes & 1,074 & 1,674 & 1.00 & $-9,364$ \\
Four classes & 1,074 & 1,671 & 1.00 & $-9,345$ \\
\hline
\end{tabular}

Note

The two-class model was 'unidentifiable', indicating that no unique computational solution could be found for model parameters. 


\section{Dual commitment}

\section{Conclusion}

The literature on new industrial relations and workplace partnership has suggested that the involvement of employees and unions in organizational decision-making at various levels might engender high levels of commitment both to the employer and to the union. The results reported here show that workplace partnership in Irish airports, although multi-stranded and multi-level in ambition and format, did not engender dual commitment in any meaningful or robust sense among a significant proportion of the workforce. Most employees and union members appear to have adopted a broadly neutral posture towards unions and the company.

That dual commitment has not emerged in any robust or widespread sense we attribute to the obstacles faced by $\mathrm{CP}$ and to the nature of the mutual gains achieved. It may be that only deeply institutionalized partnership arrangements can transform attitudes and behaviour to the degree required to foster dual commitment. In the absence of multi-level arrangements for shared decision-making at all levels, operating consistently and in depth over time, it may be that dual commitment is likely to remain a feature of a very modest number of employees. As outlined in Chapter 3 and further revealed in Chapters $4-8$, the spread of CP across the company had been uneven and contested at the time of the survey, notwithstanding the fact that partnership had also become the declared official policy of both management and unions, and involved a joint compact, an agreed set of arrangements and supportive $\mathrm{HR}$ and industrial relations policies. Some supports to partnership, such as reward systems based on gain-sharing and financial participation, were subject to deliberation through partnership structures but had yet to materialize. The same was true of plans to revise industrial relations structures and procedures. Moreover, in seeking to establish partnership, half measures may have unintended consequences, as reflected in Aer Rianta by the negative effects on attitudes of involvement in $\mathrm{CP}$ groups and committees and occupancy of CP support roles.

The most concrete and tangible areas where CP had affected organizational decision-making to a significant degree concerned the handling of the duty-free crisis and the development of proposals on the future of the company. Important though these achievements may have been, they were salient mainly to senior union officials and managers, conscious of what might have happened had partnership not provided a channel for the handling of such critical issues. For employees and union members more generally, what probably shaped attitudes to a greater degree and extent were day-to-day features of partnership in the company and, at this more mundane level, the effects of partnership were constrained by such things as the uneven diffusion of partnership principles, structures and practices; the opposition encountered from managers; the difficulty of identifying clear, systematic tangible benefits, and the modest progress recoded in such areas as instituting reward systems based on mutual gains principles. Because 
efforts to institute partnership arrangements remained focused, in the main, around a small elite group of management and union champions; pivoted mainly around exercises in strategy formulation at the apex of the company; and remained in practice 'contested terrain', it was not perhaps surprising that high commitment to the company and the unions was engendered to such a limited extent. In the circumstances that prevailed in Aer Rianta, maybe indifference and neutral attitudes to unions and the company were predictable outcomes after all. 


\section{The breakdown of partnership}

To this point, the analysis has examined the emergence of workplace partnership in Aer Rianta, its development and roll-out and its consequences for management, employees and trade unions. The discussion revealed how all parties - management, unions and workers - though critical of some or even many aspects of $\mathrm{CP}$, were able nevertheless to point to benefits and achievements that flowed from the initiative at some stages or levels in the process. The survey of employees' views in Chapter 8, which involved over 600 respondents across the three airports, revealed that, the more intimately involved employees were with $\mathrm{CP}$ activities and the greater their level of job autonomy, the more positive their attitudes to partnership; the more positively they viewed employee relations; and the higher their level of commitment to both their jobs in Aer Rianta and to their unions. Partnership also engaged constructively with the two major commercial challenges which the company faced in the late 1990s - the loss of intra-EU duty-free sales and the strategic review of the company - to the degree that traditional managerial decision-making processes and industrial relations channels were subsumed. The Compact also set down clear parameters for the company's business strategies which committed management and unions to working cooperatively to ensure that the future success of the company was based on prioritizing quality and customer service over labour costs and flexibility.

Notwithstanding these and other achievements, CP confronted significant difficulties and tensions, as reported in Chapters 3 to 7. Critically, support within management was divided across different levels of management and among groups of managers at different levels. Senior management postures, in particular, were perceived as being ambiguous. Middle management at the outset felt marginalized by $\mathrm{CP}$ and had considerable misgivings and fears as to the likely consequences of increased employee autonomy and participation for their roles and positions. Perceptions of management division fed union scepticism of partnership and its prospects, and divisions also existed within the unions regarding the operation of the Compact. Worker directors in the main remained detached from the process, and the issue of whether they had been active in advancing the case for partnership at board 
level remained highly contentious among champions of $\mathrm{CP}$. The day-to-day operation of $\mathrm{CP}$ came to depend on the energy and support of a small number of individuals in management and in the unions. To the degree that the Compact became associated with these 'champions' and lacked wider and deeper support among senior management, in particular, it became easy justifiably, or for the convenience of sceptics and opponents - to label CP as having become an independent and self-serving institution.

But it would have been a major surprise to witness an initiative of this scale and significance, certainly when viewed against international experience with management-union partnerships, advancing in a smooth and progressive path. This is especially the case where partnership was introduced in a site, as in Aer Rianta, of long-established industrial relations practices and traditional managerial processes. In short, change of the depth and extent envisaged by $\mathrm{CP}$ is difficult, faces multiple barriers and thus $\mathrm{CP}$ in Aer Rianta was never likely to develop in a linear, easy manner.

Yet the challenges and setbacks through the mid to the late 1990s were not sufficient to derail CP. But shortly thereafter, the conditions which had been conducive to the growth and development of partnership were to change fundamentally. In broad terms, two sources of change can be identified. First, the already defined tensions associated with CP, particularly those at the interface between partnership and industrial relations, became more pronounced. Second, the governance, political and commercial contexts altered significantly. This chapter considers the significance and consequences of these two sets of challenges to partnership from the end of 1999 up to 2004 . They will be treated in turn.

The analysis presented in this chapter draws on a series of in-depth interviews with senior management and union and worker representatives in Aer Rianta, conducted between November and December 2002, and also draws on various documentary sources.

The discussion begins with a brief review of why partnership arrangements may fail. The issues identified will provide the context for the chapter's examination of the demise of CP in Aer Rianta.

\section{Accounting for the breakdown of partnership arrangements}

The principal reason identified in the literature as to why voluntary partnership arrangements are likely to falter and perhaps eventually break down is their vulnerability in the absence of strong, robust institutional supports, as discussed in Chapter 1. Both critics and advocates of partnership are equally awake to this difficulty. For Streeck (1992: 323-6; 1995: 330), to reiterate, without the 'hard' institutional constraints of the kind buttressing statutory works councils in Germany, voluntary partnership arrangements are inherently unstable as they remain exposed to the pressures of short-term exigencies, fluctuations in the balance of power and opportunistic defection by 


\section{Breakdown of partnership}

employers. Essentially, workplace co-operation is at risk because it is dependent, Streeck argues, on the goodwill or enlightened self-interest of employers, and principally whether it is seen to continue to serve particular economic or competitive functions. In something of the same vein, Kochan, one of the principal advocates of partnership, has together with Rubinstein argued that, in the absence of changes in labour law and significant shifts in power and ideologies within companies and unions, partnership experiments of the kind witnessed in GM's Saturn plant are unlikely to diffuse and prosper (Kochan and Rubinstein 2000: 382).

Reasons outlined in the literature as to why the parties to voluntary workplace partnership arrangements might be compelled to defect, or think it advantageous or convenient, vary. First, defection might be seen to be the most advantageous strategy for either party once partnership is seen to have delivered all that it can possibly offer. In this scenario, management's and unions' commitment to partnership arrangements is seen to be tactical: the partnership is exploited for its possible benefits, but once these have been exhausted, or key features of the organizational context have changed, other avenues for managing workplace change and regulating the employment relationship are pursued. In our review of the existing literature in Chapter 1, we saw how turbulent markets and shifting organizational boundaries may imperil partnership agreements, even in instances where they seem to be capable of delivering significant gains. As firms seek to respond to different competitive threats, so too may they feel constrained or choose to alter their approach to union-management relations. Relatedly, continued management support for partnership arrangements is seen to depend on ostensible contributions to the economic performance of the organization (Rubinstein and Heckscher 2003: 195).

Edwards et al. (2002a: 5) place less store however on the vagaries of competitive conditions as an explanation and instead emphasize that cooperative relations between employers and workers eventually work through to make the former feel insecure. '(I)f it is possible to work with labour, then', Edwards et al. ask, 'who needs the apparatus of supervision and then who needs the capitalist at all?' Citing the case of Saturn, they suggest that this managerial insecurity was the reason why the lessons derived from that partnership initiative were kept tightly insulated and not generalized to the rest of General Motors, in spite of the explicit objective that Saturn was to serve as a laboratory for experimentation and learning for the rest of the corporation. In a similar vein, Hammer and Stern (1986) argue that employers withdraw from partnership arrangements when their prerogatives and powers are challenged, and return to a partnership approach when the threat subsides. The view that employers' strategies might move between such positions is well documented in the wider employment relations literature. The 'cycles of control' model, as it is often referred to, is associated in particular with the classic work of Friedman (1977) and Ramsay (1977). (For a critical review of this theory's usefulness in explaining the diffusion of 
participative work structures in the 1980s and 1990s, see Edwards et al. 2002b.)

In the same way, a union's calculus of the benefits of remaining within a partnership arrangement may alter over time, particularly where the potential gains are seen to be greater by making a tactical return to the adoption of adversarial postures. Hammer and Stern's (1986) insightful analysis of union participation in management decision-making liken these shifting postures to a 'yo-yo' model of co-operation. Their starting point is that partnership arrangements are inherently unstable and that, where unions enter into such arrangements, they are likely to alternate between cooperative and adversarial behaviours. This instability is premised first on the classical pluralist assumption of a conflict of interest between unions and employers. For Stern and Hammer, partnership arrangements are thus cast within a guarded mould from the outset: fundamental differences of interest are set aside on a temporary basis in favour of common interest goals, and engagement in joint problem-solving activities will be ensured for as long as co-operation benefits the union and its members or is seen not to affect them adversely. Second, there is, as Stern and Hammer see it, the on-going requirement of union leaders to maintain control over the rank and file in an effort to maintain their legitimacy and credibility in the eyes of management. Their confidence and continued support for collaborative structures is, in turn, contingent on a number of factors. These include a formal vote among the membership to endorse union participation in the partnership initiative; an assurance that partnership activities will not threaten the leadership's control over union members; and finally, that the union remains intact as a cohesive organization and avoids fragmenting into competing factions.

The influences identified as moving a union in and out of a partnership relationship with management are a combination of the strength of the incentive to co-operate, the risks and costs of continued co-operation, and managerial actions or events that decrease the costs to an acceptable level. But with each successive return, or attempt to revive the partnership initiative, unions' commitment will, Stern and Hammer argue, be progressively diminished and, especially, where both parties maintain their traditional roles and partnership and collective bargaining are expected to exist as parallel, non-overlapping structures. Such an outcome can be avoided however, the authors argue, when both parties derive benefits, gradually change their attitudes and roles, and move towards what is now referred to as integrative or mutual gains bargaining.

Second, defection is seen to be a consequence of tensions generated within unions, as decision-making processes become centralized with the establishment and operation of partnership arrangements (Heckscher 1988: 127; Kelly 1999; Rubinstein and Kochan 2001; Terry 2001; 2003b). We referred to this syndrome as the 'displaced activist thesis' (Geary and Roche 2003) and it is examined in detail in Chapter 7. In brief, as the union's leadership 


\section{Breakdown of partnership}

becomes isolated from the membership, the consequences are seen to include rank-and-file alienation leading to resistance and to the eventual abandonment of partnership. For critics such as Kelly (1999), partnership leads to the co-optation of the union leadership with the promise of an increased say in management decision-making. In turn, FTOs are seen to assume the 'managerial' task of demobilizing rank-and-file resistance. In effect, union organization becomes centralized around a small privileged group. The thrust of the critics' case - echoing earlier debates in the academic literature on union organization and representation (see, for example, Hyman 1975 and Offe and Wiesenthall 1980) - is that not only is control centralized, but that senior union representatives are also seen to act as a managerial police force, exercising control 'over' rather than control 'for' union members. The outcomes are seen to be fractious and conflict-ridden union organizations which threaten the sustainability of partnership arrangements. Advocates of partnership are also cognizant of these risks, as they see them, for trade unions. But they stress that such difficulties can be overcome and that unions' representative capacity and cohesion can be ensured where the union's leadership pays sufficient attention to the promotion and maintenance of internal union democracy (Kochan and Rubinstein 2000). Conflict, however, was observed in the paradigm case of Saturn over whether union appointees to partnership positions should be selected jointly by management and the union or whether rank-and-file members should elect these individuals (Rubinstein 2001). The method of selection, the presence or otherwise of a mandate and representatives' accountability to the membership were thus key concerns at Saturn.

Third, the relationship between workplace partnership and collective bargaining is also identified in the literature as an important factor in explaining whether partnership arrangements survive or fail, as outlined in Chapter 1. The question, however, of whether each individual process should be kept separate, and confined to parallel realms, or whether they should, as suggested by Stern and Hammer, be allowed to merge organically in a manner where partnership subsumes adversarial bargaining processes, remains the subject of some discussion and debate in the literature. The latter view, as often expounded by proponents of partnership, is premised on the view that the tenor of collective bargaining may be recast as the trust engendered by partnership spills over, or that more and more issues are resolved in partnership'. As discussed in Chapter 1, the possibility that spillover effects may flow in the opposite direction, leading to the 'capture' of partnership arrangements by adversarial processes, has been discussed less frequently in the literature. In the event that this does indeed occur, one could fairly assume that the continued survival of a partnership initiative would be seriously endangered.

Closely related is the issue of conflict management and dispute resolution. For Kochan and Rubinstein (2000: 377-8), this is identified as one of the most important organizational processes affecting the durability of partner- 
ship arrangements. Their starting point is that partnership structures allow for conflicts to be more readily aired in comparison to traditional organizations, where conflicts are either suppressed because of an imbalance in power, or are limited in their expression through hierarchical or functional specialization. In this context, Kochan and Rubinstein focus on two issues which they see as being important if partnership is to remain viable. First, as conflict surfaces, it needs to be addressed and resolved effectively. Second, established dispute resolution procedures, informed as they are by adversarial postures, will need to be replaced by alternative dispute resolution mechanisms, which are better aligned with partnership, involvement and progressive employment practices.

The other important issue here highlighted by Kochan and Rubinstein (2000) is that the structure of conflict may alter under partnership arrangements. Simple management versus worker differences and conflicts may remain, but in addition new coalitions and cleavages may emerge where, for example, the local union organization may adopt different positions and interests to its national organization, and in multi-site companies so too might local management interests come to diverge from corporate management. How these tensions are resolved then becomes critical for the future sustainability of partnership, particularly as Kochan and Rubinstein (2000: 379-80) recognize where the parties split into pro- and anti-partnership camps. When identities and interests thus diverge around partnership, this is then seen as a pivotal moment: will an executive decision be taken by senior management and/or national union officers to press on with the initiative in the face of such division, or will such division become the justification for abandoning partnership?

The final reason highlighted in the literature as to why partnership arrangements fail to prosper in the long term is because their champions retire or move on to new positions and their replacements lack the same interest or resolve in pressing ahead. This brings us back to the crux of Streeck's critique: in the absence of institutional constraints, new management and union leaders have considerable freedom in choosing whether to support or abandon voluntary partnership arrangements. But as the advocates also recognize, where HRM practices remain unaltered the latter seems a more likely scenario. To avoid such a scenario and to foment the institutionalization of partnership, Kochan and Rubinstein (2000: 380), for example, argue that senior management appointments should be agreed amongst the parties and the incentive structures under which management operate should likewise reflect the multiple interests of the different parties.

\section{The changed industrial relations and management context in Aer Rianta}

In Chapter 4 we examined in detail the manner in which CP engaged with strategic issues facing Aer Rianta, such as the loss of duty-free sales and the 
strategic review of the company's future. In a number of departments, major issues of restructuring and reorganization were also addressed under the rubric of the Compact. This was not, however, conceived by the JUCG as a programme of systematic change. Rather, there were different drivers and pressures in different areas of the company. For example, in the cleaning department there was the long-established concern with costs and the possibility that some or all of its services might be outsourced to sub-contract providers. The maintenance department was preoccupied with adjusting to skill shortages in the local labour market and with the retention of its key skill groupings in the face of intense competition for skilled workers. In the retailing department, employees and management were endeavouring to come to terms with the loss of duty-free sales, the reorganization of shopping outlets and the introduction of, and payment for, new shift rosters. In the Airport Police and Fire Service there were renewed concerns about security provision following the terrorist attacks of September 11th, 2001. As indicated in Chapter 3, groups were free to decide for themselves whether they wished to pursue change through $\mathrm{CP}$ or through traditional industrial relations channels. Where they chose the former, they could enlist the support and advice of the JUCG and facilitators, as they thought appropriate.

In contrast to the successes attained by partnership at the strategic level of the company, as recounted in Chapter 4, at the operational level, where individual departments opted to engage major issues of restructuring and reorganization, the outcomes were considerably more variable. In particular, serious problems arose with respect to CP's relationship to prevailing managerial and industrial relations processes and structures. Many of these problems had already been evident in the mid to late 1990s but they were to gain significant new ground from 2000 onwards. Principally, these included opposition to proposals associated with the Compact from worker directors, confusion as to whether agreements could be concluded under the Compact, management indifference and opposition, and union apathy and resistance. These problems were exacerbated when the key champions of the Compact retired, or moved to new positions within the company.

\section{Contrasting fortunes of $C P$ at department level}

The breakdown of partnership in Aer Rianta did not happen overnight. During the early 2000s, some occupational groups continued to adhere to the principles enshrined in the Compact and came to agree significant changes in working practices, pay and conditions of employment through that route. By contrast, other groups who had initially tried to address the restructuring of their departments and work organization through partnership, opted subsequently to revert back and conclude agreements through traditional industrial relations processes. The former included the mainte- 
nance department, principally in Dublin Airport but also at Shannon Airport, and the cleaning department in Dublin. The latter groups included the Airport Police and Fire Service (APFS), the finance department and retailing. Of those employee categories who had initially agreed to work under the principles of the Compact in the late 1990s, the APFS and retailing constituted the largest proportion. So while these occupational groups appear to have lost faith in partnership from about 1999/2000 onwards, others - although a minority in overall terms - remained committed to its principles, believing it was more appropriate than conventional distributive bargaining to advance their interests.

We will begin by providing a brief account of those groups - cleaning and maintenance in Dublin - which made the most progress under the Compact. We will then provide an account of two other groups - Dublin Airport's retailing department and the Airport Police and Fire Service which grew disenchanted with $\mathrm{CP}$ and returned to handling workplace change through traditional bargaining channels. The discussion will then offer an explanation for why the Compact proved sufficiently robust and garnered enough support from staff, their representatives and management, to succeed in some departments, but not in others.

\section{The cleaning department and the maintenance department}

The cleaning department was one of the first departments to address the restructuring of its operations under the Compact. It was perhaps the most vulnerable of all departments within Aer Rianta to outside competition. Revenues generated from duty-free sales in the past had, by common consent, created a managerial benevolence towards the continued delivery of such services from within the company. The ending of duty-free sales, however, provoked a new commercial awareness throughout the company which, in turn, compelled local management and shop stewards, in the words of the full-time union official, 'to do something pro-active and get involved in restructuring and to look at costs, (because otherwise) they would cease to exist'.

Following two years of research and deliberation, which included benchmarking the costs of resourcing the current in-house cleaning department against external contract providers, it was agreed to reorganize shift rotas; withdraw from so-called third-party cleaning (cleaning airport premises which were not owned by Aer Rianta); reduce staff numbers; introduce and recruit a new staff category to work exclusively at weekends; reorganize supervisory structures; introduce an incentive attendance scheme; and reduce working hours to match employees' preferences. Critically, too, wage rates and pay scales were jointly determined, and a once-off bonus payment was made on foot of savings of a million punts (€1.27 million). It was agreed not to reduce wage rates to the contract industry norm. One union official commented: 


\section{Breakdown of partnership}

We weren't going into the thing [partnership] to cut our pay. The deal was to make ourselves more efficient and costs, of course, were going to be an issue. But they [employees] didn't go for pay increases because they realized that if they did they'd price themselves out of it. But we increased the starting rate on the scale and reduced the length of the scale (so that) they got to the top earlier.

The union official continued, 'the members accepted it despite the ubiquitous campaign to undermine it at a very sensitive stage. It was $60 / 40$ in favour. It didn't just scrape through'.

One senior manager, anxious to emphasize the success of the partnership process, commented:

It all came through the Compact. The whole approach was we would do it on a mutual gains basis ... It wasn't a matter of taking what we had achieved in the process outside and having negotiation. That didn't happen.

The agreement was subsequently endorsed by both the company and the union.

The maintenance departments in Dublin and Shannon Airports were among the few sections within Aer Rianta where regular work groups developed in the late 1990s. In the early 2000s, these groups - organized around trade groups and sections, i.e. carpenters, plumbers, electricians and lift maintenance - came together to form a strategy group to prepare business plans under the auspices of the Compact. A variety of issues was examined, including job structures, flexibility, employee recruitment and retention, pay levels and scales, and gain-sharing plans. The two unions involved, the TEEU and AEEU, supported the workers' initiative. Their business plans with proposals for revised entry wage rates and a wage increase of 10.8 per cent were subsequently endorsed by the two unions' officials and by management.

One senior manager, who was closely involved with the maintenance group, commented:

We did a lot of work benchmarking what industry pay rates were. We looked at the threats and the need for us to be competitive. We were actually operating in my view at a very high level. It wasn't normal, it wasn't negotiation at all. There was a discussion about what would be the right rate of pay, we agreed effective dates, we agreed retrospection in relation to that and we talked about the added value. We were saying that in terms of trying to identify what those savings would be we could actually produce an amount of money that could be used as a bonus scheme. That deal was carried unanimously I believe. So that was actually a very sound process in that it went from start to finish [under the Compact]. 
A senior union official involved concurred: 'On the craft side the pay levels are very competitive and there was nearly a unanimous decision on the pay all done under the Compact'.

Thus, under CP, partnership or interest-based bargaining came to supersede traditional adversarial bargaining in the two departments of cleaning and maintenance. The process garnered considerable support from among employees, union representatives and line management, and proved sufficiently strong to address major restructuring issues from beginning to end. In two other departments, retailing and the Airport Police and Fire Service, the early mood and signs had also been propitious but, following significant early progress, partnership was subsequently displaced in preference to traditional adversarial bargaining.

\section{Retailing and the Airport Police and Fire Service (APFS)}

As outlined in earlier chapters, one of the principal success stories of CP was the jointly agreed report on how Aer Rianta might prepare the ground for the loss of revenues following the suspension of intra-EU duty-free sales. This report was prepared by a significant issue group (SIG) which drew on expertise from management, unions and employees across the three airports and across departments, and became the basis on which management and unions subsequently addressed post-duty-free retailing at the airports. In parallel, a strategy group (SG) examined the future of the retailing department in Dublin Airport and how retailing might adapt to the loss of duty-free sales. The SG's deliberations focused on issues of cost, viability, efficiency and work organization. A report was prepared and agreement reached on a wide range of issues such as a 'cushioning' payment to absorb the sudden loss of commission payments with the ending of duty-free sales; the layout of shops; the restructuring of supervision; the introduction of teamworking; the restructuring of the pay system as well as agreement on wage increases. While these items were being addressed under the remit of the Compact, another issue, which had been something of a hoary chestnut for management and union representatives for some years, that of a premium payment for Sunday working, was being pursued through traditional industrial relations avenues. It eventually went before the established, state-provided, third-party dispute resolution services (the Labour Relations Commission) which found against the union. Relations between management and staff became very embittered as a consequence. A small but significant vocal element within the department called for the workforce to withdraw from the Compact and to press for strike action in the dispute over Sunday working. They engaged in a sit-in; a ballot followed and strike action was sanctioned. A union official involved commented: 'The staff went ballistic about the fact we had lost, to put it mildly and I was under pressure to ballot for industrial action'. Any chance of resolving to completion the broader restructuring of pay 


\section{Breakdown of partnership}

and work organization within the department under the Compact had now effectively been lost.

The company was successful in having the case heard before the Labour Relations Commission (LRC) before the strike action was to take effect. Under the auspices of the LRC, an agreement was reached whereby staff were awarded 15 per cent above the terms of the national wage agreement, the Programme for Prosperity and Fairness. Under the offer, the majority of the staff who agreed to work a new, extended roster system were put on a new consolidated scale which paid IR£30,000 (€38,100) per year. It was reported that this settlement made Aer Rianta retailing staff among the highest paid sales employees in the country with a maximum hourly rate of IR£15 (€19) per hour (IRN 2001). The new pay scale combined and rationalized a number of additional payments, bonuses and commission payments into one consolidated rate. It also provided for a 'cushioning' payment to compensate for loss of earnings following the abolition of duty-free sales. The deal allowed for the introduction of new work structures, new roster arrangements, a reduction of overtime, a standard working week of 38.5 hours, the elimination of supervisory positions, and 30 voluntary redundancies. New managerial and sales-support staff positions were also created. It was also agreed to establish a joint forum to devise and install a new incentive-based rewards system.

An important consequence of the involvement of the state's dispute resolution agency and the settlement that flowed therefrom was that the successful outcome was attributed to adversarial industrial relations processes and their champions. To paraphrase one union representative, success was now attributed to those who brought the case before the LRC. The same official continued:

What we had been doing under constructive participation, the review of pay, rewards and rosters, had been run away with. It was now under the heading of industrial relations and the LRC. It was the LRC that delivered it and the IR officers of the union, and not (the people who had espoused constructive participation). History will probably show that it came out of the LRC. It won't show the four years of work that went before it.

The Airport Police and Fire Service (APFS) had agreed to work under the Compact in 1999. Significant progress was made and agreement reached on such issues as splitting its workforce into separate service groups, a police unit and a fire department; staffing levels and cost structures; skill and training requirements; the provision of new equipment; and the establishment of a new unit, the Airport Search Unit. The wage rates which applied to the various categories of employment within the ranks of the APFS, as well as that which might pertain to the new search unit - which it was agreed would have a lower entry wage rate - were also 'benchmarked' against com- 
parable occupational groups outside the company. This led significantly to an agreement - under the rubric of $\mathrm{CP}$ - on new rates of pay. However, following this agreement there was an interregnum during which the joint APFS forum considered how 'the agreement' might be presented to and agreed upon by management, union representatives and employees. It was at this point that the agreement ran into difficulties. A ballot was called not on whether the agreement should or should not be ratified by the employees per se, but rather on whether the APFS should continue its discussions with management under the aegis of the Compact. The result of the ballot was overwhelming: 80 per cent of the staff voted to withdraw from working in partnership with management. All joint discussion groups were suspended immediately in favour of traditional industrial relations postures and processes. Collective bargaining commenced with the full panoply of traditional supports, including threatened strike action. Towards the end of 2001 a new agreement was reached which gave the APFS a pay increase which on average - like that in retailing - was 15 per cent above the basic terms of the national agreement. As well as making provision for the various elements which had already been 'agreed' under partnership, as outlined above, the collective bargaining agreement contained a number of additional or modified elements: a reduction in incremental scales from 27 points to 18 , a new composite rate of pay, a new supervisory position, a voluntary redundancy package for up to 30 staff offering four weeks' pay per year of service for the first ten years and six weeks for the balance of service. The agreement also provided the APFS with a 'direct link' to the remuneration of the Gardai (Irish police force) and Dublin Fire Brigade. The external facilitator who brokered the deal was reported as stating that the wage increases were 'very considerable' and that 'they lean in favour of the union rather than the company' (IRN 2001).

It is clear from the example of the four departments illustrated above that there was considerable variation in the extent to which partnership took root and flourished at departmental level within Aer Rianta in the early 2000s. In the cleaning and maintenance departments, partnership was strongly endorsed by committed management and union representatives and prospered thereby. It encountered significant challenges not too dissimiliar from that experienced in retailing and the APFS, but in these areas it was sufficiently well rooted and supported by all parties to fend off opposition and to resolve difficulties as they arose. In these instances, $\mathrm{CP}$ entailed the almost complete encoding of partnership into mainstream departmental structures and into decision-making processes.

In contrast, worker representatives and staff in retailing and in the APFS were more divided as to the merits of $\mathrm{CP}$ from the outset. These divisions were magnified when complex issues around work organization, changes in conditions of employment and pay came to be addressed under the principles of the Compact. Thus, the penetration and the success of partnership in these areas came to be uneven, limited, and in the end its progress was 
reversed and supplanted by traditional industrial relations postures and processes.

In the next section we turn to examine in more depth the reasons for the variable successes of $\mathrm{CP}$ in the four departments reviewed above. The negative consequences engendered by the failure of partnership in retailing and the APFS - two large and significant departments - were detrimental and ultimately contributed significantly to drawing the partnership process to a halt across most of the company. Other factors, like management and union succession, the position adopted by worker directors, and - outside the company - the altered postures of the minister and of some Aer Rianta unions, were also important contributors to the eventual decline and breakdown of partnership across the company as a whole. These broader or 'summit-level' influences will also be examined and their import for the demise of CP assessed. We begin, however, with an assessment of the more immediate factors which generated tensions surrounding the operation of partnership, notably the lack of clarity and ambiguity surrounding the interface between conventional collective bargaining and partnership, and particularly the manner in which representative roles and decision-making authority were conceived within CP. While our account of the demise of CP is organized around this distinction between operational-level and summitlevel influences, it is important to recognize that the problems generated at both these levels interacted and together they constitute the principal reasons in our explanation as to why $\mathrm{CP}$ ultimately broke down in Aer Rianta.

\section{Problems at the interface between partnership and industrial relations}

One of the principal factors leading to the derailment of CP was its awkward cobabitation with industrial relations. A significant challenge to confront the parties to CP was inevitably how to manage the interface between partnership and industrial relations. Four fault lines came to fracture the predefined relationship between the two processes. First, in spite of the best efforts of the Compact's architects to devise a constitution in which decisionmaking processes and authority were defined, considerable confusion arose around this issue. Second, some of the principal actors charged with monitoring the day-to-day interface between industrial relations and $\mathrm{CP}$, the facilitators, became isolated and their activities much criticized. Third, the question of whether the parties working under the rubric of CP possessed a legitimate mandate to speak and act on behalf of workers and union members came to be very contentious. Finally, the resolution of conflicts within traditional forums and agencies had the effect of tipping relations between management and employees towards traditional postures, and, in retailing at least, undermining $\mathrm{CP}$. Each of these issues will be examined in turn. 


\section{Unclear decision-making processes}

From the outset, the architects of CP handled the interface between industrial relations and $\mathrm{CP}$ in a largely conventional way by seeking to distinguish between partnership processes and industrial relations processes, and, provided that proposals that emerged from within $\mathrm{CP}$, or any accords reached therein, were ratified by the JUCG and the parties in the industrial relations arena, they could then be given effect. A general mandate thus appeared to exist for reaching agreements within partnership that might subsequently be presented for ratification by management and unions as parties to industrial relations.

In some circumstances, as in maintenance and cleaning, employees' attitudes to partnership were sufficiently positive, and the commitment and support of management and union representatives sufficiently robust, to allow the parties to conclude agreements entirely within partnership channels. In these two departments, CP became the main means of conducting employment relations.

In most other areas, however, where the parties ventured to work under the principles of the Compact, as in the APFS and retailing, the formal understanding that had been reached as regards the interface between partnership and industrial relations broke down, or differences of understanding emerged as the parties sought to deal on a partnership basis with major issues of reorganization that had important implications for pay and conditions. Thus, in practice, the formal distinctions and interface between partnership and industrial relations became unclear and the processes became somewhat awkwardly intertwined. There were a number of points of confusion and contestation which, in turn, gave rise to tensions and to competing claims as to the merits or otherwise of pursuing significant reorganization issues to completion under the rubric of $\mathrm{CP}$. The first was whether joint groups had actually been empowered to make firm recommendations to management and unions, or whether they were merely permitted to present possible options in terms of future courses of action. Second, in instances where joint groups had opted to make recommendations in their reports, they faced the charge that they did not possess a mandate from staff and unions to act in such a capacity.

In interviews with management and union activists, it was claimed that there was much confusion among participants in joint groups as to whether proposals could be progressed or agreements could be concluded through $\mathrm{CP}$. Indeed many felt that, from the beginning it was never intended or at least required of the parties working in partnership to agree a common position. Rather, they were encouraged by facilitators and members of the JUCG to canvass all parties for suggestions and to deliberate on all possible solutions to a given problem. The objective and principal emphasis of $\mathrm{CP}$, as many interviewees experienced it, was to encourage staff to become involved and to participate so that divergent and strongly held views could be heard 
in an open debate; comparatively less stress was placed on identifying one course of action or the realization of 'bottom-line' objectives. The fact that timelines were often loose and that CP group membership was not fixed members could come and go or be replaced as thought appropriate or convenient - added to this understanding. Ultimately, it was seen that the issue of whether an item could be resolved to finality under partnership rested not with the participants in joint groups but with the JUCG and more particularly with unions and managers and whether they would agree to any proposals put forward.

The evidence from interviews with management and union representatives was that this modus operandi often gave rise to a 'long-winded process' which generated considerable impatience on both sides - referred to by one manager as generating 'analysis paralysis' - and which, when it came up against major issues of restructuring, was found to be wanting.

The Compact I think suffered from the fact that nobody around the table ever really believed they were going to take a decision. In my view there was no decision-making mechanism. It was a contradiction, because the company was saying this is the way we want to do business, through the Compact.

(senior line manager)

We were always publishing interim reports, making presentations until we were blue in the face. It was very good for staff development, there's no doubt about that, but at the end of the day you keep going around in circles and people say what's this all about? Where's it going? [At one site meeting I was told by a middle manager], 'we're not here to make proposals', and I said, 'for [expletive deleted] sake we've been here for the last day and a half and you are going to tell me we can't make recommendations'.

(full-time union official)

I sat at the JUCG where they decided the process wasn't kosher: 'no, no that wasn't proper participation. Sorry, no, take that away'. And people were enraged with this. At the end of the day it was up to management to say well this is a good idea or not. And the union could equally say at that point, we don't agree. I think there's an inherent contradiction here. At the end, people were much more likely to see the inconsistencies and contradictions in the process than they would have been in the beginning.

(senior line manager)

\section{The role of facilitators}

On the ground, stewardship of the interface between CP and industrial relations came to rest in significant part with the facilitators. They were 
appointed to guide the roll-out and operation of Compact principles and processes. Much of their time was taken up with training participants to work in joint groups and helping them in the preparation of their discussion documents. They worked full time in their positions and were usually selected from among non-managerial employees. They were provided with secretarial support and were paid salaries. However, they soon suffered isolation and became the focus for much criticism. There was criticism that they lacked the necessary skills to perform their roles. Staff occupying traditional hierarchical and representative roles feared that they might come to be marginalized by the role and status accorded facilitators under partnership.

One senior national officer in SIPTU said that the perceived threat was represented to him thus: 'These people had no mandate. They weren't the elected representatives of the workers and they were somehow trying to usurp the traditional trade union role'. Yet others saw some facilitators as aspirants to management positions.

Their position was compounded further when a JUCG proposal to regularize their role and conditions of employment was rejected by senior management and funding for their training withdrawn. Many resigned their positions as facilitators. Thus as their cohesion as a group began to fragment, CP lost one of its key props on the ground. By early 2000, there was only one remaining facilitator in Dublin Airport.

\section{Ambiguous mandates}

Parties seeking to make progress on organizational restructuring under the Compact were often faced with charges that they possessed no mandate to negotiate or conclude agreements in the areas involved. A number of objections were raised: first, whether individual unions had acquired a mandate from their union executive to work in partnership with Aer Rianta management; second, whether FTOs, union activists or employees appointed to joint discussion groups could claim legitimately to speak for or represent the employees in their departments or work groups; and finally, whether any specific proposals emanating from these joint groups could be progressed and resolved to finality through CP. These items proved to be highly contentious and ambiguous as $\mathrm{CP}$ began to engage major issues, but they came to a head, in particular, as groups came to address significant issues around organizational change. The following observations from both union representatives and members of management highlight the very different outcomes in the presence and absence of a mandate from the rank and file and the national union executive, as well as the fragility of informal understandings, especially following the retirement of influential union advocates of partnership:

There was some ambivalence towards the Compact at a high level (within the union). They (the union branch) probably made mistakes out at the airport by not getting a mandate. They did in the cleaning section. 
They looked for a mandate and got a mandate, that's where the success was. They were always kind of confident. They also got a very high level of participation from the ordinary rank-and-file members in this working group. But the union didn't do that [in every section] from the start. What they should have done was look for a mandate to get involved.

Get people involved in the process and people will come up with the right solution, because they are engaged. But I think that all worked because you had a non-threatening environment. But having solved it, once they came back to the wider group I think that's where the thing took off in the wrong direction, because (they were challenged), "hold on, hold on a sec. Who are you to put this solution, you don't represent anybody'. And that was the problem, they didn't! I think in many ways the issue came down to the fact that they didn't have a mandate. It eventually became a major blockage.

(senior line manager)

The contrasting fortunes of partnership in the four departments reviewed above is also instructive here. In the two departments - maintenance and cleaning - where significant change agreements were completed, including changes to pay and conditions of employment, from beginning to end under the principles of the Compact, a formal mandate had been sought and obtained from union members. Elsewhere, as in the APFS and in retailing, the absence of a mandate proved to be a significant stumbling block. Often when a mandate was requested, as in the case of the APFS, it was too late the group having already fractured into competing pro- and anti-Compact factions.

Thus in these circumstances, employees and union representatives participating in joint forums came to be discredited and isolated within their respective constituencies, and the claim that they possessed no mandate to negotiate or conclude agreements was pivotal in the derailing of $\mathrm{CP}$ and in the restoration of traditional industrial relations processes.

In yet other cases, the shift from partnership to industrial relations facilitated by the absence of mandates - was seen to be tactical and opportunistic, as one or both parties perceived the other to have been acting in poor faith and to have intentionally defected from partnership in order to exploit a perceived advantage in pursuing an issue through adversarial bargaining. One senior union official put it thus: 'Some groups cherry picked. They were pretty cynical about it. They brought the Compact up as far as it could take it and then they jumped off and then they dragged another couple of inches'. 


\section{Dispute resolution}

We discussed above how the formal demarcation between partnership and industrial relations processes often became blurred and confusing for participants in $\mathrm{CP}$, ultimately to the detriment of the partnership initiative. In yet other instances, where the division between the two channels was clearly defined and policed, as in the case of Sunday premium payments in retailing above, negative spillover effects were still clearly evident. In this important case, partnership came to be 'sacrificed' to collective bargaining in circumstances where employees and their representatives wanted to register their dissatisfaction not only with Aer Rianta management, but also with the findings of the state's mediation services. In this instance, the advancement of sectional demands through collective bargaining and subsequently through the state's public dispute agencies embittered relations between the parties which in turn came to contaminate otherwise good relations between the same parties in the partnership arena. In sum, there were two problems or difficulties here. First, CP failed or was unable to insulate itself from a conflict overspill in other forums. Second, the state's dispute resolution agencies mediated between the parties in adversarial mode, forcing them to lay out their positions in arguing the merits of their respective cases. There was, therefore, little complementarity between the parties' attempts to develop collaborative relations within the enterprise and the processes deployed by dispute resolution agencies.

Management and unions in retailing would seem to have learnt from this experience, and later established in-house dispute resolution mechanisms better aligned with the ethos of partnership and which involved an outside mediator. Following the intervention of the LRC and the subsequent agreement on a restructuring package, management and union representatives agreed to establish a small joint working group to oversee the agreement's implementation. It was agreed to retain key elements of the erstwhile partnership process, principally that a problem-solving approach would be retained and that every effort would be made to arrive at a consensual solution. The terms CP or Compact were not to be used again, however. In the words of one union representative, they had become 'dirty words'. There were some other important differences. Strict timelines were established, group membership was fixed, and critically in the area of dispute resolution, as indicated, an outside facilitator was recruited to help the group resolve contentious issues. Considerable progress was made.

So [the external facilitator] came in and we started the process which ended up with an agreement on a totally new pay structure, totally new work structure, totally new roster. The whole package was put on the table and we agreed everything. So we literally restructured Retailing, which was the original objective of the Compact process. You had some pro-Compact people and some from the anti-Compact group. I think the 


\section{Breakdown of partnership}

value of the Compact process came through: how to work out the figures, if you do this what's the cost, and how does it impact on the business. So I am convinced the Compact process helped a lot. But there were one or two fundamental differences: the union said we are going in to agree something by a fixed deadline, there was no membership rotation, and we had an external facilitator.

(senior manager)

Elsewhere, however, plans to re-align the dispute resolution process in accordance with the principles of $\mathrm{CP}$ never came to fruition.

In summary, one of the principal reasons why significant sections of the Aer Rianta workforce withdrew from partnership in favour of traditional industrial relations postures, lay with the manner in which $\mathrm{CP}$ was designed. The essential design flaw, as it came to be perceived by some, was that the Compact did not prescribe a process for mutual gains bargaining and that, once the parties had finalized their reports, there was no delineated path for concluding an agreement to finality on pay and conditions of employment under CP. As outlined, this demarcation was deliberate. From the outset, it was recommended by the architects of the Compact that partnership and collective bargaining be kept separate and occupy different realms. The intention, paradoxically, was to vaccinate the Compact against any possible charge that $\mathrm{CP}$ was designed to incorporate unions and displace collective bargaining. In practice, therefore, once a discussion document was completed, the 'default option' was for it to be handed over to the parties and brought back to traditional industrial relations and collective bargaining channels for final agreement. In most instances, this is indeed what happened, save for in maintenance and cleaning where there was sufficient union and management support - including, as indicated, a mandate - for progressing with partnership through to the end. But in most other cases, partnership was tipped into adversarialism, when in difficult circumstances and dealing with major issues, the parties were faced with claims that they had no mandate to negotiate or conclude agreements. And as confusion abounded as to participants' roles and mandates, together with a general lack of expertise as to how to chart a pathway into mutual gains bargaining, the space was created for some worker representatives to mobilize around employees' fears and reservations about partnership. The ambivalence of senior management and national union officers towards partnership further emboldened some union representatives and created the requisite space for them to canvass support for their own positions. In these circumstances, attitudes towards partnership in most areas of Aer Rianta were coloured in a highly negative manner. This division and confusion as to the merits of partnership ultimately forced the parties to retreat back onto a terrain where they were more sure-footed and where ground-rules and mandates seemed more clearly defined and better understood. In this way, CP was disengaged and traditional industrial relations postures and processes were reinstated. 


\section{The summit politics of partnership and the demise of CP}

The breakdown of $\mathrm{CP}$ can also be attributed to a series of influences at the summit level and their interaction with the problems already identified at the operational level of partnership. The following factors exerted the greatest influence: the postures and reservations of worker directors; changes in the commercial and political environment which endangered the mutual dependence between Aer Rianta's commercial strategy and CP; and finally, management and union succession.

\section{The postures of worker directors}

As outlined in Chapters 3 and 7, the worker directors had been excluded from the design, implementation and operation of CP. This was a deliberate decision by those who spearheaded the partnership initiative and who were critical from the outset of what they saw as the limitations of established representative participation arrangements. Not surprisingly, some worker directors felt marginalized. Until the late 1990s, worker directors' reservations and opposition to the Compact were seen by advocates of CP to have lacked wider support among employees and union representatives. Some senior union representatives were highly critical of worker directors. The clearest reprimand came in a letter from the chairman of the Group of Unions to the chairman of Aer Rianta in early 2000, in which worker directors' 'direct opposition' to unions' support for the Compact was castigated and any mandate they may have perceived themselves to hold to speak on behalf of the Group of Unions on any policy issue questioned; any views which they expressed at board level were determined instead by the Group of Unions as 'personal views'.

Shortly thereafter, however, some worker directors became more vocal in expressing their concerns and fears with recommendations emanating from various joint groups convened under CP. Initially, some worker directors endeavoured to seek national-level union support for their opposition to the privatization of Aer Rianta and subsequently they sought to forge alliances with alienated shop stewards.

As outlined in Chapter 4, the Corporate Strategy Group's shared vision for the future of Aer Rianta and its recommendation that the company pursue a partial privatization strategy, which received the endorsement of the board, management and the Group of Unions, was a major triumph for CP. It was a pivotal moment, which demonstrated how partnership could be harnessed to address fundamental business issues and to win support from virtually all quarters. Some worker directors, however, were ill at ease with this position. The focus of their opposition now switched to the objection that Aer Rianta would be privatized and that $\mathrm{CP}$ was the vehicle that had delivered this state of affairs. One worker director expressed the following misgivings: 


\section{Breakdown of partnership}

I had concerns about an IPO and I expressed them. It did not reflect staff views. I also questioned the logic of an IPO. There seemed to be no shortage of money. For example, the cap [on borrowing for investment] could have been raised so that we could have borrowed more money.

Another worker director had similar concerns: 'The workers were not asked for their views. This should have been done. When I questioned why their views weren't sought and when I argued they didn't want an IPO, I was seen as a pain'.

Some worker directors also sought support for their criticism from among senior SIPTU national officers. Around this period, SIPTU support for the privatization of state-owned companies had become discernibly lukewarm, following the debacle surrounding the privatization of the state-owned telecommunications company, Telecom Eireann, and reservations in respect of similar proposals for other state companies (see Hastings 2003). One of the Compact's principal champions believed the worker directors achieved considerable success in calling into question what had been regarded as an agreed union position.

Thereafter, it seemed far from clear whether all the unions were at one with the position as agreed under the Compact in the Corporate Strategy Group's report. It was alleged by supporters of $\mathrm{CP}$ that these divisions allowed worker directors to advance the charge that partnership had not properly reflected the very different views among union activists and members as to the desirability or otherwise of privatizing the company. By this means, some worker directors laid the claim that the Compact had fragmented unions within Aer Rianta and that a minority view had come to predominate, which claimed to speak for the company's employees.

The other focus of one worker director's challenge to partnership was to give voice, as he saw it, to employees' dissatisfaction with CP and to focus dissent among shop stewards and the rank and file on the shopfloor. As partnership came to engage with complex issues surrounding restructuring of shift rotas and work organization, and as workers' fears were raised and heightened by the unpredictability and uncertainty of change, some worker directors were effective in expressing workers' concerns, and also in forming alliances with shop stewards who were critical of CP. This was particularly evident in retailing and the APFS, the two departments in which partnership came to be displaced by traditional industrial relations processes.

One worker director expressed his views of $\mathrm{CP}$ thus:

I did not object to the aspirations behind CP. I supported it. Any process that gives workers a say before management make a decision has to be welcomed. I had doubts, however, and I was sceptical. In particular, would management make the necessary commitments for example by way of attendance - the financial resources seemed to be there - and 
would they change their style of management which had not encouraged worker participation in the past? This overnight transformation had me suspicious and skeptical. From the outset middle management did not become involved. It couldn't work without them. I then began to question $\mathrm{CP}$ when management were not true to their word as I suspected. Changes were introduced without consultation and by stealth immediately confirming all our suspicions. It appeared that some of the joint groups did not have a mandate to speak for staff. I didn't oppose it for the sake of it, as I was accused. I was representing the views of people who had real concerns. That's my job.

As far as one worker director was concerned, to have permitted CP to subsume collective bargaining would have imperilled shop stewards' and unions' influence. Moreover, he claimed, assurances had been pledged by the architects of the Compact that negotiations in respect of pay levels would remain within the preserve of collective bargaining: 'I supported $\mathrm{CP}$ at the beginning on the basis that $\mathrm{CP}$ would not encroach on collective bargaining. When pay drifted into CP, I objected. CP was now undermining the unions' role'.

Worker directors' postures would also seem to have become entangled with inter-union rivalries in regard to the merits or otherwise of advancing workers' interests through partnership arrangements or traditional collective bargaining processes. These tensions in turn posed significant difficulties for senior union officers. One such officer observed:

We did get dragged into various rows between the different parties and we tried to broker some settlement, but we certainly didn't ever go out and make a declaration, like you know we've decided we're sticking with this participation project regardless and we want to see it through. We were not in a position to do that, because at that stage it seemed to us that it was very fractured. It got to the stage where people were muttering about leaving the union [SIPTU].

The import of these developments and perceptions from the perspective of the champions of the Compact is clear. First, senior management and senior national union officers' orientations to partnership had become puzzling, confusing, ambivalent and disheartening to those advocating CP. Second, some worker directors' activities were significant in marshalling resistance to proposals and positions associated with partnership among the rank-and-file and union activists, particularly as CP moved to resolve complex issues around pay and conditions in various departments. Their opposition also appears to have amplified intra- and inter-union tensions both in respect of partnership and competitive recruitment. Finally, their opposition affected the Compact's standing at national level within the unions. 


\section{Breakdown of partnership}

\section{Changing tides: new commercial parameters and new faces}

As outlined in Chapter 4, the shared commitment to position Aer Rianta to compete on the basis of quality and to remain committed to the values and principles laid down in the Compact was honoured in spite of, or perhaps more because of, the very difficult commercial environment which the company encountered in the late 1990s. The resulting formulation of business strategy was of course dependent on a number of important factors. Chief among these was the appointment of a new CEO in 1998, just as CP was being implemented, who determined to link decision-making processes around the formulation of the company's strategy with the Compact. He was pivotal in galvanizing sufficient managerial and union support to tilt the balance in favour of engagement with the partnership process. On the ground, he actively encouraged his senior and middle management to engage with CP. Second, the wider political context was favourable. Support for the Compact was in large part underwritten by the postures set down by the government for the structures governing airport management, regulation and ownership. And the active support and sponsorship of the minister and her officials also had an important bearing on senior management postures towards partnership.

At the same time, as discussed, the development, roll-out and operation of $\mathrm{CP}$ had become closely associated with and dependent upon a small number of key individuals drawn from management and the unions, while support among the wider management grouping, particularly those occupying line management positions, was seen to be discernibly muted and ambivalent, and only a minority of senior managers actively supported the initiative. These, too, were important realities. But the combined support of the CEO and the minister for the Compact, and subsequently their shared position in respect of the privatization of the company, granted the company's management considerable control over the manner in which the company might be directed, at least in the short to medium term, and created the space within which the company's business strategies might be further integrated with the partnership process.

Central to the problems encountered by partnership on the ground from the late 1990s onwards was the unravelling of this support, endangering the integration of business strategy formulation with the principles underpinning the Compact. A number of significant influences now began to work against the equilibrium underpinning the mutual dependence between partnership and commercial strategy.

First, the governance of Aer Rianta changed with the enactment of new legislation. This permitted the company's management to extend their influence over CP. This was further facilitated with the retirement of the key management and union champions of the Compact. Second, the commercial and political contexts changed fundamentally from 2000 onwards. Both elements became closely intertwined and contrived to expose the company to 
ever-increasing pressures for greater cost reductions and efficiencies; at the same time, it had to cater for increasing passenger numbers in the face of newly defined strictures on its ability to raise finance and increase landing charges. The political tide also turned with the appointment of a new minister who set about radically altering the structures governing airport management and regulation. $\mathrm{CP}$ was thus cast into a more inimical environment than it had experienced heretofore. In this context, the possibility of restoring its flagging fortunes at departmental level, as portrayed above, became increasingly remote. We will now trace these developments in turn.

\section{New governance arrangements}

The governance arrangements of Aer Rianta changed with the passing into legislation of the Air Navigation and Transport (Amendment) Bill (1997). With the enactment of this legislation, Aer Rianta's status changed from being an 'agent' of the minister, and control over the company's assets moved from resting with the minister to being held by the company. When the status of the company changed, Aer Rianta management acquired full control over the company's revenues and profits. This had two important consequences for $\mathrm{CP}$. First, the proponents of $\mathrm{CP}$ lost their principal sponsor and ally and they could no longer lay claim, as had earlier been the case, to the Compact being a government-sponsored initiative. Second, and perhaps more critically, senior management in Aer Rianta came to acquire a greater level of influence over the direction and implementation of partnership than they had enjoyed heretofore; the decision as to whether the partnership process would continue to receive financial support came to rest with them. Thus the funds that had pumped and primed the Compact and which were earmarked for this purpose by the minister could now be withdrawn, or directed as management might wish. As one of the Compact's champions explained: 'It [the Air Navigation and Transport (Amendment) Bill] changed the whole governance issue. So now we had a difficulty because people were now using the new [structures of] governance as a mechanism of control.'

A pivotal moment in this regard was seen to be when the contract of the union official seconded to work full time on CP expired in 2001. Requests to have his contract extended were not granted. It was perceived by some of those interviewed that he was 'encouraged' to take early retirement. The position he vacated was not advertised or assumed by anyone else.

\section{The new commercial and political environment}

The wider commercial and political contexts within which Aer Rianta operated were also changing radically and in a way which had detrimental consequences for CP. Both influences, as will become apparent, were closely intertwined. 


\section{Breakdown of partnership}

Following the ending of intra-EU duty-free sales in 1999, the commercial pressures bearing on Aer Rianta intensified further. First, passenger numbers continued to grow. In 1999, 16 million people passed through the company's three airports and year on year increases since then have averaged 20 per cent or more. Second, while the revenues from passenger growth, as well as those generated from increasing car-parking fees and the addition of new shopping outlets, allowed employment levels to be retained, profits were not sufficient to meet the enormous capital requirements facing the company. These were put at IR£520 million (€660 million) for 1999-2000. The government-imposed borrowing limit of IR£250 million (€315 million) remained in place and the prospect of raising further revenues from increasing airline landing charges seemed uncertain, as the company awaited the appointment and determination of an independent aviation regulator. The principal task of the regulator was to fix airport charges and thereby extricate airport management from the political arena. Hitherto, there was a potential conflict of interest arising from the minister's dual role as both Aer Rianta's sole shareholder and the person responsible for setting the charges its customer airlines paid. The regulator's subsequent determination ruled against Aer Rianta's investment plans and associated efforts to raise additional revenues through increased landing fees and service charges. The regulator's ruling criticized the company for providing inefficient services that did not meet the requirements of airport users, focusing, in particular, on what was described as Aer Rianta's 'gold-plated investment programme'. It also castigated management's cost-benefit analyses and justification for new capital projects and, while acknowledging that Dublin's 'landing fee revenues per workload unit were lower than its peers', it ruled that there was still room for improving efficiencies. Although the determination ruled that charges per passenger could be raised at Cork and Shannon airports, charges at Dublin Airport would have to be reduced.

The appointment of the regulator had thus introduced an independent player mediating between Aer Rianta's commercial strategy and its market, and applying principles that appeared to call into question aspects of the quality-focused commercial strategy underlying $\mathrm{CP}$, endorsed by the company and its unions, and ultimately providing the overriding commercial rationale for partnership.

Third, the privatization of the company in the form of an initial public offering (IPO), as agreed jointly by management and unions, and which had seemed to both parties to provide the only possible avenue for securing significant funds to support the company's business plans, became increasingly unlikely. This had also been the favoured strategy of the then minister. Within and outside the cabinet, however, there was considerable political opposition to such a move. Employees in the hotel-arm of the company the Great Southern Hotels - also opposed the privatization strategy favoured by the unions and management and lobbied local independent parliamentary representatives upon whom the minority coalition government were 
dependent to carry a majority in parliament. The Progressive Democrats, the junior coalition partner, favoured breaking the company up into three independently managed airports, fearing that the privatization, part or otherwise, of Aer Rianta, would simply result in a state-owned monopoly being replaced by a privately owned monopoly. The unions in Aer Rianta set themselves steadfastly against such a move. Shannon management was also concerned that splitting the company into three autonomous airports might result in it losing the mandatory stop-over provision requiring a proportion of transatlantic flights to land at the airport. In the face of such opposition, and in spite of the incipient momentum which had gathered behind the IPO strategy in 1999, and the minister's desire to bring just such a proposal to cabinet, a political decision on whether to float the company was put on hold. In the background, too, was the 1999 privatization of the state-owned telecommunications company, Telecom Eireann, which, following one of the most widely distributed share offers in Europe (more than 575,000 share applications were made), went sour as equity markets collapsed shortly afterwards. There was little political appetite for another privatization of a stateowned company after such a debacle.

Fourth, the pressure on the government from airlines using Aer Rianta airports, principally Ryanair, to provide independently owned and/or operated terminal buildings, was unrelenting. Aer Rianta's own plans to build and manage new terminals, particularly at Dublin Airport, were criticized as being over-elaborate and grossly overpriced. The prospect of inter-terminal competition, feared by champions of the Compact as potentially undermining the agreed parameters of the company's business strategy, now seemed more likely with the appointment in 2002 of a new Minister for Transport, under whose authority responsibility for airport management now rested. Ryanair's proposal for a 'low-cost' terminal, if successful, would eventually, it was suggested, be followed by requests from competing airlines for similar facilities with similar price structures. Any hope of maintaining high-quality services with well-paid and secure employment would thus, it was argued, be fatally undermined. Aer Rianta resisted any such move, arguing that attempts elsewhere to pit terminals in competition with one another had failed. Government-appointed consultants, also counselled against such a move in 2000, and pointed out that, in any case, Aer Rianta was obliged by EU legislation to provide a non-discriminatory price regime. However, following the September 11th, 2001 terrorist attacks in the US and the subsequent fall-off in air traffic and tourist visitors to Ireland, government pressure on Aer Rianta to develop a 'low-cost facility for low-cost carriers' at Dublin Airport intensified.

The new minister moved to press ahead with seeking 'expressions of interest' for building a separate terminal, independent of Aer Rianta, at Dublin Airport. He subsequently moved to give Shannon and Cork airports independent boards to stimulate competition with Dublin Airport. Both proposals were resisted by the trade unions, culminating in successful ballots 
for strike action. With respect to the provision of an independent terminal at Dublin Airport, the unions reiterated their position that they did not object to a second terminal being built at Dublin Airport, and nor did they object to private financial involvement in its construction. Their point of objection was to competition between terminals. There was, the unions argued, 'no appropriate working model elsewhere in the world that could be drawn upon to support the idea', and that the problems with competing terminals were 'legion'. These included the division of airside and roadside assets and responsibilities which, they argued, would be exacerbated at a time of increasing insecurity in aviation, and the division of responsibility for passenger safety and security, which 'would be a major headache with a private competing terminal' (Begg 2004). The unions also backed their argument with the findings of four independent reports into the provision of a privately operated terminal at Dublin Airport, none of which advanced the case for it: "(o)n the contrary, all have said that landing charges would increase' (Begg 2004). The unions at Aer Rianta also levied the charge that the minister's preference for market-based solutions was ideologically driven and that his approach to handling change was unilateralist and showed little understanding of a partnership approach.

\section{Management and union succession}

Finally, there was the important issue of management and union succession. Just as a new cadre of management and union appointments had been instrumental in the development and establishment of $\mathrm{CP}$, so their retirements came to check its advance and accelerate its demise. While these individuals remained with the company, partnership was widely perceived to have possessed a fair chance of being diffused and becoming institutionalized. In their absence, however, partnership was seen to be without its champions and vulnerable to indifference or to hostile opinion. In this context, one supporter of the Compact among senior managers was critical that, 'There was no in-built succession process that ensured that whoever came along saw this process in broadly the same way'.

To a considerable degree the indifference shown towards partnership by some new and existing managers was facilitated by the company's failure to adapt its HRM practices. As outlined in Chapter 3, the intention had been to reconfigure reward systems, selection processes and other human resource practices to underpin partnership, but progress in this area was uneven and slow. As a consequence, underlying HR policies and practices remained wedded in the main to traditional organizational principles and forms of motivation.

The more some members of the new management team were seen to be sceptical and ambivalent towards partnership, the more supporters of the Compact felt obliged to advance its case in opposition. As one of the key personalities behind the Compact explained: 'We were becoming more and more 
protagonists in a major battle that was going on and that probably did more damage to us in the long run. Participation had become controversial'. Another manager observed: 'we were now under siege defending this (the Compact)'.

A key turning point was reached. From the perspective of the most senior members of management, $\mathrm{CP}$ had now come to represent a point of division and acrimony within the company. This is indeed how it was read by many of our interviewees, on both the management and union side: partnership had split management and union activists into pro- and anti-Compact camps. The likelihood that management and union activists could be brought to work together under the rubric of $\mathrm{CP}$ came to be seen by both management and senior union officers as increasingly remote. One senior national union official explained:

It got to the point where if somebody with a partnership hat said, 'good morning', the other side felt obliged to suggest the weather was about to change. It just got crazy. I mean what we had to do was try and gradually restore a bit of unity out there.

Some senior managers now looked upon Aer Rianta as possessing a contradictory decision-making and industrial relations framework: a patchwork quilt of partnership, adversarial industrial relations and obstinate resistance to partnership among significant sections of management and worker representatives. Their confidence in being able to manage their colleagues and staff under the principles of CP was now shaken fundamentally. Their intent was to bring order to an otherwise chaotic scene, as they perceived it. To restore unity and cohesion, significant sections of management thought it better to abandon the remnants of $\mathrm{CP}$. All hope of proceeding through partnership was not forsaken, however. The authors were invited by senior management and senior union representatives to conduct a review of the status of $\mathrm{CP}$ and to consider whether a way might yet be found to resurrect and recast partnership in Aer Rianta. In the event, these tentative deliberations were cut short when the minister moved to break the company up into three separate independent entities. With the bypassing of $\mathrm{CP}$ institutions, management and unions responded by reverting to traditional strategies of lobbying government and threatening work stoppages.

\section{Conclusion}

The commercial context within which Aer Rianta operated grew increasingly difficult and complex following the loss of its most profitable revenue stream from intra-EU duty-free sales. Its ability to raise capital to meet new demands placed upon it was severely constrained. Yet, as outlined in Chapter 4, CP had managed to develop and prosper, helping management and staff to confront difficult challenges in this new environment. 


\section{Breakdown of partnership}

The development and operation of $\mathrm{CP}$ was however 'top-heavy'. Greatest effort and resources were directed towards 'strategic' and representative initiatives of various types and commensurately less effort devoted to day-today employee involvement, the promotion of teamworking and new forms of work organization. This meant that for many workers partnership was a distant activity, engaged in by an elite group located somewhere else above them. CP was thus 'long' and 'thin': long in the sense of operating at a variety of levels within the organization; thin because it had little real consequence for workers' daily routines. There was little employee involvement or teamworking of any consequence. As a result, CP, even at its high-water mark, was a peripheral initiative for employees. The result was that employees' attitudes to CP, the company, work and unions were not influenced on any widespread or significant basis by the process.

At departmental level, its fortunes varied significantly; in some instances, partnership was capable of attracting sufficient support and generating enough confidence to handle complex issues surrounding work reorganization and adjustments to pay levels. In other cases, while partnership did marshal considerable support and was responsible for overseeing joint research and deliberation, it was not sufficiently robust to handle complex issues through to completion. The absence of mandates, an uneasy coexistence with traditional industrial relations processes and structures, and resistance from some worker directors and shop stewards were critical factors.

Above the level of the workplace, however, where partnership was strongest and had delivered the most significant benefits, support for and confidence in $\mathrm{CP}$ was being steadily eroded. Proponents of $\mathrm{CP}$ were concerned that new members of management were less likely to endorse and make the case for partnership. In their view, management's delimiting of the resources available to fund the activities of partnership, principally through their failure to adequately train and support facilitators, or to extend the contracts of those championing $\mathrm{CP}$, or to have them replaced with people as committed to its principles, confirmed their fears and concerns. Later, with the appointment of a new minister, the signals became increasingly mixed and confusing. A shared and agreed vision of the company's future was unilaterally revoked and replaced by an imposed - and contested - strategy. Together with the appointment of a regulator, restrictions on the company's freedom to raise capital or raise landing charges, the company's management lost control, in significant part, over the future direction of the business and the formulation of its business strategy. The prospect of competing terminals, in particular, endangered the company's pledge to compete on the basis of service quality and workforce skill rather than on the basis of cost minimization and low pay. In these ways, CP came to be uncoupled from the management of the company. Perhaps not surprisingly, workers' existing reservations as to the viability and tenacity of partnership at departmental level were aggravated further by the feelings of vulnerability and uncertainty engendered by what was perceived as waning 
senior management support for the Compact and by the altered postures of the new minister.

In respect of the literature and its theoretical claims as to why partnership arrangements might break down, the arguments as proposed by the advocates would seem to provide the greatest purchase on explaining events in Aer Rianta. In the absence of legislative supports for partnership, advocates have laid great stress on the need for other institutional supports to be present if partnership is to survive. Many of these supports were weak or absent in Aer Rianta. CP was poorly institutionalized; it was, to reiterate, 'top-heavy', 'long', and 'thin'. Critically, it suffered from poor 'vertical alignment'. Aer Rianta's human resource management and industrial relations policies had not been aligned with CP activities. For example, performance management systems and dispute resolution processes remained substantially unaltered and, in the main, affixed to traditional forms of motivation, principles and postures. Other institutional supports identified by advocates, such as devising appropriate mechanisms for involving middle managers, planning for management and union succession and, critically, managing the interface between partnership and conventional collective bargaining processes, were also weak or absent. These weaknesses were accentuated further when the regulatory and political environment within which the company operated changed fundamentally, putting at risk the company's commitment to compete on the basis of service quality, good wages and conditions of employment. In large part, then, the reasons we identify for the breakdown in CP accord closely to the absence or weak institutionalization of the factors identified by advocates as being necessary preconditions for the sustainability of voluntary partnership arrangements.

The critics' argument, as exemplified by Streeck, that partnership arrangements are weakened by an inherent asymmetry of power whereupon unions are less trustful of management's intentions and thus cannot commit wholeheartedly to working in partnership with management, does not adequately capture the complexity of the dynamics of the Aer Rianta case. Senior union representatives did trust management's motives and believed they were acting in good faith. Significant and effective co-operation did occur between the parties. That these co-operative relations subsequently broke down had more to do with unanticipated difficulties in the design and implementation of $\mathrm{CP}$, particularly the weak institutional supports identified above. This is not to ignore the fact that management support was variable and ambivalent, or that there was opposition from worker representatives, especially from among the worker directors, but these factors are very different in nature to a chronic trust deficit as identified by Streeck. It also bears emphasis that the disconnection that subsequently emerged between the company's business strategy and its avowed employment relations policies was not of senior management's making, but was in large part beyond their powers and offices to determine; these were changes imposed on the company by outside agencies. 


\section{Breakdown of partnership}

Similarly, there is little evidence in the Aer Rianta case to support the theoretical claims of Kelly. CP did not disadvantage workers. Neither did partnership privilege the role of full-time union officers to the detriment and displacement of shopfloor activists. The inter- and intra-union tensions witnessed in Aer Rianta were very different to those anticipated by critics of partnership. Where partnership broke down in specific departments, it was against a background of inter-union rivalries over membership recruitment and representation, the postures of worker directors, and ambiguities and confusion surrounding CP's relationship with conventional industrial relations processes and structures. With the resulting uncertainty, workers' confidence in CP's ability to address workplace restructuring was lost. Union representatives, including both lay activists and full-time officers, were equally unnerved, but in addition feared that to proceed with $\mathrm{CP}$ would have endangered union cohesion and security. Thus the collapse of CP is attributed to a complex variety of operational problems. These difficulties interacted with summit-level problems and the combined impact of both sets of problems led to the breakdown of partnership in Aer Rianta. 


\section{Advocates, critics and partnership}

The partnership arrangements agreed between management and unions in Aer Rianta in the mid 1990s were among the most radical of their kind in providing for union and staff involvement in all aspects of company decision-making. Less than ten years later, these arrangements had broken down and relations between the parties had returned to a more conventional pattern. Between the genesis and breakdown of partnership, the parties had experimented with new forms of decision-making and a new approach to industrial relations. At the high tide of partnership in the late 1990s, CP had provided a basis for a joint response to major commercial challenges such as the disappearance of duty-free sales and a review of the future status of the company. In these areas, partnership had effectively displaced traditional modes of decision-making and established industrial relations arrangements. Later, partnership had provided the basis for reaching agreement on changes in work practices and pay systems in two departments, cleaning and maintenance.

It was clear from the survey reported in Chapters 8 and 9 that $\mathrm{CP}$ had not transformed attitudes or behaviour in Aer Rianta and that employees in general remained sceptical or critical of partnership and its effects. Pervasive dual commitment had not arisen from the joint operation of CP in the company. The survey also revealed that the more involved staff had become in various facets of partnership, the more positive their assessments of the processes and arrangements entailed and the more positive their attitudes towards both trade unions and the company. Partnership eventually broke down through the interaction of operational-level problems in several departments, especially retailing and the Airport Police and Fire Service, and summit-level difficulties in such areas as government and national union policy towards privatization, opposition from worker directors, changes in regulatory arrangements, problems of succession within CP itself and ultimately senior management disillusionment. Such in outline is the story told in the book. In this concluding chapter the major themes examined in the book's core chapters are summarized in analytical context and a series of comments are addressed to the debate between advocates and critics of workplace partnership. 


\section{Influences on the mainstreaming of partnership}

Workplace partnership in Aer Rianta had its origins in the extension to the company of legislative arrangements for the election of worker directors to the board and for the creation of sub-board participative structures. Visionary senior managers and trade union officials in the company formed the view that the conventional model of worker directors and related channels for industrial democracy were of limited effectiveness for both the companies affected and for trade unions. Their shared alternative vision envisaged more radical proposals that would involve shared decision-making at all levels of the company, with no pre-defined limits to the areas or issues that might be subject to joint decision-making. From this emerged 'constructive participation', which was given expression in two major formal documents, the Compact and Requisite Arrangements. Radical though the arrangements were, the champions of CP felt it necessary to steer a course through prevailing industrial relations arrangements by formally separating partnership and collective bargaining, allowing the parties to collective bargaining to veto or endorse proposals developed in partnership forums. Senior managers also remained ambivalent and divided in their postures towards $\mathrm{CP}$, and middle managers were formally disconnected from the initiative, through their union's demand for formal representation on the JUCG and estrangement from partnership when this demand was denied.

Against such a background, CP initially had little major effect on decisionmaking in Aer Rianta and came to occupy what was in effect a shadow and subsidiary decision-making channel. This changed when the external commercial circumstances of the company were transformed by burgeoning airport traffic, the imminent disappearance of duty-free sales and evolving government policy on state companies. At this critical juncture for the company, a new chief executive, who had previously been a supporter of $\mathrm{CP}$, was appointed to lead the company. He sought to elevate $\mathrm{CP}$ to a key channel through which the company and its unions might respond to the series of acute pressures facing the company. The new management regime that he instituted also led to changes in senior-level personnel and reporting arrangements, which were seen by champions of CP to have bolstered partnership substantially.

The conjuncture of a new CEO, discontinuous and acute commercial pressures, change in government policy and some pre-existing features that included visionary managers and senior union officials, made for a 'configuration' of influences that brought $\mathrm{CP}$ into alignment with mainstream decision-making in Aer Rianta at a strategic level. For a time, arising from this conjuncture, joint governance effectively occurred with respect to significant commercial and staff concerns and conventional collective bargaining was displaced. The Aer Rianta case thus illustrates how configurations of influences may become the antecedents shifting partnership arrangements from the status of formal agreements to significant decisionmaking forums. 


\section{Influences shaping the dynamics of partnership}

The dynamics of partnership were shaped by a series of influences examined in the body of the book. CP was aligned with a commercial strategy that sought to compete on the basis of quality and that disavowed low pay and poor working conditions. For much of the period covered, the viability of this strategy was unconstrained by market pressures or regulatory arrangements, although some senior managers were sceptical about the long-term sustainability of quality-based differentiation in the light of industry trends. The board of Aer Rianta had also formally endorsed CP, as had the company's parent state department. Though these factors were significant in building support for $\mathrm{CP}$ within the company, partnership nevertheless remained 'loosely coupled' with commercial and strategic decision-making, because, as reported by senior managers interviewed, the board essentially viewed $\mathrm{CP}$ as a 'sub-board' concern.

An important consequence of the fusion of $\mathrm{CP}$ and mainstream decisionmaking around major commercial challenges was that partnership became characterized by poor 'vertical alignment'. CP soon came to be 'top-heavy', with most activity focused on problems affecting business units and the company as a whole. Relatively little attention was devoted to departmental arrangements, and less still to the creation of 'regular work groups'. That regular work groups became the 'Cinderella of CP' was inconsistent with the original plan that had envisaged teamwork as the main vehicle for higher levels of employee participation in day-to-day work. This unevenness and top-heaviness was to have important implications for staff experiences and perceptions of CP.

Senior management's attitudes and postures also played a critical role in shaping the dynamics of $\mathrm{CP}$. While $\mathrm{CP}$ had become formal company policy and was supported from the outset by the CEO, most senior managers remained sceptical of partnership. It is significant that CP had arisen not from line management-led responses to commercial or operational pressures, but from the vision and foresight of a small number of management and union champions, and in largely benign commercial conditions. Champions of $\mathrm{CP}$ were a minority and they tended to occupy staff or support roles in the company rather than key line management roles. Outright critics were also a minority, but some occupied key roles in the airports, and their early opposition was tolerated.

While corporate values in Aer Rianta had long been 'progressive' with respect to staff issues, a strong current of paternalism also underpinned the company's ethos. This affected the development of CP in three ways. First, the personnel department had traditionally enjoyed a virtual monopoly over people management but conventionally operated on the basis of an approach that attributed priority to the management of industrial relations and administrative personnel concerns. Little priority had thus been accorded to the type of initiatives involved in CP. From such a background the 
personnel department had not been in the vanguard of the process of innovation that led to CP. Second, by tradition many line managers had not acted as proactive people managers, and effective human resource management was not viewed as integral to successful management practice. Third, as outlined in Chapter 4, at the apex of the company, personnel-related issues were perceived as sub-strategy-level concerns rather than as fundamental attributes of competitive strategy and business success. The values and commitments represented by $\mathrm{CP}$ thus involved a sharp discontinuity with traditional management values and postures in Aer Rianta concerning the role of personnel and industrial relations issues in management and business decision-making.

Of the three groups of senior managers identified in Chapter 5, 'supporters' were convinced that $\mathrm{CP}$ provided the most effective way of running the company and that it would ultimately succeed in transforming decisionmaking and industrial relations in Aer Rianta. 'Opponents' saw little value in CP and took the view that it was attractive mainly to union activists. 'Sceptics' had more complicated attitudes to partnership. They generally recognized 'process advantages' and some even pointed to 'bottom-line advantages' and achievements. But they also showed a strong awareness of costs and of both process and bottom-line disadvantages.

Senior management ambiguity and division with respect to $\mathrm{CP}$ interacted with prolonged middle management opposition. Middle managers had not been centrally involved in the genesis or development of $\mathrm{CP}$ and remained outside the JUCG due to a dispute over the prospective status of IAESA nominees. These experiences fed the concern and anxiety of middle managers regarding the implications of partnership for their work, status and job security. The attitudes and postures of middle managers were also conditioned by prevailing organizational systems and related human resource practices. Few formal changes had been made in organizational systems, such as objective setting, or in such HR areas as performance and rewards management, that might have fostered middle management support for $\mathrm{CP}$. In spite of being expected to manage on the basis of the principles set down in the Compact, middle managers continued to be held accountable for the achievement of traditional business objectives. Inevitably, 'hard', bottom-line results continued to be seen as what really counted with respect to performance and prospects. Finding themselves in an invidious position between the policy of their union, which enjoined them to boycott $\mathrm{CP}$, and official management policy that enjoined them to engage with partnership, some middle managers appear to have co-operated on a covert basis. Many managers, however, appear to have remained aloof from the process. Perceptions of senior management ambivalence and opposition also contributed to middle managers' lack of enthusiasm for CP. With the advent of a new $\mathrm{CEO}$ and the merger of the middle managers' union, middle managers abandoned their formal opposition to CP.

The consequences of union involvement in partnership have been the subject of a deep division of views in the academic literature, with advocates 
and critics adopting sharply contrasting positions. Union involvement in $\mathrm{CP}$ was seen by many union officials and activists to have been beneficial in terms of making for more effective representation and extending the frontier of union influence into company decision-making. The issue of potential or actual union incorporation scarcely arose as a concern for those who had been instrumental in the development and operation of CP. Yet most union officials, activists and worker directors remained sceptical with regard to the sustainability of CP. Their scepticism appeared to have been fed mainly by their perception of management division and ambivalence. Opposition to proposals emanating from partnership and to the application of partnership to areas hitherto covered by collective bargaining came from among elected worker directors, who, like middle managers, had been effectively excluded from CP.

The widely reported phenomenon of the 'displaced activist' was not evident in Aer Rianta. This was so in spite of the centralized arrangements instituted by $\mathrm{CP}$ - as evidenced by the level of control exercised by the JUCG over partnership-related initiatives - and the widely shared perception that a small group of management and union figures held most influence over all aspects of the process. Little of the intra-union conflict and factionalism reported in the partnership literature was manifest in Aer Rianta. Nor, the survey data revealed, were shop stewards and activists an alienated or disaffected group within the ranks of union membership. The non-displacement of activists in Aer Rianta was attributed in Chapter 7 to the origin of $\mathrm{CP}$ in joint commitment to build a new form of organization and a new style of industrial relations. There had been little formal realignment of the roles of shop stewards or activists and no rolling back of the traditional activities of lay representatives had occurred. The involvement of shop stewards and activists in training for $\mathrm{CP}$ had also diluted resistance. The architecture of $\mathrm{CP}$ was also influential in allowing shop stewards and activists scope to represent their members within conventional industrial relations channels if these were preferred over partnership channels. The main line of intra-union tension during the roll-out of $\mathrm{CP}$ was between worker directors, a group at the apex of governance and decision-making in Aer Rianta, and champions of CP within the unions. Differences between union officials and some worker directors were later to find expression in conflict over reorganization in several departments, but differences of perspective and posture had little effect on the early development or operation of $\mathrm{CP}$, or on union engagement in major strategic initiatives. National union organizations endorsed the activities of their Aer Rianta branches and had supported partnership - a posture symbolized by the appointment of the General Secretary of the ICTU as a 'sponsor' of CP. This too was to change later.

While officials and activists were willing to identify advantages that had arisen from operating through partnership and while little alienation or disaffection had resulted, union members in general were divided concerning 
the effectiveness and influence of their unions and relatively few reported that union influence had increased over the period during which partnership had developed to its fullest extent. Survey data also revealed that the more scope union members had enjoyed for participation and autonomy in their work - a major objective of $\mathrm{CP}$ - the more positively they assessed union effectiveness and changes in union influence over the period covered by CP. The survey also revealed that the more union members had engaged with $\mathrm{CP}$ - that is, the greater their knowledge of $\mathrm{CP}$ initiatives and the more they had discussed these in union and other forums - the higher their level of union commitment. If CP delivered positive spin-offs for unions among those of their members who had enjoyed substantial scope for participation in their jobs and who had engaged with CP activities, the middle managers' union appeared to have garnered little commitment from their members as a result of their alienation from $\mathrm{CP}$.

A major objective of introducing partnership arrangements, as outlined in Chapters 1 and 8 , is that they are expected to reshape attitudes to work and employment, and thereby to unlock latent sources of motivation and commitment, unattainable on the basis of more traditional work arrangements and forms of industrial relations. This postulate has long provided the theoretical bridge between the work and decision-making innovations associated with involvement, participation and partnership and organizational outcomes and performance. The literature on involvement and participation has also long reported strong employee interest in new forms of participative work organization. The literature on teamwork as one specific innovation in work organization is more divided, as outlined in Chapter 8. Some commentators have associated teams with more scope for participation, higher levels of autonomy and positive work attitudes; others have equated teams with work intensification and more complex and variable patterns of attitudes and behaviour. While much of the more recent literature on partnership has concentrated on organizational outcomes and performance effects, without focusing directly on employees' attitudes and behaviour, positive effects on attitudes and behaviour are commonly inferred from management reports of employees' responses or are assumed to underlie partnership-based innovations. The literature on partnership has nevertheless introduced several new themes. One such theme concerns the possible effects on work-related attitudes and behaviour of different channels for involvement and participation. Another addresses the effects of simultaneous involvement in direct and indirect partnership channels. A third theme concerns whether attitudes and behaviour are positively affected in areas of likely benefit to the company (organizational commitment and productivity) as well as in areas of more immediate importance for employees (job satisfaction, fairness and well-being).

Attitude surveys conducted in Aer Rianta prior to the advent of $\mathrm{CP}$ revealed high levels of interest among staff in greater scope for involvement and participation than enjoyed under prevailing arrangements in the 
company. Latent in the attitudes revealed, in all probability, were high expectations with respect to $\mathrm{CP}$ and its consequences for employees. The survey conducted in conjunction with this study revealed that staff in general assessed CP in negative terms. Only minorities expressed positive or strongly positive attitudes towards the achievements and effects of partnership. Initial high expectations, uneven penetration, the 'top-heavy' nature of $\mathrm{CP}$ initiatives and perceptions of management divisions and resistance help explain the underlying pattern of attitudes revealed. A more positive assessment of CP emerged when an analysis was undertaken of the effects on attitudes of levels of involvement and participation in different aspects of CP. This revealed that the more job autonomy employees enjoyed and the greater their level of overall engagement with $\mathrm{CP}$, the more positive their assessments of the effects of partnership. Levels of job autonomy also influenced perceptions of the climate of industrial relations and thereby positively affected levels of organizational commitment. But higher levels of participation in formal $\mathrm{CP}$ groups and committees and occupancy of $\mathrm{CP}$ support roles negatively influenced perceptions of the climate of industrial relations and, thereby, levels of organizational commitment. This probably occurred because those with higher levels of formal involvement felt frustration with the pace and scale of change associated with CP. The survey analysis found that $\mathrm{CP}$ had no significant effect on changes in a range of work practices - these occurring mainly as a result of conventional pressures.

The establishment of regular work groups among skilled employees in the maintenance department was also shown to have had no distinctive effects on the attitudes and behaviour of those involved. This must count as a significant failure for the $\mathrm{CP}$ initiative, given the underlying objective of bringing about major changes in day-to-day working practices and work experiences through the creation of a new form of teamwork. Different CP channels appeared to influence attitudes in a specific or selective manner, in ways not envisaged by the partnership literature: 'more was not better' in the sense that the different $\mathrm{CP}$ channels created had not exerted discrete positive effects across a range of attitudes to work. High levels of involvement in multiple CP channels, direct and indirect, also exerted no robust positive effects on the attitudes and behaviour examined. Whatever may be the significance of 'vertical integration' with respect to the behaviour of institutional actors, like management and unions, or with respect to their joint activities, simultaneous involvement in, or engagement with, direct and indirect participation, was revealed not to have affected attitudes and behaviour on an individual level in Aer Rianta. The higher the level of involvement of staff in $\mathrm{CP}$ channels, however, the more pronounced the positive attitudinal effects for both the company and for employees themselves. In other words, 'mutual gains' were in this sense apparent at the level of individual attitudes and behaviour.

Developing on a long-running theme in the 'pre-partnership' literature, workplace partnership has also been associated by some writers with high 


\section{Advocates, critics and partnership}

levels of commitment towards organizations and trade unions: so-called 'dual commitment'. Dual commitment was shown not to have been a pervasive feature of the attitudes of employees and trade union members in Aer Rianta. This was accounted for by the limited, uneven, top-heavy and contested penetration of CP across the company, even at the high-water mark of partnership. Perhaps only highly institutionalized and systemic partnership arrangements can be expected to transform attitudes in a manner that results in dual commitment. CP never reached such a level of institutionalization in Aer Rianta.

\section{The breakdown of partnership}

The weak level of institutionalization of CP, even at its high-water mark, reflected the interplay of the forces outlined above on the dynamics of partnership. Partnership arrangements in the company broke down over a period of two to three years, as some of these forces were further affected by changes in the internal and external context of CP in Aer Rianta. In Chapter 10 , the breakdown of partnership was attributed to the interaction of operational-level and summit-level problems, and their joint interaction in turn with blurred boundaries between $\mathrm{CP}$ and conventional collective bargaining arrangements.

At the summit level, prolonged indecision and inaction by government regarding the future of Aer Rianta and a failure to implement the strategy formulated by the company and its unions introduced a damaging hiatus into relations between the parties to partnership, raising questions regarding the value of CP. One of the supreme achievements of $\mathrm{CP}$, the joint proposals on the company's future, now appeared to those involved to have led nowhere. At national level, one of the key unions, SIPTU, was also reported by some champions of $\mathrm{CP}$ to have had second thoughts regarding the partial privatization recommendation at the core of the joint proposals. The union's posture, in turn, reinforced the opposition of worker directors to privatization and to CP as a channel for privatization. A history of inter-union tensions at Dublin Airport, resulting in fears regarding further possible defections of members, hardened the resolve of union head offices against any activities on the ground that might put union security in jeopardy.

Though of less direct impact, the deliberations of the newly appointed aviation regulator appeared to raise questions with respect to one of the key commercial parameters of the Compact. Criticism of Aer Rianta's 'goldplated investment programme' appeared especially ominous for a company that had pledged itself to compete on the basis of service quality and that had offered major human resource pledges consistent with such a posture. Proposals to build a second, privately operated terminal at Dublin Airport, Aer Rianta's most profitable location, avidly backed by the low-cost carrier Ryanair, also called into question the long-term sustainability of the competitive posture underlying the Compact. 
It is conceivable that $\mathrm{CP}$ might have weathered even these storms had serious problems not simultaneously arisen at an operational or day-to-day level. Shortly after the parties had agreed a common position on the company's future and on the loss of duty-free sales, the pace of CP activity at departmental level increased considerably as management and unions sought to tackle on a partnership basis significant changes that affected work practices, pay and conditions. There were some significant achievements in two departments, cleaning and maintenance, but partnership effectively collapsed in two other major departments, Retailing and the Airport Police and Fire Service, amid much bitterness and recrimination. Opposition by worker directors to the use of $\mathrm{CP}$ to address areas hitherto covered by collective bargaining and background inter-union tensions interacted with difficulties encountered in finding agreement at departmental level and both sets of factors exposed ambiguities and uncertainties at the interface between partnership and collective bargaining. The resulting volatility displaced $\mathrm{CP}$ and discredited partnership among staff and union representatives in two major Aer Rianta departments. Active support on the part of remaining senior management champions also abated, as $\mathrm{CP}$ came to be viewed as divisive and ineffective. While these forces were being played out, the succession crisis engendered by the retirement of the major champions of $\mathrm{CP}$ on the management and union sides rendered $\mathrm{CP}$ highly vulnerable at a time when partnership confronted challenges of extreme and unprecedented magnitude.

The cumulative effect of summit- and operational-level problems and their interaction with ambiguities and uncertainties at the interface between collective bargaining and partnership was to bring about the collapse of partnership in Aer Rianta. The collapse of CP left a bitter heritage for many who had laboured to develop partnership in the company, and for union representatives and staff in major departments. All that remained among senior managers and trade union officials was a willingness to consider whether some way forward might still be found through partnership. The tentative explorations arising from residual goodwill towards the process were subsequently derailed by the announcement of proposals to break Aer Rianta into independently managed airport management companies. Management and the Aer Rianta unions now confronted the most serious crisis in the company's history through conventional modes of lobbying, decisionmaking and through traditional industrial relations postures.

\section{Advocates, critics and the case of Aer Rianta}

As outlined in Chapter 1 and at various points in the body of the book, academic opinion concerning workplace partnership has been polarized between advocates and critics. We will conclude the book with some comments on the import of the study's findings for this debate. First, it might be noted that the Aer Rianta case is significant in theoretical terms because the parties set out to adopt partnership as a basis for radical organizational 


\section{Advocates, critics and partnership}

change based on staff and union involvement and participation at multiple levels. In this regard Aer Rianta has few peers in the international literature and provides a rich context in which to examine the antecedents, dynamics and effects of voluntary partnership. In assessing the import of the findings for the debate between advocates and critics, it will be helpful to address separately the themes of the outcomes and sustainability of partnership.

\section{Outcomes}

Advocates of partnership point to a series of positive outcomes for all stakeholders, employers, employees and trade unions. Critics of partnership either argue that the benefits for employers grossly outweigh those for employees and unions, or that partnership, due to its essentially voluntary nature, delivers few significant benefits for any party.

In the case of Aer Rianta, the company and the unions could point to a series of benefits seen to have accrued from partnership, albeit that most of the benefits identified in the intensive interviews related to 'process' as distinct from 'bottom-line' advantages. The major achievements of CP, as presented in this book, were the joint strategy for the future status of the company and the joint strategic response to the loss of duty-free sales. Without partnership, as the parties involved made clear, each of these issues would have provoked major division and, in all probability, would have sparked acute industrial disorder. That the joint strategy for the future of Aer Rianta came to nought and that the joint strategic response to the loss of duty-free revenues failed to carry over into successful joint action across all the issues involved in the reorganization of retailing in the airports qualifies the extent of the successes achieved in these areas, but cannot erase them from the record.

Other outcomes identified by the advocates such as significant gains in productivity or quality, or reductions in labour costs, rooted in new work practices, better industrial relations and more committed staff, were not reported in Aer Rianta, though the changes introduced into some departments through partnership, as outlined in Chapter 10, were deemed significant by the parties involved on both sides. It is also relevant in assessing outcomes that attitudes towards, as well as commitment to, the company increased commensurate with employees' involvement in $\mathrm{CP}$, and their opportunity to work in a manner consistent with the principles of the Compact. The exception here was the effect of membership of CP groups, committees and occupancy of support roles, which made for more negative assessments of industrial relations and thereby for lower levels of organizational commitment. Unions were also assessed more positively and enjoyed higher levels of commitment commensurate with their members' involvement in CP. These findings, allied with the finding that attitudes on the whole were positively affected in areas of relevance to the company, as well as areas of concern to employees, indicate that significant positive outcomes had accrued through CP. 
That significant outcomes resulted with respect to the parties' response to strategic challenges, with respect to the changes introduced in some departments and with respect to the attitudes of at least some highly involved employees and union members, supports the position of the advocates and counts against the position of critics, such as Streeck, who see voluntary partnership as incapable of delivering significant gains for any party. The pattern of outcomes also seems inconsistent with the views of critics like Kelly, who claim that the outcomes of partnership are grossly asymmetrical, favouring employers significantly more than employees or trade unions. No claims consistent with perceptions of asymmetric outcomes were encountered in our interviews, save for some managers who felt that partnership had worked mainly to the advantage of trade unions. Also the pattern of outcomes with respect to strategic initiatives, departmental initiatives and attitudes pointed towards benefits for all parties. Certainly the kind of outcomes identified by Kelly (2004), involving reduced or indeterminate union influence, setbacks in work practices and relatively limited advances in pay and conditions were not evident in Aer Rianta, perhaps because CP, whatever its difficulties, occupied the 'labour-parity' end of Kelly's continuum.

\section{Sustainability}

Whatever its advantages for the parties, the Aer Rianta partnership broke down, and this also has a bearing on the arguments of advocates and critics. While Kelly's work contains no explicit theory of how partnerships might break down, implicit in his view of outcomes is the possibility that breakdown might occur as an outcome of asymmetrical gains, perhaps when unions are emboldened by improvements in the labour market or in their bargaining power. In the Aer Rianta case, gross disparities in the outcomes of partnership never became an issue for the parties, and so no such dynamic took effect. We are left then with two further theories of breakdown. One of these is at the core of the writings of advocates, where, as discussed, a series of influences is identified as important in shaping the functioning of partnership and ultimately the sustainability of partnership arrangements. The second is to be found in the contention of Wolfgang Streeck that voluntary partnership arrangements are capable only of engendering weak and unstable co-operation, and ultimately result in one side or other defecting, either opportunistically or strategically, where market or other forces are seen by them to warrant the withdrawal of support. As discussed in Chapter 1, Streeck's later work (1995) moves closer to the position of the advocates in its recognition that institutional supports might buttress voluntary cooperation and counteract the tendency to withhold earnest co-operation. The same supports might also counteract any tendency towards defection from partnership.

It is clear from the analysis presented in the book that strong and secure organization enabled the Aer Rianta unions to enter partnership with little 
fear concerning incorporation or loss of commitment from members. At the same time, it was also clear that the sustainability of partnership was limited by the weakness of other institutional supports identified by the advocates, principally compatible HR and industrial relations practices in critical areas such as rewards, performance management and conflict resolution. CP envisaged changes in these areas but failed to deliver those changes, with serious implications for the sustainability of voluntary co-operation. Other institutional supports identified by the advocates related to the overall architecture' of partnership itself: senior management support, a modus for involving middle managers, planning for management and union succession, the effective handling of the interface with collective bargaining, strategic integration and vertical alignment. In all these areas, the analysis presented in the core of the book also identified significant weaknesses that limited the effectiveness and ultimately the sustainability of partnership in Aer Rianta.

In major respects, therefore, we can understand the breakdown of partnership in terms of the absence or weakness of the kinds of institutional supports identified by advocates. Moreover, the dynamics of the breakdown of CP do not appear consistent with the position outlined by Streeck. CP did not collapse because it had been debilitated by chronically weak cooperation on either side. The level of co-operation proffered with respect to joint strategic initiatives was significant. Persistent union and workerdirector scepticism regarding the sustainability of partnership arose less from perceptions of management bad faith or underhandedness in partnership processes than from perceptions of divided and ambivalent management opinion and support. The breakdown of partnership, when it eventually came about, arose less from the dynamic identified by Streeck than from a different dynamic set in train by the summit-level and operational problems examined in Chapter 10. Arguably, these reflected not so much chronically weak and ineffective co-operation than overreach, excessive ambition and concurrent extreme pressures at multiple levels.

Assuredly, a point was reached when some of the union representatives and line managers responsible for change negotiations involving several categories of staff defected from CP in favour of collective bargaining, and when senior managers and union officials withdrew support from partnership in the light of operational and summit-level problems that had now come to appear intractable. But the dynamic involved here was both different to and more complex than that posited in Streeck's critique of voluntary partnership and his emphasis on the chronic 'co-operation deficit' inherent in forms of partnership without the 'hard' institutional supports provided by legislation. 


\section{Appendix}

Table A1 Scales of involvement and engagement with constructive participation

1 Membership of constructive participation groups

Mean S.D. and committees and occupancy of support roles

7 -item scale; each item scored: $1=$ yes; no/don't know $=0$.

Scale range: $0-7$.

0.64

Member of a regular work group

0.26

Member of a departmental steering or work group $\quad 0.14$

Member of a departmental strategy group $\quad 0.13$

Member of a significant issues group $\quad 0.11$

Observer of any of the above groups $\quad 0.17$

Participation mentor with a department $\quad 0.06$

Participation office facilitator $\quad 0.00$

Cronbach Alpha $=0.7225$.

\section{Engagement with constructive participation}

9-item scale; each item scored: 2 = frequently; 1 = occasionally; $0=$ never.

Scale range: $0-18$.

Have you ever attended departmental meetings or training sessions at which constructive participation was discussed?

Have you read departmental newsletters on constructive participation?

Have you read company/union newsletters on constructive participation?

Have you attended any staff seminars on constructive participation arranged by the Joint Union Company Group?

Have you attended any exhibitions on constructive participation arranged by the Joint Union Company Group?

Have you attended union meetings where constructive participation was discussed?

Have you used the constructive-participation library?

$0.13 \quad 0.42$

Have you discussed constructive participation with colleagues?

Have you received feedback from colleagues who are involved in constructive-participation groups and committees?

Cronbach Alpha $=0.8590$.

\section{Communicative involvement}

4 -item scale; each item scored: $3=$ a great deal; $2=$ a moderate amount; 1 = only a little; $0=$ none.

Scale range: $0-12$. 
Table A1 continued

How much information do you usually get about what is going on at each of the following?

Board meetings

Corporate senior management meetings

$0.58 \quad 0.81$

Airport senior management meetings

$0.80 \quad 0.90$

Local departmental meetings

1.381 .06

Cronbach Alpha $=0.8351$.

\section{Work participation}

9-item scale: 4 task participation items and 5 items relating to management/supervisory style as experienced by employees.

The task participation items are scored: $3=$ a great deal; $2=\mathrm{a}$ moderate amount; 1 = a little; $0=$ none.

The management/supervisory style items are scored 2 = frequently; $1=$ occasionally; 0 = never.

To allow all items to exert equal influence on respondents' overall scale scores, the scale scores for the management/ supervisory scale items were adjusted by multiplying the raw scores by 1.5.

Scale range $=0-27$.

\section{Task participation}

Thinking about your work, can you indicate the degree to which you have a say in the following activities?

Planning your work

Setting work targets

Organizing workload

Management/supervisory style

We would like to ask about your experiences of decision-making and communication in Aer Rianta.

How often are you consulted before decisions are taken that affect your work?

If changes in your work occur, how often are you given the reason why?

Are you given the opportunity to make work decisions on your own?

If you have an opinion different from your supervisor, can you say so?

If you can say so, is any attention paid to it?

Cronbach Alpha $=0.9273$.

* Scale means and standard deviations calculated based on unadjusted scale scores (0-2).

Note

All means, proportions and statistics presented in respect of the weighted sample. 
Table A2 Union commitment scale and sub-scales

Composite union commitment scale

Mean

S.D.

A 12-item scale, each item scored: $1=$ strongly disagree to

$5=$ strongly agree. Items marked with an asterisk are reverse

coded for consistency, from $1=$ strongly agree to 5 = strongly

disagree.

1 I feel a sense of pride at being part of the union or staff association.

2 The record of my union or staff association is a good example of what dedicated people can get done.

3 My loyalty is to my work and not to my union or staff association.*

4 It's every union or staff association member's responsibility to see that management lives up to the terms of the 'Awards and Agreements'.

5 As long as I'm doing the kind of work that I enjoy, it does not matter if I belong to a union or staff association.*

6 I am willing to put a great deal of effort in beyond that normally expected of me in order to make the union or staff association successful.

7 It's every member's duty to support or help another worker with his or her grievances.

8 There's a lot to be gained from joining the union or staff association.

9 I would not do special work to help the union or staff association.*

10 If asked, I would serve on a committee for the union or staff association.

11 Every union or staff association member must be prepared to take the time and risk of making a complaint.

12 I could just as well work in another organization where there was no union or staff association, as long as the type of work was similar.*

Cronbach Alpha $=0.8381$.

Sub-scales measuring different dimensions of union commitment

1 Union loyalty (Items 1, 2 and 8 above).

2 Belief in union (Items 3, 5 and 12 above).

$8.7 \quad 2.5$

3 Responsibility to union (Items 4, 7 and 11 above).

$11.5 \quad 1.8$

4 Willingness to work for union (Items 6,9 and 10 above).

$9.4 \quad 2.3$

Notes

Asterisked items are reverse-coded. Descriptive and scale statistics are based on weighted sample data. 
Table A3 Attitudes to constructive participation: scale and sub-scales

Attitudes to constructive participation

Mean S.D.

5-item scale; each item scored: 1 = strongly disagree; 2 = disagree;

3 = can't decide; 4 = agree; 5 = strongly agree.

$13.9 \quad 4.3$

Please indicate the extent to which you agree with the following statements:

I know more about what is going on because of constructive participation.

I accept work decisions more easily because of constructive participation.

$2.56 \quad 0.98$

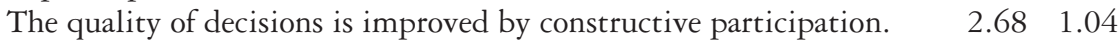

$\begin{array}{lll}\text { Employee interests are better served by constructive participation. } & 3.21 & 1.01\end{array}$

Better understanding and trust exist between management and employees as a result of constructive participation.

Cronbach Alpha = 0.8839 .

Note

All means, proportions and statistics presented in respect of the weighted sample. 
Table A4 Organizational commitment: composite scale and sub-scales

Composite organizational commitment scale

Mean S.D.

A 15 -item scale, each item scored: $1=$ strongly disagree to

$5=$ strongly agree. Items marked with an asterisk are reverse

coded for consistency, from $5=$ strongly disagree to $1=$ strongly agree.

1 I am willing to put in a great deal of effort beyond that normally expected in order to help this organization to be successful.

2 I talk up this organization to my friends as a great organization to work for.

3 I feel very little loyalty to this organization.*

4 I would accept almost any type of job assignment in order to keep working for this organization.

5 I find that my values and the organization's values are very similar.

6 I am proud to tell others that I am part of this organization.

7 I could just as well be working for a different organization as long as the type of work was similar.*

8 This organization really inspires the very best in me in the way of job performance.

9 It would take very little change in my present circumstances to cause me to leave this organization.*

$3.7 \quad 1.0$

$3.8 \quad 1.0$

$2.5 \quad 1.0$

$3.3 \quad 0.9$

$3.9 \quad 0.7$

$3.0 \quad 1.0$

$3.0 \quad 1.1$

$3.5 \quad 1.0$

10 I am extremely glad that I chose this organization to work for over others I was considering at the time I joined.

11 There's not much to be gained by sticking with this organization indefinitely.*

12 Often I find it difficult to agree with this organization's policies on important matters relating to its employees.*

13 I really care about the fate of this organization.

14 For me this is the best of all possible organizations for which to work.

15 Deciding to work for this organization was a definite mistake on my part.*

Cronbach Alpha $=0.8567$.

Sub-scales measuring different dimensions of organizational commitment

1 Effort commitment (Items 1 and 8 above). $\quad \begin{array}{lll}7.1 & 1.4\end{array}$

2 Flexibility commitment (Item 4 above). $\quad 2.5 \quad 1.0$

3 Value commitment (Items 3, 5 and 6 above). $\quad 11.0 \quad 2.0$

4 Continuance commitment (Items 7, 9 and 11 above). $\quad 10.0 \quad 2.3$

Note

Summary and scale statistics based on weighted sample data. 


\section{Bibliography}

\section{Constructive participation documents}

Aer Rianta (April 1999) Future Strategic Direction: A Report to the Minister for Public Enterprise.

Corporate Strategy SIG (Significant Issues Group) (March 1999) Corporate Strategy SIG Discussion Document.

- (n.d.) Corporate Strategy SIG Submission on Company Review.

Future Strategic Directions: A Report to the Minister for Public Enterprise (1999) Dublin: Aer Rianta.

Report to the Minister, Future Strategic Directions: A Report to the Minister for Public Enterprise (1999) Dublin: Aer Rianta.

JUCG (Joint Union Company Group) (1992) Minutes of JUCG Meeting, 21st April. (1993) Worker Participation in Aer Rianta.

— (1994) Towards Constructive Participation: A Positive Approach to Management/Union Relationships.

— (1995) Requisite Arrangements: Towards Constructive Participation.

(December 1997) Report on the Middle Management Group in Shannon Airport (research report prepared for the JUCG).

- (n.d.) The Anticipated Effects of Participation on the Role of the Middle Manager (research report prepared for the JUCG).

(1999) Aer Rianta/Unions Constructive Participation Report 1998/99.

JWG (Joint Working Group) (1990) Position Paper on Participation within Aer Rianta, Joint Working Group, October, Dublin: Aer Rianta.

(SIG) Significant Issues Group (n.d.) Change of Status Discussion Document.

\section{General references}

Ackers, P. and Payne, J. (1998) 'British trade unions and social partnership: rhetoric, reality and strategy', International Journal of Human Resource Management, 9: 529-50.

Angle, H.L. and Perry, J.L. (1986) 'Dual commitment and labor-management relationship climates', Academy of Management Journal, 29: 31-50.

Appelbaum, E. and Batt, R. (1994) The New American Workplace: Transforming Work Systems in the United States, Ithaca, NY: Cornell University Press.

Appelbaum, E., Bailey, T., Berg, P. and Kalleberg, A. (2000) Manufacturing Advantage, Why High-performance Work Systems Pay Off, Ithaca, NY: Cornell University Press. 
Arthur, J.B. (1992) 'The link between business strategy and industrial relations systems in American steel mills', Industrial and Labor Relations Review, 45, 3: $488-506$.

Bacon, N. and Storey, J. (2000) 'New employee relations strategies in Britain: towards individualism or partnership?', British Journal of Industrial Relations, 38, 3: 407-28.

Barker, J.R. (1993) 'Tightening the iron cage: concertive control in self-managing teams', Administrative Science Quarterly, 38: 408-37.

Barling, J., Wade, B. and Fullagar, C. (1990) 'Predicting employee commitment to company and union: divergent models', Journal of Occupational Psychology, 63: 49-61.

Batt, R. (2004) 'Who benefits from teams? Comparing workers, supervisors and managers', Industrial Relations, 43, 1: 183-210.

Begg, David (2004) 'Unions have a right to an input into long-term transport policy', Irish Times, 13 February.

Black, J. and Ackers, P. (1994) 'Between adversarial relations and incorporation: a study of the "joint process" in an American auto-components plant', in T. Elger and C. Smith (eds) Global Japanization? The Transnational Transformation of the Labour Process, London: Routledge.

Black, S.E. and Lynch, L.M. (1997) 'How to compete: the impact of workplace practices and information technology on productivity', National Bureau of Economic Research Working Paper No. 6120, Cambridge, MA.

- (2000) 'What's driving the new economy: the benefits of workplace innovation', National Bureau of Economic Research Working Paper No. 7479, Cambridge, MA.

Black, S.E., Lynch, L.M. and Krivelyova, A. (2004) 'How workers fare when employers innovate', Industrial Relations, 43, 1: 44-66.

Blumberg, P. (1968) Industrial Democracy: The Sociology of Participation, London: Constable.

Boxall, P. and Haynes, P. (1997) 'Strategy and trade union effectiveness in a neoliberal environment', British Journal of Industrial Relations, 35, 4: 567-91.

Cappelli, P. (1999) The New Deal at Work: Managing the Market-driven Workforce, Boston, MA: Harvard Business School Press.

Clarke, L. and Haiven, L. (1999) 'Workplace change and continuous bargaining: Saskatoon chemicals then and now', Relations Industrielles, 54, 1: 168-91.

Cohen-Rosenthal, E. and Burton, C.E. (1993) Mutual Gains: A Guide to Union-Management Cooperation, Ithaca, NY: ILR Press

Colling, T. (1995) 'Renewal or rigor mortis?', Industrial Relations Journal, 26, 2: $134-45$.

Cooke, W. (1990) Labor-Management Cooperation: New Partnerships or Going in Circles, Kalamazoo, MI: W.E. Upjohn Institute for Employment Research.

Cooke, W. and Meyer, D.G. (1990) 'Structural and market predictors of corporate labor relations strategies', Industrial and Labor Relations Review, 43, 2: 280-93.

Crouch, C. and Streeck, W. (1997) 'Introduction: the future of capitalist diversity', in C. Crouch and W. Streeck (eds) Political Economy of Modern Capitalism: Mapping Convergence and Divergence, London: Sage.

Cully, M., Woodland, S., O'Reilly, A. and Dix, G. (1999) Britain at Work, as Depicted by the 1998 Workplace Employee Relations Survey, London: Routledge.

Cutcher-Gershenfeld, J. (1988) The Case of Xerox Corporation and the Amalgamated Clothing and Textile Workers Union, U.S. Department of Labor, BLMR 123. 


\section{Bibliography}

Cutcher-Gershenfeld, J. and Verma, A. (1994) 'Joint governance in North American workplaces: a glimpse of the future or the end of an era?', The International Journal of Human Resource Management, 5, 3: 547-80.

Deery, S.J., Iverson, R.D. and Erwin, P.J. (1994) 'Predicting organizational and union commitment: the effect of industrial relations climate', British Journal of Industrial Relations, 32, 4: 581-97.

Department of Public Enterprise (December 1999) Report to the Minister for Public Enterprise and the Minister for Finance: Review of Strategic Options for the Future of Aer Rianta, Dublin: Department of Public Enterprise.

Drago, R. and Wooden, M. (1991) 'The determinants of participatory management', British Journal of Industrial Relations, 29, 2: 177-204.

Dyer, L., Foltman, F. and Milkovich, G. (1985) 'Contemporary employment stabilization practices', in T.A. Kochan and T.A. Barocci (eds) Human Resource Management and Industrial Relations: Texts, Readings and Cases, Boston, MA: Little, Brown.

Eaton, S.C., Kochan, T.A. and McKersie, R.B. (2003) The Kaiser Permanente Labor Management Partnership: The First Five Years, Boston, MA: MIT, Sloan School of Management.

Edwards, P. (2001) 'The puzzles of work', ESRC Centre on Skills, Knowledge and Organisational Performance, Paper 16, Universities of Oxford and Warwick.

Edwards, P., Belanger, J. and Wright, M. (2002a) 'The micro-foundations of class compromise', paper presented at the International Sociological Association World Congress, Research Committee 10, Brisbane, July.

Edwards, P., Geary, J. and Sisson, K. (2002b) 'New forms of work organization in the workplace: transformative, exploitative, or limited and controlled?', in G. Murray, J. Belanger, A. Giles, P.-A. Lapointe (eds) Work and Employment in the High Performance Workplace, London: Continuum International Publishing.

EPOC (1997) New Forms of Work Organisation. Can Europe Realise Its Potential? Results of a Survey of Direct Employee Participation in Europe, Luxembourg: Office for the Official Publications of the European Communities.

Fenton-O'Creevy, M. (1998) 'Employee involvement and the middle manager: evidence from a survey of organisations', Journal of Organisational Behaviour, 19, 1: 67-84.

- (2001) 'Employee involvement and the middle manager: saboteur or scapegoat?', Human Resource Management Journal, 11, 1: 24-40.

Ferner, A. (1988) Governments, Managers and Industrial Relations: Public Enterprises and Their Political Environment, Oxford: Basil Blackwell.

Ferner, A. and Quintanilla, J. (1998) 'Multinationals, national business systems and HRM: the enduring influence of national identity or a process of Anglo-Saxonisation', International Journal of Human Resource Management, 9, 4: 710-31.

Fransella, F. (1995) George Kelly, London: Sage.

Freeman, R.B. and Rogers, J. (1999) What Workers Want, Ithaca, NY: ILR Press.

Friedman, A.L. (1977) Industry and Labour, London: Macmillan.

Fukami, C.V. and Larson, E.W. (1984) 'Commitment to company and union: parallel models', Journal of Applied Psychology, 69: 367-71.

Fullagar, C. and Barling, J. (1991) 'Predictors and outcomes of different patterns of organizational and union loyalty', Journal of Occupational Psychology, 64: 129-43.

Gallie, D. and White, M. (1993) Employee Commitment and the Skills Revolution: First Findings from the Employment in Britain Survey, London: Policy Studies Institute.

Gallie, D., White, M., Cheng, Y. and Tomlinson, M. (1998) Restructuring the Employment Relationship, Oxford: Oxford University Press. 
Geary, J. (1995) 'Work practices: the structure of work', in P. Edwards (ed.) Industrial Relations: Theory and Practice in Britain, Oxford: Basil Blackwell.

(2003) 'New forms of work organization: still limited, still controlled, but still welcome?', in P. Edwards (ed.) Industrial Relations: Theory and Practice in Britain, 2nd edn, Oxford: Basil Blackwell.

Geary, J. and Dobbins, A. (2001) 'Teamworking: a new dynamic in the pursuit of management control', Human Resource Management Journal, 11, 1: 3-24.

Geary, J. and Roche, W. (2003) 'Workplace partnership and the displaced activist thesis', Industrial Relations Journal, 34, 1: 32-51.

Gill, C. and Krieger, H. (2000) 'Recent survey evidence on participation in Europe: towards a European model?', European Journal of Industrial Relations, 6: 109-32.

Godard, J. and Delaney, J. (2000) 'Reflections on the "high performance" paradigm's implications for industrial relations as a field', Industrial and Labor Relations Review, 53, 3: 482-502.

Gordon, M.E. and Ladd, R.T. (1990): 'Dual allegiance: renewal, reconsideration and recantation', Personnel Psychology, 43: 37-69.

Gordon, M.E., Philbot, J.W., Burt, R., Thompson, C.A. and Spiller, W.A. (1980) 'Commitment to the union: development of a measure and an examination of its correlates', Journal of Applied Psychology, 43: 37-64.

Grattan, L. (1997) 'Tomorrow people’, People Management, 24, July: 22-7.

Guest, D. (1987) 'Human resource management and industrial relations', Journal of Management Studies, 24, 5: 503-21.

- (1995) 'Human resource management, trade unions and industrial relations', in J. Storey (ed.) Human Resource Management: A Critical Text, London: Routledge.

Guest, D. and Dewe, P. (1991) 'Company or trade union: which wins workers' allegiance: a study of commitment in the UK electronics industry', British Journal of Industrial Relations, 29, 1: 75-96.

Guest, D. and Peccei, R. (1998) The Partnership Company: Benchmarks for the Future, London: IPA.

(2001) '"Partnership at work": mutuality and the balance of advantage', British Journal of Industrial Relations, 39, 2: 207-36.

Guest, D., Michie, J., Conway, N. and Sheehan, M. (2003) 'Human resource management and corporate performance in the UK', British Journal of Industrial Relations, 41, 2: 291-314.

Hagenaars, J.A. and McCutcheon, A.L. (eds) (2002) Applied Latent Class Analysis, Cambridge: Cambridge University Press.

Hales, C. (2000) 'Management and empowerment programmes', Work, Employment and Society, 14, 3: 501-20.

Hammer, T.H. and Stern, R.N. (1986) 'A yo-yo model of cooperation: union participation in management at the rath packing company', Industrial Relations and Labor Review, 39, 3: 337-49.

Handel, M.J. and Levine, D.I. (2004) 'Editors' introduction: the effects of new work practices on workers', Industrial Relations, 43, 1: 1-43.

Hastings, T. (1994) Semi-States in Crisis: The Challenge for Industrial Relations in the ESB and Other Major Semi-state Companies, Dublin: Oak Tree Press.

(2003) Politics, Management and Industrial Relations: Semi-state Companies and the Challenges of Marketization, Dublin: Blackhall Publishing.

Heckscher, C.C (1988) The New Unionism: Employee Involvement in the Changing Corporation, Ithaca, NY: ILR Press. 


\section{Bibliography}

Heller, F., Pusic, E., Strauss, G. and Wilpert, B. (eds) (1998) Organizational Participation: Myth and Reality, Oxford: Oxford University Press.

Herrick, M. (1990) Joint Management and Employee Participation: Labor and Management at the Crossroads, San Francisco, CA, Jossey-Bass.

Huselid, M. (1995) 'The impact of human resource management practices on turnover, productivity, and corporate financial performance', Academy of Management Journal, 38: 635-70.

Huselid, M.A., Jackson, S.E. and Schuler, R.S. (1997) 'The significance of human resource management effectiveness for corporate financial performance', Academy of Management Journal, 40: 171-88.

Hutton, W. (1995) The State We're In, London: Jonathan Cape.

Hyman, J. and Mason, B. (1995) Managing Employee Involvement and Participation, London: Sage.

Hyman, R. (1975) Industrial Relations: A Marxist Introduction, London: Macmillan.

(1979) 'The politics of workplace trade unionism: recent tendencies and some problems for theory', Capital and Class, 8, 54-67.

(1996) 'Changing union identities in Europe', in P. Leisink, J. Van Leemput and J. Vilrokx (eds) The Challenges to Trade Unions in Europe: Innovation and Adaptation, Cheltenham: Edward Elgar.

Ichniowski, C., Kochan, T., Levine, D., Olson, C. and Strauss, G. (1996) 'What works at work: overview and assessment', Industrial Relations, 35, 3: 299-333.

ICTU (1998) What People Think of Trade Unions: Results of a National Survey Conducted by Research and Evaluation Services for the Irish Congress of Trade Unions, Dublin: Irish Congress of Trade Unions.

(2001) Unions and Work: Highlights of a Survey of Attitudes Conducted by Research and Evaluation Services for the Irish Congress of Trade Unions, Dublin: Irish Congress of Trade Unions.

IDE (1981) Industrial Democracy in Europe Revisited, Oxford: Oxford University Press.

Inglehart, R. (1990) Culture Shift in Advanced Industrial Society, Princeton, NJ: Princeton University Press.

Inglehart, R. (1997) Modernization and Postmodernization, Princeton, NJ: Princeton University Press.

IRN (2001) '250 police and fire staff secure 15\% above PPF', Industrial Relations News, 18.

Jacoby, S. (1997) Modern Manors: Welfare Capitalism since the New Deal, Princeton, NJ: Princeton University Press.

Kanter, R. (1978) 'Work in a new America', Daedalus, 107: 47-78.

Kelly, A. and Hourihan, F. (1994) 'Employee participation', in W. Roche and T. Murphy (eds) Irish Industrial Relations in Practice, Dublin: Oak Tree Press.

Kelly, G.A. (1991) The Psychology of Personal Constructs. Volume One: Theory and Personality, London: Routledge.

Kelly, J. (1996) 'Union militancy and social partnership', in P. Ackers, C. Smith and P. Smith (eds) The New Workplace and Trade Unionism, London: Routledge.

- (1998) Rethinking Industrial Relations: Mobilization, Collectivism and Long Waves, London: Routledge.

(1999) 'Social partnership in Britain: good for profits, bad for jobs and unions', Communist Review, Autumn, 30, 3-10.

- (2004) 'Social partnership agreements in Britain: labor cooperation and compliance', Industrial Relations, 43, 1: 267-92. 
Kelly, J. and Kelly, C. (1991) "“Them and us": social psychology and the "new industrial relations"', British Journal of Industrial Relations, 29, 1: 25-48.

Klein, J.A. (1984) 'Why supervisors resist employee involvement', Harvard Business Review, 62: 87-95.

Knell, J. (1999) Partnership at Work, Employment Relations Research Series 7, London: Department of Trade and Industry.

Kochan, T. (1995) 'Using the Dunlop report to achieve mutual gains', Industrial Relations, 34, 3: 350-66.

(2000) 'A new social contract for a new economy', in P. Gunnigle, M. Morley and M. McDonnell (eds) The John Lovett Memorial Lectures: A Decade of Developments in Human Resource Management, Dublin: Liffey Press.

Kochan, T. and Osterman, P. (1994) The Mutual Gains Enterprise: Forging a Winning Partnership among Labor, Management and Government, Boston, MA: Harvard Business School Press.

Kochan, T. and Rubinstein, S. (2000) 'Toward a stakeholder theory of the firm: the Saturn partnership', Organization Science, 11: 367-86.

Kochan, T., Katz, H. and McKersie, R.B. (1986) The Transformation of American Industrial Relations, New York: Basic Books.

Lawler, E. and Mohrman, S. (1987) 'Unions and the new management', Academy of Management Executive, 1, 3: 293-300.

Lincoln, J.R. and Kalleberg, A.L. (1990) Culture, Control and Commitment: A Study of Work Organization and Work Attitudes in the United States and Japan, Cambridge: Cambridge University Press.

Locke, R., Kochan, T. and Piore, P. (1995) Employment Relations in a Changing World Economy, Boston, MA: MIT Press.

Magenau, J.M., Martin, J.E. and Peterson, M.M. (1988) 'Dual and unilateral commitment among stewards and rank-and-file union members', Academy of Management Journal, 31: 359-76.

Marchington, M. (1995) 'Employee involvement', in J. Storey (ed.) HRM: A Critical Text, London: Routledge.

Marchington, M., Wilkinson, A., Ackers, P. and Goodman, J. (1994) 'Understanding the meaning of participation', Human Relations, 47: 867-94.

Marginson, P. and Sisson, K. (1994) 'The structure of transnational capital in Europe: the emerging Euro-company and its implications for industrial relations', in R. Hyman and A. Ferner (eds) New Frontiers in European Industrial Relations, Oxford: Blackwell.

Marks, A., Findlay, P., Hine, J., McKinlay, A. and Thompson, P. (1998) 'The politics of partnership: innovation in employment relations in the Scottish spirits industry', British Journal of Industrial Relations, 36, 2: 209-26.

McCabe, D. (2000) 'Factory innovations and management machinations: the productive and repressive relations of power', Journal of Management Studies, 37, 7: 931-53.

Meyer, J.P. and Allen, N.J. (1997) Commitment in the Workplace: Theory, Research and Application, London: Sage.

NCPP (2001) Strategic Planning Discussion Document, mimeo, Dublin: National Centre for Partnership and Performance.

O’Dowd, J. (2002) 'Workplace partnership - how does it affect industrial relations?', paper presented at the IRN Annual Conference, 'Facing Reality - Competitiveness, Partnership and Organization Change in a Cool Climate', February, Dublin. 
Offe, C. and Wiesenthall, H. (1980) 'Two logics of collective action', Political Power and Social Theory, 1: 67-115.

Offer, M. (1998) The Views of Shop Stewards at Shannon Airport: Key Points from the Report, Dublin: Aer Rianta (unpublished).

O'Reilly, C.A. and Chatman, J.A. (1986) 'Organizational commitment and psychological attachment: the effects of compliance, identification and internalization on pro-social behaviour', Journal of Applied Psychology, 71: 492-9.

Osterman, P. (1994) 'How common is workplace transformation and how can we explain who adopts it?', Industrial and Labor Relations Review, 47, 1: 173-87.

(1999) Securing Prosperity, the American Labor Market: How It Has Changed and What to Do about It, Princeton, NJ: Princeton University Press.

Osterman, P., Kochan, T.A., Locke, R.M. and Piore, M. J. (2001) Working in America: A Blueprint for the New Labor Market, Boston, MA: MIT Press.

Pfeffer, J. (1994) Competitive Advantage through People: Unleashing the Power of the Work Force, Boston, MA: Harvard Business School Press.

Porter, L.W., Steers, R.M., Mowday, R. and Boulian, P.V. (1974) 'Organizational commitment, job satisfaction and turnover among psychiatric technicians', Journal of Applied Psychology, 59: 599-608.

Purcell, J. (1999) 'Best practice and best fit: chimera or cul-de-sac?', Human Resource Management Journal, 9, 3: 26-41.

Ramsay, H. (1977) 'Cycles of control', Sociology, 11, 3: 481-506.

Ramsay, H., Scholarios, D. and Harley, B. (2000) 'Employees and high-performance work systems: testing inside the black box', British Journal of Industrial Relations, 38, 4: 501-31.

Regini, M. (1995) Uncertain Boundaries: The Social and Political Construction of European Economies, Cambridge: Cambridge University Press.

Roche, W. (1999) 'In search of commitment-oriented HRM practices and the conditions that sustain them', Journal of Management Studies, 36, 5: 653-78.

- (2000) 'The end of new industrial relations?', European Journal of Industrial Relations, 6, 3: 261-82.

- (2002) 'Whither partnership in the public sector', Administration, 50, 4: 3-26.

Roche, W.K. and Geary, J.F. (2000) "Collaborative production" and the Irish boom: work organization, partnership and direct involvement in Irish workplaces', Economic and Social Review, 31, 1: 1-36.

- (2002) 'Advocates, critics and union involvement in workplace partnership: Irish airports', British Journal of Industrial Relations, 40, 4: 659-88.

(2004) 'Partnership and the prospect of dual commitment', in M. Stuart and M. Martinez (eds) Assessing Partnership, London: Routledge.

Roche, W. and Turner, T. (1998) 'Human resource management and industrial relations: substitution, dualism and partnership', in W. Roche, K. Monks and J. Walsh (eds) Human Resource Strategies: Policy and Practice in Ireland, Dublin: Oak Tree Press.

Rogers, J. and Streeck, W. (1995) (eds) Works Councils: Consultation, Representation and Co-operation in Industrial Relations, Chicago, IL: University of Chicago Press.

Rose, M. (1989) 'Attachment to work and social values', in D. Gallie (ed.) Employment in Britain, Oxford: Blackwell, pp. 128-56.

Royle, T. (1998) 'Avoidance strategies and the German system of co-determination', International Journal of Human Resource Management, 9, 6: 1026-47.

Rubinstein, S.A. (2000) 'The impact of co-management on quality performance: the case of the Saturn corporation', Industrial and Labor Relations Review, 53, 2: 197-218. 
(2001) 'A different kind of union: balancing co-management and representation', Industrial Relations, 40: 163-203.

Rubinstein, S.A. and Heckscher, C.C. (2003) 'Partnerships and flexible networks: alternatives or complimentary models of labor-management relations?', in T. Kochan and D. Lipsky (eds) Negotiations and Change: From the Workplace to Society, Ithaca, NY: Cornell University Press.

Rubinstein, S.A. and Kochan, T. (2001) Learning from Saturn, Ithaca: Cornell University Press.

Schuler, R. and Jackson, S. (1987) 'Linking competitive strategies with human resource management practices', Academy of Management Executive, 1, 3: 209-13.

Sewell, G. (1998) 'The discipline of teams: the control of team-based industrial work through electronic and peer surveillance', Administrative Science Quarterly, 43: $397-428$.

Sewell, G. and Wilkinson, B. (1992) 'Someone to watch over me: surveillance, discipline and the just-in-time labour process', Sociology, 26: 271-90.

Shaiken, H., Lopez, S. and Mankita, I. (1997) 'Two routes to team production: Saturn and Chrylser compared', Industrial Relations, 36: 17-45.

Sherer, P.D. and Morishima, M. (1989) 'Roads and roadblocks to dual commitment: similar and dissimilar antecedents of union and company commitment', Journal of Labor Research, 10: 311-30.

Snape, E. and Chan, A.W. (2000) 'Commitment to company and union: evidence from Hong Kong', Industrial Relations, 39: 445-59.

Sorge, A. and Streeck, W. (1988) 'Industrial relations and technical change: the case for an extended perspective', in R. Hyman and W. Streeck (eds) New Technology and Industrial Relations, Oxford: Basil Blackwell.

Storey, J. (1992) Developments in the Management of Human Resources, Oxford: Blackwell.

Storey, J. and Sisson, K. (1993) Managing Human Resources and Industrial Relations, Buckingham: Open University Press.

Strauss, G. (1998a) 'Collective bargaining, unions and participation', in F. Heller, E. Pusic, G. Strauss and B. Wilpert (eds) Organizational Participation: Myth and Reality, Oxford: Oxford University Press.

- (1998b) 'Participation works - if conditions are appropriate', in F. Heller, E. Pusic, G. Strauss and B. Wilpert (eds) Organizational Participation: Myth and Reality, Oxford: Oxford University Press.

Streeck, W. (1992) 'National diversity, regime competition and institutional deadlock: problems in forming a European industrial relations system', Journal of Public Policy, 12, 4, 301-30.

(1994) 'European social policy after Maastricht: the social dialogue and subsidiarity', Economic and Industrial Democracy, 15, 1: 151-77.

- (1995) 'Works councils in Western Europe: from consultation to participation', in J. Rogers and W. Streeck (eds) Works Councils: Consultation, Representation and Co-operation in Industrial Relations, Chicago, IL: University of Chicago Press.

(1997) 'Citizenship under regime competition: the case of the "European work councils"', Jean Monnet Chair Papers, 42, European University Institute, Robert Schuman Centre, Florence.

Sverke, M. and Sjoberg, A. (1994) 'Dual commitment to company and union in Sweden: an examination of predictors and taxonomic split methods', Economic and Industrial Democracy, 15: 531-64.

Tailby, S. and Winchester, D. (2000) 'Management and trade unions: towards social 
partnership', in S. Bach and K. Sisson (eds) Personnel Management, Oxford: Blackwell.

Taylor, P. and Ramsay, H. (1998) 'Unions, partnership and HRM: sleeping with the enemy', International Journal of Employment Relations, 6: 115-43.

Terry, M. (2000) 'Employee representation in the UK: from collective bargaining to social partnership?', paper presented at University College Dublin, March 2000.

_ (2001) 'Can "social partnership" reverse the decline of British trade unions?', mimeo, March.

- (2003a) 'Employee representation: shop stewards and the new legal framework', in P. Edwards (ed.) Industrial Relations: Theory and Practice in Britain, 2nd edn, Oxford: Basil Blackwell.

(2003b) 'Can "partnership" reverse the decline of British trade unions?', Work, Employment and Society, 17, 3: 459-72.

Thelen, K. (1991) Union of Parts: Labor Politics in Postwar Germany, Ithaca, NY: Cornell University Press.

Turnbull, P. and Wass, V. (1998) 'Marksist management: sophisticated human relations in a High Street retail store', Industrial Relations Journal, 29, 2: 98-111.

US Department of Labor (1996) Working Together for Public Service, Washington, DC: Department of Labor.

Verma, A. and Chaykowski, R. (eds) (1999) Contract and Commitment: Employment Relations in the New Economy, Kingston, ON: Queen's University, IRC Press.

Vermunt, J.K. and Magidson, J. (2001) 'Latent class modelling as a probabilistic extension of K-means clustering', online, available HTTP http:/www.statisticalinnovations.com $/ \mathrm{lg} / \mathrm{kmeans} / \mathrm{kmeans} 2 \mathrm{a} \cdot \mathrm{htm}$.

Wall, T.D. and Lischeron, J.A. (1977) Worker Participation: A Critique of the Literature and Some Fresh Evidence, London: McGraw-Hill.

Walton, R.E. (1985) 'From control to commitment in the workplace', Harvard Business Review, 63, March-April: 76-84.

Walton, R.E. and McKersie, R.B. (1965) A Behavioral Theory of Labor Negotiations: An Analysis of Social Interaction Systems, New York: McGraw-Hill.

Webb, J. (1996) 'Vocabularies of motive and the "NEW" management', Work, Employment and Society, 10, 2: 251-71.

Weiler, P.C. (1990) Governing the Workplace: The Future of Labor and Employment Law, Cambridge, MA: Harvard University Press.

Wilkinson, A., Redman, T., Snape, E. and Marchington, M. (1998) Managing with Total Quality Management: Theory and Practice, London: Macmillan.

Wilpert, B. (1998) 'A view from psychology', in G. Strauss, B. Wilpert, F. Heller and E. Pusic, Organizational Participation: Myth and Reality, Oxford: Oxford University Press, pp. 40-64.

Wood, S. and Albanese, M. (1995) 'Can we speak of high commitment management on the shop floor?', Journal of Management Studies, 32: 215-47.

Woodworth, W.P. and Meek, C.B. (1995) Creating Labor-Management Partnerships, Reading, MA: Addison Wesley Publishing.

Wright, M. and Edwards, P. (1998) 'Does teamworking work, and if so, why? A case study in the aluminium industry', Economic and Industrial Democracy, 19: 59-90. 


\section{Index}

Page numbers in italics represent Tables and Figures

accountability 80

activists 9-10, 161; displaced 17; involved 156; semi-state 77

acute corporate crisis 21

acute industrial relations crisis 21

adversarialism 146, 232

advocates of partnership 25-9, 253-6

Aer Lingus 85, 99

Aer Rianta 1, 25, 36; Board of Directors

45, 53, 98; changed industrial

relations context in 219-26; changed

management context in 219-26;

cleaning department 221-3, 253;

contrasting fortunes of $\mathrm{CP}$ at

departmental level 220-1; corporate

values in 94-8; dispute over Sunday

working 223, 231-2; dual

commitment in 208-13; effect of CP

on organizational commitment 190-1;

emergence and development of

partnership in 43-65; governance of 236-7; interest in CP 174-8; levels of involvement in CP 178-99;

maintenance department 221-3, 251, 253; middle managers in 119-37;

new commercial environment 237-40;

new political environment 237-40;

partnership and business context at

61-2; partnership and industrial relations context in 57-60; partnership in 245-56; personnel department 248-9; retailing staff 223-6; senior managers in 94-115; strategic review 82; survey of workforce 39-40; and trade unions 145-66; unclear decisionmaking process $227-8$; union and management succession in 240-1
Aer Rianta Group of Unions 47, 57-8, $75,81-2,233$

airline: major customer 114

airport: charges 87,238 ; congestion 114; Cork 36, 112, 160, 185; Dublin 36, 38, 57, 61, 63, 85-6, 106, 109-10, 114-15, 120-37, 160; low cost 86; Shannon 36, 61, 71, 120-37, 195

Airport Police and Fire Service (APFS) 39, 57, 220-1, 223-6, 253

Airport Search Unit 224

airport services: provision of 63

Airports Authority 98

Allied Distillers Limited (ADL) 2, $143-5$

alternative dispute resolution (ADR) 13

Appelbaum, E. 22

authority 80; lines of 105

autonomy 168-9; job 29, 169, 251; task 186-8

Batt, R. 22, 172-3

Black, S.E. 26

British Airways 69

business unit arrangements 53

business-unit structures 57

capital investment 37

capital market pressure 31

Cassells, P. 49

centralization 115,165 ; of decisionmaking 10, 144, 155-9, 165, 217-18; of power 32; of union influence 144

Change of Status SIG 74-5, 157

chronic co-operation deficit 256 
chronic trust deficit 243

Chrysler: North Jefferson plants 167

co-operation: cycles of control model of 216; employer-dominated modes of 139; union-management 140; yo-yo model of 217

co-operation deficit 34

collective bargaining 15-17, 23, 33, 80-4, 141, 146, 235, 253, 256 commercial strategy 66-90, 236 commitment: company 210 ; continuance 190; dual 29, 204-13; effort 190; flexibility 190; levels of 208; management of 171 ; organizational 170, 190-1, 192, 202-3, 208, 208, 250-1; scales 209; union 153-5, 154, 206, 208, 210; value 190

commitment scales: cluster analysis of

211; latent class cluster models fitted to 211 ; organizational 261; union 259 committee-based programmes 11 committee membership 180, 181 communication: between departments 131

communicative involvement 150 communicative participation 176 Compact document 40, 51, 60-2, 66, 70-90, 94-115, 119, 146, 148, 185, 214, 220-41

Compact forums 124-5

Compact SIG 81

company: semi-state $74,77,94$

compensation practices 4

competing initiatives 117

competition 44

competition theory 18-21, 23

competitive market 69

competitive priorities: sustainability of 84-8

competitive strategy 6, 54, 68-9; quality-focused 141

concrete advantages 104, 107

configuration theories: of partnership $21-4$

constrained mutuality 14

constructive participation (CP) 37-42, 43-65, 66-90; achievements of 254-5; advantages and disadvantages of 108; attitudes to 163,184 ; attitudes to scales 260; business-unit engagement of 73 ; and commercial strategy 66-90; concrete advantages 107 ; contours of 51 ; contrasting fortunes at departmental level 220-1; coverage 131; demise of 233-44; development of 43-65, 50; dynamics of 247-52; effects of 169-71; effects of involvement in multiple channels 197-9; and industrial relations 226-32; interest of Aer Rianta in 174-8; involvement in 201; involvement of Aer Rianta in 178-99; levels of engagement with 182 ; mainstreaming of 246 ; and major corporate challenges 73-9; management scepticism about 103-6, 114; middle managers' attitudes to 116-37; middle managers' opposition to 155 ; opponents within management 102-3; outcomes of 254-5; perceived advantages and disadvantages of 107-10; process advantages 107; scales of involvement with 257-8; senior managers' attitude to 91-115; shop stewards' attitudes to 159-62; supporters within management 102; sustainability of 255-6; trade unions' assessments of the effects of 145-62; union involvement in 248-9; union involvement in development of 138-66; weak level of institutionalization of 252 consultation 120 continuance commitment 190 contradictory rationales 117 control: management of 171 Cooke, W. 1, 4, 11, 44; deductive theory of partnership 18-21

Cork Airport 36, 112, 160, 185 corporate arrangements 53 corporate governance 85,90 corporate priorities 115

Corporate Strategy Group 56, 82-3, 233-4

Corporate Strategy SIG 75-6, 81, 83

corporate values 91-2, 94-8; paternalist 92

cost-based competition 6

cost-control 44

cost minimization 54, 68-9, 242

crisis: acute corporate 21 ; acute industrial relations 21; deep 22; management responses to 22

critics: of partnership 29-31, 253-6

Cutcher-Gershenfeld, J. 4, 12-13, 16-17, 21, 44, 197 
decentralization: of management 96-7, 102

decision-making 1-2, 4, 135; authority 54; business unit 70-3; centralization of $10,144,155,165,217-18$; corporate 70-3; employee involvement in 169; high-level 66; innovation 250; joint 83-4, 135; of management 59, 79-80, 112; operational aspects of 92 ; organizational 25, 28, 29; quality of 183; speed of 104,183 ; strategic 12 , $70-3,78$; strategic aspects of 92 ; task-level 186; traditional modes of 153-6; unclear process of 227-8; union involvement 35

deep crisis 22

departmental communication 131 departmental work group (DWG) 54-5

deregulated market 69

deregulation 99

disjunctive commercial change 37

displaced activists 17

dispute: over Sunday working 223, 231-2

dispute resolution 33, 231-2

dual commitment 29, 204-13; in Aer Rianta 208-13; conceptualization and measurement of 206-7; dimensional approach to 206-8; and partnership 204-5; research findings 205-6; taxonomic approach to 206-8

Dublin Airport 36, 38, 57, 61, 63, 85-6, 106, 109-10, 114-15, 120-37, 160, 221-6; building of new terminal at 87, 239-40, 252; maintenance department 57; two terminals strategy at 76

Dublin Fire Brigade 225

duty-free 37, 71, 74, 108, 241; group 56; job losses 78; loss of sales 39, 60, 61, 73, 79, 83-4, 90, 109, 223-4, 238, 246; shops 57

Duty-Free Group 56

Economic and Social Research Institute (ESRI) 40, 45

economic performance 54

effort commitment 190

employee: attitudes and behaviour 167-203; involvement in decision making 169; involvement initiatives 118; involvement programmes 170 ; middle managers' view of 126-8; outcomes of partnership 27; priorities 168; responsibilities 3; work influences 193

employee shared ownership programme (ESOP) 3, 13, 77, 82, 90

employer: negative attitudes towards 188; outcomes of partnership 25-7, 30-1

employer-dominant partnership 30

employment: practices 12-13; security

$27,28,86,146$; stabilization 13

empowerment $117,171-2$

executive: airport level 91-115;

company level 91-115

executive dictatorship 68

facilitator: role of 228-9

Fenton-O'Creevy, M. 118

flexibility commitment 190

full-time union official (FTO) 142-5, 155-9, 164, 218

Gardai (Irish Police Force) 225

general manager: airport level 91-115; company level 91-115

General Motors (GM) 2, 46, 144, 216; Saturn plant 2, 5, 16, 143-4, 166, $167,216,218$

German labour code 140

German legal code 31

German works council 31, 140-1, 215

governance 4, 5-6, 21-2; of Aer Rianta 236-7; corporate 85, 90; joint 5, 16, 21-2, 246

grand labour relations strategies 19

Great Southern Hotels 36, 56, 77, 238

group membership 180, 181

Guest, D. 2-3, 5, 12-14

hierarchical structures 171

high performance work practice (HPWP) 26, 27

high performance work system (HPWS) 28,170

human resource management (HRM) 5 , 62, 66-8, 91, 93-4, 240; innovative approaches to $66,93-4$

humanistic values 91, 112

Industrial Democracy Council (IDC) 45, 59 
industrial relations 29, 44, 57-60, 62, 66, 84, 90, 91, 93-4, 186, 215; change in Aer Rianta 219-26; and CP 226-32; new 204; New Deal system of 138; positive 102; research in the USA 204

Initial Public Offering (IPO) 56, 77, 82, 90, 234, 238

innovation 93, 116

institutional security 26,54

intra-union relations 144-5, 244

involved activists 156

involvement: aspects and assessments of 187

Involvement and Participation

Association (IPA) 2, 13-14, 37; member companies 3, 14

involvement initiatives: incomplete coverage of 117

Irish Airports Authority 1

Irish Aviation Executive Staff Association (IAESA) 39, 58, 75, 128-31, 135, 146, 155, 158-9, 164, 179

Irish Congress of Trade Unions 49

Irish Department of Enterprise and Employment 100

Irish Department of Public Enterprise 37

Irish labour market 61

Irish Productivity Centre 45

Irish public service 99

job autonomy 29, 169, 251

job complexity 169

job losses 30; from duty-free retailing 78

job satisfaction 170, 171, 200

job security 200

joint decision-making 83-4, 135

joint discussion 80

joint governance 5, 16, 21-2, 246; antecedents of 21

joint problem-solving 16

joint responsibility 4

Joint Union Company Group (JUCG) $37,38,39,47-57,59,64-5,73$, 128-31, 135, 146, 156, 227-9;

formation of 47-50

joint working group (JWG) 45-7, 119 jointness 46, 101

Kaiser Permanente 17

Kelly, G.A. 48
Kelly, J. 15, 30-1, 34, 139-40, 142, 255

Knell, J. 2-3, 23

Kochan, T. 11, 13, 66-9, 138-9, 218-19

labour: cost 20; intensity 20; law 216; market 61

labour-management co-operation 16, 17

Labour-Management Co-operation (Cooke) 2

labour market 61 ; improvements in 255; Irish 61; local 37

labour-parity partnership 30-1

Labour Relations Commission (LRC) 224, 231

landing charges 114

Lawler, E. 16

liberalization 99-100

line management 95-8

local labour market 37

low cost airport 86

Lynch, L.M. 26

maintenance trades: regular work group membership in 196

management: change in Aer Rianta 219-26; co-operation with unions 16 , 146, 204, 215; of commitment 171; of control 171; decentralization of 96-7, 102; decision-making 59, 79-80, 112; division in hierarchy 117, 133-4; effects of CP on attitudes to 189 ; line 95-8; middle 8-9, 116-37, 248; opponents of CP 102-3; organizational power of 19; participation approaches to 119 ; perceptions of division in 214; responses to crisis 22; scepticism about CP 103-6, 114; senior 7-8, 34, 91-115, 248; senior line 93; succession 33-4, 110-12, 240-1, 256; supporters of CP 102; top-level 94, 110-12

management-staff interaction 83

management-union relations 16,84 , 146, 204; quality of 170

mandarin revolution 99

Marchington, M. 117-18

market: competitive 69; deregulated 69

membership: of committee 180, 181; of group 180, 181

middle management 8-9, 116-37, 181; 
in Aer Rianta 119-37; attitudes in organizational context 128-35; attitudes to CP 116-37; opposition to CP 155, 248; opposition to union commitment 155; views of employee attitudes $126-8$

Mohram, S. 16

mutual gains 14-15, 29, 66-9, 199-200, 232; bargaining 232

Mutual Gains Enterprise (Kochan and Osterman) 14, 66

networked partnership 7

New Deal: system of industrial relations 138

new public management 99

Nissan 30; Sunderland facility 139

organizational change 132

organizational commitment 170 , 190-1, 202-3, 208, 208, 250-1; effect of CP on 190-1; influences on 192; scales 261

organizational development (OD) 96, 101

organizational subsystems 118

Osterman, P. 11, 13, 15, 66-9

participation mentor 179

participation office facilitator 179

partnership: advocates of 25-9, 253-6; breakdown of 32-4, 214-44, 252-3; configuration theories of 21-4; critics of 29-31, 253-6; philosophy 3; practices 3 ; sustainability of 33 partnership arrangements: evolution of 58

Partnership Two Thousand 100

passenger volumes 61

paternalism 95, 113, 247

pay: good 146; low 54, 242

Peccei, R. 2-3, 5, 12-14

people-centred values 95, 98

performance-monitoring costs 171

personal construct psychology (PCP) 48

personnel 95-8, 247-8

plant level syndicalism 10

private investment: in state companies 100

privatization $74,87,100,159,236$; of

Telecom Eireann 238

problem-solving 123

process advantages 107 product market volatility 31

production costs 20

productivity $26-7,127$

promotional ladder 116

public service endorsement 101

quality 26; enhancement 68-9

realpolitik 80

regular work group (RWG) 52, 54-5, 56, 179; membership 179

relative power 19

Requisite Arrangements document 51, 79, 89, 119, 148, 195

research 36-42; first intensive fieldwork phase 38; second intensive fieldwork

phase 38

retail price index 87

Roche, W. 23

Royal Oak City Authority 46

Rubinstein, S. 218-19

Ryanair 61, 85-6, 106; strike 106

Saskatoon Chemicals 143, 166

Saturn experiment 2, 5, 16, 143-4, 166, 167, 216, 218; see also General Motors (GM)

sectional interest 128-31

self-actualisation 168

semi state activists 77

semi-state company $74,77,94$

semi-state sector 74

senior civil servant 92, 112

senior line management: and innovation 93

senior management 7-8, 34, 91-115; in

Aer Rianta 94-115; ambivalence to

CP 248; attitude to CP 91-115;

contrasting postures among 101-6;

ethos of 92; and the shareholder

98-101

service quality 54, 68-9

Services: Industrial, Professional and Technical Union (SIPTU) 39, 75

Shannon Airport 36, 61, 71, 120-37, 148, 195; maintenance department 57

share-capping 90

shareholder 92, 98-101, 112, 238

Shell: Sarnia plant 2, 5

shop steward 148, 159-62, 161, 165-6; advocacy role of 10 ; attitudes to $\mathrm{CP}$ 159-62; senior 142-5

Siemens plant 46 
significant issue group (SIG) 53, 55-7, 89, 157, 223; change of status 74-5, 108; Compact 81; Corporate Strategy $75-6,81,83$

single-union arrangements 30

skill development 86

staff: category 177; location 177

staff empowerment 83

staff sharing 120

state company: private investment in 100

strategic bargaining 22

strategic decision-making 12, 70-3, 78

strategic integration 141, 256

strategic-level joint forum 68

strategy 4, 5-6; competitive 6

strategy group (SG) 54-7, 157, 223

Streeck, W. 31, 34, 140, 255-6

strike: by Ryanair 106

succession: impact of 110-12;

management 33-4, 110-12, 240-1,

256; union 33-4, 240-1, 256

supervisor-employee relations 26

sustainability: of competitive priorities

84-8; of partnership 33

Sweden 46

task: autonomy 186-8; participation 175

team-based working 11,83

team leader mediation 13

teamwork 171-3, 195-7, 250

Technical Engineering and Electrical Union (TEEU) 39

Telecom Eireann 99, 234, 238; privatization of 238

Terry, M. 31, 140

top-level management 94

total quality management (TQM) 26

total utility 19

Toyota 2

trade union 9-10, 138-66, 248-9; assessments of the effects of CP 145-62; attitudes to 163; attitudes to effectiveness of 150; bargaining power 149-53; co-operation with management 16, 146, 204, 215; commitment 153-5, 154; commitment scales 259; density 23; effectiveness 149-53, 164; fractionalism 32; involvement in decision-making 35; involvement in development of CP 138-66; membership recruitment 244 ; moderation 139; outcomes of partnership 27-8, 30-1; and partnerships 152; presence of 23; single-union arrangements 30 ; succession 33-4, 240-1, 256; views on role of 125-6; weakness 31

Turner, T. 23

Uddevalla shipyard 46

union see trade union

unionate worforce 21

unionization 21, 99; effects of 28

United Automobile Workers (UAW) 10,144

United Distillers (UD) 2, 143-5

value: of workplace 121

value commitment 190

values: corporate 91-2, 94-8;

humanistic 91, 112; people centred 95, 98

Verma, A. 4, 12-13, 16-17, 21, 44, 197

vertical alignment 10-12, 247, 256

vertical integration 197-8, 251

voluntarism 140-1

voluntary partnership 1-35

work practices: effects of $\mathrm{CP}$ on changes in 193

work reorganization 171-3

work task restructuring 135

worker director 233-5, 243, 248

Worker Participation Act (1988) 45, 155

workforce: survey 41; unionate 21

workplace: value of 121

workplace partnership principles 52-3

works council 68 
eBooks - at www.eBookstore.tandf.co.uk

\section{A library at your fingertips!}

eBooks are electronic versions of printed books. You can store them on your PC/laptop or browse them online.

They have advantages for anyone needing rapid access to a wide variety of published, copyright information.

eBooks can help your research by enabling you to bookmark chapters, annotate text and use instant searches to find specific words or phrases. Several eBook files would fit on even a small laptop or PDA.

NEW: Save money by eSubscribing: cheap, online access to any eBook for as long as you need it.

\section{Annual subscription packages}

We now offer special low-cost bulk subscriptions to packages of eBooks in certain subject areas. These are available to libraries or to individuals.

For more information please contact webmaster.ebooks@tandf.co.uk

We're continually developing the eBook concept, so keep up to date by visiting the website.

www.eBookstore.tandf.co.uk 




